\title{
HOW CHILDREN TELL: CONTAINING THE SECRET OF CHILD SEXUAL ABUSE
}

\author{
Rosaleen McElvaney
}

A thesis submitted in fulfilment of the requirement for the degree of Ph.D.

Supervisors:

Professor Sheila Greene

Dr. Diane Hogan

School of Psychology

Trinity College Dublin

June 2008 
DECLARATION

I confirm that:

a) this thesis has not been previously submitted as an exercise for a degree at this or any other University

b) it is entirely my own work

c) the Library may lend or copy this thesis upon request

Signed

Rosaleen McElvaney

Date 


\section{ACKNOWLEDGEMENTS}

I wish to acknowledge those who supported me on my doctoral journey.

"to teach is to touch a life forever" (fridge magnet, 2005!)

I have had the benefit of many teachers on this journey: Diane, who introduced me to the world of qualitative research and who took great pleasure in sharing with me her own talents of critical inquiry; Clare and Fi, who gave me my induction as a doctoral student in Trinity College and were always available in those early years to answer my every little query; Dave and Jean, who modeled what the appraisal process is really about - being supportive, constructively critical, and caring; Silvana who shared her wisdom of NVivo, through her workshops, consultation and even on a walk in the woods; Caoilte and James, who were my Clare and Fi in the final months; and Sheila, my new role model, who took me in when Diane could no longer be there, challenged me to reflect on my thinking, my language, my practice, taught me new meanings of clarity and gave me an academic training to be proud of.

The support of fellow clinicians has nurtured me in my work as a Clinical Psychologist for many years. As a Researcher, I owe a debt of gratitude to the team in St. Clare's, both past and present, for their encouragement, enthusiasm, interest and unwavering support for this research. Similarly, to the team in LARAGH, for helping me reach those who could share their story with me and to the team in St. Louise's, who despite their best attempts, were not able to be a part of this study.

The support of staff in the School of Psychology, administrative, technical and academic is much appreciated.

To those who invited me into their lives, to share their stories, I am grateful for the privilege of being touched by their pain, their joy and their courage. I hope I have done justice to their words.

To my big sister Tricia, and to Pat, who were always there to take the kids when I needed some more time - which was frequent - I am as always indebted. And to my friends who never doubted me.

To Tara, Jen and Liz, for their friendship, sharing the journey, knowing what it's really like and saying all the right things.

To the Health Research Board for awarding me a Fellowship that enabled me to enjoy the journey.

Finally, I wish to acknowledge my gratitude to those to whom I dedicate this work: the men in my life, Fergus, Lorcan and Frank, who taught me to love and to be loved and who are my containment. 


\section{SUMMARY}

Despite considerable empirical evidence that most adults do not disclose experiences of childhood sexual abuse until adulthood and many children who have been abused do not disclose this abuse when asked in a professional context (London, Bruck, Ceci \& Shuman, 2005, 2007), little attention has been focussed on how children negotiate the psycho-social task of confiding their experiences of sexual abuse. Attention has focussed on identifying those variables which are associated with delays in disclosing (Paine \& Hanson, 2002) and exploring which variables are predictive of a delay in reporting such experiences (Goodman-Brown et al., 2003). Although the experience of telling has been recognised as a process, it is only recently that qualitative research methods have been utilised in such studies. The complexity and individual variability in experiences of disclosing calls for such an approach. Chapter 1 gives an overview of the research on this subject and theoretical contributions to our understanding of the disclosure process for children and adults. A critique is offered of the literature, highlighting the methodological challenges of researching such a sensitive subject with a vulnerable population. The need for a both a qualitative research methodology and a developmental systemic approach to this field of study is identified.

This study uses Grounded Theory methods to explore how children tell about experiences of sexual abuse. Twenty two children and young people were interviewed using an open ended interview guide to explore their first and subsequent experiences of telling. Parents of fourteen of these young people were interviewed to explore their perspective on this subject. An additional seven children's stories were told by their parents and thus included in the study. Ten adults, five of whom also participated in the study as parents, were interviewed to explore their experiences of confiding. Children's files were accessed to obtain demographic information and details of the young people's experiences of abuse. Chapter 2 describes in detail the rationale for choosing a Grounded Theory approach, how participants were recruited for the study, the pilot study, the procedure for data collection, management and analysis and an overview of ethical issues encountered during the course of the study.

The findings of the study are presented in Chapters 3, 4 and 5. Chapter 3 presents the theoretical framework developed from this study that captures the primary research question in this study: how children tell. It is suggested that experiences of disclosing need to be viewed as part of a cyclical adaptive process of containing the secret, consisting of three key dynamics: active withholding, the pressure cooker effect and confiding. Children, and others, actively withheld information about the 
abuse experience and, often in response to a pressure cooker effect, confided in another. The pressure cooker effect may consist of an accumulation of pressure, gradual or abrupt, both internal and external, leading to the secret being shared. The experience of confiding was often in the context of mutual sharing of confidences, and for the most part, kept in confidence by those to whom the abuse was disclosed. The evidence from this study suggests that this process may need to be re-negotiated in different relationships across the lifespan, is influenced by the various subsystems surrounding and impacting on the child's development - individual, family, peer, school and wider society - and by various factors operating at the various levels of these sub-systems.

Chapter 4 presents the findings that address the question of why children tell and why children do not tell, i.e. those factors that influence the process of containing the secret. The key motivating influences for participants in this study were: being believed, being asked, concern for others, shame/embarrassment/self blame, peer influence, fear, contact with the alleged abuser, being told not to tell, the role of alcohol and the role of media and film.

Chapter 5 offers a developmental systemic perspective on the findings of this study, drawing on Belsky's $(1980,1993)$ ecological perspective on the etiology of child maltreatment. Influencing factors operating at the level of individual (age and gender), and family (intrafamilial vs. extrafamilial abuse, parental history of abuse and young people's concerns about their parents) are considered, along with the influences of schools and wider social systems. Finally, comments about professional services and wider society issues are presented.

The final chapter draws on the extant literature to consider the findings of this study. The theoretical framework suggested here, with its various components and characteristics, is analysed in the light of existing research and theoretical literature. Reflections on both the methods used in the study and theoretical issues emerging that point to future directions for research are suggested and implications for prevention and intervention are outlined. 


\section{TABLE OF CONTENTS}

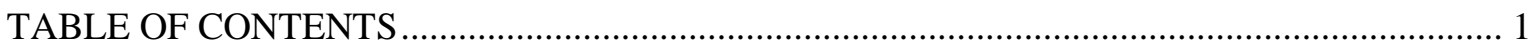

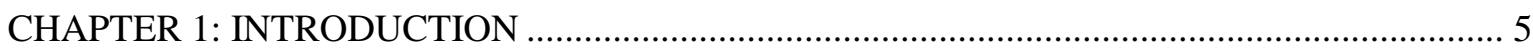

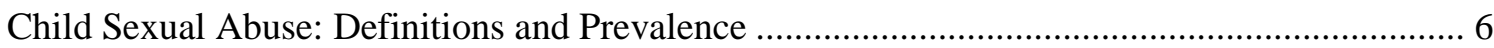

Child Sexual Abuse: Legal, Child Protection and Therapeutic Concerns ……............................ 8

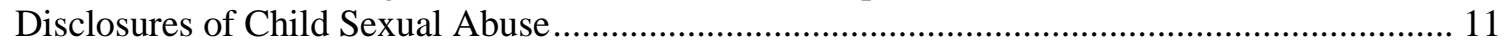

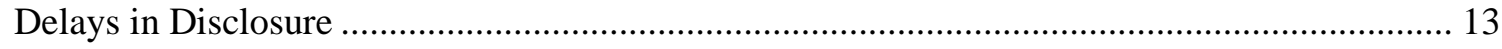

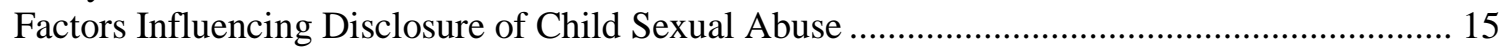

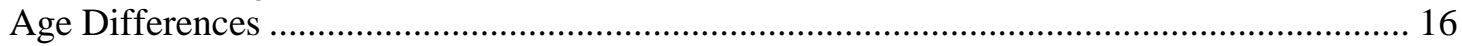

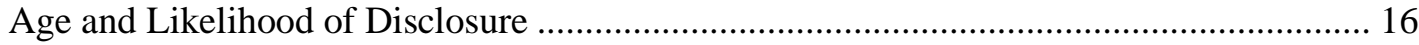

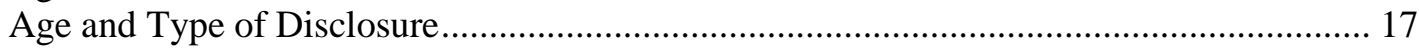

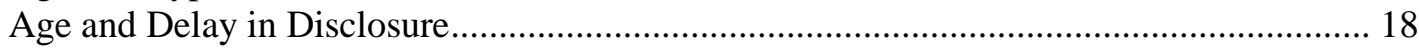

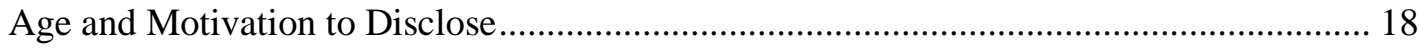

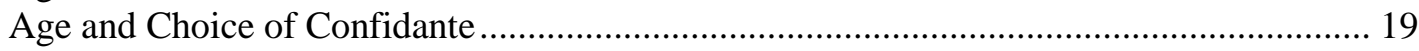

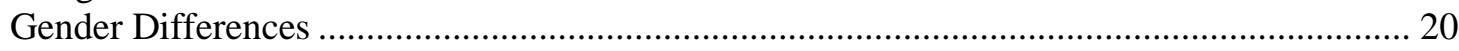

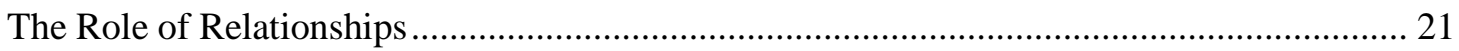

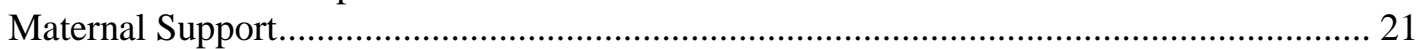

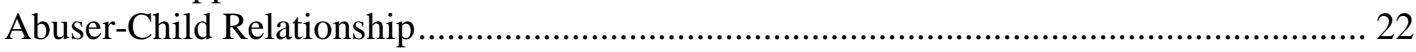

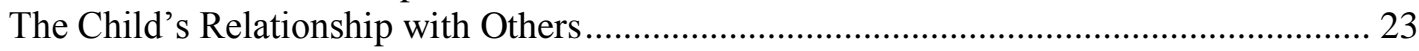

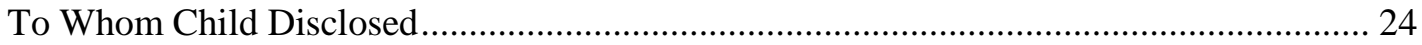

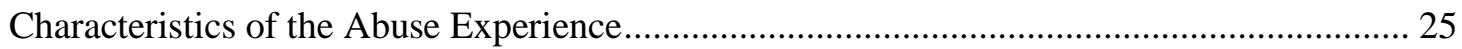

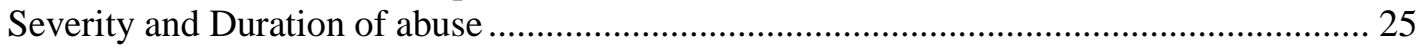

Strategies Used to Gain/Maintain Compliance ……............................................................ 26

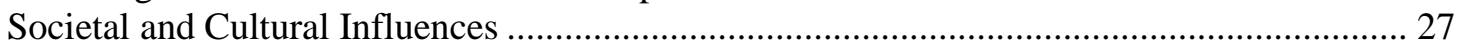

Child Abuse Prevention Programmes ……….................................................................... 28

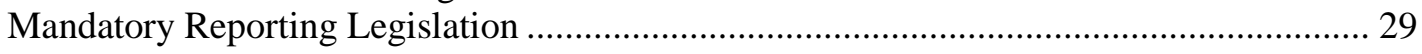

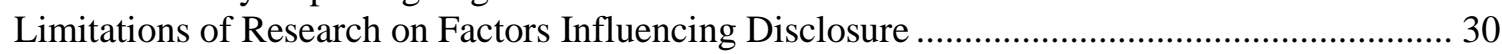

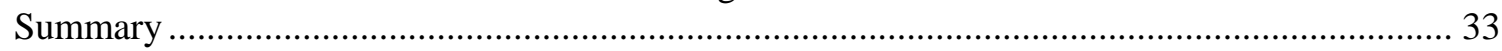

Theoretical Contributions to our Understanding of the Disclosure Process ................................ 34

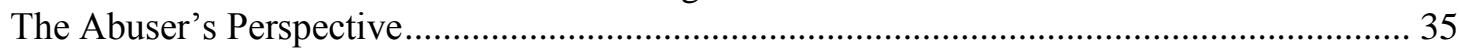

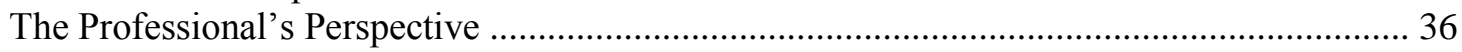

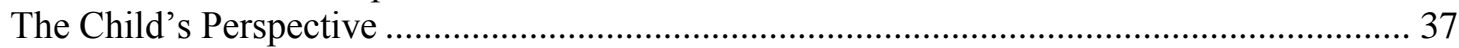

Child Sexual Abuse Accommodation Syndrome (Summit, 1983)...................................... 38

Child Sexual Abuse as Syndrome of Secrecy (Furniss, 1990) .............................................. 44

Bussey and Grimbeek's Socio-Cognitive Model (1995) ...................................................... 44

Goodman-Brown et al's Model Predicting Delays in Disclosing (2003)............................ 45

Staller and Nelson-Gardell's Temporal Framework (2005)................................................ 45

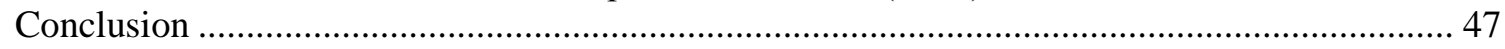

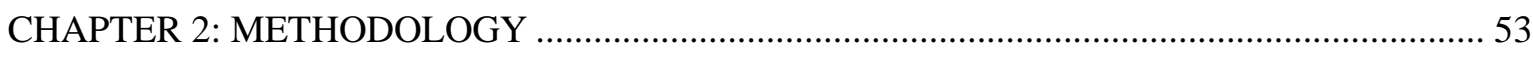

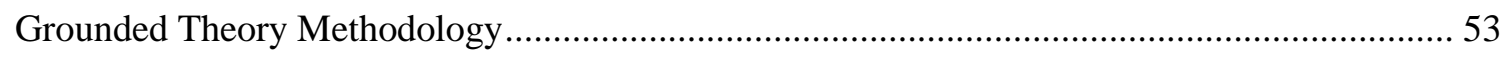

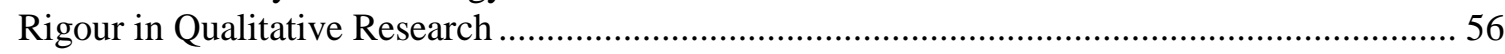

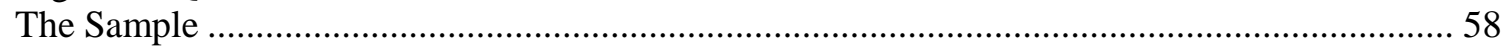

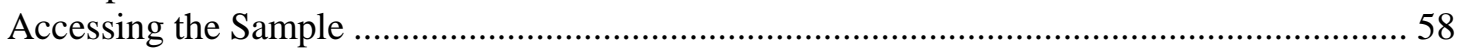

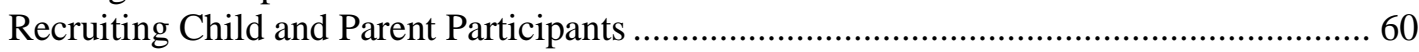

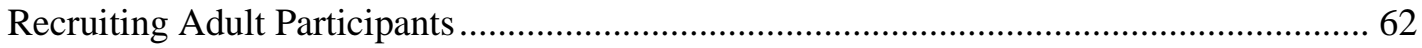

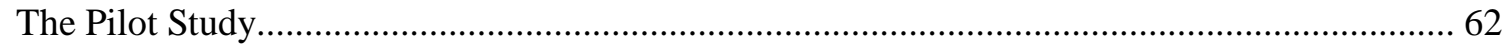

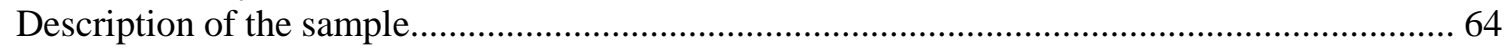

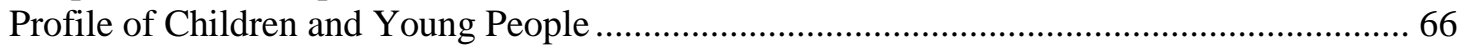

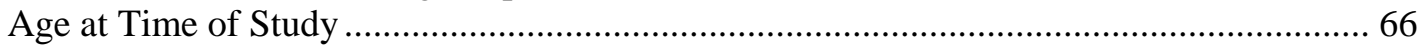

Age at Time Abuse Began and First Disclosure ................................................................. 66

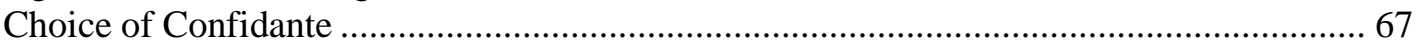

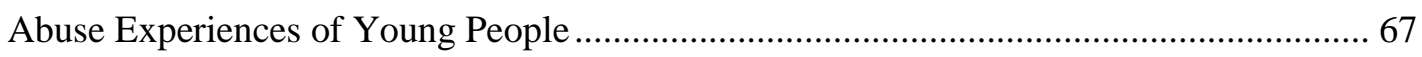

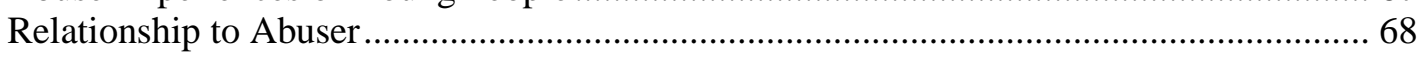

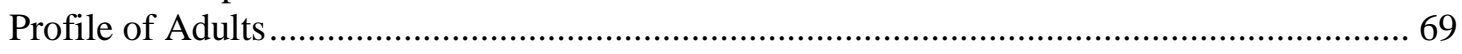

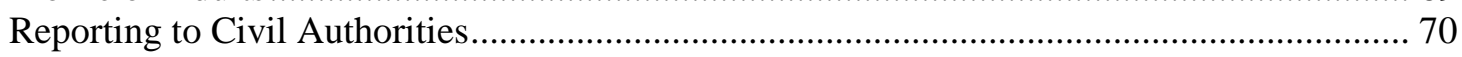

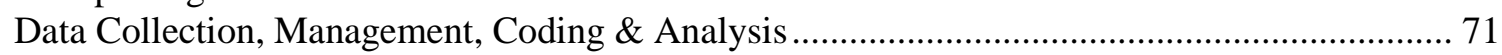




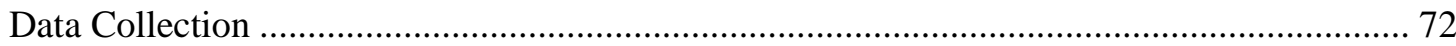

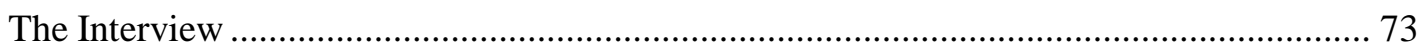

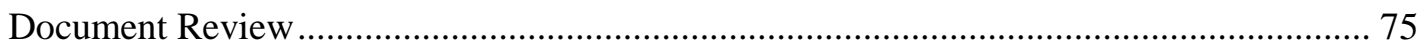

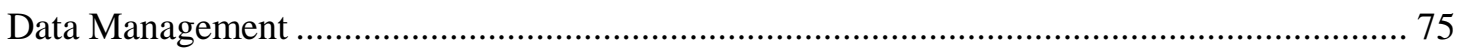

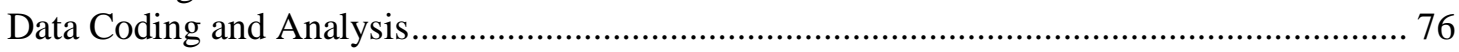

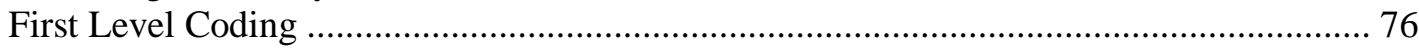

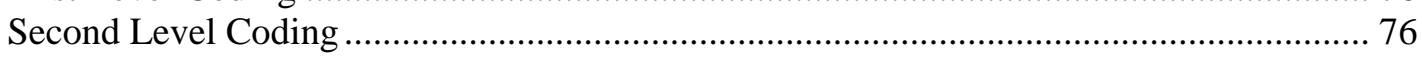

Containing the Secret: Denial - Active Withholding - Containing the Secret ..................... 80

Pressure Cooker Effect: Being Asked - Psychological Distress - Breaking the Secret -

Triggers - Pressure Cooker Effect ..................................................................................... 81

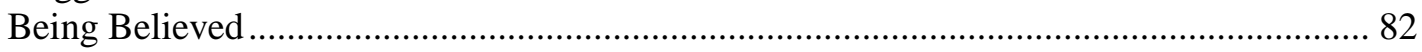

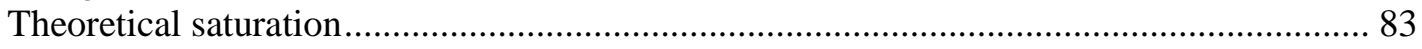

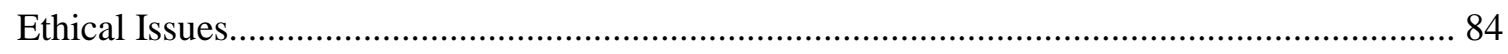

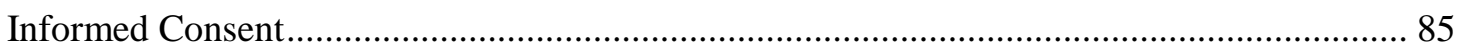

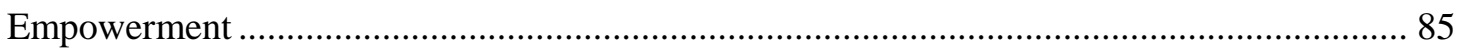

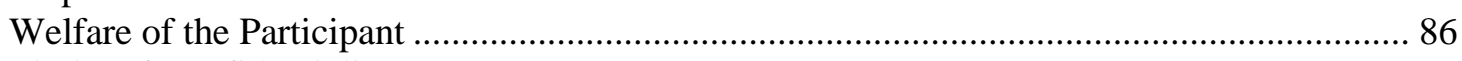

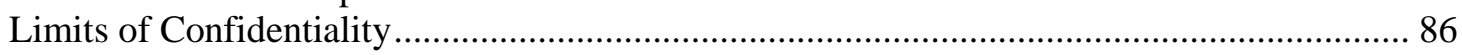

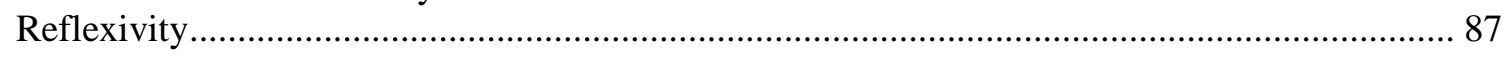

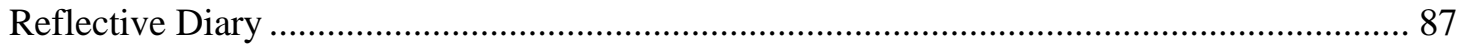

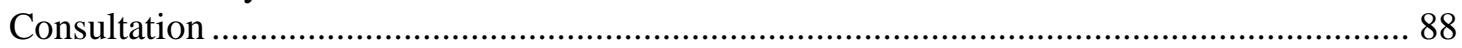

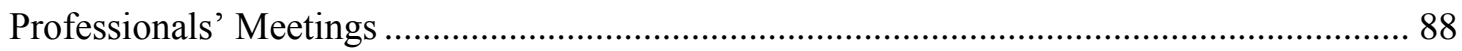

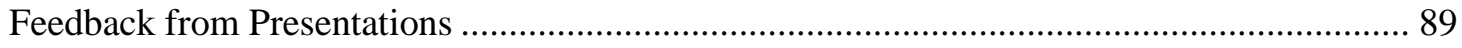

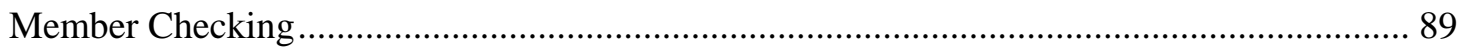

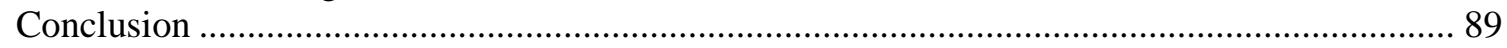

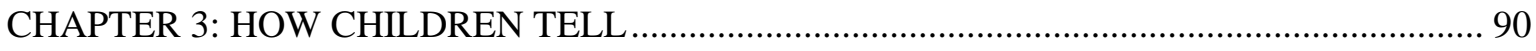

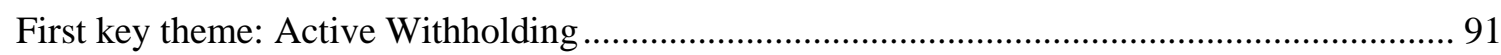

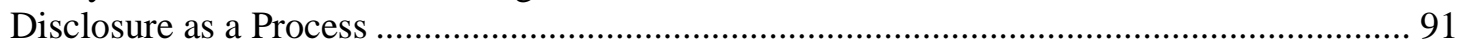

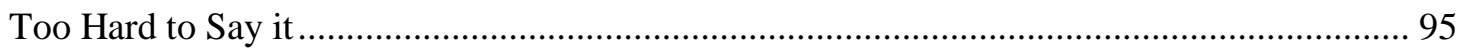

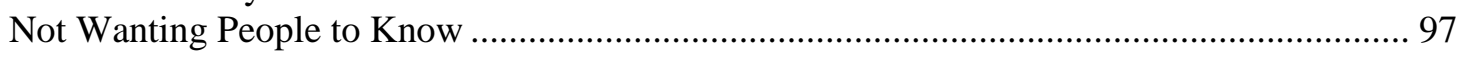

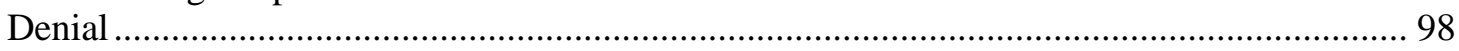

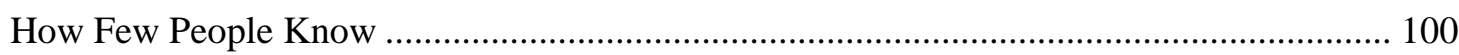

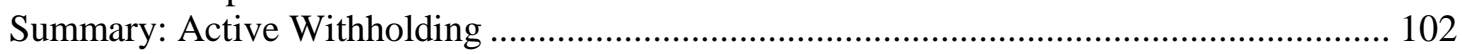

Second Key Theme: The Pressure Cooker Effect .................................................................... 104

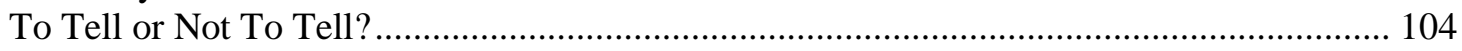

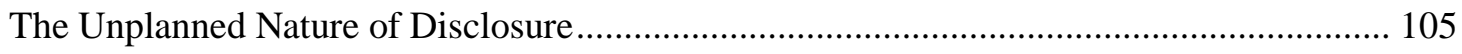

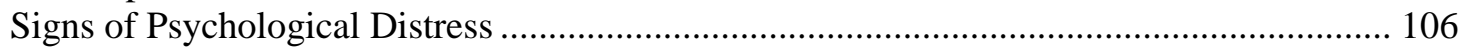

If They had not Told Then ..................................................................................... 109

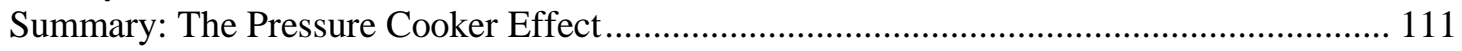

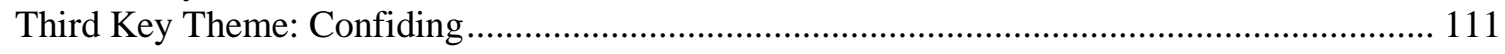

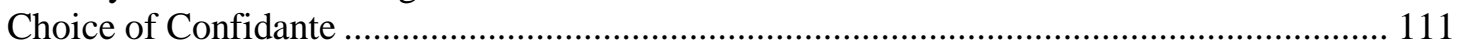

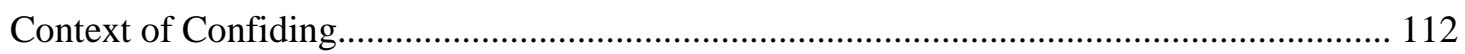

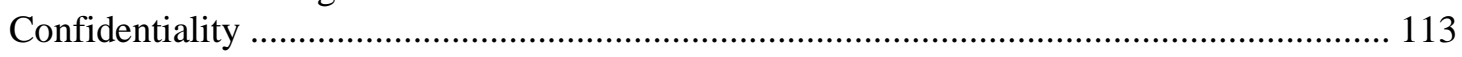

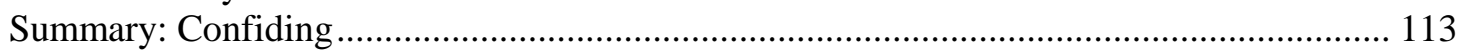

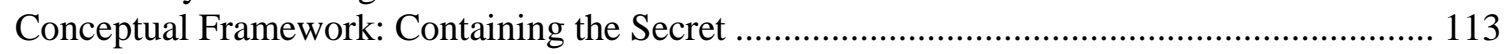

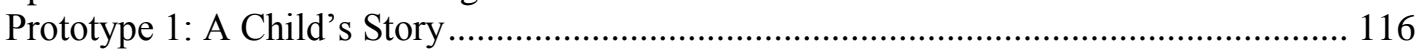

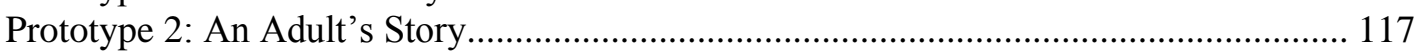

CHAPTER 4: WHY CHILDREN DO NOT TELL, WHY CHILDREN TELL ............................ 117

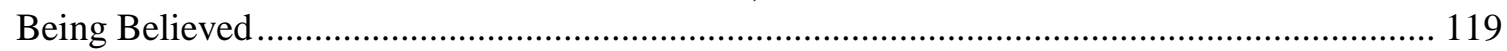

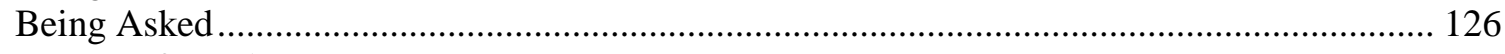

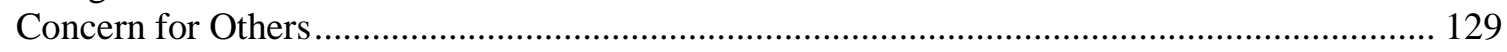

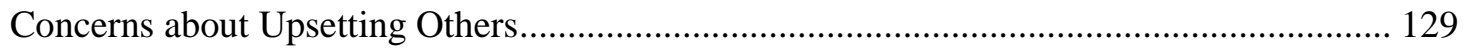

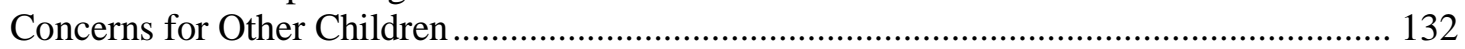

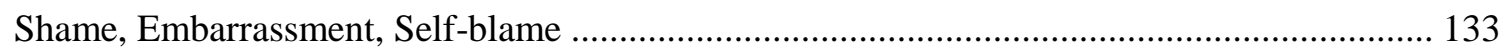

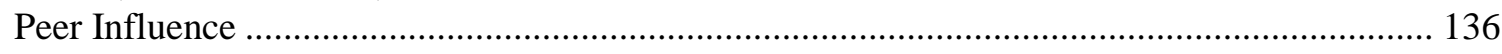

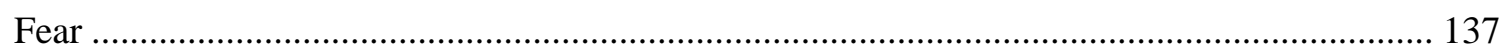

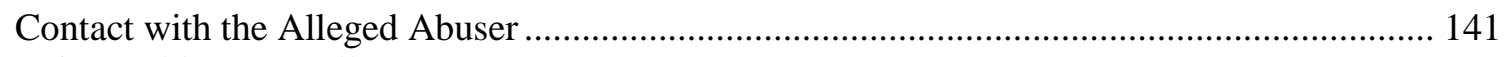

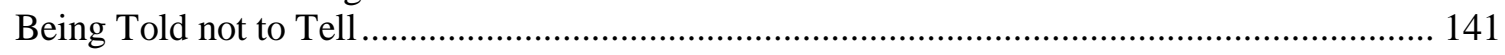




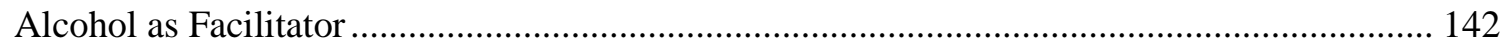

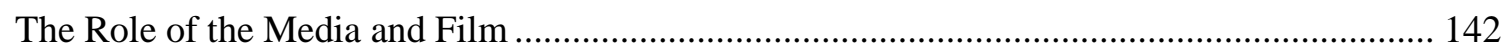

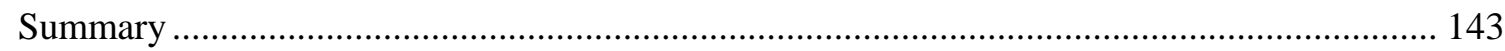

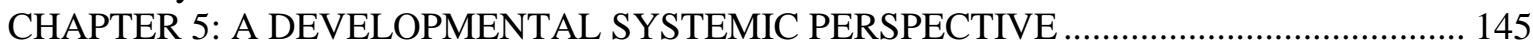

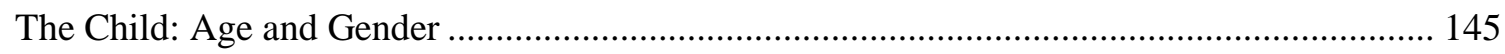

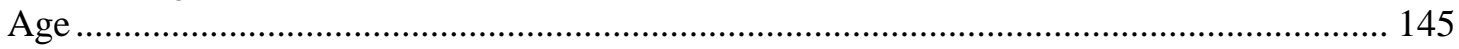

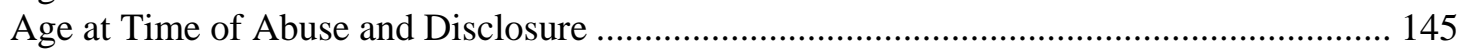

Knowledge as Both an Inhibitor and Facilitator to Telling ................................................ 146

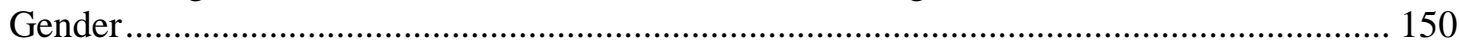

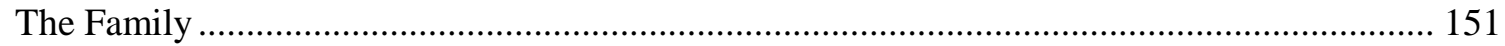

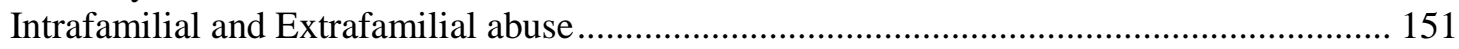

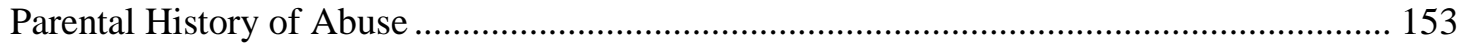

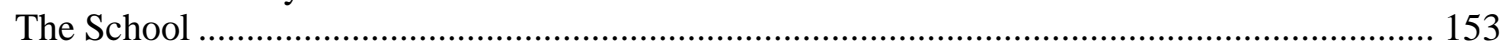

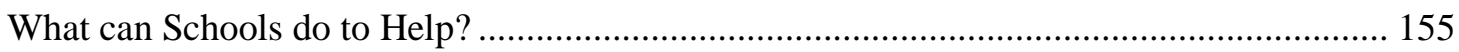

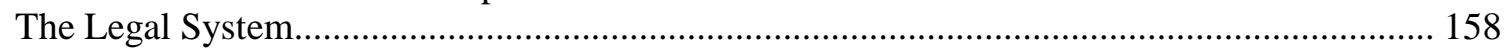

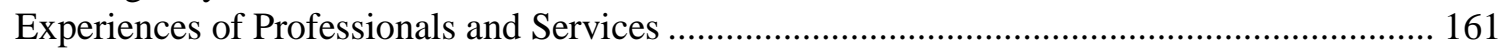

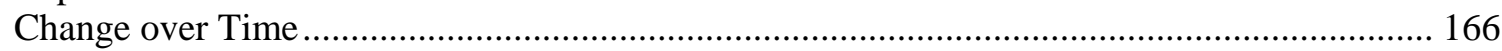

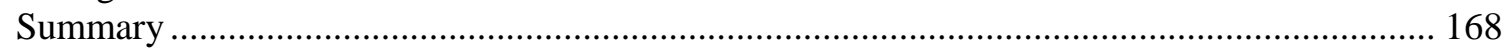

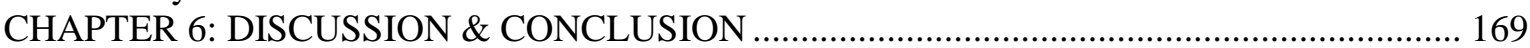

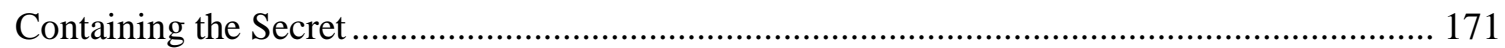

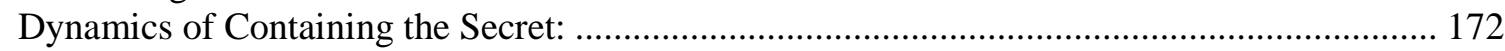

Active Withholding, Pressure Cooker Effect and Confiding ................................................... 172

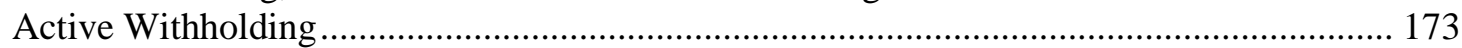

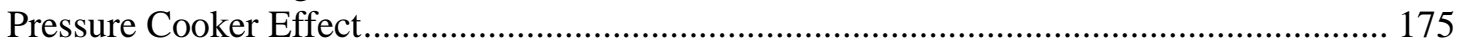

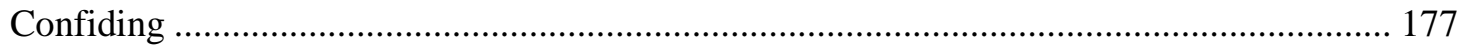

Characteristics of the Process of Containing the Secret........................................................... 178

Containing the Secret as an Adaptive Response ........................................................... 178

Containing the Secret and Confiding as a Cyclical Process that may be Re-negotiated Across

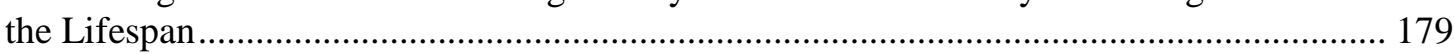

The Process of Containing the Secret as Influenced by Multiple Factors at Multiple Levels of

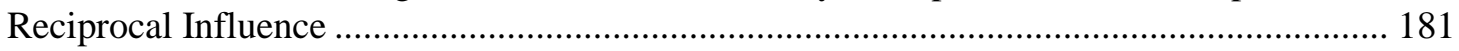

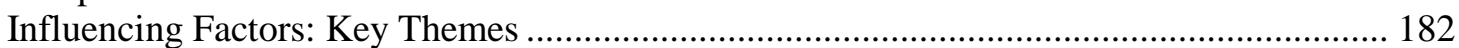

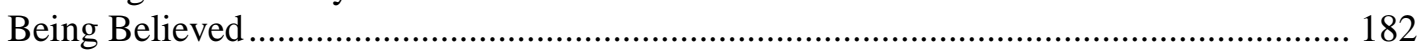

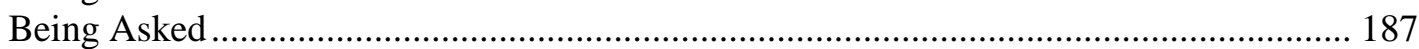

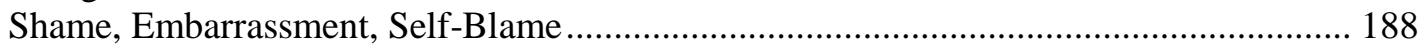

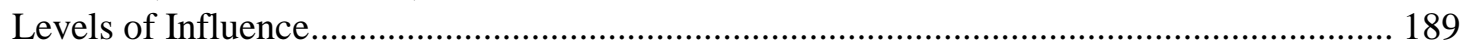

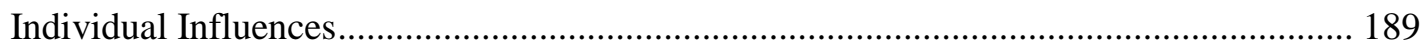

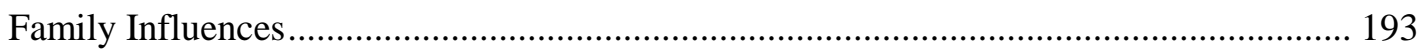

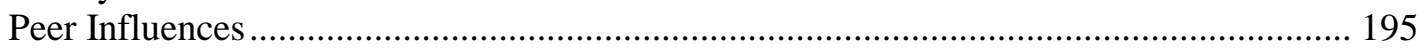

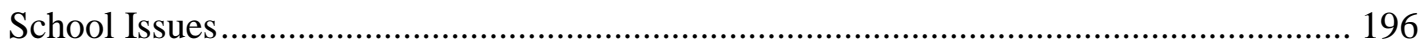

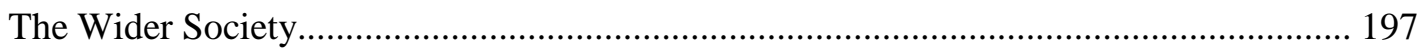

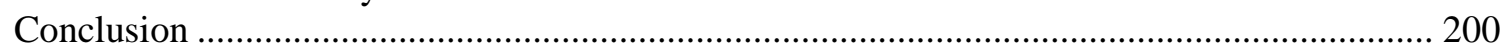

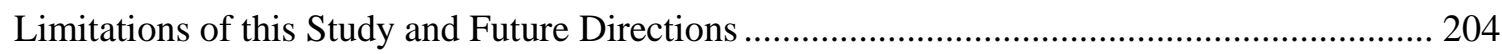

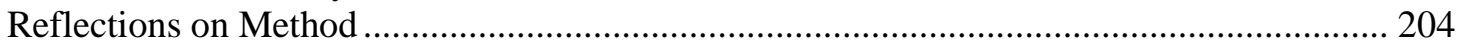

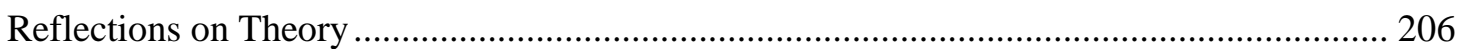

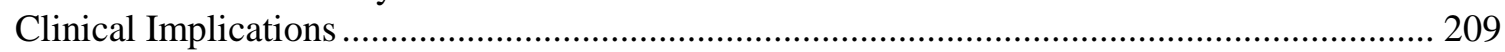

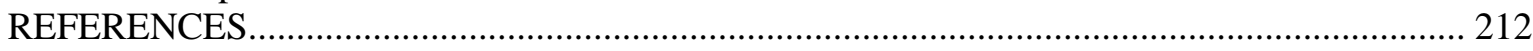

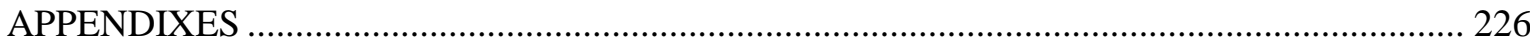

APPENDIX A: LETTER TO PARENTS INTRODUCING STUDY ………........................... 227

APPENDIX B: INFORMATION SHEET FOR PARENTS, INCORPORATING CONSENT

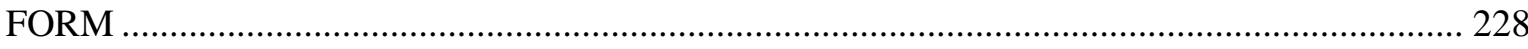

APPENDIX C: INTRODUCING THE RESEARCH PROJECT TO PARENTS ......................... 229

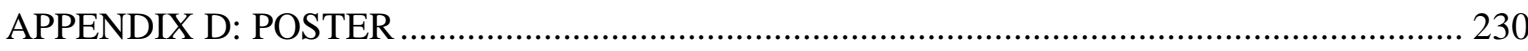

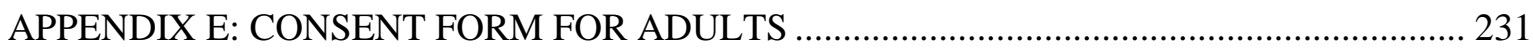

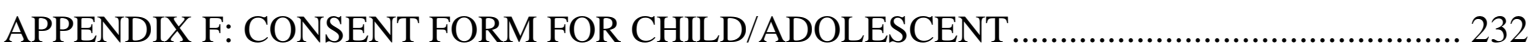

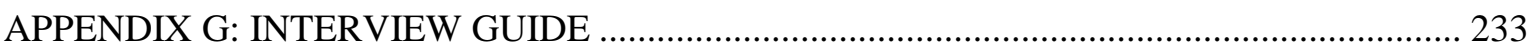

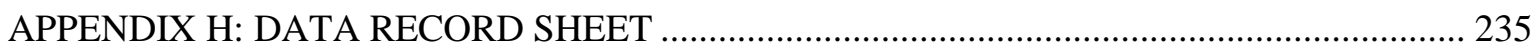




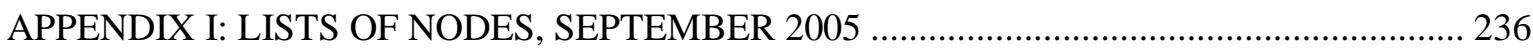

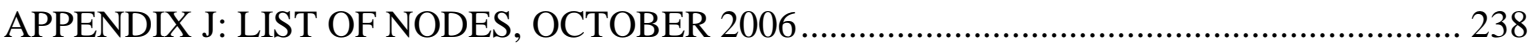

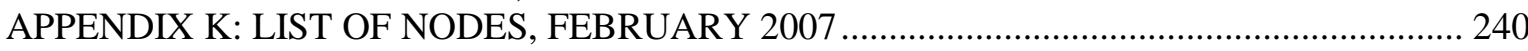

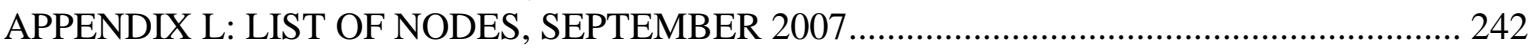

List of Figures

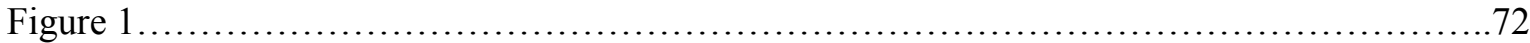

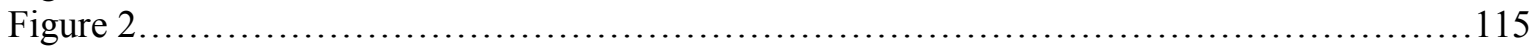

List of Tables

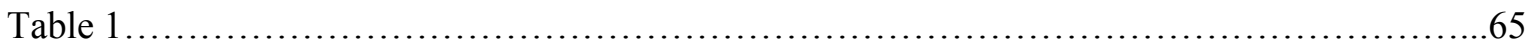

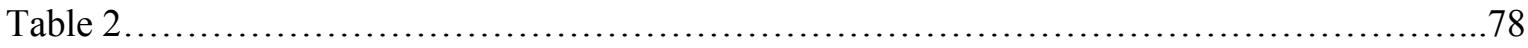

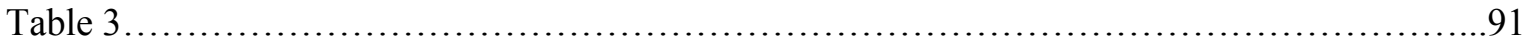

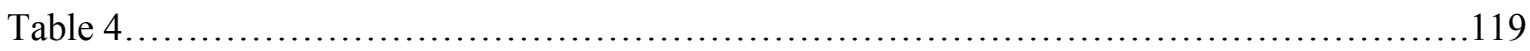




\section{CHAPTER 1: INTRODUCTION}

Child sexual abuse is a major social and psychological problem with far reaching consequences for society. The effects of the abuse extend well beyond the abused individual and may have a significant effect on the family members of the abused and the abuser.

This chapter will review the literature on child sexual abuse disclosures. Attempts at establishing reliable prevalence rates highlight the difficulties both children and adults have in disclosing experiences of sexual abuse. Many of the factors influencing the disclosure of children and adults have been identified (Paine \& Hansen, 2002). This research is reviewed here, followed by a review of theoretical contributions to our understanding of the disclosure process.

One of the striking features of the literature on disclosure is the limited attempt at integration between theory and research. Research studies have tended to be descriptive in nature with some isolated references to existing theoretical models and little attempt at developing new theory from the research findings. Studies have identified factors influencing disclosure or investigated the prevalence of such factors. While attempts at theory building such as Summit's (1983) Child Sexual Abuse Accommodation Syndrome have been influential in informing clinical practice (Oates \& Donnelly, 1997), theoretical endeavours have not generated sufficient empirical studies to test their validity. While developmental factors are acknowledged as having a critical influence on the disclosure experience (Paine \& Hansen, 2002), there has been little attempt to integrate research in the field of child sexual abuse with that of mainstream developmental psychology.

It is important from the outset to highlight the limitations of the extant research in terms of the lack of representativeness of those who have experienced childhood sexual abuse. Non-disclosure of sexual abuse experience is well documented, thus presenting a unique challenge to research on the topic. Studies show that a substantial majority of adults surveyed who experienced childhood sexual abuse did not disclose their experience to anyone until adulthood and that a substantial minority of children who are believed to have been sexually abused, do not disclose sexual abuse even when asked in a formal investigative interview (for review see London, Bruck, Ceci, \& Shuman, 2005; London, Bruck, Ceci, \& Shuman, 2007). This has been found in both selective and national probability samples. These findings raise concerns about the representativeness of study samples. How can a representative sample be sought if the parameters of the population we are hoping to study are unknown? Prevalence studies are hampered from the outset.

In addition, there is the dilemma of some people reporting sexual abuse when they have not been abused. This issue has received much attention over the past few decades and considerable attempts have been made to minimize the possibility of "false positive cases" being included in research 
studies by for example, using inclusion criteria such as corroborative evidence, offender confession, or conviction. However, child sexual abuse by its very nature often precludes corroborative evidence, offenders frequently deny the abuse and excessively low complaint rates result in comparatively low conviction rates. Thus, the selectivity of such samples limits the contribution of such studies to the knowledge base on child sexual abuse disclosures. Even studies that use self-report as the criterion for inclusion obviously rely on samples of individuals who have disclosed. We cannot make claims about whether these findings also apply to those who have never disclosed to anyone and given the evidence to date, this represents a substantial proportion of people who have been abused.

This chapter will review the literature on prevalence rates and definitions of child sexual abuse. The terms child sexual abuse and sexual abuse will be used interchangeably. While it is acknowledged that both boys and girls experience child sexual abuse, the pronoun 'she' will be used throughout this thesis but can be taken to refer to both boys and girls. The meaning of the term 'disclosure' will be discussed both in the context of the research literature and in the context of this study. Research identifying those factors that have been found to influence disclosure will be reviewed including developmental factors, gender, the role of relationships (maternal support, child-offender relationship and to whom the child disclosed), characteristics of the abuse experience (such as severity, duration and strategies used to gain or maintain compliance), and societal or cultural factors (such as prevention programmes, mandatory reporting legislation and cultural differences). I will then present an overview of the theoretical literature that contributes to our understanding of the reluctance to disclose child sexual abuse. This literature can be seen as representing various perspectives: the offender's perspective, the professional's perspective, and the child's perspective. Finally, theoretical models that emphasise disclosure as a process will be presented. A critique is then offered which highlights the need to address gaps in our understanding of this crucial issue. It is hoped that this study will go some way towards addressing such gaps.

Child Sexual Abuse: Definitions and Prevalence

Child sexual abuse is a complex phenomenon to understand. It is multi-faceted in that the definition includes a broad range of behaviours, which can be perpetrated across a broad range of intra-familial and extra-familial relationships, and there is considerable variability in the duration and frequency of the abuse (Paine \& Hansen, 2002). This multi-faceted nature also accounts for the heterogeneity of children's reactions to abuse, ranging from severe psychological impact to no evidence of negative psychological sequelae (Kendall-Tackett, Williams, \& Finkelhor, 1993).

Research studies reflect great diversity in how child sexual abuse is defined. Many general population surveys define it as 'unwanted sexual contact' without asking for specific details of the 
behaviour. Some studies distinguish between "contact abuse" and "non-contact abuse" or 'penetrative abuse' and 'non-penetrative abuse'. Studies may use different age cut off points to define child sexual abuse such as before the age of $15,16,17$ or 18 . While legal definitions and age of consent vary across different states, this does not fully account for the differences noted.

There is considerable diversity in the prevalence rates quoted in studies of child sexual abuse. Differences in prevalence rates have often been attributed to differences in the definition of sexual abuse (e.g. contact vs. non-contact, age of child under 16 years vs. under 18 years), the focus of the study (childhood victimisation, lifetime sexual assault), the samples used (college samples, convenience samples, national probability samples) and the differences in methodology employed (use of questionnaires, mail survey, direct interviews) (McGee, Garavan, deBarra, Byrne, \& Conroy, 2002).

Studies which focus on more broadly-based definitions of child sexual abuse not surprisingly indicate higher prevalence rates. Russell (1984) in direct interviews with a randomly selected sample of adults ( $\mathrm{N}=930)$ found a prevalence rate for 'unwanted sexual experiences' prior to 18 years to be $38 \%$. Wyatt and Newcomb (1990) also conducted direct interviews with 18-36 year old women $(\mathrm{N}=248)$ and found child sexual abuse prior to age 18 at a rate of $62 \%$.

The literature suggests that a disproportionately higher number of children with disabilities are victims of sexual abuse (Browning \& Boatman, 1977; Goldman, 1994; Sullivan \& Knutzon, 2000). Sullivan and Knutzon (2000) found differences by type of disability, with those identified as having behaviour disorder the most likely to experience sexual abuse, followed by those with learning disability. The limited research and clinical literature indicates that children with disabilities are likely to encounter special problems disclosing their abuse. These impediments may include physical and social isolation related to their disability, impaired ability to communicate, and increased dependency and vulnerability (Goldman, 1994; Steward, Bussey, Goodman, \& Saywitz, 1993).

The most comprehensive data available for prevalence rates in Ireland comes from the Sexual Assault and Violence in Ireland (SAVI) adult telephone survey study $(\mathrm{N}=3,118)$ where $30 \%$ of women and $24 \%$ of men reported experiencing sexual abuse in childhood (McGee et al., 2002). These rates are somewhat higher than a recent study in the United Kingdom, our closest neighbour, both geographically and culturally. May-Chahal and Cawson (2005) in their random probability sample of adults aged 18-24 (interviewed face-to-face) found a prevalence rate of $21 \%$ for females and $11 \%$ for males reporting being sexually abused during childhood. A feature highlighted in the latter study was the distinction between the definition of abuse adopted by the researchers and abuse as defined by the research participants. While the researchers considered that $16 \%$ of the 
total had been sexually abused as children, in terms of self-assessed sexual abuse, just $6 \%$ considered themselves to have been abused. The researchers considered sexual behaviour to be abusive if the other person was a parent or carer, the behaviour occurred against the respondent's wishes or the other person was five or more years older when the child was aged 12 years or under.

Prevalence rates provide information in relation to the extent of the problem of child sexual abuse in society. In order to gather accurate information it is necessary for children and adults to be able to disclose this information. The reluctance to disclose child sexual abuse impacts on the reliability of prevalence studies. Problems with reliability in estimating prevalence from general population or clinical samples are exacerbated in legal contexts when samples of people referred to prosecution services or conviction records are used. Low reporting rates have been a consistent feature of child sexual abuse research. D.W. Smith et al. (2000) found that $12 \%$ of young people who disclosed abuse had made a formal report to the police. Also, studies of incarcerated sex offenders have found that they confessed to committing many more crimes against children than those for which they had been investigated and/or convicted (A. N. Elliott \& Carnes, 2001; Groth, Longo, \& McFadin, 1982). Groth et al. (1982) found that perpetrators had committed between two and five times as many crimes as they were apprehended for. Thus, neither the children nor the abusers who engage with the legal system are reliable samples on which to base prevalence estimations.

An inability to disclose child sexual abuse at an individual level contributes to a reduced acknowledgement of the extent of the problem in society and in turn influences the resources made available to detect and intervene where sexual abuse occurs. McGee et al. (2002) note that prevalence rates from surveys can be viewed as an underestimate of the problem due in part to the sensitivity of the topic. Yet their finding of $47 \%$ disclosing childhood sexual abuse for the first time in their survey and other similar findings from other survey studies suggest that adults are more willing to inform survey researchers that they had been abused than they were to inform anyone else. McGee et al. asked their survey participants why they had not told before. Some noted that they had never been asked. However, there is research evidence, outlined in this chapter that even when asked, many children deny having had sexually abusive experiences when there is strong evidence to suggest that they have been abused.

\section{Child Sexual Abuse: Legal, Child Protection and Therapeutic Concerns}

Three major systems in society are particularly concerned with the issue of child sexual abuse, the legal system, the child protection system and the mental health or therapeutic system. Each system in turn places a different emphasis on issues such as the definition of the abusive behaviour and what is meant by an abuse 'disclosure' or 'reporting of sexual abuse'. The criminal justice system 
is concerned with the criminality of the behaviour, whether the statutes are sufficiently comprehensive to encompass the wide range of sexually abusive behaviours that human beings perpetrate on each other. The legal age of consent varies, usually from 14 years to 18 years. Issues of consent, the age difference between perpetrator and victim, the details of the offence, the filial relationship between the victim and the perpetrator, are of central concern to legislators. At the present time there is no criminal offence in Ireland labelled child sexual abuse although the Irish government did propose a new offence of child sexual abuse which would encompass all sexual offences against children (Dept. of Justice, 1998). In their discussion document on sexual offences the appendix lists 27 sexual offences, 9 of which refer to persons under 17. These do not include the generic offences such as 'rape' and 'sexual assault'. For the purposes of criminal law in Ireland, the age of consent to sexual intercourse is 17 years.

The legal system's involvement with the issue of child sexual abuse is dependent on children making formal complaints to law enforcement agencies to enable the prosecution of sex offenders. There is a strong emphasis on a well-articulated consistent account of the sexual abuse experience, something many children are unable to provide to the standards required by the courts. In addition, children rely to a great extent on their parents' willingness to make a formal complaint. The civic duty to report a criminal offence may be outweighed for parents by their own concern about the potential impact on both their child and themselves and the consequences for all concerned of engaging with the legal system. Not wanting other people to know about it, fear of relationship breakdown, and distrust of law enforcement agencies may outweigh their wish to have the abuser prosecuted. Concerns that children could be re-traumatised through engagement with the court process were highlighted in early research on the subject (Goodman, 1984) while the potential benefits of testifying were also highlighted (D. K. Runyan, Everson, Edelsohn, Hunter, \& Coulter, 1988). Edelstein et al. (2002) reviewed the literature in this area and suggested that children may experience heightened emotional and behavioural distress during and soon after the legal hearing but the long-term effects are not clear. A prospective longitudinal study conducted by Quas et al. (2005) indicated that the consequences of legal involvement change over the course of development and as a function of the child's reactions to and experiences during the legal case. The associations between legal involvement and outcomes varied with age. The authors suggested that although younger children may be at increased risk for some adverse outcomes such as mental health problems, older children may be at increased risk for other undesirable sequelae such as the negative attitudes of others towards them.

The difficulties in obtaining convictions of sexual crimes do little to encourage reporting to the police. Underreporting of sexual crimes is a problem that has been acknowledged in the literature (Edwards, 1996; Torrey, 1991). Formal reports made by adults range from 9\% (Bottoms, Rudnicki, \& Epstein, 2007), 10\% (Arata, 1998) and 12\% by young people (D.W. Smith et al., 2000). As 
Summit points out in an interview with David Corwin (Corwin, 2002) "for every thousand children who are sexually molested, probably five or ten ever testify in court" (p.21). A recent development in Ireland in the past two decades has been the significant increase in adults making formal complaints of sexual abuse experienced in childhood (McElvaney \& O'Shea, 2001). Recent studies have noted the potential impact of delayed disclosure on the credibility of victims as witnesses (D.W. Smith et al., 2000).

The second major system concerned with child sexual abuse is the Child Protection System. Child sexual abuse, because of the potential psychological sequelae and the repetitive nature of the behaviour, falls within the brief of statutory child protection agencies. Child protection agencies are concerned with the protection of children from harm. Many countries have introduced mandatory reporting, requiring all professionals to report a concern that a child is at risk of abuse. While significant increases in reports followed the introduction of such legislation, there has not been a parallel increase in the proportion of substantiated reports. In fact, trends in the U.S. indicate a decline in the 1990s in substantiated reports of child sexual abuse (L. M. Jones, Finkelhor, \& Kopiec, 2001). Child protection agencies are concerned with risk factors for perpetrators in reoffending, motivation to abuse, intentionality, the addictive nature and repetitiveness of the behaviour, the duration of the abuse, the grooming process and the capacity of parents to protect their children from future abuse. Sexual abuse is a very private experience and one difficult to detect. For the most part, only two people are present and the abuser is the less likely of the two to want the behaviour discovered. The child protection system is heavily reliant on children being able to give a clear disclosure of sexual abuse in order to make decisions in relation to protecting children from abuse. Standardised interviews are conducted with children (Home Office, 1992, 2000; Poole \& Lamb, 1998) often referred to as investigative interviews, to assist in making a deliberation as to whether the child is giving a credible account of an experience of sexual abuse. Concern about the credibility of children's accounts has fuelled much research on suggestibility, children's memories, and interviewing strategies.

Finally, therapeutic agencies for those who have been abused are concerned with the psychological impact of the behaviour on the child and family. Issues such as the relationship between the child and perpetrator, the age of the child, and methods of coercion used in gaining and maintaining the child's compliance are of concern. The psychological coping strategies which the child had to develop in order to cope with the psychological impact of sustained abuse (perhaps over a period of months or years by a loved family member) is important in determining the extent of intervention needed and the prognosis for the future. The therapist is less concerned with the child's ability to give a coherent comprehensive account of the abuse experience and is guided more from an assessment of the child's therapeutic needs. Many of the psychological difficulties arising from sexual abuse may only be satisfactorily addressed if the child is able to disclose the abuse. There is 
evidence that children who experience abuse over longer periods of time are at greater risk of negative long-term outcomes (Arata, 1998; Conte \& Schuerman, 1987; Kendall-Tackett, Williams, \& Finkelhor, 1993).

Thus, the focus of concern in relation to child sexual abuse can vary across the three professional systems that come into contact with the issue. For the legal system the emphasis is on the sexually abusive behaviour, whether this constitutes a crime and whether the child is a reliable witness and can engage in the legal process. For the child protection system, the focus is on whether the behaviour gives rise to concerns for protecting the child and/or other children and similarly whether the child is a reliable informant on which child protection decisions can be based. And finally, for the therapeutic system, how the child reacted to the abuse is of primary importance. Each system nevertheless relies on the child being able to give an initial disclosure of the experience of sexual abuse. Inhibitors to disclosure and how children can be helped to articulate their experiences are therefore a concern across all three systems.

\section{Disclosures of Child Sexual Abuse}

There has been a considerable amount of research in recent years on the subject of how children disclose experiences of sexual abuse in an attempt to describe typical patterns of disclosure. According to Paine and Hansen (2002), children's disclosures have been described as (a) purposeful, when a child consciously decides to tell another or accidental, when the abuse is revealed by chance rather than a deliberate effort on the part of the child; (b) spontaneous or prompted/elicited, for example, occurring only in response to direct questioning, often prompted by some behaviour or non-verbal communication from the child; and (c) explicit giving clear details of the abusive behaviour or vague/tentative referring to generic terms such as 'he touched me' (Bybee \& Mowbray, 1993; Kelley, Brant, \& Waterman, 1993; Sauzier, 1989; T. Sorenson \& Snow, 1991). Alaggia (2004) found these categories inadequate to encompass the broad range of disclosure experiences. In her qualitative study of 24 male and female survivors of child sexual abuse, she developed an expanded conceptualisation of disclosure patterns. This included four categories: (1) Purposeful Disclosure to describe direct and indirect verbal attempts and intentional behavioural attempts to disclose; (2) Behavioural Manifestations to include intentional and non-intentional behavioural attempts to disclose or behavioural effects or symptoms; (3) Disclosures Intentionally Withheld, to include intentional withholding, false denial, accidental discovery and prompted or elicited disclosure; and finally, (4) Triggered Disclosures of Delayed Memories. The latter referred to disclosure following recovery of memories which may have been inaccessible due to developmental factors and which has received more attention in the research literature in the last decade. In Alaggia's study, $58 \%$ of participants $(n=14)$ had not disclosed in childhood. Half of 
these did not disclose either because they had repressed or forgotten the memory or the abuse had occurred in preschool years and they had difficulty with recall.

Collings, Griffiths, and Kumalo (2005) studied patterns of disclosure in a sample of children who had experienced penetrative abuse attending a hospital clinic for medical evaluation. They suggested four discrete categories of disclosure: purposeful, indirect, eyewitness detection and accidental detection. In their study, 30\% of disclosures were purposeful, $9 \%$ were indirect, $18 \%$ of the abuse incidents were witnessed and $43 \%$ of cases were classified as accidental detection. Collings et al.'s study highlights the extent of purposeful versus other types of disclosures, albeit from a selective sample. Jensen, Gulbrandsen, Mossige, Reichelt, and Tjersland (2005) conducted a qualitative study of the disclosure process with 20 families of 22 children attending a therapy service due to concerns of a sexual abuse nature. They found that almost all of the initial remarks that led to the suspicion and referral of the child were prompted by someone engaging the child in a dialogue about what was bothering them. When the children did disclose, they did so in situations where the theme of child sexual abuse was in some way addressed. They suggest that disclosure is fundamentally a dialogical process where children need to perceive an opportunity to talk, where there is a purpose for speaking and where a connection has been established as to what they are talking about. Jensen et al.'s study raises the question: how much help do children need in order to disclose their experiences of abuse and how can adults offer this help? However, none of these studies claim to be representative of the population of children who have experienced sexual abuse. Both Allagia's and Jensen et al.'s studies involved small samples. Collings et al.'s study, while large $(\mathrm{N}=1737)$, was drawn from a hospital clinic where children were seen for medical evaluation. All the children in their sample had experienced penetrative abuse that was reported to the police, two characteristics unrepresentative of what we know about patterns of child sexual abuse.

It is only recently that dissatisfaction with the concept of disclosure and how it is defined has been documented in the literature. Jones (2000) refers to the lack of clarity as to whether the term disclosure refers to simply telling someone or to the formal report made to civil authorities. Lindblad (2007) emphasises the importance of clarifying what one means by the term 'disclosure' when discussing child sexual abuse disclosures. He acknowledges that the initial disclosure is usually informal and occurs to a close family member or friend. Alaggia (2004) notes that the term "disclosure" is more commonly used when describing a child's reporting of abuse in an investigative interview or therapy context whereas "telling" is more often used in studies that describe adult disclosures to family or friends. London et al. $(2005,2007)$ did highlight this distinction implicitly by providing separate reviews of child and adult studies in their reviews of the literature on disclosure but neglected to point out the difference in context, i.e. that for the most part the child studies were referring to formal disclosure, with little interest shown in the child's 
experience of disclosing prior to the formal interview, whereas the adults were referring to informal disclosure.

Most studies that examine the phenomenon of disclosure describe disclosures in the context of investigative interviews with a particular focus on interviewer variables such as questioning styles (Hershkowitz, Orbach, Lamb, Sternberg, \& Horowitz, 2006; Sternberg, Lamb, Davies, \& Westcott, 2001). Yet Keary and Fitzpatrick (1994) found that most of the children who disclosed in interview had already disclosed their abuse prior to the interview. Nevertheless conclusions are drawn about the way in which children disclose and the factors that influence such disclosure without drawing the distinction between these formal and informal contexts. Most of the available literature on disclosures of children has been examined in the context of specialised forensic or clinical interviews. However, London et al. and others rely on adult retrospective studies in drawing conclusions about disclosures - disclosures that for the most part occur in an informal context.

\section{Delays in Disclosure}

Studies of adults who reported having experienced sexual abuse in childhood indicate a strong tendency on the part of children not to tell anyone about the abuse (Russell, 1983). London et al. (2005) conducted a review of 11 retrospective adult studies. Despite differences in definitions of abuse, methodology employed and characteristics of the samples in studies reviewed, they noted a consistent finding that 10 out of the 11 retrospective studies indicated that only one third of adults who suffered childhood sexual abuse revealed the abuse to anyone during childhood. Definitions ranged from a narrow definition e.g. rape prior to $18^{\text {th }}$ birthday (D.W. Smith et al., 2000) to unwanted sexual contact (Arata, 1998). Samples ranged from those who opted into the study because they identified themselves as having been abused to convenience samples of college student or clients attending specialist abuse services to national probability samples. General population surveys of adults have found that of those reporting a history of child sexual abuse, $28 \%$ to $50 \%$ report never having disclosed their abuse to anyone (McGee et al., 2002; D.W. Smith et al., 2000). Length of delay varies considerably. Studies of adults have found delays up of to 50 years (McElvaney, 2002). Lamb and Edgar-Smith (1994) found that the mean age for first disclosure was 18 years, while the mean age of abuse onset for those in the sample was 8 years, resulting in an average delay of 10 years in their sample of adults.

Research involving child samples suggests that significant proportions of children do not disclose immediately and for many children their abuse is discovered in some other manner and they have never spontaneously disclosed (Gomes-Schwartz, Horowitz, \& Cardarelli, 1990; Kelley, Brant, \& Waterman, 1993; Sorenson \& Snow, 1991). Findings differ in the proportions of children who tell 
promptly and those who delay for significant periods of time. Sas and Cunningham (1995) found that $42 \%$ of their sample of children told within 48 hours of the abuse experience while D.M. Elliott and Briere (1994) report that $75 \%$ of their sample did not disclose within the first year and $17 \%$ waited more than five years to tell. Gomes-Schwartz et al. (1990) found that $17 \%$ of children with an objectively confirmed history of child sexual abuse had delayed reporting their sexual victimization for more than a year. Brannon and Larson (1991) studied a sample of adjudicated adolescent male offenders and found that $67.7 \%$ of the youth reporting a history of sexual victimization indicated that they had never disclosed their abuse to anyone prior to the study. Recent studies of children also reflect variability in the delays reported in disclosing experiences of abuse. In Collings et al.'s (2005) study of children who had experienced penetrative abuse, $47 \%$ had reported the abuse within 72 hours, $31 \%$ from 72 hours to 1 month after the abuse, and $22 \%$ more than a month after the abuse. However, D.W. Smith et al. (2000) estimated that $48 \%$ of young women in their survey had told no one for more than 5 years after the event.

In summary, there is great variation in how sexual abuse is defined across different jurisdictions, across different systems that deal with the issue of sexual abuse and across research studies. These definitions range from narrow and clearly defined sexually abusive behaviours to broad ranging and vague references to inappropriate or unwanted sexual contact. This variation accounts in part for quite disparate prevalence rates quoted from different studies. Difficulties in establishing accurate prevalence estimates have been highlighted, in particular due to the reluctance on the part of children and adults to disclose. Although the term disclosure may refer to various levels of disclosure, for example to a friend or family member, to a health care professional in a formal investigative interview context or to the police, the evidence is overwhelming that a significant proportion of children and adults who have experienced childhood sexual abuse are reluctant to disclose such experiences. Legal, child protection and therapeutic agencies rely on children's disclosures in initiating intervention to stop the abuse, addressing its immediate effects, decreasing the likelihood of negative long term outcome and preventing the abuse of other children. The secretive nature of sexual abuse and the frequent absence of physical findings place part of the responsibility of initiating intervention on to children themselves. Thus educational preventative programmes focus on helping children recognize abusive behaviour and encouraging children to tell a trusted adult about the abuse. The hope is that by helping children to disclose more promptly the more insidious psychological effects of abuse can be prevented or ameliorated and other children can be protected.

The following section will describe and critique the literature that has contributed to our understanding of the disclosure process for children and adults. Firstly, factors that influence the disclosure of child sexual abuse experiences are reviewed. Secondly, theoretical attempts to explain 
children's reluctance to disclose by either drawing on clinical experience or research studies will be presented.

Factors Influencing Disclosure of Child Sexual Abuse

Research in the field of child sexual abuse has tended to neglect the issue of how children disclose such experiences. As a result, earlier data on disclosure have for the most part been gathered as a peripheral aspect to studies focussing on other aspects of sexual abuse. Often the information was limited to that which is easily measured, thus, qualitative information was absent. Concerns about false allegations resulted in much research on how interviewers elicited information from children where there were concerns about sexual abuse. The focus of such research is not on the disclosure process per se but on how children disclosed in the context of investigative interviews, with particular focus on the influence of the interviewer in eliciting this information. Some of the research used samples of children attending therapy (Sorenson, \& Snow, 1991) and were therefore more likely to include information on disclosure in informal contexts, to family or friends. The studies of adults refer exclusively to disclosure in an informal context, except in the case of disclosure to survey researchers. As has been noted already, there is an implicit assumption in the literature that the contexts of adult disclosures and child disclosures are comparable and that the same factors apply. This is as yet unproven and indeed for the most part, un-investigated. Until recently, studies appear to have assumed that children have one experience of abuse by one abuser leading to one experience of disclosure. There has been a significant increase in interest in the subject of disclosure of sexual abuse experiences in the past few years with an edited book devoted to the subject (M. E. Pipe, Lamb, Orbach, \& Cederborg, 2007a). Some recent studies have taken a broader view of the disclosure process, acknowledging the experience as occurring over time and on occasion in incremental phases. This recognition of disclosure as a process has necessitated reliance on qualitative methodologies and the need to ask children and young people directly about their experiences. Those factors, which have been identified as influencing the disclosure of child sexual abuse experiences, are developmental differences, gender differences, the role of relationships (maternal support, child-abuser relationship and relationship to others and to whom the child disclosed), characteristics of the abuse experience (severity and duration, strategies used to gain or maintain compliance or secrecy), and societal and cultural factors (mandatory reporting, child abuse prevention programmes and cultural differences). 


\section{Age Differences}

Age and Likelihood of Disclosure

Age differences in prevalence rates of child sexual abuse are unknown. Age differences in disclosures of child sexual abuse have been found in studies of children seen for investigative interview. The largest such study was conducted by Hershkowitz, Horowitz and Lamb (2005) and involved an analysis of a database of all children seen in Israel between 1998 and 2002 for suspected physical and sexual abuse $(\mathrm{N}=26,446)$. Of those children where sexual abuse was substantiated, 20\% were aged 3 to 6 years, 39\% were aged 7 to 10 years and $41 \%$ were aged 11 to 14 years. This pattern of a higher incidence of disclosure with increasing age was held regardless of type of abuse suspected or the relationship with the suspected abuser. This finding is consistent with previous studies that noted that pre-school children were less likely to disclose during the context of formal investigation than older children (DiPietro, Runyan, \& Fredrickson, 1997; Gries, Goh, \& Cavanaugh, 1996; Keary \& Fitzpatrick, 1994). However, one of the difficulties with studying disclosures in the context of formal interviews is that children who have made a disclosure prior to formal investigative interview do not necessarily repeat that disclosure during interview. Keary and Fitzpatrick (1994) in their study of 251 children referred for sexual abuse evaluation found that $59 \%$ of children younger than 5 , who had made an earlier disclosure, did not describe the abuse during the investigative interview. Hershkowitz, Horowitz and Lamb (2005) point out that cognitive and motivational factors may be involved in the surprisingly large proportion of 3 to 6 year old children who did not allege abuse when questioned. They suggest that these children are disproportionately likely to misunderstand the purpose or focus of the interview or the abuse and this may result in a failure to report experiences of abuse. In their study, the younger age cohort were more likely to make allegations against familiar non-family members and strangers than against parents or step-parents and the authors suggest that non-allegations may have been motivated by threats or fears about possible repercussions of making an allegation. According to the authors: "it seems unlikely, though possible, that only one-fifth of the suspected sexual abuse by parents or partner figures actually occurred, as suggested by the disclosure rates reported" (Hershkowitz et al., 2005, p.1212).

Saywitz, Snyder and Nathanson (1999) found that in addition to the difficulties they may experience in communicating their abuse to others, the disclosures of disabled children (especially those with cognitive impairments) were less likely to be viewed as credible. This latter finding would appear to be relevant to the young pre-school child who is required to articulate their experiences at quite a sophisticated level, sometimes beyond their cognitive capacities, in order to be believed. 
Age and Type of Disclosure

Research studies have indicated that whether a child discloses accidentally or purposefully can depend on the age of the child. When younger children, particularly preschool age children, are compared to older school-age children, it has been found that the former are more likely to disclose accidentally while older children are more likely to disclose in a purposeful manner (Campis, Hebden-Curtis, \& DeMaso, 1993; Fontanella, Harrington, \& Zuravin, 2000; Nagel, Putnam, Noll, \& Trickett, 1997; Sorenson \& Snow, 1991). Kogan (2004) also found that the likelihood of purposeful disclosure increased with age. Collings et al. (2005) found that purposeful disclosure (as opposed to it being detected by another) was more common in older children and younger children but not among children of the middle-childhood age range (i.e. 7 to 9 year olds). This latter group was more likely to have their experience of abuse detected by others. Bussey and Grimbeek (1995) have suggested that children learn to inhibit disclosure as they get older. According to Collings et al., pre-school children may wish to keep the secret but do not have the cognitive competence and social experience to appreciate that indirect comments will raise the suspicion of others. Children in the seven- to nine-year old age group have learned this skill and are more effective in regulating disclosure. Older children because of their increased cognitive capacities recognise the abuse as wrong and are more likely to be motivated to disclose their abuse in a purposeful manner. Thus, children in the middle childhood years may be more vulnerable to non-disclosure: they realise the abuse is wrong and someone needs to be told but they are better able to withhold the information and are more capable of deception than their younger counterparts.

It has been suggested that purposeful disclosure may be inhibited in children who are developmentally immature or delayed due to limited knowledge of the social norms and behaviours that constitute abuse (Bussey \& Grimbeek, 1995; Sorenson \& Snow, 1991). However, it is also noteworthy that while younger children may not be aware of the social taboo associated with sexual behaviour, they also have less appreciation of the possible consequences of disclosing these experiences and of the impact of this knowledge on those to whom they disclose.

Children and young people have only recently been asked directly about their experiences of disclosure through the use of qualitative methods. These studies have provided more detailed information on disclosures in informal contexts i.e. prior to the child being seen for investigative interview. In particular, they have highlighted the frequency with which older children's disclosures have been prompted or elicited rather than being spontaneous or purposeful as described in research studies above. Hershkowitz, Lanes and Lamb's (2007) study found that $43 \%$ of their 7 to 12 year olds only disclosed after they were prompted.

Conflicting findings are evident in the literature as to the relationship between age and whether disclosure is timely or delayed. D.W. Smith et al., (2000) found that younger children are more 
likely to delay disclosure while Goodman-Brown, Edelstein, Goodman, Jones, and Gordon (2003) found that older children were more likely to delay in disclosing.

\section{Age and Delay in Disclosure}

Goodman-Brown and her colleagues (2003) investigated variables that contribute to a delay in disclosing and found that age and fear of consequences were significant influencing variables. They reported that $42 \%$ disclosed within 48 hours of the last assault, and 15\% more than 6 months after the last assault. However, while the authors defined time to disclosure as "time lapse between the last assault and the victim's disclosure to anyone" (p.533), duration of abuse, i.e. whether it was a once-off assault or occurred over a period of time, was not accounted for in their analysis. In their study, there was a significant interaction effect between age, perceived negative consequences and relationships to abuser. Older children perceived more negative consequences than younger children, as did children who were abused by a family member. Older children felt greater responsibility for the abuse. Children who feared negative consequences and who felt more responsible for the abuse took longer to disclose. The authors noted that children often weigh the consequences of their actions prior to disclosing. Kogan (2004) however, found that younger children (under the age of seven) were less likely to tell immediately and thus were more vulnerable to delayed disclosure than older children. Kogan reviewed data from a sub-sample ( $n=263$ female adolescents) of the National Survey of Adolescents in the United States (Kilpatrick \& Saunders, 1995, cited in Kogan, 2004). He suggested that younger children may be less able to overcome the barriers of immaturity and susceptibility to the strategies used by abusers to secure secrecy. Hershkowitz, Lanes and Lamb (2007) explored the disclosure processes of 30 children between the age of 7 and 12 years and found that the tendency to delay disclosure was related to age with significantly more of the older children (aged 10 to 12) delaying disclosure than younger children (aged 7 to 9 years). London et al. (2005) in their literature review suggested that there might be a U-shaped association between age and disclosure rate with younger children and adolescents less likely to disclose abuse, the former due to lack of awareness of the seriousness of the behaviour and the latter due to their increased awareness of the consequences of disclosure making them more likely to withhold information about their experiences. However, Kogan's and Hershkowitz et al's findings do not support this hypothesis.

\section{Age and Motivation to Disclose}

Motivating factors to disclose have been found to vary with age. Sorenson and Snow (1991) suggested that adolescents' anger at parental restrictions serves to override inhibitions and fears and becomes the fuel that drives the adolescent to disclose. In their study, anger was the main motivating factor to disclose among adolescents (25\%). When disclosures were purposeful, ongoing or renewed contact with perpetrator was seen to be the most frequent impetus to disclosure in all age groups (28\%). Involvement in educational programmes was the main impetus for 
disclosure for the younger school-age children when disclosures were accidental (T. Sorenson \& Snow, 1991). Lamb and Edgar-Smith (1994) found that children in their study disclosed the abuse in order to stop the abuse (47\%), to get support (21\%) or because they were asked to or encouraged to do so (10\%).

\section{Age and Choice of Confidante}

Roesler and Wind (1994) in their study of adult female incest victims ( $\mathrm{N}=228)$ identified three patterns of disclosure associated with age and choice of confidante. The first group had told in childhood, usually to a parent first. The second group had told in adulthood, mainly to a friend, other family members or partners. The third group had told their therapists in later adulthood. Hershkowitz et al. (2007) also found that older children were more likely to confide in peers and younger children to confide in parents and in Kogan's (2004) study of adolescent girls, young women between the ages of 7 and 13 were most likely to tell an adult while those aged 14 to 17 were more likely to tell peers. Similarly, Crisma, Bascelli, Paci and Romito (2004), in a study of mostly female adolescents aged 12 to $16(\mathrm{~N}=36)$, found that peers were by far the most popular choice of first confidante. London et al. (2007) in their review of relevant studies concluded that adults who told someone as a school-age child told a parent rather than a peer and "the most common confidant was another adolescent" (p.201). Kogan (2004) also found that the older teenagers were more likely to disclose experiences of unwanted sexual experiences with peers to other peers than childhood abuse experiences with adults. Thus in addition to there being developmental differences in choice of confidante with younger children tending to tell parents and older teenagers tending to tell their peers, the nature of the abuse experience may influence the choice of confidante at different stages of development.

Recent qualitative studies have highlighted the role of feelings about the abuse, fears of not being believed and shame and self-blame although no developmental differences have been noted for these variables (Crisma et al., 2004; Hershkowitz et al., 2007). Attempts to explain why older children differ from younger children have been confined to attributing these differences to the increased linguistic, cognitive and social capacities of older children. It may be that the emotional challenges of the adolescent years need to be taken into account when attempting to understand why teenagers withhold information about their abusive experiences. For example, the egocentricity of the younger child is referred to in the clinical literature to explain the phenomenon of self-blame for the abuse that in turn is seen as a factor inhibiting the child from disclosing. Yet this self-blame is also seen in older children and adolescents. Goodman-Brown et al. (2003) found perceptions of responsibility for the abuse to be a significant factor in older children's reluctance to disclose. They suggest that longitudinal studies are needed to explore whether children experience increased self-blame for actual negative consequences for the family after their disclosure. 
McGee et al. (2002) found that $67 \%$ of abused girls and $62 \%$ of abused boys in their sample had experienced abuse by twelve years of age. If children are more likely to be abused in their prepubescent years, the research on delays in disclosure would suggest that most children will not disclose abuse until adulthood, if at all. This suggestion is consistent with the research from adult retrospective studies.

In summary, developmental factors have been recognised as having an influential impact on the disclosure process for children and adolescents. While there is insufficient evidence to support an identifiable pattern of disclosure associated with age differences, various patterns have been found. Older children and adolescent are more likely to disclose purposefully than younger pre-school children. However, within this older age cohort, significant proportions of children only disclose when asked or prompted. Some studies have found that younger children disclose more spontaneously and are less likely to delay in disclosing that their older counterparts. One study found a different pattern, targeting the younger child as the one most vulnerable to delaying their disclosure. A recent review of the literature suggested that there might be a U-shaped association between age and disclosure with both younger children and adolescents being more likely to disclose soon after the event while children of the middle childhood years might delay disclosure but other studies have not supported this hypothesis. Motivating factors for disclosure have been found to be associated with age, with teenagers more likely to disclose out of anger and younger children more likely to disclose following an education programme. However, this is based on one study alone and few studies have examined what helps children tell but have focussed more on the barriers to telling. Patterns have been identified in choice of confidante with younger children more likely to confide in parents and teenagers more likely to confide in peers.

\section{Gender Differences}

Most studies have found that boys are more hesitant and more unlikely to disclose than girls (Bolton, Morris, \& MacEachron, 1989; Keary \& Fitzpatrick, 1994; Lamb \& Edgar-Smith, 1994; Reinhart, 1987; Watkins \& Bentovim, 1992). Ullman and Filipas (2005) in their survey of 733 college students found that women in their study were more likely to have disclosed their childhood sexual abuse experience to others and to have received positive reactions than men in the study. DiPietro et al. (1997) and Keary and Fitzpatrick (1994) found no gender differences in their studies. Goodman-Brown et al. (2003) suggest that gender differences may be suppressed by other abuse-related variables associated with gender, such as prior disclosure or relationship to perpetrator.

Gender differences may increase with age, as adolescent boys have been observed to be least likely to report their sexual victimization (Hecht \& Hansen, 1999; Lamb \& Edgar-Smith, 1994; Watkins 
\& Bentovim, 1992). Faller (1989) has noted that boys' reluctance to disclose emanates from "the fact boys are socialized not to have doubts, weaknesses, and fears, and the fact that, since more of the abusers are male, boys have the additional taboo of homosexuality to overcome if they tell" (p.282). Additionally boys sexually abused by a female are faced with societal norms that endorse and even glorify “older woman/young boy" sexual relationships and fantasies (Hecht \& Hansen, 1999; Jennings, 1993). Alaggia (2005) suggests that victimization can, in these circumstances, be minimized or denied.

Collings et al. (2005) suggest that while boys may be significantly less likely to report sexual abuse than girls, when they do disclose, they tend to use similar strategies to girls. It is difficult to isolate variables such as age, gender, disability and motivation to disclose from each other and from other variables that are outlined above and there is an increasing recognition of how factors interact with each other to influence disclosure.

\section{The Role of Relationships}

Children are by nature dependent on others. It is through their relationship with others that they gain a sense of security and a belief that the world is a safe place (Bowlby, 1998; A. Miller, 1987). When these relationships are a source of danger rather than safety, it is crucial for children that they have a good enough balance in their repertoire of relationships so that the 'good' outweighs the 'bad' and that the child can find someone in their world in whom they can trust and confide their abuse experiences. As the mother-child relationship has traditionally been seen as the primary relationship for the developing child, the limited research that is available has tended to focus on this relationship. Similarly, the focus has been on whether the abuse was intra or extra familial rather than taking a broader view of whether the relationship was significant to the child or not.

\section{Maternal Support}

The child's willingness to disclose is influenced by parental (typically maternal) support (Lawson \& Chaffin, 1992; D. K. Runyan, Everson, Edelsohn, Hunter, \& Coulter, 1988) which is in turn linked to the caretaker's relationship with the offender (Faller, 1989). D.M. Elliot and Briere (1994) examined the role of maternal support in a sample of children for whom sexual abuse was substantiated ( $\mathrm{N}=248)$. Those children who did disclose in formal interviews were more likely to have supportive mothers than those who did not disclose abuse that was subsequently substantiated. The latter were also more likely to have been abused by a perpetrator in the home. The importance of maternal support has been emphasised both for its role in encouraging disclosure but also in mediating the impact of the abuse. Maternal response to the child who has disclosed sexual abuse has been found to be the strongest predictor of outcome for the sexually abused child. According to A.N. Elliott and Carnes (2001), one of the most consistent findings in the literature indicates that support or protection from non-offending caregivers is associated with the positive emotional and 
behaviour adjustment of children who have been sexually abused. Maternal support can be dependent on the mother's own psychological resources, her relationship with the abuser and whether or not she believes the child's disclosure. Studies of maternal support and relationship to the abuser have been complicated by family contexts such as intra-familial abuse by the child's father who is non-resident with the family. A.N.Elliott and Carnes point out methodological differences between studies such as inconsistency in defining abuse by step-fathers, or by mothers' partners as intra-familial and stating whether families are intact or not. These differences have implications for whether the mothers in these studies have emotional attachments to or are financially dependent on the abuser. Finally, differences can emerge in terms of how maternal support or protection is defined and from whose perspective, i.e. the child's, the family's or the professional's. As Jensen et al. (2005) note, "it is not uncommon for parents to harbour some doubts about abuse and at the same time act in order to protect the child as well as they can" (p.1407).

\section{Abuser-Child Relationship}

Studies consistently indicate that children are most often abused by someone known to them. (Finkelhor, 2007). The child is often emotionally close to the perpetrator, as the latter is often a parent or parent figure (Berliner \& Conte, 1990; Faller, 1989; Gomes-Schwarz et al., 1990; Sorenson \& Snow, 1991). The perpetrator is frequently in a position of power and authority over the child and /or charged with providing for the child's care (Berliner \& Conte, 1990; Sorenson \& Snow, 1991). Berliner and Conte noted that most of the children in their study described their relationship with the perpetrator as positive. Many expressed ambivalent feelings towards the individual perpetrating the abuse. "Over half said that they loved him, liked him, needed or depended on him" (p.32).

Both child and adult studies have indicated that children abused by a close family member are less likely to report their abuse than those abused by a stranger (DiPietro et al., 1997; Hershkowitz et al., 2005; Sauzier, 1989; Sorenson \& Snow, 1991). Wyatt and Newcomb (1990), in their study of adult women found that the more closely children are related to the abuser the less likely they are to disclose. Clinicians have also observed children who are sexually abused by a close family member are particularly hesitant to disclose their abuse (Furniss, 1990; Reiser, 1991; Summit, 1983). Faller's (1989) study of 157 children concluded that the nature of the relationship between victim and offender affects the length of delay to disclosure as children abused by those closer to them will take longer to reveal the abuse. Other authors support this finding that delays are longer for those abused within the family (Goodman-Brown et al., 2003; Sjoberg \& Lindblad, 2002; Kogan, 2004). Sauzier (1989) in her follow up study of 156 sexually abused children found that disclosure was a more difficult process in victims who were abused by family members. Clinical experience suggests that children often believe that if they keep quiet about the abuse, everything will be 
alright, the status quo will be maintained and that children have little awareness that offenders often progress to more serious forms of abuse over time (Salter, 1995). According to Kogan (2004), disclosure of intra-familial abuse is often accompanied by a greater degree of disruption within the family and a greater sense of shame among family members. The consequences therefore are more dramatic while a disclosure of abuse by a stranger has fewer potential costs. He also cites Ullman (1999) in suggesting that reports of an unwanted sexual experiences by a stranger are more likely to be believed by family members and may result in less self attributions of blame or shame. Collings et al. (2005) also found that the type of disclosure varied with the relationship to the abuser.

Children who made explicit purposeful disclosures were less likely to have been abused by family members.

One of the difficulties with research in this area is that of accessing research participants to enable meaningful comparisons between children who are supported within their families and those who are not, as the latter may not be willing to participate in studies. Goodman-Brown et al. (2003) found that families involved in intra-familial abuse were significantly less likely to participate in their study compared to those involved in extra-familial cases. They also found higher rates of participation in families where the charges involved more severe and invasive abuse.

In more recent years, children have increasingly presented to services following reports of abuse by peers, referred to in the literature as sexualised behaviour when occurring between younger children (Gil \& Johnson, 1993). Whether this relationship impacts on willingness or reluctance to disclose such experiences has received little attention but Sperry and Gilbert (2005) compared the disclosure histories of a sample of college students and noted that those who reported abuse by peers anticipated less support from their parents than those who were abused by an adult.

\section{The Child's Relationship with Others}

Many studies have highlighted the perception that young people believe they are protecting others by not disclosing their abuse experiences. While initially attention focussed on the child's wish to protect the abuser, particularly in the case of intra-familial abuse, more recent studies have highlighted the child's wish to protect the primary caregiver, usually the mother. Jensen et al. (2005) found that although mothers were most often the ones who prompted disclosure, they were also the ones the children wanted to protect by not telling. Concerns for mothers outweighed concerns for either self or the alleged abuser. Crisma et al. (2004) found in their sample of 36 adolescents that a quarter of their sample said they did not disclose because they wished to protect their parents from what they perceived to be the possible negative consequences of such a revelation. 


\section{To Whom Child Disclosed}

Several studies have indicated that children are more likely to reveal abuse to their primary caregiver than anyone else (Gray, 1993). However, this finding may be dependent on such factors as age at the time of abuse, and whether the source of information for the study was children themselves or their files, with the latter perhaps being dependent on parent informants. Adults who disclosed their experience of abuse as a school-age child did so to a parent rather than to a peer (Arata, 1998; Lamb \& Edgar-Smith, 1994; Palmer, Brown Rae-Grant \& Loughlin, 1999; Roesler \& Wind, 1994). Sperry and Gilbert (2005) found that less than a quarter of their sample of undergraduate students who had disclosed sexual abuse had told a parent. Berliner and Conte (1990) interviewed 82 children and their caretakers and found that only $43 \%$ of the children had told their parents first. Kogan (2004) found in his sample of adolescents that the most common initial confidante was a close friend (36\%), followed by mother (35\%), other relatives ( $8 \%$ ) and other authority figures $(6 \%)$. According to London et al. $(2005,2007)$ adolescents may have a greater appreciation of the consequences of disclosing intra-familial abuse and thus withhold information. It is possible that they do not disclose extra-familial abuse because they see it as a personal matter or have already told their peers. London et al. (2005) point out that disclosure rates may be associated with the onset of the abuse that in turn is associated with the availability of a same-age confidante. Collings et al. (2005) noted that of their sample that disclosed purposefully (30\%), the confidante was a family member in $48 \%$ of cases, a community member in $32 \%$ of cases, a policeman in $12 \%$ of cases, and a teacher in $8 \%$ of cases. They highlight the role played by both children and significant others in the process of child sexual abuse recognition and reporting. Detection by another was found to be more likely as the stimulus for disclosure than purposeful disclosure by the child. They suggest that prevention programmes need to more actively engage members of the broader community in the process of detecting and responding to the problem of child sexual abuse. Jensen et al. (2005) note that in their study, the context for disclosure resulted in someone recognising the child's cues and probing further. They suggest that a certain 'preparedness' and 'sensitivity' is required from the caregiver to initiate conversations or follow up on the cues the child has offered in order to facilitate disclosure. They also refer to the need for a certain 'readiness' on the part of the child to tell about the abuse experience.

The interaction between variables such as maternal support and choice of confidante was highlighted by Cyr et al. (2003) who discovered that adolescents in their study who first reported abuse to their mothers received significantly more support than those who first told someone other than their mother. Similarly, Plummer (2006) highlights the interaction between maternal support and child's relationships with others. She cites research by Donalek (2001) which revealed that adolescents may not disclose their abuse to their mothers if these mothers are perceived as needy, thus potentially leading to more negative consequences than if they kept the secret. The role of 
peers as confidante has already been outlined in the section above on developmental differences in disclosure patterns.

\section{Characteristics of the Abuse Experience}

As Furniss (1990) has noted, child sexual abuse is a syndrome of secrecy. The abuse itself often takes place in a secretive environment with no witnesses and is accompanied by admonishments, implicit or explicit, to keep it a secret. In addition, the psychological impact of sexual abuse often leads to the development of symptoms that in turn deter the child from disclosing the abuse. Salter (1995) describes non-disclosure of sexual abuse as a way of coping with the emotional impact of the abuse. Defense mechanisms are developed, such as denial, distraction, dissociation, as coping strategies, as a means of coping with the overwhelming affect which would be experienced if the abuse was talked about or thought about. Salter describes a continuum of denial in victims of abuse ranging from amnesia, to not admitting the event to not defining the event as abusive to not considering it important. Dissociative symptoms refer to behaviour such as avoiding places or people that remind the child of the abuse, trying not to think about it as a means of coping with the psychological distress the child experiences when she does think about it. Some empirical evidence is available to support these assertions in that children exhibiting high levels of post-traumatic stress have been found to be more reluctant to disclose their experiences of abuse (Koverola \& Foy, 1993; Sauzier, 1989). In addition the feelings of shame often engendered in children as a result of sexual abuse and the fact that children often blame themselves for the abuse, believing it was something in them that either attracted the abusive behaviour or that they in some way are responsible for it, may act as further deterrents to disclosure. However, psychological impact is itself a complex subject and is generally confined to generating lists of presenting symptoms of people who have been sexually abused with little reference to any objective measure of causality. No known studies have examined in any detail the relationship between psychological impact and disclosure patterns. Those factors, which have been identified in research studies, can be categorized into the severity and duration of the abuse, and strategies used by the abuser to gain or maintain compliance on the part of the child.

\section{Severity and Duration of abuse}

Gomes-Schwartz et al. (1990) conducted a large-scale study and found that children who suffered abuse at either the more severe (sexual intercourse) or the milder end of the spectrum (attempted sexual activity or non-contact forms of sexual abuse) of abuse were least likely to disclose their victimization. Sauzier (1989) and Farrell (1988) found a similar pattern of non-disclosure associated with more serious forms of abuse. The researchers did not explore with the participants their reasons for disclosing but clinical experience indicates that many children who suffer mild forms of abuse do either not recognise the behaviour as abusive and therefore do not see the need to tell anyone or dismiss the behaviour as unimportant. Children who suffer more extreme forms of 
abuse suffer more psychological sequelae, and experience more shame all of which has been found to be associated with high levels of secrecy and non-disclosure. Arata (1998) found that participants reporting contact sexual abuse were significantly less likely to disclose than those reporting non-contact sexual abuse. Research suggests that the longer children are abused, the more hesitant they may be to disclose their abuse (Arata, 1998; D.M. Elliott \& Briere, 1994; Sauzier, 1989).

\section{Strategies Used to Gain/Maintain Compliance}

The methods used by perpetrators to gain and maintain the victim's compliance and silence have been well documented in the clinical and research literature (Budin \& Johnson, 1989; Christianson \& Blake, 1990; Furniss, 1990; Kaufman, Hilliker, \& Daleiden, 1996; Lyon, 2007; Singer, Hussey, $\&$ Strom, 1992; Steward, Bussey, Goodman, \& Saywitz, 1993). Both victims and perpetrators have identified a gradual process whereby perpetrators employ successively inappropriate comments and increasingly inappropriate touches and behaviours so insidious that the abuse is often well under way before the child recognizes the situation as sexual or inappropriate. Strategies employed to gain the compliance of victims include rewarding the child with attention, gifts, promises, misrepresenting society's or other's moral standards and/or the abusive acts themselves, and putting responsibility for the abuse onto the child or another. Children are told they will be thought poorly of, blamed or punished in some way (Kaufman et al., 1996). Threats can take many forms including physical harm to victim and/or their loved ones (Kaufman et al., 1996; Kelley et al., 1993) or forecasting negative or dire outcomes for the victim, their loved ones, and/or the perpetrator. In a general study investigating how children respond to adults' request for secrecy, the authors found that young children's disclosures of an adult's misdeeds were significantly suppressed when the request for secrecy was delivered in a more stern tone (Bussey, Lee \& Richard, 1990 as cited in Bussey \& Grimbeek, 1995).

Studies provide conflicting findings on the relationship between disclosure and method of coercion. Some have found no relationship (Arata, 1998; Lamb \& Edgar-Smith, 1994) although these studies were exclusively of adults' retrospective accounts in the context of a survey. Face to face interviews may elicit more detailed information about methods of coercion that are often subtle and may be difficult to recognize and articulate. Adults are relying on their memory of such subtle interactions that may not be represented in a questionnaire-type response. In one study children subjected to aggressive strategies either told immediately (39\%) or refrained from reporting the abuse at all (43\%) (Gomes-Schwartz et al., 1990). In an archival study of children's disclosures of sexual abuse, findings revealed that delay to disclosure was nearly twice as long when records contained indications of physical aggression by the perpetrator against the victim or members of the victim's family (Paine \& Hansen, 2002). However, D.W. Smith et al. (2000) found no relationship between use of threats and force, injury to the victim, the use of a weapon or severity 
of the assault and caution against generalizations about the likelihood of disclosure based on the severity of the assault. However, some evidence exists for increased disclosure rates when abuse is perceived as life threatening and involves physical injury. Other studies have found no significant relationship between severity and method of coercion and disclosure (Lamb \& Edgar-Smith, 1994; D.W. Smith et al., 2000).

Sauzier (1989) found that disclosure was more difficult when the abuser used attention and special favours as methods of gaining victim compliance. Sas and Cunningham (1995) also found that delays in disclosure were more evident when the perpetrator 'groomed' the children and established a close relationship with them than if the perpetrator used force.

\section{Societal and Cultural Influences}

Little research is available on the contribution of societal and cultural influences on the disclosure process. Yet as Greene \& Moane (2000) point out, "children live their lives in families, schools and neighbourhoods but the quality of their daily experiences is influenced by the political, legal, educational and social welfare systems put into place in their society. These systems in turn reflect the values of that society." (p.135). The value placed on children and children's experiences of sexual abuse is therefore reflected in societal structures and mechanisms. Legislation for protecting children, how offenders are dealt with by the legal system, the availability of therapeutic services for both victims and offenders, national policies for child protection, and school educational programmes all impact indirectly on the experience of disclosure. Cultural influences reflect how childhood is valued and how children are perceived in a society, for example as the possession of the parent or as independent beings in their own right. Views on sexuality and sexual mores vary from one culture to another. All these factors contribute to the influences on the individual child in disclosing experiences of abuse.

Variations in belief systems and value orientations related to one's cultural background have been identified as factors influencing an individual's willingness to disclose sexual abuse (Toukmanian $\&$ Brouwers, 1998). Toukmanian \& Brouwers note that children raised within cultures espousing what they refer to as a collectivistic (rather than individualistic) value system may be more hesitant to disclose their abuse due to heightened concerns regarding the negative impact their disclosure will bring upon their family and ancestors. Cultural attitudes towards purity-virginity and/or stigmatisation of those sexually victimized greatly impede disclosure for some (Kazarian \& Kazarian, 1998; Muntarbhorn, 1996).

Media representations of child abuse can reflect societal or cultural attitudes to such issues. This has received some attention in the research literature with a special issue of Child Abuse Review devoted to the subject in 1996. Goddard \& Saunders (2000) studied the language used in the print 
media when reporting cases of sexual abuse. They refer to the tendency to use the pronoun 'it' to describe a child while 'he or she' is used to represent adults. They suggest that the use of the word 'it' may reflect an emotional response of distancing due to the unsavoury nature of child abuse . They also refer to abuse being redefined in the media and quote an example of a man jailed for twenty five years for the repeated sexual assault of his ten year old stepdaughter. This was described in the media as an "affair" between "the couple". In Ireland, an explosion of awareness of child sexual abuse has occurred in the past two decades. Media coverage, both print and electronic, as well as the publication of both biographical and autobiographical accounts of harrowing experiences of child sexual abuse has highlighted abuse in Irish orphanages and institutions in the 1950s and 1960s. Goode, McGee and O'Boyle, (2003) discuss how Irish legislation and governmental policies in this country contributed to the suppression of public awareness of child sexual abuse in Ireland, including a reference to a low prosecution rate of sexual crimes (15\%) "because of the desire of parents to keep the abuse secret and their reluctance to have their child appear in court" (p.281).

Social commentators have referred to sexual repression in Irish society as promulgated by the Catholic Church. The development of the Irish State has been strongly influenced by the Roman Catholic Church, not least in the form of involvement in the education system through patronage and management of schools. Goode et al. (2003) point out that the interaction between Church and State is important in understanding the evolution of social policy in Ireland. Although immigration rates have been high in recent years, the country is still predominantly Catholic, and this extends to the provision of schooling, hospitals and many voluntary agencies providing services for children. Catholic ethos in Ireland is strong including Catholic values concerning sexuality. In Goode et al.'s study of sexual abuse by Clergy and Religious, they conducted a public survey (N=1081) and found that $66 \%$ of the public reported that they look to priests for moral guidance while $32 \%$ looked to the Church for guidance on sexuality issues. Nevertheless, state inquiries and changes in legislation in Ireland in the past decade reflects a growing awareness on the part of the public and a growing commitment on the part of the government to legislate for the issue of sexual abuse.

\section{Child Abuse Prevention Programmes}

Internationally, the implementation of child abuse prevention programmes in schools has shown some promising results. Twenty four per cent of Sorenson \& Snow's (1991) sample of children who disclosed purposefully did so because of school programmes. These programmes addressed such issues as touching but also divorce and social skills. Early school age children were the group most influenced. Views expressed in the literature have been mixed in relation to the effectiveness and indeed the appropriateness of educational programmes that have prevention of sexual abuse as their aim. Some have criticised such programmes for placing an undue burden on children to prevent abuse but the majority of reviews have found them effective in enhancing children's, 
parents' and teachers' safety knowledge and skills (MacIntyre \& Carr, 2000) and in promoting disclosure (Davis \& Gidycz, 2000; Finkelhor \& Strapko, 1992 ; Rispens, Aleman \& Goudena, 1997; all cited in Finkelhor, 2007) and one study has found a reduction in self-blame in children participating in such programmes (Finkelhor, Asdigian, \& Dziuba-Leatherman, 1995). In Ireland, the Stay Safe programme (MacIntyre \& Lawlor, 1991) was introduced into primary schools in 1991 as a child abuse prevention programme aimed at children, parents and teachers. One of its primary goals is the prevention of sexual abuse by increasing children's disclosure skills. The programme includes discussions with children on the barriers to disclosure and a rehearsal of strategies, skills and developing a vocabulary for disclosing abuse. An evaluation of the study indicated that significant gains in knowledge and skills were maintained for children participating in the programme at three months follow-up (MacIntyre \& Carr, 1999a, 1999b).

\section{Mandatory Reporting Legislation}

All 50 states in the United States of America have reporting statutes which require relevant professionals to report cases of known or suspected abuse to the appropriate investigative agency. In many states, the statutes require all adults to report known or suspected abuse. Numerous studies have shown that significant numbers of professionals mandated to report fail to do so (Faller, 1985; Paine \& Hansen, 2002; Pope, Tabachnick, \& Keith-Spiegel, 1987; Swoboda, Elwork, Sales, \& Levine, 1987). One study showed that although three quarters of respondents in a public attitudes survey were aware of their obligation to report, only one third had actually reported the abuse to the authorities (Dhooper, Royce, \& Wolfe, 1991). It has been suggested that the introduction of mandatory reporting can inhibit children from disclosing experiences of sexual abuse because of their fears of the consequences of such disclosures. Those in favour of mandatory reporting legislation as a child protection measure point out that introducing such legislation represents a commitment on the part of governments to deal with the issue which in turn influences public attitudes (ISPCC, 1996).

In Ireland, reporting of child abuse is not mandatory. The Child Care Act (Government of Ireland, 1991) strengthened the powers of the national child protection agency, now the Health Service Executive (HSE) to intervene in cases of child abuse and reflected a commitment on the part of the government to strengthen the rights of the individual child. However, in Ireland, the rights of the child compete with the paramountcy of the family as recognised in the Irish Constitution (Government of Ireland, 1939) except in cases of extreme deprivation or abuse (Greene, 1994). The first published guidelines on dealing with reports of child sexual abuse were published in 1987 (Dept. of Health, 1987) and following a public debate on mandatory reporting in the mid 90s, the Department of Health and Children published national guidelines in 1999, Children First (Dept. of Health \& Children, 1999), which placed a civil duty on citizens to report suspicions of child abuse to the HSE. While the impact of such developments has not been evaluated in the Irish context, 
such measures do inherently reflect a greater vigilance on the part of the state in responding to sexual abuse disclosures.

\section{Limitations of Research on Factors Influencing Disclosure}

As is clear from the literature described above, traditionally studies that focus in detail on those factors that influence children in disclosing sexual abuse tended to focus on variables that are quantifiable and easily measured, and relied on adults' accounts of abuse in childhood or children's files. Mention was made of difficulties in establishing prevalence rates of child sexual abuse at the beginning of this chapter. These difficulties are exacerbated when we look at the literature on disclosure.

Adult retrospective studies have the obvious limitations of reliance on memory and the possibility of a change in perception or understanding over time. Most of the literature referred to above involves studies of adults who have been sexually abused in childhood. People's understanding of their actions change with the passage of time, with increased understanding of themselves and their situation, with ongoing psychological impact issues and with the help of support in the form of friends, family or professional counselling. Adults' accounts of their reasons for non disclosure 20 years after the event may be more a reflection of their understanding of this phenomenon as adults than their understanding of the issue as a child, 20 years beforehand.

The strength of retrospective studies lies in their ability to capture the process of disclosure over a substantial period of time. Thus, retrospective adult studies give a fuller picture of the overall process. Kogan (2004) also points out that adult retrospective studies include individuals who did not present to services and who may not have disclosed until the survey. He suggests that despite the difficulty of recall bias, these studies may be more generalisable in outlining the factors that are associated with disclosure. Disclosures made to friends or family are not considered in many studies even though these types of disclosures have important consequences for whether or not abuse is reported to civil authorities and if the child is believed, blamed or ignored (Roesler \& Wind, 1994).

Most of the studies involving child samples involved retrospective analyses of files with a more recent trend evident of interviewing young people directly about their experiences. There are distinct differences between the types of sample included. Samples vary in terms not just of how abuse is defined but also in terms of how the determination is made that the child was abused. In the absence of an objective measure of abuse, researchers rely on factors such as perpetrator convictions, confessions, physical evidence, witnesses to the incidents, and professional opinion 
based on interviews with children in different contexts. In adult studies, self-reported abuse is the typical criteria used for inclusion in studies. Problems with all of these methods have been identified in the literature. Even in the case of convictions, the accused may accept a plea bargain to avoid a lengthy trial while some convictions have been overturned (Lyon, 2007). Lyon also highlights the difficulties with medical evidence that may result from another injury. Samples range therefore from highly selective samples where there is a high probability that all the children were abused to large probability samples where the information gathered is limited to descriptive statistics and frequencies. Varying inclusion criteria therefore impedes comparison and generalisation.

The level of information available in these studies also varies. Some studies have used samples of children attending therapy, where the researcher is reliant on the type of information recorded by the therapist. Sorenson and Snow's (1991) study is a good example of this. They developed their model of stages of disclosure from a large sample $(\mathrm{N}=630)$ of children's files and then tested their model on a smaller sample $(n=116)$, again of retrospective files. Other studies have used child protection files or files from state prosecution services which by nature would contain much more specific and detailed information about the child's experience of sexual abuse and would rely more on what the child said than the professional's interpretation of the child's story. However, these files may not have detailed information about the experience of disclosing the abuse that a therapist would have access to given their ongoing work with the child. In the Goodman-Brown et al. (2003) study of the variables associated with delay of disclosure among children, the data were obtained for 218 children, most of which were obtained from files and from interviews with parents. Although children were interviewed in the latter study, the researchers were not permitted to question the children about abuse directly, but relied on comments the children spontaneously made or in response to questions by others. It is difficult therefore to make meaningful comparisons among such diverse samples.

The broad range of sexually abusive behaviours that are perpetrated on children also makes comparison among studies difficult. Studies relying on prosecution files represent the tiny percentage of children who make formal complaints and which in turn tend to be extra-familial cases and representing more severe forms of abuse. Larger samples tend not to be representative. Collings et al.'s (2005) sample of 1737 in South Africa, were accessed through a medico-legal service provided by a hospital and had all experienced penetrative abuse.

It is extremely difficult to access children from the general population as participants in studies of disclosures of child sexual abuse. Due to legal constraints, there is a danger that discussions about the disclosure can contaminate the evidence required for legal proceedings. Child Protection Agencies encourage as little intervention as possible prior to a formal investigation of the child's 
allegations. Response time varies across different services in different parts of a country and so the time delay from initial disclosure to formal interview varies considerably. While families are discouraged from discussing the child's disclosure before formal interview, it is difficult to discourage a child who needs to talk or an anxious parent who needs to know. If prevalence rates are underestimated and children coming to the attention of child protection agencies are underrepresentative of the population of children who have been sexually abused, it is difficult to make any helpful generalisations.

London et al. (2007) claim that "it is difficult if not impossible to obtain accurate information if the first disclosure is made outside a formal setting (e.g. to a parent, friend or teacher). We have to rely on studies in which children are questioned in formal investigative interviews" (p.217). However, these authors do not appear to have the same difficulty relying on adult retrospective accounts of first disclosures in their review even though the passage of time since that disclosure is considerable in the latter samples. If children are able to give consistent accurate accounts of sexual abuse experiences, why would they not be able to give accurate accounts of their disclosure experiences?

In reviewing the literature outlined above, a striking feature of the body of research is the lack of a theoretical framework to inform research in this area. Research has been conducted on an ad hoc basis with an emphasis on descriptive variables with little reference to theory and little attempt to draw the relevant variables together into a framework that would inform future research. One theoretical framework that could inform this area of research draws on the work of Uri Bronfenbrenner. Bronfenbrenner's model of the ecology of human development $(1977,1979)$ has informed thinking in the field of child maltreatment (Belsky, 1980, , 1993) and more specifically the field of child sexual abuse (Westcott, 1999). Belsky conceptualised child maltreatment as a social-psychological phenomenon that is "multiply determined by forces at work in the individual (ontogenic development) and the family (the microsystem), as well as in the community (the exosystem) and the culture (the macrosystem) in which both the individual and the family are embedded "(Belsky, 1980, p. 320). Belsky emphasized how these different forces interact with one another in the etiology of child maltreatment. Westcott (1999) uses Bronfenbrenner's framework to inform our understanding of the investigative interviewing process in child sexual abuse in England. At the microsystem level is the interviewer and child. The mesosystem refers to the relationship between the interview and the child's home situation, social support networks, and the school. The exosystem may include social services departments, police stations and crown prosecution service offices where decisions are made about interviewing and protecting children, prosecuting offenders, and developing related policies and procedures. Finally, the macrosystem consists of current societal beliefs concerning children, and particularly their responses as 
witnesses and victims of abuse. These beliefs will be reflected in different ways in the professional subcultures involved, such as social work, the police and the law.

As Belsky's focus was on child maltreatment within the family, his 'individual' is the abusing parent and the characteristics of the individual he refers to are the childhood experiences and personal resources of the individual parent. In his conceptual framework he situates the abused child in the microsystem, as does Westcott (1999). However, in considering the issue of children disclosing experiences of sexual abuse, Belsky's framework is helpful in providing a structure for integrating the research outlined above. The individual in Belsky's framework would then become the child in such a structure and would refer to the developmental and gender differences outlined above. The microsystem would contain the child's relationships to others and characteristics of the abuse experience while the influences of the wider society and culture would be manifest in the exosystem through the local community and the macrosystem through child protection legislation and policies and cultural attitudes. How abuse is perceived and responded to at the various systemic levels impacts both directly and indirectly on the individual child's ability to disclose and others' ability to receive and believe the disclosure.

\section{Summary}

In summary, while few studies have addressed the issue of disclosures of sexual abuse, factors have been identified which influence children's disclosures. There are mixed findings as to whether differences exist between different age groups in prevalence of disclosing abuse, but there is evidence to suggest that older children will disclose more purposefully and will give more clear details than younger pre-school children whose disclosures tend to be more vague and will more typically occur accidentally. It may be that patterns are different for adults than for children. Boys are more reluctant to disclose experiences of sexual abuse than girls and added vulnerabilities such as cognitive or physical disability, shyness or family circumstances such as single-parent families may act as inhibitors to children in disclosing sexual abuse. Factors pertaining to the child's relationship with others are particularly relevant with respect to maternal support, concern for others, to whom the child will disclose and the relationship between the child and the abuser. Children who feel supported by their mothers are more likely to disclose sexual abuse. Children abused by a close family member are less likely to disclose than children abused by a stranger. Those factors pertaining to the abuse experience itself which influence disclosure of child sexual abuse include the severity and duration of the abuse, the psychological impact as manifested in posttraumatic symptomatology and the strategies used by the abuser to gain/maintain compliance and secrecy on the part of the child. Children who experience abuse of a more severe nature i.e. penetrative and over a longer period of time are less likely to disclose than children who experience 
non-penetrative abuse on a once-off occasion. Children who suffer posttraumatic symptomatology are less likely to disclose than children who do not. When aggressive strategies to gain compliance and secrecy are employed by abusers, children find it more difficult to disclose. However, when strategies consisting of special attentiveness or giving favours are used, this has also made it difficult for children to disclose. Socio-cultural factors and the role they might play in influencing disclosure have received little attention in the research literature. However, the development and implementation of school education programmes, legislation and statutory guidelines highlights the problem and aspires to influence society in how it deals with the issue of child sexual abuse in the hope that children will be encouraged to disclose sexual abusive experiences immediately.

The limitations of the research on disclosure were outlined which include sampling variations and differing definitions of disclosure which limit the potential to compare studies and apply findings to the general population of children who have been sexually abused. There has been no concerted effort in the international research or clinical community to systematically investigate the issue of how children disclose sexual abuse. Thus, we have a plethora of small-scale studies of highly selective samples asking different questions using different methodologies and different definitions of both abuse and disclosure. Finally, it is suggested that Belsky's $(1980,1993)$ conceptualisation of child maltreatment is useful in examining the factors that influence disclosure and highlights the complex interrelationships between the influencing variables outlined above.

Theoretical Contributions to our Understanding of the Disclosure Process

In order to understand people's reluctance to disclose their childhood experiences of sexual abuse, various theoretical models have been proposed with varying success. These are discussed here as representing the abuser's perspective, the professionals' perspective, and the child's perspective. The literature on sexual offenders has assisted in developing our understanding of the disclosure process for children and Salter's Deviant Cycle (Salter, 1995) model of sexual offending provides useful information on the implications for the child in disclosing, drawn from Salter's experience of working with sex offenders. Finkelhor and Browne's Traumagenic Dynamics Model of Child Sexual Abuse (Finkelhor \& Browne, 1985) and the psychiatric diagnostic category Post Traumatic Stress Disorder or PTSD as it is commonly referred to (American Psychiatric Association, 2000) are briefly discussed as helpful frameworks within which to understand the psychological impact of the abuse and the subsequent impact on disclosure. Three 'syndromes' have described the experience of abuse from the perspective of the child - Sgroi's Child Sexual Abuse Syndrome (Sgroi, Blick, \& Porter, 1982), Summit's Child Sexual Abuse Accommodation Syndrome (Summit, 1983) and Furniss' Child Sexual Abuse as Syndrome of Secrecy (Furniss, 1990). Detailed discussion will be confined to Summit's syndrome with its particular emphasis on three aspects of how children adapt to the experience of abuse: accommodation, denial and recantation. 
Other attempts at theory development in this area will be briefly reviewed, including GoodmanBrown et al.'s (2003) model predicting delays in disclosure, Bussey \& Grimbeek's (1995) sociocognitive model outlining those factors which determine whether children will tell or not, the preoccupation model of secrecy (Hershkowitz et al., 2007) and the social organization of telling (Wattam, 1999). Finally, Staller \& Nelson-Gardell's (2005) three stage temporal model of the disclosure process, it is suggested, brings the field full circle to the ideas put forward by Summit in the early 1980's and the concern with the internal psychological world of the sexually abused child while reflecting the increased use of qualitative methodology for exploring the complex multifaceted nature of child sexual abuse disclosures from the perspective of the child.

\section{The Abuser's Perspective}

The discipline of psychology has probably contributed more to the field of child sexual abuse through its study of sexual offending behaviour in an attempt to both understand and change this behaviour than to many other aspects of the phenomenon of child sexual abuse. There is now a vast body of literature on theories of why people abuse children and various treatment techniques for working with those who sexually offend against children. Some of this literature has revealed crucial information about how children are selected for abuse and the strategies used by abusers to ensure that the child does not disclose the abuse experience.

Psychologist Anna Salter describes a cycle of sex offending behaviour that offers some insight into children's disclosure patterns. According to Salter (1995), target selection, the decision on the part of the offender to target a particular child, is influenced by who the offender perceives they can 'safely victimize' and who is less likely to tell. The grooming process, a process that the offender engages in to achieve the compliance of the child is also designed to maximize secrecy.

The slow progression of grooming often produces a catch-22 for disclosures: If the disclosure is early enough, the offender has not broken the law, or has broken it minimally. Later disclosures concern behaviour more difficult to minimize, but it produces more negative sequelae for survivors. (Salter, 1995, p.83).

According to Salter, the sex offender manipulates children into silence in a number of ways: by bribes, threats and exploiting trust. Offenders often try to convince the child that secrecy is best not only for the offender but for the child and his family as well. On the other hand, many do not even discuss disclosure because they assume the child either will not tell or will not be credible. They may not discuss it with young children because they do not want the child to know there is anything inappropriate about the behaviour.

The unique contribution of writers such as Salter is the access they provide to the perspective of the abuser. As the other key person in the abusive interaction, the abuser has a valuable contribution to make in identifying how children can be helped to disclose child sexual abuse. Offenders have 
described strategies used over a number of years, which have been well refined and are often subtle and undetected by the children they abuse. For a comprehensive understanding of the dynamics of sexual abuse that inhibit disclosure their views are crucial in helping to understand why many victims delay disclosure or never disclose their abuse experience. In a study of 72 adult male inmates incarcerated for child sexual abuse, participants identified a preference for abusing their own children and/or choosing "passive, quiet, troubled, lonely children from single parent or broken homes" (Budin \& Johnson, 1989, p. 79). Another study has indicated that perpetrators target children who are quiet and withdrawn and/or appear vulnerable because of their age or friendliness (Berliner \& Conte, 1990). Perpetrators frequently seek out children who are particularly trusting (Conte \& Schuerman, 1987) and work proactively to establish a trusting relationship with them before assaulting them (Budin \& Johnson, 1989). This may also extend to establishing a trusting relationship with the victim's family as well (A.N. Elliott \& Carnes, 2001), affording the perpetrator greater access to and control of the child and providing a further barrier to disclosure.

As with research on victims of abuse, there is a difficulty accessing samples that are representative of those who abuse children. Research studies are typically conducted in prison settings, therapeutic programmes or during the course of legal proceedings. In simplistic terms, these are the ones who got caught and are in prison, want help or see their participation as a contributory factor to reducing their sentence. As Finkelhor (2007) points out, correctional and treatment populations are not representative of all offenders as these are individuals who have committed more serious and more repetitive crimes or simply those who have been caught.

\section{The Professional's Perspective}

A psychological model of the psychological impact of child sexual abuse is the Traumagenic Dynamics Model of Child Sexual Abuse (Finkehor \& Browne, 1985). Finkelhor and Browne suggested that the experience of child sexual abuse was unique and distinct from other forms of child abuse due to the presence of four main dynamics in one set of circumstances - traumatic sexualisation, betrayal, powerlessness and stigmatization. Although the model has not been applied to the issue of disclosing child sexual abuse, it is clear that all four dynamics could contribute to the maintenance of the secret of child sexual abuse. The traumatic sexualisation of children can invite reactions from adults that blame the child for their precocity or inappropriate interest in sexual matters, thus reinforcing the belief for the child that they were to blame for the abuse. Betrayal by a trusted person also influences the child's ability to trust enough in others to be able to tell them about the abuse. Children fear that they will be blamed or punished if the abuse is discovered. Powerlessness produces fear in the child: fear of the perpetrator; and fear of the consequences of disclosure. Stigmatization produces shame and embarrassment on the part of the child, reinforcing the child's desire to keep the abuse a secret. 
The primary focus of Finkelhor and Browne's model is on the psychological impact of the abuse on the child, rather than the abuse experience in general and as such only contributes to an understanding of disclosure insofar as difficulties in disclosing are directly related to the impact of the abuse. It neglects to take account of the child's resources prior to the abuse experience, the child's relationships with others and the context in which the child lives, i.e. the microsystem, mesosystem and exosystem and the proximal processes which in turn may influence how the abuse impacts on the child (Bronfenbrenner, 1979; 2000).

The need for psychological intervention following the first world war of veterans presenting with what was commonly known as 'shell shock' led gradually to the recognition of Post Traumatic Stress Disorder (PTSD), as an adaptive response to a traumatic event. Child sexual abuse is listed as constituting such a traumatic life event, both in terms of the nature of the event and the symptoms arising from the psychological impact. Symptoms such as avoidance e.g. avoiding thinking about the event, are common in adults who have delayed disclosure for many years and have been cited as one of the reasons why they did not report their abuse to the authorities (McElvaney, 2002). There is also evidence that children suffering from PTSD often deny abuse or recant because of difficulties coping with the anxiety aroused by thinking of the abuse (Koverola \& Foy, 1993). This is similar to the concept of dissociation, that information is encoded differently when the individual is in a state of heightened arousal thus leading to retention difficulties resulting in amnesia for the event (Van der Kolk, 1994, , 1996; Van der Kolk \& Fisler, 1995). Post

Traumatic Stress Disorder, however, is simply a constellation of symptoms rather than a theoretical model or framework. Nevertheless, the introduction of this diagnosis by the American Psychiatric Association was welcomed as an acknowledgement of the extreme distress and severe symptomatology experienced by individuals following a traumatic event and the distinction that needs to be made between reaction to a traumatic event and psychosis. However, as a diagnostic label it offers little in the way of explanation as to why people react in the way they do. While useful in understanding the group of sexually abused children who suffer extreme symptomatology following abuse, the PTSD model is severely limited when applied to children who suffer no such symptoms and whose difficulties lie in their thoughts and beliefs about the experience or in the range of emotional reactions that are not manifested in behavioural symptoms.

\section{The Child's Perspective}

Both clinical and research evidence suggest that for most children, disclosing child sexual abuse is not a discrete event but rather a process, often consisting of incremental revelations over time which may or may not include denials or recantation of some aspects of the earlier disclosure (Koverola \& Foy, 1993; Lawson \& Chaffin, 1992; T. Sorenson \& Snow, 1991; Summit, 1983). 
Some authors have described it as a gradual unfolding, accompanied by embarrassment, shame or fear (DeVoe \& Faller, 1999).

\section{Child Sexual Abuse Accommodation Syndrome (Summit, 1983)}

Roland Summit contended that in order to understand child sexual abuse, it is necessary to take the child's perspective. He was concerned that a tendency to rely on adult logic accounted for many people's lack of understanding of the issue, thus reinforcing the most damaging effect of the abuse. "A child with no knowledge or awareness of sex and even with no pain or embarrassment from the sexual experience itself will still be stigmatized with a sense of badness and danger from the pervasive secrecy" (Summit, 1983, p.181). According to Summit, it was possible to identify a syndrome associated with child sexual abuse composed of five categories, which address both the vulnerability of the child and the reality of the sexual assault: (1) secrecy; (2) helplessness; (3) entrapment and accommodation; (4) delayed, unconvincing disclosure; and (5) retraction. The first two categories he noted were preconditions to the occurrence of sexual abuse, the last three "sequential contingencies that take on increasing variability and complexity". (p.181). Summit later regretted his contention that this model represented sequential stages and his model, while heavily relied on by clinicians particularly in the legal context, has attracted wide criticism which will be discussed below.

The secrecy category refers to the all-pervasive aspect of sexual abuse. The secrecy is both the source of fear and the promise of safety: keeping the secret will maintain the status quo. Summit noted that if the child does attempt to disclose, she is met with adult disbelief and shock or with minimization or rationalization of the offending adult's behaviour. Helplessness refers to the child's dependent and subordinate position "the fact that the perpetrator is in a trusted position of authority with the child "(Summit, 1983, p.183). The expectation of others that children will selfprotect and immediately disclose "ignores the basic subordination and helplessness of children within authoritarian relationships" (Summit, 1983, p.182). The third phase, Entrapment and accommodation describes how the only option for the child is to accommodate to the situation.

The child cannot understand the contradiction between who the adult is and what he is supposed to be and copes with it by preserving an image of the perpetrator as good in order to protect herself from the disillusionment that would result if she were to view him as bad. Thus she sees herself as bad, somehow provoking the behaviour. The means by which children accommodate include assuming personal responsibility for the abuse, adopting the distorted beliefs of the perpetrator, dissociating and suppressing or repressing memories of the abuse.

The fourth stage of delayed, conflicted unconvincing disclosure typically refers to the adolescent disclosing in the context of conflict in the family whose disclosure is disbelieved or the apparently normal child who appears to have coped so well thus leading to doubts in the story. The final 
phase of retraction is, like in Sgroi's syndrome, typically a response to the lack of support following the disclosure. Many of the threats used to maintain the secret may come true, with the child being blamed or trouble ensuing in the family so that the child sees that the only option is to recant and restore the equilibrium in the family in an attempt to undo the damage done by disclosure. Summit argued that adults are more comfortable with retraction, therefore it is easier to believe than the original allegation. Summit (1992) later emphasized that these stages were never intended as a linear progression but rather reflect different possible patterns of how children disclose.

Leonard (1996) analysed the Child Sexual Abuse Accommodation Syndrome from the perspective of social exchange theory. Exchange theories are based on the premise that "individuals pursue those social relationships and interactions in which, based on perceptions of rewards and costs, they get the best payoffs, or the greatest reward for the least cost" (Leonard, 1996, p.107). According to Leonard, each component in Summit's syndrome represents the least unprofitable of the limited options child victims perceive are available. He offers the example of the entrapment phase where the child grows increasingly distressed as the inequity mounts. In order to reduce distress, the child is faced with two options, that of restoring equity (rarely an option for the child in the abuse situation) or what Leonard refers to as psychological equity. Psychological equity is achieved when people distort reality in order to convince themselves that the treatment they are receiving is deserved (accommodation). As Paine and Hansen (2002) point out, research has shown that both victims and perpetrators are capable of convincing themselves that even the most inequitable exchanges are fair (Walster, 1978; Walster, Walster, \& Bersceid, 1978, cited in Paine \& Hansen, 2002). Summit's concepts are not unlike those psychological adaptation mechanisms of concentration camp prisoners in the second world war, as described by the psychologist, Bruno Bettelheim, himself a prisoner (Bettelheim, 1943, 1961).

Support for Summit's theory has been minimal with few attempts to prove or disprove his 'syndrome' and what research has been conducted has addressed only the delayed disclosure and recantation aspects of his model. The study most frequently cited as supporting his ideas is that of Sorenson and Snow (1991). They retrospectively analysed 630 children's files and on that basis proposed a model of four progressive phases of disclosure: denial, disclosure (tentative and active), recantation, and reaffirmation. They then tested their hypotheses retrospectively with a smaller sample of 116 'high certainty' cases of children (defined as having additional corroborative elements such as substantiation by offender confession, offender conviction, or compelling medical evidence). Almost three quarters of the sample denied having been sexually abused. Denial statements were most commonly made when (a) children were initially questioned by a concerned parent or adult authority figure, and (b) children were identified as potential victims and initially questioned in a formalized investigative process. Most children (78\%) made what the authors 
termed a 'tentative disclosure'. Children frequently appeared confused, inaccurate and uncertain, often vascillating between acknowledgement and denial. Only $11 \%$ were able to provide a disclosure of sexual abuse without denying or demonstrating tentative features. Active disclosure eventually was made by $96 \%$ with two thirds of participants being currently abused. 'Active' disclosure was defined as able to give a detailed, coherent, first-person account of the abuse. $22 \%$ of the children recanted. Several denied responsibility for earlier disclosures, saying someone else (parents, therapists) made them say those things. $92 \%$ of the children who recanted, reaffirmed at a later point in the therapy. Some children moved from denial to tentative to active in a single session; others took several months to reach the active phase. According to Sorenson \& Snow, retraction was influenced by such factors as pressure from the offender or family, negative personal consequences, and judicial or investigative proceedings.

Summit was at the forefront of the child sexual abuse field in the early 1980s and his writings were influential in helping clinicians working with children who had been abused to understand the hitherto unknown dynamics of child sexual abuse and how they related to children's reluctance to disclose their experiences of sexual abuse. His 1983 paper was rated by the profession as one of the most influential papers in the field of child sexual abuse (Oates \& Donnelly, 1997). His inclusion of a secrecy and retraction stage in the process of the sexual abuse experience underlined the importance of understanding children's difficulties in disclosing. However, the presentation of the model in a stage format has attracted criticism as there is an implication that the phases follow an inevitable sequence. This does not take account of the children who a) disclose their experiences immediately after the event and b) do not retract their disclosures. The research outlined in the earlier section of this chapter on prevalence rates and underreporting of sexual abuse highlighted the fact that delays in disclosure or non disclosure are common yet many children can and do disclose immediately. There is limited empirical evidence however for the proposal that disclosure is part of a stage-based process that includes phases of denial, recantation and reaffirmation as suggested by Summit, and Sorenson and Snow. Conflicting findings in relation to denial and retraction have been found and there is no empirical evidence for the assumption that either of these stages are an inevitable outcome of sexual abuse. Some studies have found that significant numbers of children deny their sexual victimization when asked in a formal setting, even when compelling evidence exists to the contrary such as medical findings of sexually transmitted diseases, confessions by perpetrators or criminal convictions (DiPietro, Runyan, \& Fredrickson, 1997; Lawson \& Chaffin, 1992; T. Sorenson \& Snow, 1991). Allagia (2004) conducted a qualitative study with 24 adults who experienced childhood sexual abuse. Some of her participants described being asked as children but consciously denying their experience of abuse at the time even though one woman's sister had already disclosed abuse by the same abuser, their father. 
Bradley and Wood (1996), using Sorenson and Snow's five stages, provided operational definitions for each stage to enable independent raters to record data. According to Bradley and Wood, their study did not support the view that disclosure is a developmental process or that most children will progress through these stages of disclosure as described by Summit or Sorenson and Snow.

Contrary to the high rates of denial (75\%) and recantation (25\%) Bradley and Wood found in their study respective rates of $6 \%$ and $4 \%$ for denial and recantation. Sorenson and Snow's data are derived from retrospective therapy files of children and from information gathered from children's therapists. It is unclear to what extent the data relied on interpretations of file data by either therapist or researcher. Richardson (2003) points out, however, that the nature of the information and the level of detail recorded in Bradley and Wood's Child Protection Service (CPS) files would differ from that recorded on therapy files. In particular, she highlights the possible gap in information on CPS files relating to the disclosure made prior to the children's interviews with CPS workers due to this information being either unknown or unrecorded. Richardson suggests that the characterization of disclosure as a one off event by Bradley and Wood may be because children had already disclosed before the interview with the CPS worker. Richardson, herself a CPS worker, points out that most cases referred to CPS are already in the 'active disclosure' phase. This contrasts sharply with Sorenson \& Snow's sample where $74 \%$ of children were not in this phase. As single interviews are the most common intervention by CPS and Bradley and Wood excluded unsubstantiated cases, they eliminated from their study children who may have disclosed if seen over time, as was the case with Sorenson and Snow's sample.

London et al. $(2005,2007)$ reviewed 16 articles published since 1990 that "contained statistics on the frequency of denial" (2005, p.205) and concluded that there is little empirical support for Summit's pattern of denial. However, in their analysis, they make four assumptions that undermine their argument. Firstly, they interpret 'non-disclosure rates' as being the same as denial "the pooled mean of disclosures for the studies listed...is $64 \%$...or, put another way, the mean of denials is $36 \%$ " (2007, p.21). Thus, they assume that those children who did not disclose were in fact abused but were denying that abuse. While in the adult retrospective studies, only those people who initially denied that they had been abused and later disclosed abuse were considered as cases of denial, this criterion did not apply to the studies of children. One could argue that only those children who later disclosed should have been considered in the analysis as having denied. For the most part, these studies did not include information about earlier denial in the case of children who disclosed at interview. Sorenson and Snow (1991) specifically refer to denial as denying when initially questioned about the concern - either by a parent or concerned carer or in the context of a formal evaluation. The second assumption relates to a circular argument that London et al. acknowledge in their review but still proceed to engage in. That is, "with few exceptions, high disclosure rates characterize those samples that contain sexually abused children with highcertainty diagnoses, and low disclosure rates are associated with samples for which the diagnoses 
of abuse are either unknown or questionable" (p.21). It is unclear what other argument could be made given the universal reliance on children's statements to substantiate abuse. These cases are more likely to be substantiated because there was a disclosure.

The third assumption that London et al. make is that Summit's model was intended to be applicable to patterns of disclosure in the context of investigative interviews. Summit was attempting to describe children in their ecological context, not in the context of investigative interviews that were not in existence at the time of Summit's writing. He was describing what has above been referred to as informal disclosures to close family members or friends, not to professionals in the formal context of assessment or therapy where they might be directly asked about abuse. London et al. take Summit's model and evaluate it (in the case of the child studies) on the basis of how well it reflects disclosure in the context of formal investigative interviews where there is a high concern that the child has been abused. It may well be that if such studies existed, there would be empirical evidence for Summit's patterns in the context of informal disclosures. Finally, the emphasis in London et al.'s critique appears to be on whether denial was typical when children were directly asked about abuse experiences. They do not dispute that some children deny when asked. Alaggia (2004) suggests that the statistics on non-disclosure, delay and denial indicate that not disclosing during victimization may be more common than disclosing.

London et al.'s critique must be viewed in the context of what Pipe et al. (2007b) refer to as the "Disclosure wars" which has replaced the "memory wars" of the previous decade. Within the field, some professionals argue that disclosure is a discrete event occurring as a one off incident and that children who have been sexually abused are both willing and able to give a clear comprehensive account of such experiences if they are asked directly by professionals (Bradley \& Wood, 1996). Others argue that disclosure is a process often characterized by tentative partial exchanges of information and testing out behaviour on the part of the child of others' reactions, followed by further disclosures. In the view of these professionals, denial and recantation are not uncommon, some have suggested even typical. Few authors appear to promote the possibility that both positions are valid. The search has been for typical patterns rather than on the range of individual experiences.

Summit himself noted in more recent years (Corwin, 2003) that he was not referring to prevalence in patterns of disclosure but rather attempting to highlight the variations of patterns that exist. Instead of investigating the empirical basis for the existence of such patterns, research appears to have been driven towards questioning the empirical basis for the typicality of these patterns. Research clearly supports the view that some children are able to give clear consistent accounts of abuse in single interviews while some children disclose over a series of interviews in incremental fashion and a further subset of children do exhibit patterns of denial and retractions (Berliner \& 
Conte, 1990; Bradley \& Wood, 1996; Gonzales, Waterman, Kelly, McCord, \& Olivieri, 1993; D. Jones \& McGraw, 1987; Koverola \& Foy, 1993; London et al., 2005). The rates of retraction do vary significantly from to as high as $27 \%$ (Gonzales et al., 1993). So too do the samples, the former being a court witness project in the UK and the latter being a therapy sample in the US, both exceptionally select samples. Sorenson and Snow's sample represents a small percentage of a select sample of children, who revealed by chance rather than any deliberate act on their part, abuse by a family member or a person in a trusted authority position. London et al. were critical of Sorenson $\&$ Snow's therapeutic techniques, suggesting that the children who recanted had not in fact been abused. However, Malloy, Lindsay, Lyon and Quas (2007) found a 23\% recantation rate in a randomly selected sample of all substantiated cases resulting in a dependency court filing in a U.S. county between 1999 and 2000. The latter study included recantations made across both formal and informal interviews. The authors suggest that abuse victims who were more vulnerable to familial adult influences (i.e. younger children, those who were abused by a parent or carer figure and who lacked support from the non-abusing caregiver) were more likely to recant.

Summit's model is still arguably the most psychologically aware model in terms of attempting to understand the child's perspective and the internal psychological dynamics of coping with the abuse experience. A significant weakness in the model is that it does not account for the possibility of a legitimate retraction and to the misfortune of both sexually abused children and clinicians working in the field, this issue has received more research attention than those children who have denied abuse when they have been abused and who have retracted genuine allegations. The Disclosure war positions have significantly influenced both the focus of research and clinical practice in the field of child sexual abuse. The assumption that disclosure is a discrete event has resulted in interview protocols that require children who have been abused to disclose in a single interview according to a prescribed format i.e. standardised interview protocols. While the adherence to such protocols has been shown to result in more accurate and more detailed accounts by those children who were able to disclose in this context (Sternberg et al., 1997), concerns remain about those children who do not disclose and have been or are being abused. According to Coulborn Faller (2007), "these structures are best suited to children who are latency-aged, who have already disclosed, and who are willing to disclose" (p.88). Children who are younger and for emotional reasons are not able to disclose such experiences in a single interview have been found to benefit from multiple interviews in an extended evaluation (Carnes, Nelson-Gardell, Wilson, \& Orgassa, 2001; Carnes, Wilson, \& Nelson-Gardell, 1999). However, as Coulborn Faller points out, there has been little progress in developing improved techniques for assisting nondisclosing children. 


\section{Child Sexual Abuse as Syndrome of Secrecy (Furniss, 1990)}

Furniss (1990), a child psychiatrist and family therapist, described the experience of child sexual abuse as a syndrome of secrecy. He suggested that there are three aspects of the child sexual abuse experience that contribute to secrecy: external factors, interactional aspects and internal psychological factors. External factors might be the lack of forensic proof for much sexual abuse, implicit or explicit pressure on the child not to tell, primarily from the abuser, the reliance on the word of the child as the child is typically the only one to report the behaviour or disbelief of the child due to the strangeness of the behaviour disclosed. Aspects of the abusive interaction itself refer to the dynamic whereby the behaviour often occurs with no conversation, no eye contact, sometimes in total darkness with no acknowledgement by the perpetrator that the behaviour is occurring, and the often strange presentation of the abuser who is sexually aroused leading the child to experience the interaction as un-interpretable. The internal psychological factors of the child refer to internal processes within the child such as perceptions that the child is responsible for the abuse, fear of the perpetrator or consequences of telling. All of these factors contribute to the secret being maintained. Furniss' detailed analysis of the secrecy inherent in the experience of sexual abuse provides insight into the child's perspective. Internal psychological factors as outlined by Furniss have received more attention in the research literature in recent years.

\section{Bussey and Grimbeek's Socio-Cognitive Model (1995)}

Bussey and Grimbeek, drawing on the work of Bandura (1986; , 1989a), proposed "a dynamic interactional model in which disclosure is multi-determined" (Bussey \& Grimbeek, 1995, p.175). They identified four socio-cognitive elements which determine non-disclosure - attention, where children have not paid sufficient attention to the event; retention where children are unable to remember it in sufficient detail; production, where children are unable to adequately communicate about the event; and motivation where children are unwilling to report it. Bussey and Grimbeek note that the course of disclosure varies according to children's cognitive capacities, their social experiences and the particular situation in which they find themselves. As Paine \& Hansen (2002) point out, Bussey and Grimbeek's model does offer a theoretical basis for the research finding that lower rates of disclosure have been noted among older children. From a cognitive perspective, older children are better able to report their abuse due to increased attentional, retentional and production skills. However, with increased cognitive abilities and social experience, children become more aware of the costs and benefits of disclosure, so it is anticipated that children's disclosure will be more self-regulated as they mature, "they learn to inhibit their disclosure of events, particularly events that they anticipate others might respond to in an unfavorable manner, even when not explicitly asked not to disclose" (Bussey \& Grimbeek, 1995, p.183). However as noted earlier, studies have provided conflicting evidence on the association between developmental factors and patterns of disclosing. Bussey and Grimbeek's model depicts the disclosure process as a cognitive task, one of weighing up considerations and coming to a conscious decision, based on a 
cost-benefit analysis. It does not take account of the emotional impact of the abusive experience and the emotional inability to disclose as opposed to the unwillingness to do so.

Goodman-Brown et al's Model Predicting Delays in Disclosing (2003)

Goodman-Brown and colleagues (2003) proposed a model of delay of disclosure based on previous research on this subject that suggested that fears of consequences of telling and perceptions of selfblame were key factors inhibiting children from telling about their experiences of abuse. Their model proposed relationships between variables such as child's age at time of reporting abuse, child's gender, whether abuse was intra-familial or extra-familial, to other variables such as child's perception of responsibility and fear of negative consequences in terms of being predictive of a delay in disclosing. They tested this model on a sample of 218 children whose cases had been referred to District Attorney's Offices. They found that age, type of abuse (intra or extra familial), perceived responsibility for the abuse and fear of negative consequences of disclosure had predictive power in determining time to disclosure. The authors emphasised the importance of children's expectations as to whether others would tolerate disclosure and their own perceptions of responsibility for the abuse and the influence of these on children's decisions to disclose.

\section{Staller and Nelson-Gardell's Temporal Framework (2005)}

The final theoretical model reviewed here is that proposed by Staller and Nelson-Gardell (2005) who conducted a secondary analysis of data from a focus group study of girls' experiences of therapy. Staller and Nelson-Gardell draw on the work of Petronio, Flores and Hecht (1997) who conceptualised the disclosure process in terms of access rules and boundary protection rules. Access rules refer to the dynamic of "receiving permission" from potential confidantes to disclose, seeking out favourable circumstances to make a disclosure and testing confidantes' reactions through incremental disclosure. Boundary protection rules include evaluating the trustworthiness and likely response of potential confidantes and evaluating anticipated reactions. Staller and Nelson-Gardell suggested that the disclosure process can be conceptualised as a three stage temporal framework: Self, where girls came to terms with feelings about abuse, the abuser and made their decision to tell; Confidant Selection-Reaction where they chose who, when and where to tell and coped with the reaction to their disclosure (supportive and hostile) and Consequences, both positive and negative which informed their ongoing decision making about telling. Staller and Nelson-Gardell's first phase implies that the decision to disclose is a conscious decision, having weighed up the costs and benefits but incorporating an emotional component which is lacking in Bussey and Grimbeek's model. The authors while acknowledging that disclosure is not always purposeful do imply a certain readiness on the part of the young people in the study to tell. Although research supports that adolescents are more likely to purposefully disclose than younger children, there is no evidence that within the population of adolescents, purposeful disclosure is more typical than spontaneous, accidental disclosure or disclosing in response to being asked. 
Indeed recent qualitative studies suggest that prompted disclosure may be much more common than had been previously represented in the research, even for older children.

There are two aspects of Staller and Nelson-Gardell's model that make a significant contribution to the literature on disclosure processes. Firstly, they emphasise the interactive nature of disclosure: "disclosure is not a one-way process. Children receive, process, evaluate, and react to information based on how adults respond to them" (p.1423). Thus, the young person's disclosure is seen in the context of communicating and relating to others. The person to whom they are disclosing plays an important role in this dialogue and influences future decisions about telling. This is supported by research highlighting the importance of others' response, particularly the mother, to disclosure not just in terms of encouraging disclosure (Lawson \& Chaffin, 1992) but in relation to long term mental health outcomes mediating the psychological impact of the abuse (Lovett, 2004). The second unique contribution of Staller and Nelson-Gardell's model is that there are life-long implications to disclosure. The child's world, according to Staller and Nelson-Gardell is divided into those who know and those who don't. Young people must continue to make what the authors refer to as 'first disclosure decisions' continually evaluating trust, likely response and consequences of telling in each new relationship. As referred to earlier in this chapter, research studies have neglected to acknowledge the multiplicity of experiences of disclosure with more recent studies incorporating questions which identify the first, second, third, fourth etc person to whom the person disclosed their abuse experience (Hershkowitz, Lanes, \& Lamb, 2007). In the words of one of Staller and Nelson Gardell's research participants "It's never finished, never. Nothing is ever fully brought about or you know, fully explained" (p.1426). The authors advocate integrating existing theories and research into a model that takes account of both the child's perspective and adults' concerns while taking a broader perspective that includes the pre-disclosure and post-initial public disclosure experiences.

Summit (1983) suggested that there are stages through which the child progresses in his or her attempts to cope with the experience of abuse. He was writing at a time when child sexual abuse was a relatively new area of work for clinicians, when public awareness was at a minimum and when there was considerable scepticism and disbelief in relation to the extent of the problem. His focus on delaying, unconvincing disclosure and retraction may have been as much a product of the societal attitude to sexual abuse as it was a facet of the experience of sexual abuse in itself. Societal attitudes influence greatly how children experience the process of disclosing sexual abuse. Thus a model put forward in the United States in 1983 is not likely to remain as relevant either in the United States of the $21^{\text {st }}$ century or indeed in another country.

Typical patterns have not emerged from the research conducted. Goodman-Brown et al. (2003) highlighted the danger of isolating variables and the contributing influence of interacting variables 
that may account for the disparity in findings. Perhaps the reduction of complex phenomena to distinct phases does not and never will capture the experience of disclosure for the child. The complexity of the issue may not lend itself to traditional quantitative methodology and may demand more creative and flexible methods to explore these issues. Until the last decade, there has been little emphasis in research studies on the psychological dynamics operating in the internal world of the child to inform our understanding of the disclosure process and why it is that children experience such difficulty in disclosing experiences of child sexual abuse. While there have been some attempts to develop theoretical frameworks in the field of sexual abuse, these are for the most part primarily descriptive and developed almost exclusively by clinicians based on their clinical experience. Few of these highlight the complexity and variability of children's experiences or the influence of personality and contextual differences.

The emphasis in both the theoretical literature and the empirical research literature has been on why it is that children do not disclose their experiences of abuse. Models such as Summit's and Sorenson and Snow's do not take account of children who do make disclosures and who do not retract. Similarly, Furniss' syndrome while providing a detailed account of the social and psychological dynamics at work in preventing the child from being able to disclose their abuse, does not attempt to explain how children do overcome these barriers and are successful in disclosing their experiences. As Jensen et al. (2005) point out, few studies provide data regarding what motivates children to disclose of the circumstances that facilitate disclosure. More emphasis has been placed on what stops children telling.

Finally, although Summit's 'delayed, unconvincing disclosure' phase of his syndrome was referring to disclosure in adolescence, little attempt has been made to draw on the developmental literature in facilitating our understanding of the disclosure process. This is despite the empirical evidence for developmental differences being evident in the experience of disclosure. There has been little attempt to take into account developmental differences that may impact on the secretive nature of sexual abuse, difficulties in disclosing the abuse or how children overcome these difficulties.

\section{Conclusion}

Methodological limitations of the research reviewed in this chapter have been acknowledged above. Disparate sampling techniques with little representative value, differences in how abuse is defined, reliance on retrospective surveys in adult studies and investigative interviews or therapy sessions in child studies have not resulted in consensus on the existence of typical patterns of disclosing. Notwithstanding these difficulties, some patterns of the disclosure process have 
emerged which may or may not be applicable to most children who have been sexually abused. Firstly, there is a marked reluctance to disclose sexual abuse and support for this thesis is consistent through both adult and child studies. There is evidence that some children deny sexual abuse when there is substantial evidence that they have been abused. There is also some evidence that some children retract statements about abuse and later re-state their allegation in a credible manner. Developmental differences have been noted both in the manner of disclosure (accidental/spontaneous or purposeful) with some evidence suggesting an interaction of age with other variables such as intra-familial or extra-familial abuse, and fear of consequences of disclosing. There has been no focussed attention on how and why these changes occur. Gender differences are also evident, although not in all studies and again, it has been suggested that gender differences may be masked by the interaction of other variables such as relationship to perpetrator. Finally, the importance of viewing disclosure in the context of the child's relationship to others family, friends in terms of having a supportive confidante available to them and the impact of other's reactions to disclosure on future disclosure has been acknowledged. For the most part, information on the process of disclosure for children and adolescents is sparse, with many authors calling for further investigation of these issues.

Despite support for viewing disclosure as a process rather than a one off event (with some exceptions) few qualitative studies have been conducted in this area. The idea of disclosure being a process that gradually unfolds would suggest that a qualitative methodology is needed to explore such a process. Only in very recent years has this been evident. An emerging literature on determining complex processes underlying the experience of disclosure is steadily growing (Alaggia, 2005). Also evident from recent literature is the importance of viewing disclosure not just as an experience occurring at a particular period in a child's life, but as a developmental task that needs to be negotiated for the developing person across the lifespan.

These recent studies have shifted the focus away from the search for typical patterns of disclosure and back to some of the ideas articulated by early theorists in the field such as Summit and Furniss. As D. Jones (2000) suggests, the assumption that patterns exist and can be generalised to all children may be misleading. He notes that the variability and multiplicity of influences needs to be better understood if we are to help children. While Summit and others also placed an emphasis on describing phases of the abuse experience, implying typical patterns, they did identify key concepts which have not been explored through research and they did emphasise the importance of understanding this issue from the child's perspective. Fear of the consequences of disclosure and the actual consequences for the child and others have highlighted the emotional complexity of young people's experiences of keeping the abuse secret. Attention has shifted from simply identifying and exploring the frequency of factors that inhibit disclosure to how these factors prevent a child from telling, and to a lesser extent, how young people overcome these barriers to 
disclosure. Despite growing concerns about how to best help young people disclose their experiences of abuse and a growing interest in and recognition of the importance of the voice of the child, young people have not been asked directly: what helps a child tell? According to GoodmanBrown et al. (2003),

Research is needed on ways to help sexually abused children disclose and to identify factors that may mitigate the tremendous pressures placed on children to maintain the silence so often associated with child sexual abuse (p. 538).

Research needs to go further than identifying a list of factors influencing disclosure as if these were static influences impacting on a passive child, fixed in time and place. Jones (2000) in his commentary on the D.W. Smith et al. (2000) study notes:

Qualitative studies which are able to track the individual experiences of children and their perception of the influences upon them which led to their disclosure of information are needed in order to complement the picture obtained from this very impressive quantitative study of disclosure in the field of childhood rape (p.270).

There has been a growing trend in the research literature on disclosure to move away from the search for typical patterns to an acknowledgement of the need to explore individual experiences through asking young people, mostly adolescents, and adults about their disclosure experiences in direct interviews. As a young person in Mudaly and Goddard's (2006) study put it: "get the kids interviewed from a kid's point of view. No one knows kids better than the kids" (p.10). While it is important to explore how children understand the barriers to disclosure, there is a significant gap in our knowledge base on how children succeed in telling. There is a need for research to focus on how children negotiate the task of telling, how they overcome the many barriers to disclosure: "to better understand disclosure, it is critical to investigate these moments of private and personal negotiation" (Staller \& Nelson-Gardell, 2005, p.1427).

In addition to the need to explore these issues from the child's perspective through qualitative methods and the need to focus on how children do tell, there is a need to develop new theory in this area. Research in this area has not been founded on the early theoretical contributions outlined in this chapter. Theoretical contributions remain insufficiently tested empirically other than in a piecemeal fashion focused on particular themes such as denial and recantation. Research has not been theory-driven, nor has it been focussed on theory generation other than in a few exceptional cases (Sorenson \& Snow, Bussey \& Grimbeek, Alaggia, Staller \& Nelson-Gardell). What is needed is a comprehensive theory that can explain how children disclose (or do not disclose) their experiences of sexual abuse. This theory needs to build on existing knowledge in the field. An overemphasis on identifying the barriers to disclosure has resulted in inadequate attention to what facilitates disclosure. More recent qualitative studies on the process of disclosure from the child's perspective have built on the theoretical models of Summit and Furniss. This tradition needs to continue. 
A final issue highlighted in this review of the literature on children's disclosure of sexual abuse experiences is the need for a developmental perspective in studying this complex issue. There is now considerable evidence to support the position that developmental differences are evident in the patterns of how children disclose i.e. accidentally or purposefully, verbally or non-verbally, the choice of confidante - parents or peers, and the delay in disclosing - immediate, delayed or disclosing only in a research context. A greater understanding of what can be expected from children at different stages of development is clearly needed to inform the debate on how we can help children disclose sexual abuse. Kogan (2004) highlighted the need to consider developmental stage as a primary factor in efforts to encourage disclosure. He noted that public awareness campaigns and the training of helping professionals needed to take account of young people's understanding of the experience as "a disclosable event" and consider the consequences of disclosing. Alternative outcomes of disclosure needed to be highlighted to young people to address beliefs about family disruption and social stigma. He suggested that efforts also need to be targeted at adolescents' peers indicating what young people might do if a friend confides in them. He also advocated addressing the relationship of the child to the abuser in acknowledging the often contradictory and confusing feelings that accompany an abuse experience. Studies have referred to the child's cognitive capacity, language and communicative ability and cognitive appraisal of an experience of sexual abuse but little reference has been made to children's moral development, the development of conscience and their emotional development.

A developmental perspective needs to take account of the child as active decision maker in the process of whether to tell or not. Bandura (1989b) emphasises the importance of self-efficacy as a key dynamic in human agency. Bussey and Grimbeek (1995) in their social cognitive model of disclosure applied Bandura's ideas to the process of disclosure but saw non-disclosure as an expression of a "lack of perceived self-efficacy" (p.185). Children who are abused, according to Bussey and Grimbeek, judge themselves as not being able to disclose the abuse. Yet these authors clearly acknowledge the child as decision maker in their subjective appraisal of their own and others' potential reactions to a disclosure as well as their perceived capability for disclosure. The child is not a passive object in the aftermath of the abuse experience. Agency and self-efficacy are at the centre of feminist thinking which redefines the 'victim' of abuse as the 'survivor' (Poston \& Lison, 1989). As will be discussed later in this thesis, the developmental perspective needs to take account of not just the rational decision maker who weighs the benefits and dangers of disclosing but the emotional and psychodynamic processes operating for the child as decision-maker.

According to Greene (2006), contemporary developmental science where a dynamic systems approach is the predominant framework for thinking about development, emphasises children's contributions to their own development. This is exercised through both evocative influences when the child evokes a reaction in others through characteristics such as attractiveness or 
temperament - and active influences, when the child actively interprets her experience and is an effective actor in her world. Greene (2003) is critical of Psychology as a discipline for not recognising humans as subjects and agents but acknowledges a current "recognition of the person as an active agent in their own development whose efforts after meaning and understanding of their own life situations need to be taken into account" (Greene, 1997a, cited in Greene, 2003, p.35). When a child is sexually abused, there are ripple effects that are immeasurable and stretch out to the family, friends, school and the wider community when the abuse is discovered. The anticipation of these effects in turn influences the process of disclosure. Understanding how the child, as decision maker, negotiates these influences is central to our understanding of how children overcome the barriers to disclosure and succeed in telling someone of their abuse experiences. This perspective is commensurate with the view of children as agents in line with more recent developmental theory (Bronfenbrenner \& Morris, 1998; Lerner, 1998).

A developmental perspective also needs to take account of changes over time. Bronfenbrenner, according to Greene (1994), emphasises the need to view the developing person as "a growing, dynamic entity that progressively moves into and restructures the environment in which it resides" (1994, p.21). Reasons for non-disclosure change over time, resulting from both changes within the developing child and changes in the systems with which the child interacts. Research on disclosure has to date not taken account of the changing person, the changing context and the changing understanding of the abuse experience. With the exception of Staller and Nelson-Gardell's study, interest has focused on disclosure as occurring at a point in a child's or adult's life, even when this has been viewed as a process or gradual unfolding of a story.

Qualitative studies which explore the perspective of the child, which focus on how children succeed in telling, which contribute to generating new theory in this field of study and which take a developmental systemic perspective are needed to address the significant gaps in our understanding of how children disclose experiences of sexual abuse.

The present study is a qualitative investigation of how the process of disclosure of child sexual abuse unfolds. Sexual abuse is defined in this study in line with the definition used in Children First (Dept. of Health \& Children, 1999) as follows:

Sexual abuse occurs when a child is used by another person for his or her gratification or sexual arousal or for that of others. Examples of child sexual abuse include the following:

(i) exposure of the sexual organs or any sexual act intentionally performed in the presence of the child;

(ii) intentional touching or molesting of the body of a child whether by a person or object for the purpose of sexual arousal or gratification;

(iii) masturbation in the presence of the child or the involvement of the child in an act of masturbation;

(iv) sexual intercourse with the child whether oral, vaginal or anal;

(v) sexual exploitation of a child includes inciting, encouraging propositioning, requiring or permitting a child to solicit for, or to engage in, prostitution or other 
sexual acts. Sexual exploitation also occurs when a child is involved in the exhibition, modelling or posing for the purpose of sexual arousal, gratification or sexual act, including its recording (on film, video tape or other media) or the manipulation, for those purposes, of the image by computer or other means. It may also include showing sexually explicit material to children which is often a feature of the "grooming" process by perpetrators of abuse.

(vi) Consensual sexual activity involving an adult and an under-age person. In relation to child sexual abuse, it should be noted that, for the purposes of the criminal law, the age of consent to sexual intercourse is 17 years. The means, for example, that sexual intercourse between a 16 year-old girl and her 17 year-old boyfriend is illegal, although it might not be regarded as constituting child sexual abuse. (p.33)

The term disclosure is taken to mean when the child/adolescent/adult told, whether this be in an informal or formal context. While particular interest is focussed on the first disclosure, subsequent disclosures are also explored. Grounded Theory Methodology is employed to assist in building a theory of how young people disclose that is based on the perspectives of key participants in the disclosure process: children and adolescents who have been abused, their parents, adults who were abused in childhood and professionals who work in the field of sexual abuse. A developmental perspective is taken in four respects. Firstly by purposive sampling of a sample of young people and a sample of adults who were abused as children; secondly by asking participants directly about their views on age as an influencing factor in disclosure and why this might be; thirdly by exploring changes in feelings and thoughts about disclosure of the research participants over time; and finally, by integrating theory based on the experiences of these research participants with developmental theories to help our understanding of how children tell. 


\section{CHAPTER 2: METHODOLOGY}

This chapter outlines the methodological paradigm that informed this study, how the study participants were accessed, a description of the sample, how data were collected and analysed, and ethical issues encountered during the course of the study.

In conducting a review of the relevant literature for this study, a number of methods were used. A search was conducted of the following databases: PsycINFO, PsycARTICLES,

CINAHL/PROQUEST, ISI, and PUBMED using search words "child sexual abuse", "child abuse", "childhood abuse", "sexual abuse" and "sex abuse" at particular points in time between 2002 and 2007. Key journals in the field of child sexual abuse were consulted manually on an ongoing basis. Trinity College Dublin Online Catalogue was consulted for textbooks in the field and the library in a specialist sexual abuse agency was consulted. Conferences in the field of child maltreatment and child development were a useful source both in terms of papers attended and publishers' book stalls. Key journals and textbooks in qualitative research methodology were consulted and attendance at qualitative research conferences in addition to training workshops in the use of nVIVO software facilitated access to a knowledge base of qualitative research methods.

\section{Grounded Theory Methodology}

How do children disclose experiences of child sexual abuse? What are the obstacles to immediate disclosure? How do children overcome these obstacles? Does age make a difference? Does gender make a difference? How can we help children tell? The research questions in this study are exploratory ones, seeking to discover how the process of disclosure unfolds and the mechanisms involved, from the research participant's perspective. A qualitative approach is therefore indicated. R. Elliott, Fischer and Rennie (1999) state that in qualitative research "the researcher attempts to develop understandings of the phenomena under study, based as much as possible on the perspective of those being studied" (p.216). According to Hogan (2005), much of the research in the last century has not sought to understand children's subjective experiences. Rather the approach has been to access children's views through adults or through structured questionnaires. This has resulted in research that consists of predominantly quantitative data that leaves no room for children to describe their own views and experiences. According to Hogan, the recognition of children as active agents in their own development, as meaning-makers of their own unique experiences was not acknowledged through the use of these research methods. As seen in the previous chapter, the field of child sexual abuse was also dominated by quantitative research methods until the last decade. The focus of early research was on establishing prevalence rates, identifying variables and the relationships between variables and searching for a typical pattern of 
disclosing. According to Mudaly \& Goddard (2006), "the traditional positivist social science research methods from which most child abuse information was historically derived does not allow for the subjective realm of victims of abuse to be explored." (p.66). However, as highlighted in Chapter 1 , the need for more qualitative studies has been recognised in the last decade as being integral to our search for understanding children's experiences of telling about abuse.

A qualitative research approach "aims to capture children's lived experiences of the world and the meanings they attach to those experiences from their own perspectives" (Hogan, 1998, p. 6). Qualitative research draws on a broad range of schools of thought, many of which could usefully be relied on to investigate the research questions of this study. Discourse analysis could be used to focus on the language used in disclosing and how the process of disclosing for the child reflects broader social and political influences such as how society deals with the issue of sexual abuse, 'how societies tell' and how matters pertaining to the sexual abuse of children are dealt with in the media, through legislation, governmental policies and statutory services. An ethnographic approach would facilitate the emphasis placed on uncovering participants' understanding of their social and symbolic worlds (Denzin, 1970; Goffman, 1968 as cited in Emond, 2005) "where children become the instructors and we, as researchers, become the pupils" (Emond, 2005 p.124). These various methodologies share many of the characteristics of qualitative research.

Four factors in particular influenced the choice of Grounded Theory as the methodology of choice for this study. Firstly, the theoretical basis for Grounded Theory is phenomenology, and symbolic interactionism. Phenomenology, elaborated in the work of Husserl, Heidegger and Sartre is concerned with how individuals construct meaning in the world around them (Bryman, 1988). According to Baker, Wuest \& Noerager Stern (1992), the philosophical approach of phenomenology is designed to describe psychological realities by uncovering the essential meaning of lived experience. Symbolic Interactionism has its roots in Sociology, and is concerned with how individuals conceptualise meaning in relation to a social process, seeing this meaning as a social product, as a creation that is formed in and through the defining activities of people as they interact (Blumer, 1969). Phenomenology seeks to describe psychological structures and symbolic interactionism seeks to explain social processes. Grounded theory then attempts to explain social or psychological realities by identifying processes at work in the situation being investigated.

According to Charmaz (2006),

a process consists of unfolding temporal sequences that may have identifiable markers with clear beginnings and endings and benchmarks in between. The temporal sequences are linked in a process and lead to change. Thus, single events become linked as part of a larger whole (p.10)

The process of disclosing sexual abuse for a child is both a psychological and a social process, and is influenced by both psychological and social factors. Thus the disclosure experience is a psychosocial phenomenon. This study intended to explore children's experiences of disclosing a 
personal experience and the meaning that the child bestows on that experience. There was, therefore, a theoretical fit between Grounded Theory methodology and the research question being investigated.

A second factor influencing the choice of methodology was access to procedural guidelines. Strauss and Corbin's (1998) detailed procedures gives a good basis for a rigorous approach to conducting qualitative research.

Thirdly, the methods of data collection and analysis in Grounded Theory place an emphasis on both flexibility and staying with the unique voice of the research participant in the analysis. The flexibility in data collection facilitates eliciting the research participant's account of their experience in their own words rather than imposing predetermined structures or ideas on the participant's story. Thus attention is paid to the child's subjective story in order to better understand children's experiences. Children who are abused are not a homogenous group; their circumstances and the dynamics within their families are as individual as they are. Flexible interview methods can capture this individuality. The importance of staying with the voice of the research participant in the analysis is also an important principle in therapeutic work in the field of sexual abuse, particularly with adults who have been abused in childhood. This work has been strongly influenced by the feminist tradition where "the survivor is seen as the authority on her own experience which she is assisted to explore" (Courtois, 1988 p.120). In both qualitative research and therapy in the field of sexual abuse there is an emphasis on the research participant being the expert on their own experience.

The inductive coding methods used in Grounded Theory of staying close to the data ensure an adherence to the integrity of the perspective of the research participant not unlike Winnicott's (1971) description of therapy as "not making clever and apt interpretations: by and large it is a long-term giving the patient back what the patient brings." (p.117). The methods of qualitative research used in Grounded Theory studies have much in common with a process-oriented psychoanalytic psychotherapeutic approach. The author, as a clinical psychologist with additional training in psychotherapy of which the basis was Object Relations Theory, and many years experience working in therapeutic services for both children and adults who were sexually abused, shares many of the underlying values of the Grounded Theory tradition.

As well as a theoretical fit between Grounded Theory and the research question, there is also a theoretical fit between Grounded Theory and the theoretical orientation of the researcher as a clinician.

Finally, as already identified in the literature reviewed in Chapter 1, a significant shortcoming of the literature on child sexual abuse disclosures is the lack of theory to guide research and practice 
on this issue. Grounded Theory aims to build new theory grounded in the experience of research participants. Thus, the method attempts to go beyond describing experiences, the predominant approach in child sexual abuse research, and attempts to explain the processes underlying such experiences. Henwood \& Pidgeon (1992) see the development of theoretical frameworks to explain behaviour and processes as a distinguishing characteristic of Grounded Theory. As Charmaz (2006) points out, "because grounded theory methods are designed to study processes, these methods enable psychologists to study the development, maintenance and change of individual and interpersonal processes" (p.30). Charmaz sees grounded theory methodology as bridging the gap between traditional positivist approaches and interpretative analyses because "they are used to discover research participants' meanings; they assume an empirical enterprise, and they provide a set of procedures to follow" (p.30).

There are diverse views within the Grounded Theory tradition. The approach undertaken in this study is that promoted by Charmaz (2006) who advocates a constructivist version of grounded theory. The originators of Grounded Theory, Barney Glaser \& Anhelm Strauss referred to themes or categories 'emerging' from the data (Glaser \& Strauss, 1967). This aspect of the approach has attracted some criticism. Although Glaser \& Strauss acknowledge that the researcher does not approach reality as a 'tabula rasa', the extent to which the researcher relies on or is influenced by their own theoretical background is not explicitly addressed by them. According to Charmaz, the use of the term 'discovery' in the original monograph implied that categories and theories can simply 'emerge' from data without any mediation from the researcher's own interpretation of the data, thus reflecting the belief that phenomena are represented in a way that can be directly perceived by observers (Willig, 2001). According to Charmaz, categories do not emerge from the data but are rather constructed by the researcher who interacts with the data. "The discovery process consists of discovering the ideas the researcher has about the data after interacting with it" (Charmaz, 2006, p.1169). Pidgeon, Henwood and Hayes (1997) prefer the use of the term 'theory generation' to 'discovery'. Charmaz contends that any observer's worldview, disciplinary assumptions, theoretical proclivities and research interests will influence his or her observations and emerging categories. The theory produced represents, therefore, one particular reading of the data rather than 'the one true position'.

\section{Rigour in Qualitative Research}

While methodological criteria such as validity and reliability are generally used in evaluating quantitative research, as Henwood and Pidgeon (1992) point out, the emphasis in qualitative research is on good practice, which guides both the progress of the study and its evaluation, and demonstrates the rigour of qualitative research. Following best practice guidelines ensures that the 
procedures of coding and analysis are transparent to enable the reader to make a judgement as to the credibility of the analysis. Such guidelines also reflect the distinguishing characteristics of grounded theory methods (Charmaz, 2006; Glaser \& Strauss, 1967; Strauss and Corbin, 1998). The guidelines outlined below are informed by those developed by Henwood and Pidgeon (1992) and R. Elliott, Fischer and Rennie (1999).

Simultaneous involvement in data collection and analysis phases of research, keeps the researcher focused on the task of theory building through integrating themes at a basic level to produce higher-level categories. The creation of analytic codes and categories is part of an ongoing process therefore that is conducted throughout the study. Norton (1999) describes this distinguishing characteristic of Grounded Theory methods as the abductive strategy of theory generation, whereby theory generation is part of the process of research. This, according to Norton, is distinct from deductive methods whereby the research is designed to test apriori theory or inductive methods whereby observations lead to theory formation. Norton suggests that abduction relies on the cyclical processes of data collection, hypothesis formation, testing and theorizing. Codes and categories must stay close to the data, i.e. fit well with the data and theory must be grounded in examples through the use of quotes thus demonstrating the analytic procedures used and the resultant findings. The process of coding and analysis is documented throughout to maintain transparency and enable the reader to judge the credibility of the analysis. Two main methods of documentation are used. Firstly, the use of memos involves writing analytic notes to define, explain and elaborate categories. Secondly, the use of a reflective journal constitutes a personal diary which keeps account of the role of the researcher's values and interests as well as a log of methodological decisions and accompanying rationales (Henwood \& Pidgeon, 1992; Lincoln \& Guba, 1985). The reflective journal in addition to facilitating transparency also serves the function of reflexivity that acknowledges the interdependent relationship between the researcher and what is being researched. According to R. Elliott, Fischer and Rennie (1999), reflexivity on the part of the researcher enables readers to consider alternative interpretations of the analysis.

Sampling is informed by developing theory rather than for representativeness of a given population and is referred to as theoretical sampling. The purpose of sampling in this way is to check and refine the analyst's emerging conceptual categories. Theoretical sampling also directs the researcher to seek out cases that help to explain variations from the theory being developed, referred to in Grounded Theory as negative case analysis. As Burman (1994) points out, the emphasis in qualitative research studies is on divergence and variety rather than convergence and replicability. The use of theoretical sampling and negative case analysis enables the researcher to continually test hypotheses through selecting research participants on the basis of theoretical concepts to both confirm and disconfirm the hypotheses. By exploring situations that do not fit the emerging conceptual framework, a richer more complex understanding emerges, thus modifying 
and elaborating theory where necessary. R. Elliott, Fischer \& Rennie (1999) recommend that samples are described in sufficient detail to allow readers to consider the applicability of findings to other populations. Henwood \& Pidgeon (1992) advocate that the researcher must be sensitive to negotiated realities. This refers to the practice of member checking or validating theory through seeking agreement from participants that the theory fits the data they offered.

\section{The Sample \\ Accessing the Sample}

Access to children who have been sexually abused is inherently difficult. Reluctance to disclose sexual abuse has been highlighted in Chapter 1 along with the implications of this for researching this population.

In addition to a reluctance to initially disclose abuse, there is an ongoing reluctance on the part of many children to discuss their experiences of abuse. Engaging in research involves discussing painful memories that many wish to avoid thinking about. Parents therefore may be reluctant to allow their children to be interviewed due to concerns that it will be distressing for the child. Many children who have been sexually abused want to forget about the experience and get on with their lives. Talking about the experience, unless it is absolutely necessary, may be a low priority for many families. On the other hand, many families who have experienced sexual abuse are particularly anxious to assist professionals in any way they can, if this will lead to the prevention of abuse of other children. From an ethical point of view, it is important to ensure that a) families are well informed about the nature of research studies and the potential distress or benefit emanating from their participation and b) support is available for those children and families who may be distressed as a result of participating in the research. This is discussed further in the section on ethical issues.

One approach to accessing this population is that employed by many of the studies reviewed in Chapter 1, i.e. through child protection services where children are seen for investigative interviews to establish the credibility of the allegation of abuse. The Health Service Executive (HSE), is the statutory provider of health care services in Ireland with responsibility for the protection and welfare of children. This service is regionalised and practice varies throughout the country in how allegations of child sexual abuse are processed. In the Dublin city and county, referrals are made to specialist child sexual abuse assessment services. The purpose of assessments is to offer a professional opinion as to whether the child has given a credible account of being sexually abused. These assessments are comparable to the forensic assessment conducted in the United Kingdom (U.K.) and the United States (U.S.) with an additional element of assessing the therapeutic needs of children and families. Assessments are informed by practice guidelines developed in the U.K., the 
Memorandum of Good Practice (Home Office, 1992, 2000) and by the American Professional Society on the Abuse of Children in the U.S. (APSAC, 1999). These services also offer a therapy service for children and adolescents.

Access to children was obtained through one of these assessment and therapy services where the author had been employed as a clinical psychologist at the outset of the study. Access to adults was obtained through a statutory counselling service for adults who had been sexually abused in childhood, where the author had been employed in the past. Thus, the author had a long-term professional relationship with both services and was able to rely on a high degree of co-operation in accessing research participants from an enthusiastic and motivated group of professionals. Disciplines that were represented in these staff groups included psychology, social work, psychiatry, psychotherapy and counselling. Potential participants were therefore already engaged with a service and being supported so that any distress caused from participation in the research could be addressed without delay. Ongoing discussions with staff members were held in relation to the following issues: how best to introduce the research project to clients, how best to ensure that informed consent was genuinely given by clients and the related issue of how best to make the distinction between research and therapy clear to clients. Also the issue of where clients should be interviewed was discussed with the staff groups.

Four samples were targeted for inclusion in this study: a sample of young people who had been sexually abused, a sample of young people's stories as told by their parents (where parents did not give permission for their child to participate but wished to participate themselves), a sample of parents of the young people interviewed, and a sample of adults who had experienced sexual abuse in childhood. Theoretical sampling, referred to earlier, is used in grounded theory studies to develop theory through "checking emergent theory against reality by sampling incidents that may challenge or elaborate its developing claims" (Willig, 2001, p.49). In its purest form, samples would not be planned in advance but would be targeted as a result of theoretical concepts emerging from the data already gathered. One such example might be targeting different groups of individuals (such as parents or adults who have been abused as children) who might offer a different perspective on the research question. Another example could be targeting children of different age groups following the identification of the theme of developmental differences early in the study. However, there are limitations both practical and ethical to the use of theoretical sampling in a study such as this. Ethical approval was required from all the relevant bodies before any data collection began. Nevertheless, as Charmaz (2006) points out, "theoretical sampling is less of an explicit procedure than a strategy that you invoke and fit to your specific study. Methods for conducting theoretical sampling vary accordingly" (p.107). It was therefore necessary to be explicit from the outset about the sample and who, where and how individuals would be targeted for inclusion in the study. In this study, the strategy of theoretical sampling therefore differed from 
traditional methods. Participants were not explicitly selected to develop on themes that emerged through earlier stages of data analysis or to fulfill the 'negative case analysis' criterion. Rather, samples were targeted that could potentially provide multiple perspectives on the research question i.e. children and young people who had been sexually abused, their parents, and adults who had experienced sexual abuse in childhood. In addition, emerging theoretical ideas were tested and elaborated through exploring these ideas with study participants as the study progressed and they were also discussed with the service teams during the development of the theoretical framework.

The attempt to target different age groups in this study was unsuccessful. Firstly, it became clear as the study progressed that most of the young people seen in the service during the study period where abuse was substantiated were in the adolescent age range. In the case of three young children between the ages of three years and six years, parents did not give consent for their children to be interviewed although they did agree to participate themselves and so these children's stories are represented in the study. Despite specifically targeting the younger age group and approaching a second service due to the limited availability of study participants in the first service, only a small number of pre-adolescent children were interviewed in this study.

\section{Recruiting Child and Parent Participants}

There were three strategies used in recruiting children as participants in this study. Initially, following a meeting with staff in the child sexual abuse service, an introduction letter and information sheet was given to all parents/carers attending for assessment (See Appendixes A \& B). At the completion of the assessment, those parents whose children met the inclusion criterion (where the outcome of the assessment was that the child had been deemed to have given a credible account of abuse) were asked for permission for the researcher to make telephone contact to discuss the research further, according to an agreed protocol indicating what would be involved in participating in the study and reassuring parents that their access to a service would not be affected by their participation or non-participation (See Appendix C: Introducing Research Project to Parents). All families who were asked, agreed to further contact by the author who asked parents to speak to their children, to explain the study and emphasize that it was their choice whether to participate or not. Two children agreed to participate using this strategy. One young person participated and although the other child attended, a decision was made by the researcher not to proceed with the interview. This was due to her young age (six years old) and the uncertainty about her consent to participate given her reluctant presentation.

A second strategy used to recruit participants was agreed with the service staff due to difficulties recruiting. Some changes in the structure of the service and the changing practice in the HSE resulted in smaller numbers of children where the outcome of the assessment met the criteria for the study. Following a meeting with the therapy team staff, it was decided that all children 
attending the therapy service would be approached (if appropriate), informed about the study and asked to think about participating. This strategy was markedly different from the initial strategy in that children were now being asked in the first instance while in the initial method, parents were approached first. It was considered that as children were already engaged with the therapy service and for the most part, attending every week, any concerns about the potential for young people to feel distressed by participating in the study could be addressed in advance. Therapists, in deciding to raise the issue of the study with young people would have already made a determination as to whether participation in the study would be harmful for the young person (and thus these young people were not approached). They would be able to address the issue of consent with the young person directly. For the most part, if the professional agreed to raise the research with the parents or child, it was likely that access would be gained. Professionals' clinical judgement as to the timing of introducing the research project was crucial to the success of gaining access.

Thirty one young people were approached through this method and given the information sheet about the study. Twenty indicated an interest in participating. These young people's parents (or, in the case of two young people, their social worker or foster parents) were then approached by the therapist concerned, given the information sheet and permission was sought for the researcher to make direct contact by telephone with the parent. These parents/carers were contacted and an arrangement made through either the parent or the therapist for the young person to be seen.

A third strategy was introduced parallel to the second strategy. This consisted of posting a notice about the study on the wall of the waiting room in the unit (See Appendix D). One young person who had not been approached by their therapist to participate volunteered for the study through this method. However, this young person subsequently declined the invitation. There were ongoing complex family difficulties for this person which influenced both the decision of the therapist not to raise the study with her and her subsequent decision not to participate.

Parents of young people seen in the study were invited to participate for the most part, through their children and the children's therapist. Parents of nineteen children were invited and the parents of fourteen children participated. This consisted of one father, and three couples (father and mother) and ten mothers. An additional seven children's stories were represented in this study through interviews with their parents. These parents agreed to participate even though they did not want their child to be interviewed due to concerns about the potential impact of participating in the research study for their child. This group consisted of two sets of parents (father and mother), and three mothers. 


\section{Recruiting Adult Participants}

Strategies for recruiting adult participants were discussed in detail with the counselling staff in the adult counselling service. Initially it was proposed that a letter be sent to all adults attending the service. However, during the period when ethical approval was being sought and contact was being made with this service, the service had engaged in a national evaluation study. Staff members were concerned about overloading clients with research demands. It was agreed therefore that therapists would make a determination as to whether to approach their clients and introduce the research study. Therapists were also concerned that the research study be presented to clients as completely separate from their contact with the counselling service. Agreement was reached that staff would approach clients where it was deemed by the therapist that participation in the research study would not be unduly distressing for the client. An information letter, incorporating the consent form, was given to these clients outlining the study (see Appendix E). A brief verbal description was also given by the therapist and permission sought for the researcher to contact the client by telephone. Five adults were recruited in this way. Two adults were attending individual therapy and three were attending group therapy.

A second strategy used for recruiting adults for this study was not anticipated at the beginning of the study. During the course of recruiting a young person for the study, her mother disclosed on the telephone that she herself had been abused and that she wished to participate in the study and share her story of disclosing her experience of abuse. This person, coincidentally, was attending the adult counselling service where adults for this study were being recruited. As the study progressed, it became clear that some of the young people who were participating in the study had parents who had experienced childhood abuse. It was decided to invite these parents to participate in the study, not just as parents but to tell their own story. As these parents were recruited through the child sexual abuse service, the Ethics Committee of the agency was informed of this and the committee responded that there was no objection to recruiting these individuals for the study. All but one of these individuals was attending counselling while the remaining adult was awaiting an appointment.

\section{The Pilot Study}

Methods of approaching young people for the pilot phase of this study were discussed with the service staff. It was decided to approach a therapy group that was being delivered by an art therapist in the service for a small group of teenage girls. These young people had been engaged with the service for several months and the art therapist considered it appropriate to introduce the research study to the group and ask for volunteers to participate. The first young person to 
volunteer (a seventeen year old girl) was asked to participate in a pilot interview. This interview was conducted over two sessions, took place in the service in one of the interview rooms used for assessing young people and was videotaped. It was intended at that stage to interview all young people and parents in the assessment centre where facilities were available for videotaping as this was the standard method of recording interviews in the centre. In addition to conducting a pilot interview with a young person, an adult was also seen for the pilot phase of this study. This adult woman was attending individual therapy with the manager of the adult counselling service and was targeted by her as someone who would be likely to want to participate and who would not be unduly stressed by the experience. This interview was conducted in one session in the therapist's office.

Both pilot interviews were transcribed and coded according to the open coding guidelines of Grounded Theory (Strauss \& Corbin, 1998) to elicit preliminary themes. Details of the coding procedures in this study are outlined later in this chapter. Following the pilot phase, some changes were made to the design of the study. In the case of the child interview, a decision was made to audiotape interviews rather than videotape them. In reviewing the video it became clear that the value of having visual material for the research question in this study was outweighed by the importance of protecting the privacy of the individual. A video record of the interview removed anonymity. It was also decided to offer research participants a choice of venue for the interview (i.e. their home or the service). Some alterations were made to both interview schedules. In particular, questions about life history were deleted from the adult interview as these had the potential to broaden the scope of the interview and may have presented a difficulty in focusing on the research question. Also, it was decided not to use questionnaires as part of the data gathering process. The use of these questionnaires was queried by the University's School of Psychology Ethics Committee as to their relevance to the research question. One questionnaire, the Trauma Symptom Checklist for Children (Briere, 1996) and the Trauma Symptom Inventory for adults (Briere, 1995) was being used to assess psychological symptomatology in the six months prior to interview. In particular, the measures elicit information about possible avoidant symptoms that may be relevant to the issue of reluctance to disclose sexual abuse. The second questionnaire was designed by the researcher and consisted of a list of possible reasons why people are reluctant to disclose experiences of sexual abuse. This questionnaire was designed to elicit information about the frequency and extent to which these reasons applied in this study. It was considered that their use was inconsistent with the methodological approach being used in this study. 


\section{Description of the sample}

A number of distinct samples were drawn on in this study (See Table 1). Firstly and representing the core of the study, is a sample of twenty two young people (sixteen girls and six boys) ranging in age from 7 years to 18 years who were interviewed and who form the basis for the foundation of the theoretical framework arrived at in this study. Secondly, a sample of seven children's stories is represented in the study through their parents' interviews. These children (four boys and three girls) ranged in age from three years to sixteen years. This parent group included two couples (father and mother) and five mothers. Thirdly, a number of parents of those young people interviewed participated in the study. This group consisted of two couples (father and mother), one father and eleven mothers. Finally, a sample of ten adults who had experienced sexual abuse in childhood were interviewed, five of whom were also parents of the young people. This group of two men and eight women ranged in age from 36 years to 63 years. Profiles for each of these samples are given below. 
Table 1. Characteristics of the Sample

Sample 1: Young people interviewed $(n=22)$

$\begin{array}{lllr}\text { Age } & \mathbf{n} & \text { Gender } & \text { n } \\ \text { 17-19 years } & 7 & \text { Girls } & 16 \\ \text { 15-16 years } & 7 & \text { Boys } & 6 \\ \text { 13-14 years } & 6 & & \\ \text { 7-12 years } & 2 & & \mathbf{2 2} \\ \text { Total } & \mathbf{2 2} & & \end{array}$

Sample 2: Young people's stories as told through parent interview $(n=7)$

Age

$11-15$ years

4-10 years

Total n

2

5

7
Gender

Girls

Boys
6

22 


\section{Profile of Children and Young People}

This section presents demographic information on the children who participated in this study. Young people's age at the time of the study, their age at the time the abuse began, and at the time of the first disclosure is first outlined. Information on delays in making a first disclosure and to whom the child first disclosed is presented.

Age at Time of Study

Twenty two young people were interviewed in this study and an additional seven young people's stories were represented through their parents' interviews. Fifty two per cent $(n=15)$ of the total twenty nine children were between the age of 15 years and 19 years, $27 \%(n=8)$ were between the ages of 11 years and 14 years and the remaining $21 \%(n=6)$ were under ten years of age. In all, $79 \%$ were over the age of 11 years. Thus the sample was predominantly an adolescent group. It is worth noting that most of the younger children in the under 10 age category were represented through their parents being interviewed. The youngest child directly interviewed in this study was aged 8 years. Of the young people whose parents were interviewed in their stead, one child was aged four years, two children were aged six years, two children were aged nine years, one was aged eleven years and one was aged fifteen years. In all but one of these cases (due to disengagement with the service), parents had declined permission for their child to be interviewed as they believed it would be too upsetting or disruptive for their children.

\section{Age at Time Abuse Began and First Disclosure}

As the vast majority of the children and young people in this study had told someone of their experiences of abuse some time before the study, it is important to distinguish between the age at time of the study and the age at time of the abuse. This variable has been treated in the literature as a discrete variable despite including children in such samples who have experienced abuse over a period of time. There has been some discrepancy in how this data has been presented in research studies. Goodman-Brown et al. (2003) define the age at time of abuse as the age at the time the abuse finished despite the focus of the research being on what factors predict delays in disclosure. The present study interprets age at time of abuse as age at the time of the first experience of abuse. While this age is not exact in many instances due to poor recall and the young age of the child at the time of the abuse beginning, where an estimation was offered by the child such as ' 7 or 8 ', the younger age was used.

The majority of children in this study, 66\% ( $\mathrm{n}=19)$, reported abuse that occurred before the age of ten years, $24 \%(n=7)$ were abused between the age of 11 years and 14 years and just $10 \%(n=3)$ were abused between the age of 15 and 19 years. Delays in disclosing were evident for most children in this study. Although the majority of children were abused when they were under ten years of age, only half of this group disclosed while under ten. While the average age of children in 
this study was 13.5 years, the average age at time of abuse was 8.86 years and the average age at time of first disclosure was 10.8 year resulting in an average delay of approximately 2 years, a delay constituting a quarter of a lifetime for an eight year old child. Within each age cohort, approximately half did not disclose within that age period.

Delays in disclosing the abuse ranged from immediate disclosure to 9 years. Of the total number of children, $14 \%(\mathrm{n}=4)$ told immediately, $17 \%(\mathrm{n}=5)$ told within weeks, $10 \%(\mathrm{n}=3)$ told within months and 59\% $(\mathrm{n}=17)$ delayed more than a year before confiding about the abuse. Within this group of 17 young people who delayed telling anyone for at least one year, four children delayed by one year, five by two years, four by four years, two by seven years and two by nine years. These results are markedly different from those of studies such as Goodman-Brown et al. (2003). They found in their sample an average delay of 48 hours. Only four young people in this study disclosed the abuse experience immediately after the event. Two of these told a parent (in one case, immediately after telling a sibling) and they were both aged six years. The other two young people were both fifteen years old and while both told a friend immediately, one did not tell her parents for another week while the other did not tell an adult until a year later. Goodman-Brown et al.'s sample had been accessed through a district attorney's office. It may be that prosecution samples are less likely to feature significant delays in disclosures as delay in reporting may be a factor in deciding whether to prosecute. Only $22 \%$ of Collings et al.'s (2005) large- scale sample of children who had experienced penetrative abuse had delayed disclosing for more than a month. However, $48 \%$ of young women in D.W. Smith et al.'s study had told no one of their experiences of sexual abuse for more than five years.

\section{Choice of Confidante}

The most common choice of confidante in this study was peers (including friends and cousins) with $52 \%(\mathrm{n}=15)$ of young people first confiding in peers, followed by $24 \%(\mathrm{n}=7)$ confiding in parents and the same number confiding in others. The younger children in this study were more likely to first tell a parent and as has already been noted, the majority of children in this study were adolescents. Other choices of confidante included a teacher, adult family friends, other relative and in one case, a professional.

\section{Abuse Experiences of Young People}

Four of the children in this study had experienced more than one abusive episode. An abusive episode is defined here as an experience of abuse which was disclosed, even if occurring over a period of time by one abuser. In the case of three of these young people they had two or more distinct abuse experiences with different abusers while in one case a girl experienced abuse by her brother, the abuse was discovered but at a later time she was abused again by her brother. The latter is considered here as two abuse episodes. One of the children in this study experienced abuse by 
two or more abusers in the same abuse episode and in one case a young person was being abused by two people in separate episodes over a similar period of time. Taking the first abusive episode for all 29 young people, five young people reported once off abusive experiences, twelve had experienced the abuse experience on a few occasions (two to three times), four had experienced abuse over a period of months and the remaining eight had experienced abuse over a period of years. The type of abuse reported by these young people in the course of their assessments covered a range of abusive behaviours from kissing to anal or vaginal penetrative abuse. Sexual fondling was the most common type of abuse with nineteen children reporting this behaviour. Eight young people confided anal or vaginal penetrative abuse with an additional three confiding attempted anal or vaginal penetration and two girls confiding digital-vaginal penetrative abuse. Four young people confided oral sexual abuse (in one case, cunnilingus and in three cases, fellatio). One young person reported kissing.

\section{Relationship to Abuser}

In all cases, the abuser was known to the young person although in one case, the young person had just met a male peer on a social occasion which resulted in the sexual assault. Most studies treat this variable as a dichotomous yes/no variable in providing descriptive statistics on children who were abused by either someone in the family or someone outside the family. Connolly and Read (2007) used eight categories of relationship between the abused child and the abuser, acknowledging the complexity of relationships not captured by a traditional dichotomy of intrafamilial and extra-familial abuse. Bottoms et al. (2007) asked participants to indicate closeness of relationship. In the present study, intra-familial relationships included brother, father, sister's husband, mother's partner (where he was living in the family home), male carer (in a substitute parent role), cousin, uncle, and grandmother's partner with no predominant group. Extra-familial relationships included teenage neighbour or friend of family, church worker, local man, adult family friend. The most common perpetrator in the extra-familial group was a teenage boy. In the sample of 29 children whose stories are represented in this study, 17 of these children experienced intra-familial abuse and 14 experienced extra-familial abuse, thus two children experienced both intra-familial and extra-familial abuse.

Children's experiences of abuse by multiple perpetrators have often been either excluded from research data or masked. Connolly and Read (2007) for instance, asked participants to consider the "most intrusive experience" in responding while Bottoms et al. (2007) asked participants to consider the experience that they felt was the "most traumatic". Sperry and Gilbert (2005) excluded those participants who had experienced multiple incidents of abuse from their study. Although this practice may be expedient in managing data, it does serve to mask the complexity of both abuse experiences and disclosure experiences, neglecting the variability inherent in these processes. For qualitative studies, involving smaller samples, one option used in the literature is to detail the 
number of abuse experiences and provide descriptive data on abuse experiences rather than on children (Crisma et al., 2004; Hershkowitz et al., 2007). This approach takes account of the fact that some children experience multiple abuse by different abusers, some of whom are family members and some of whom are not. Given the recognition in the research literature of the influence of familial relationships on both reluctance and delay in disclosing, it may be that reluctance to disclose intra-familial abuse also has an impact on a child's willingness to disclose extra-familial abuse. In the present study, where a child was abused by more than one individual, details were recorded separately for each abuse relationship.

Eleven children in this study were abused by other children, i.e. those under 18 years of age. Two of these children also experienced abuse by an adult. Six children (three girls and three boys) were abused by male peers, mostly in the context of a one-on -one interaction but in two cases a child was abused by two or more peers in the same abuse incident. Six children (three girls and three boys) were abused by teenage boys. It was clear from the children's files that these children were coerced into engaging in unwanted sexual behaviour by another young person or persons.

Three girls were abused by their mother's partner. In two of these families, the girl's mother had already separated from her partner.

\section{Parental History of Abuse}

Nine of the children whose stories are represented in this study had parents who had experienced childhood sexual abuse. For five children, both their parents experienced childhood abuse and for the remaining four children, their mother reported having been sexually abused as a child. The parents in this study were not asked directly if they had been abused. This information was either offered spontaneously or was available in the file information accessed during the study.

\section{Profile of Adults}

Ten adults who themselves had experienced sexual abuse in childhood were interviewed in this study. This group consisted of eight women and two men, ranging in age from forty to sixty three years. Age at time abuse began ranged from two years to eleven years, with eight of the sample reporting abuse from the age of six to twelve years. Five of the adult sample had experienced abuse by more than one individual in separate abuse incidents. Eight individuals experienced intrafamilial abuse while two individuals experienced both intra-familial and extra-familial abuse. Five of the abusers were relatives including father, brothers, mother's partners and uncles. Extra-familial relationships included male adult family acquaintances, and a teacher. 
In one instance, an adult described a once off incident of abuse by a stranger. The remaining adults described abusive experiences as follows: on a few occasions $(n=4)$; over a period of months $(n=2)$; and over a period of years $(n=3)$. The type of abuse experienced included penetrative abuse (vaginal or anal) for four of the sample and sexual touching for the remaining six. One of the latter was abused at a later stage where penetration was attempted. The age at which they first disclosed ranged from six years to 40 years with five of these disclosures occurring during the childhood years up to age eleven and the remaining occurring between age of 19 and 40 . Thus delays in disclosing ranged from no delay in one instance to 29 years. Those who disclosed during childhood had delays ranging from no delay for one person to a few weeks for two people to three years for one and eight years for another. The person to whom they first disclosed included peers in adulthood for five of the adults, four of whom were boyfriend/girlfriend/wife. The remaining five people confided in a mother or grandmother. One person confided in a friend as a child, having already told her mother. One of the adults reported that one of their parents had also been abused.

\section{Reporting to Civil Authorities}

The 22 children interviewed disclosed allegations of child sexual abuse in relation to 34 alleged abusers. In the case of the child sample, all cases had been notified to the child protection authorities while sixteen of these young people had either made or were in the process of making formal complaints to the gardai in relation to seventeen alleged abusers. Of the seven children whose stories were told in the research study by their parents, seven abusers were allegedly involved and three children made formal complaints. In all, one case had been returned by the Director of Public Prosecutions as he was not going to proceed with a prosecution due to lack of evidence. One alleged abuser had been charged and was awaiting trial. The remaining cases were pending.

The ten adults interviewed disclosed abuse by seventeen alleged abusers. Two formal complaints were made of these seventeen allegations, both initiated by the children's parents immediately following disclosure. Both of these adults were subsequently abused within the family and did not disclose or report the later experience of abuse to the gardai.

In summary, the sample in this study consists of three sub-samples. The first sub-sample consisted of a sample of young people who were directly interviewed $(n=22)$ and a sample of young people's stories that were told by their parents ( $\mathrm{n}=8$ young people). The second sub-sample was of ten adults who had experienced sexual abuse in childhood and the third sub-sample was of parents of 14 of the children directly interviewed. Seventy nine percent of the sample of young people in this study were over the age of eleven years thus predominantly adolescent at the time of interview. However, $66 \%$ of this sample was under the age of ten years when they were sexually abused. Of those young people who were abused under the age of ten, $38 \%$ disclosed under the age of ten while $41 \%$ 
disclosed between the ages of eleven to fourteen years. Abuse experiences ranged from sexual touching to vaginal, anal and oral penetration. Eight percent disclosed immediately, twenty one percent disclosed within weeks of the abuse experience, eight percent within months and the vast majority (66\%) delayed disclosure by at least a year. Fifty two percent of young people first disclosed to peers. It is likely that the preponderance of peers as a choice of confidante is due to the age profile of young people in the study.

\section{Data Collection, Management, Coding \& Analysis}

In Grounded Theory studies, the process of data collection and analysis is cyclical rather than sequential. Therefore data collection does not consist of a distinct phase, followed by a data analysis phase as is the case in traditional quantitative studies. Rather, following an initial phase of data collection, data are coded and analysed followed by another phase of data collection, coding and analysis, which is informed by the first cycle. This cycle continues throughout the study. In this study, interviews were conducted in clusters, as access to participants became possible. Interviews were transcribed and coded as the study progressed so that subsequent interviews were informed by the analysis of data already gathered. This enabled emerging themes to be explored with research participants in the later phases of the study. The procedure followed for data collection, coding and analysis is outlined in a flow chart in Figure 1 and details given later in this section.

Figure 1

The Process of Data Collection, Coding and Analysis 
Seven child interviews

Open Coding \& Comparative Analysis

Database Sept05

Key themes identified

Theory Building 1

Presentation of Findings \& Feedback

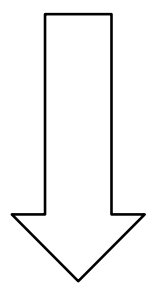

Five child interviews

Open Coding \& ComparativeAnalysis

Database Oct06

Additional key themes identified

Eight child interviews

14 parent interviews

Ten adult interviews

Open Coding \& Comparative Analysis

Database Feb07

Final two child \& five parent interviews

Open Coding \& Comparative Analysis

Database Oct07

Theory Building 2

Member Checking - child, parents \& adult

Final Meetings with Professionals

Theoretical Framework

\section{Data Collection}

Two methods of data collection were used in this study, research interviews and file reviews using data record sheets. 


\section{The Interview}

The semi-structured research interview was the primary method of collecting data in this study. The advantages of a semi-structured interview, according to J.A. Smith (1995) are that "it facilitates rapport/empathy, allows a greater flexibility of coverage and enables the interview to enter novel areas, and it tends to produce richer data." (p.12). A structured standardized method of gathering data would limit the child's response to questions predetermined by the researcher, limiting the scope of the enquiry. Burman (1994) describes four reasons for conducting interviews as a research tool: a concern with subjective meanings, the potential for exploring complex issues and tailoring questions to the interviewee; it demands reflexivity; and it helps to address power relations through working together. As has been discussed in Chapter 1, there has been insufficient concern with subjectivity in exploring the process of disclosing sexual abuse experiences until the past decade when this has been redressed through the increasing popularity of qualitative methodologies. Research has indicated that children's accounts of their own experiences of sexual abuse are more detailed and more accurate if they are given in response to open-ended questions (Sternberg et al., 1997).

The interview procedure with children in this study was informed by international guidelines for forensic investigative interviewing of children who have been sexually abused (APSAC, 1999; Home Office, 1992, 2000, Sternberg et al., 1997) An initial rapport building stage set the scene for the interview and included a detailed description of what the child or adult could expect from the interview, an outline of the "rules of the interview" for pre-teenage children and a reminder to participants of the freedom to withdraw at any time during the study. The rules of the interview were adapted from NICHD protocol (Sternberg et al., 1997) and consisted of four rules, as follows:

(1) 'If you don't know the answers to any of the questions, you need to tell me 'I don't know'. If I asked you what kind of dog I have, what would you say: (don't know) that's right, because you don't know, do you? Well done;

(2) "If I get something wrong or make a mistake, I need you to tell me 'No, that's not right'. So if I said your sister's brother's name is Jane/Jim, what would you say? (no) That's right, because it's ... Well done;

(3) "If you want to stop at any time, I need you to say 'I want to stop now'; and

(4) "We only talk here about things that really happened" (give example).

The consent form was then discussed and signed (See Appendix E for adult consent form and Appendix F for child consent form). The rapport building stage of the interview was followed by a free narrative stage where the child is invited in his or her own words to relate the story (in this case the story of how she or he told of the abuse as opposed to the details of the abuse experience). The child was then asked detailed questions intended to clarify or elaborate on information 
provided. An emphasis was placed on asking the child to give more information through the use of questions such as "Tell me more about that" and avoiding leading questions that might overinfluence the child's responses. While these guidelines did inform how the research interview was conducted, the interview in the context of this study is conceived not so much as a questions and answers session but more as a dynamic conversation, a collaborative effort to make sense of the story, much as Westcott and Littleton (2005) describe a research interview as "about constructing an account with the child". This collaborative approach of working with the child to build an account also attempts to address issues of disempowerment which are endemic to both adult-child and professional-client interactions and to situations where a child has been abused. It must be acknowledged, however, that issues of disempowerment can only be partially addressed in the context of a one-off interview between a professional and a child in the research context.

The extent to which the free narrative stage can be truly open ended varies according to the cognitive abilities of the child and their emotional presentation. The rapport building stage gives an opportunity to assess the extent of the scaffolding support a younger child will need in order to respond to questions, and enables the interviewer to frame her questions in a manner appropriate to the child's developmental level. Hewitt (1999) recommends shorter sentence structure, using the child's own terms, concrete focus, the use of prompts, and avoiding multiple constructs in a question.

A small number of key questions guided the interviewer in providing some structure to the conversations with participants in this study (See Appendix G for Interview Guide). For the most part, the first question asked, following a rapport-building phase, was to invite the participant to give an account of how they first told someone about their experience of being abused. To support this account, questions such as "what helped you tell?", "what stopped you from telling earlier?" were asked of all participants to elicit details about those factors which influenced the disclosure experience. As J.A. Smith (1995) notes "the interviewer uses the schedule to indicate the general area of interest and to provide cues when the participant has difficulties, but the respondent should be allowed a strong role in determining how the interview proceeds." (p.17).

Details of all disclosure experiences were explored, where possible. Two general questions addressing developmental and gender differences were also asked: "do you think age makes a difference?' and 'do you think it makes any difference if you are a boy or a girl?" Finally, participants were asked what advice they could offer to children who are being abused and "what can we do to help children tell?". Themes identified from the coding of earlier transcripts in the study were added to the interview protocol over time. Such questions included "Would it make a difference if people talked about it more?" and "If you had not told then, would you have told later?". 
Methods of trying to address the power imbalance between the researcher and the child are discussed in the section on ethical issues. Within the interview itself, this included giving as much information as possible about what was going to happen both in the interview and with the material gathered. For example, young people were told that the interviewer did not know what happened and so was reliant on the child to tell their story; that they could stop at any time during the interview or even decide after the interview that they did not want their story to be used in the study. They were told that the study would be published and they may be able to identify their own words but that no one else would know who it was. They were offered as much choice as possible i.e. choice to participate or withdraw, choice of location, and within that, choice of room. For the most part, families chose to be seen in their own home. Several teenage girls chose their bedroom often referred to by their parents as "their own space" or "where they feel safe".

\section{Document Review}

The researcher had permission from the young people in this study, their parents and the parents who participated in 'parent only' interviews to access assessment reports on the children's files. Information gleaned from these files was recorded on a 'Data Record Sheet' and consisted of demographic information, relevant family and developmental history, details of the disclosure as noted on the report, child's functioning at the time of assessment, the details of the abuse experiences disclosed at interview and other relevant information. A copy of this Data Record Sheet is included in Appendix H.

\section{Data Management}

Data in this study were managed using the software programme NVivo (QSR, 2002). According to one of the developers of NVivo, "This programme helps you to manage and synthesize your ideas, providing a range of tools for clarifying understanding of the data and for arriving at answers to research questions" (L. Richardson, 2002, p. 11). Firstly, interviews were transcribed by the researcher onto a Microsoft Word document. The decision to transcribe all interviews was taken to facilitate "immersion in the data" and to maintain the emotional integrity of the participants' stories through a detailed listening to the audiotapes. The word document was then saved as a rich text file to enable it to be imported into the NVivo programme. The document was defined as a child, adult or parent document and a brief definition of the document included the age of the child or adult, by whom the person was abused and the age and duration of abuse. Each document in NVivo is allocated a number of attributes that facilitate later analysis. Attributes refer to characteristics such as demographic variables and can be viewed as a table that details all attributes of all research participants in the study. This table can then be used to provide a cross tabulation of the relationship between variables such as delay in disclosing and intra-familial or extra-familial abuse or indeed the relationship between particular themes emerging from the data, such as 'denial' and 
attributes of the child such as age. The attributes table facilitates cross-comparisons to be made and facilitates in questioning the data. The attribute table can be exported into an Excel table to facilitate computation of numeric data to produce descriptive statistics such as age at time of abuse, or age at time of disclosure.

\section{Data Coding and Analysis}

Coding and analysis using Grounded Theory methods involves specific strategies formulated for handling, and making sense of, initially ill-structured qualitative data. Data analysis in this study was informed by literature on both qualitative research and Grounded Theory (Charmaz, 2006; Henwood \& Pidgeon, 1992; Strauss \& Corbin, 1998). Strauss \& Corbin (1992) advocate a progression from reading transcripts, open coding line by line, revisiting the transcripts and through a process of constant comparison, generating more conceptual coding ("axial coding") categories which inform further sampling, repeating the process with the new transcript and gradually developing a theoretical framework from which theory can be built.

\section{First Level Coding}

At the first reading of each document, text not relevant to the research questions was highlighted in red so that the text to be coded remained in black ink. An open coding phase was then conducted, involving a line-by-line perusal of the transcripts generating as many categories as possible that best described what was being said in the text. Categories are defined as "concepts that stand for phenomena" (Strauss \& Corbin, 1998). The name chosen for a category is the one that reflects most logically a description for what is going on. The name may be contained in the data itself i.e. "in vivo coding". Categories are not mutually exclusive in that the same data can be allocated simultaneously to more than one category. When NVivo is used to code documents, the relevant text is highlighted, a category is created, which represents the text being coded, and a click on the category label allocates the highlighted text to that category. This category, referred to as a 'node' is "a container in NVivo for categories and coding" (Richardson, 2002, p.15). As each new category is created, it is defined clearly. This category is then available in the "Coding Bar" which appears as a toolbar on the screen. The coding bar shows all the current categories. By clicking on any particular category label, it is possible to bring onto the screen all other text coded at that category for comparative purposes. These categories are then available for all subsequent coding activity. This represents the first level of category used in grounded theory, referred to as a subordinate category (diGregorio, 2003). Definitions are expanded or refined throughout the process of coding and comparative analysis. Following this procedure, transcripts were read and reread to elicit these category labels. The categories created through open coding represent the lower level categories or subcategories of Grounded Theory analysis. 
Axial coding involves reviewing the categories developed from the open coding phase. Similarities and differences between categories are highlighted and on the basis of this analysis, new category labels are generated representing 'higher conceptual level' themes which may have lower level themes associated with them. A range of potential meanings contained within the words is explored for the purpose of establishing the properties and dimensions of each category. According to Strauss \& Corbin, it is only by discovering the properties and dimensions that true comparisons can be made and that the categories can be developed into theory. Properties are "the general or specific characteristics or attributes of a category, dimensions represent the location of a property along a continuum or range" (Strauss \& Corbin, 1998, p.117). In order to share a higher level category the lower level categories must share some characteristics with each other. The distinction between higher level categories and subcategories becomes evident as the analysis progresses. The linking takes place at a conceptual level.

The process of coding and analysis outlined above was repeated at various stages in the study, following the same format. Thus, coding of interviews followed the same open and axial coding procedure. As new categories were created, earlier transcripts were reviewed and re-coded using the new categories where and if appropriate. All child interviews up to C20 were coded before adult interviews were coded. After the adult interviews were coded, parent interviews were coded. An additional comparative analysis was conducted on those parent interviews that corresponded to child interviews to highlight varying perspectives on similar experiences, where appropriate. Adult interviews were all coded one by one following the same format. Finally, Data record sheets were completed, abstracting the relevant information from the child's file. These were used primarily to elicit attributes for the child interview transcripts. All categories and themes were identified from the data, not pre-determined.

As detailed above, the approach to each transcript was to use open coding to generate as many categories as possible to adequately represent the meaning conveyed in the text. However, the first attempt at generating coding for the first three interviews revealed a tendency on my part to move to higher conceptual categories prematurely. Thus an initial list of 20 categories was generated. My reflective journal records that in August 2005, I re-read Strauss \& Corbin's (1998) as it appeared that the categories were reflecting a structure imposed on the data by the questions from the interview schedule. These were as follows: actual consequences, advice, age of disclosure, family difficulties, feeling guilt, made up story, mental health difficulties, method of disclosure, others reactions, own feelings after disclosure, person to whom disclosed, pressure put on to tell, questionnaire, reasons for not telling, safe place, seek asylum, someone encouraged to tell, triggers, type of abuse and wouldn't have told. It is clear that some of these categories reflect higher order categories such as reasons for not telling or triggers. Following a re-reading of Strauss $\&$ Corbin, these three interviews were re-coded through a process of comparative analysis resulting 
in the coding structure outlined below in Figure 2 and abstracted from the Nvivo database dated September 2005. A total of 100 categories were created, including 11 'stand-alone' categories or 'free nodes', 9 higher level categories or 'tree nodes' within which were incorporated a further 80 subordinate categories (see Appendix I for full details). This coding structure represents the second level of coding where higher level categories were created on the basis of comparative analyses of lower level categories.

Table 2 .Coding Structure, September 2005

\begin{tabular}{|l|}
\hline Stand alone categories (Free Nodes, $\mathrm{n}=11$ ) \\
Actual consequences \\
Age of disclosure \\
Family difficulties \\
Fear \\
Know of abuse not disclosed \\
Luck \\
Made up story \\
Police-lawyer \\
To whom disclosed \\
Trust - safe place \\
Who knows \\
Higher Level Categories (Tree Nodes, $\mathrm{n}=9$ ) \\
Advice \\
Psychological distress \\
Feelings after told \\
Beliefs \\
Difficult to talk about \\
How child told \\
Others' reactions \\
Reasons for not telling \\
What helped tell \\
\end{tabular}

${ }^{1}$ All subordinate categories are listed in Appendix I

A matrix analysis conducted in NVivo cross referenced the nodes created with individual interview transcripts. Using a criterion of at least four children mentioning this theme, a list of seven key themes was generated: Two subordinate categories of the category, reasons for not telling i.e. telling will cause trouble, felt ashamed and embarrassed; Two subordinate categories of the 
category, how child told, i.e. were asked and denial; Two subordinate categories of the category beliefs, i.e. people don't believe children and wouldn't have told; Three subordinate categories of the category, feelings after told, i.e. glad, relieved and regretted; and one subordinate category of category, advice, i.e. tell. Using these themes as a basis, the first stage of theory building was developed, as follows:

Children believe that when a child is sexually abused, it is a good thing to tell someone about this. This is despite some ambivalence about their own experiences following telling. They were glad and relieved but also regretted telling. However, children believe that people don't believe what children say.

It is difficult for children to tell as evidenced in the extent to which children deny having been abused when directly asked.

Yet children who disclose have invariably been asked, indicating the need to be asked. They won't tell if not asked or some pressure put on them to tell due to their beliefs that telling will cause trouble and they feel ashamed and embarrassed about what happened.

A significant conceptual shift occurred in the analysis of data between January 2006 and October 2006. This was influenced by my attending a lecture by Cathy Charmaz in Leicester, U.K., and my reading of her newly published book "Constructing Grounded Theory" (Charmaz, 2006). In January, the themes reflected descriptive themes that resulted in a list of factors e.g. reasons for not telling or what helped the young person tell? Data appeared to be structured according to the questions asked in the interview schedule despite the adherence to open coding and the funnelling approach of open coding to axial coding. It appeared that in the development of higher-level categories, the structure of the interview schedule was being imposed on the data. Charmaz recommends that themes emerging from data should be active if they are to portray an underlying process. One of the coding problems she identifies is that of "identifying topics instead of actions and processes" (p.69). She suggests that certain questions be asked of the data such as "What process(es) is at issue here? How can I define it? How does this process develop?" (p.51) and in testing whether the code is an appropriate one "can you explicate what is happening in this line or segment of data with this concept?" (p.68).

The raw data were re-read with a particular emphasis on seeking a theme-driven approach that reflected active processes. Through this process, certain themes that had previously been subordinate categories were 'promoted' to higher level categories. For example, being believed, which had been a subordinate category of reasons for not telling became a higher level category, reflecting a process in itself.

At all times in the coding process, the number of "free nodes" or nodes representing open coding at this stage in the analysis were kept to under 100 in line with advice offered by diGregorio who cautions against 'the coding trap' for users of NVivo (diGregorio, 2003). Because the technology of this programme facilitates coding so easily, the user can get caught in the trap of creating a 
limitless number of codes, postponing the more abstract comparative analysis phase of theory building central to the Grounded Theory approach.

Appendixes I to L include a list of all categories at various stages of the analysis, i.e. September 2005, October 2006, February 2007 and October 2007 representing the stages of coding and analysis outlined in Figure 1 above. As each transcript was coded, new categories were created as either stand alone categories or subordinate categories to keep the analysis at a lower conceptual level. Then coding reviews were conducted where through comparative analysis categories were compared on their dimensions and properties and either merged with other themes, categorised under existing categories or clustered into new categories under newly created higher level categories. The 'paper trail' for how these codes developed through the course of the study can be seen in the appendixes. However, as an illustration, the development of the key process of containing the secret, the key dynamic of pressure cooker effect and one of the key influences on this process, being believed, are detailed below to illustrate the process of analysis.

\section{Containing the Secret: Denial - Active Withholding - Containing the Secret}

In the first phase of axial coding in September 2005, two themes were identified as somewhat interrelated: the observation that children appeared reluctant to tell unless asked and that when asked many of the children already interviewed had denied when asked. This suggested to the researcher that an active process was involved here of withholding information. However these nodes were not interrelated in the coding framework. Denial was a child node of the parent node difficult to talk about and being asked was a child node of the parent node what helped tell. Other less significant themes at that time which supported the idea of actively withholding information at that stage were made up story and told not to tell. The theme made up story referred to a young person making up a story to deflect attention away from possible questioning which might lead to disclosure. The theme told not to tell represented the idea of young people asking others not to tell anyone when they did disclose. In addition the codes to whom and who knows had been created as descriptive variables to take note of who the young person disclosed to and how many people knew at the time of the research interview. The latter four themes were stand alone codes in September 2005.

In the October 2006 database, the category actively withholding was created. The definition of the category at that time was 'evidence of active effort to withhold information, actively not telling; to include making up a story to cover up; hiding distress and also to include missed opportunities for telling that may be regretted' (Database Oct06). Actively withholding was created as a subordinate category to a higher level theme, containing the secret, representing attempts on the part of the child to keep the secret and containing the subordinate categories actively withholding, confiding in friends, made up story, denial, I'll show you mine (representing reciprocal confiding between 
friends), ready to tell, who knows, blocked out, tried to tell, partial disclosure, self-blame, didn't occur to tell, and telling would make it worse. A memo written on theory building in September 2006 reflects an attempt to describe the process for young people. Following the experience of abuse, many young people experience an active process of withholding information and actively keeping the experience secret. The adaptive function of not disclosing was becoming clear from the data and this, along with the negative associations with the phrase 'keeping the secret' led to choosing the term 'containing the secret' to reflect this active process. It was also considered that the term 'containing the secret' more readily fit with the idea of the secret being contained at an interpersonal level in addition to it being kept at an intrapersonal level, while active withholding appeared to reflect an intrapersonal process. The inclusion of the two categories to whom and who knows took on greater significance as more data were collected and it became clearer that those to whom disclosures were made were for the most part trusted individuals and this consisted of a relatively small group of people at the time of the research interview.

In February 2007 a distinction was made between those subordinate categories of containing the secret that constituted evidence for this process and those subordinate categories that contained data about the reasons why children contain the secret. The evidence for containing the secret lay in the categories actively withholding, denial and who knows while the reasons for containing the secret were merged to the existing higher level category, reasons for not telling. The term reasons for not telling was replaced with containing the secret-reasons as this term was considered more conceptually relevant and thus carrying greater explanatory power. It also reflected a move to coding from that of describing passive phenomena to reflecting active processes as advocated by Charmaz (2006).

Pressure Cooker Effect: Being Asked - Psychological Distress - Breaking the Secret - Triggers Pressure Cooker Effect

In the first attempt at theory building ambivalence was identified based on young people's descriptions of how they felt following disclosure: part regret, part relief. The idea of pressure was introduced into the analysis referring to the pressure coming from others in the form of young people being asked. The idea of pressure coming from without, i.e. through being asked, competing with intrapersonal dynamics i.e. beliefs about the trouble telling might cause and feelings of shame and embarrassment was beginning to surface in the analysis. Less significant themes at this point but related to pressure from within the young person was psychological distress and difficult to talk about. In October 2006, allied to the conceptual thinking of the process involving containing the secret was the experience of breaking the secret. This latter category was created as a higher level category in October 2006, incorporating the categories aware of other person abused, being asked, being believed, pressure cooker and unplanned. The former three categories reflected earlier themes that had been organised as subcategories of what helped tell (was asked and fact that 
someone else was abused) and were now moved to being subcategories of breaking the secret.

Both these higher level categories - breaking the secret and what helped tell were re-examined and two new higher level categories were created in February 2007, i.e. Triggers - internal and Triggers-external, operating at both the intrapersonal level (e.g. anger) and the interpersonal level (e.g. being asked).

A memo (20/02/2007) on Triggers notes my dissatisfaction at the time with both the terms 'breaking the secret' and 'triggers'. The former while capturing the active process of telling did not convey the gradual nature of the experience. Some of the sub-categories constituted immediate triggers while others could best be conceptualised as contributing influences, not resulting immediately in a disclosure but perhaps contributing to the readiness to disclose over time. One of the subordinate categories of the category, triggers - internal, i.e. pressure cooker, which had been created in October 2006 to represent signs of a build up of triggers before telling, was promoted in September 2007 to the level of higher level category to capture both the internal and external dynamics operating to influence the child in disclosing.

\section{Being Believed}

Being believed was identified by at least four of the seven children interviewed in the first phase of data collection. At this stage, the meaning of the theme being believed was that children were reluctant to tell due to fears that they would not be believed. Being believed then was a child node of reasons for not telling. At a later stage of analysis, some children noted that they felt confident that they would be believed. This, it is suggested, could therefore represent a theme that might have helped children to tell: thus it may represent not only a reason for not telling i.e. not being believed, but also a factor that helped children tell, i.e. being believed. In later analyses of both children's and adults' interview transcripts, it became clear that for many young people and adults, the actual consequence of disclosure was that they were not believed. In addition, when asked what advice they might offer young people, the issue of adults believing children was raised. Thus data on the issue of being believed referred to four superordinate categories at various stages of the analysis: reasons for not telling, what helped tell, consequences or reactions of others, and advice. The definition of the theme being believed therefore required expansion to incorporate these different aspects of the theme and warranted re-categorizing this theme as a free node representing a strong influencing factor on the overall process of containing the secret. One of the limitations of the structure driven approach was that there was considerable overlap between themes. By merging themes such as fear of not being believed and data referring to the experience of being believed or not being believed, coded in reactions of others to disclosure, it was possible to consider the importance of the issue of being believed at a higher conceptual level, rather than as a descriptive factor either facilitating disclosure or representing consequences of disclosure. 
Coding and analysis in the grounded theory tradition continues not just throughout the data collection, coding and analysis phases of a study but into the writing of the dissertation (Charmaz, 2006). As Charmaz (2006) notes "the comparative analysis continues into the writing-up phase of the study as the findings of the study are re-examined in the context of the extant literature" (p.32). Decisions regarding a structure for presenting the findings of this study were both influenced by and influenced the coding used in the study. Codes spoke to structural themes as well as content themes. Charmaz suggests: "rethink and adapt a prescribed format in ways that work for your ideas rather than compromise your analysis" (p.154). The final theoretical framework is presented as Figure 3 in Chapter 3.

\section{Theoretical saturation}

Theoretical saturation is one of the hallmarks of Grounded Theory methods. According to Charmaz (2006), "categories are saturated when gathering fresh data no longer sparks new theoretical insights, nor reveals new properties of your theoretical categories" (p.113). Theoretical sampling as a strategy is linked to theoretical saturation. The building of theory depends on testing the themes that emerge from a study on additional participants through the processes of theoretical sampling and negative case analysis. Theoretical sampling enables the researcher to direct the sampling techniques from the theory developed so that the theory can be tested and thus either supported or negated. Similarly, through the process of negative case analysis the theory is tested against individuals' stories which do not conform or fit with the theoretical ideas being developed. Theoretical saturation then is reached when no new themes are emerging from interviews: "you keep sampling until your categories are saturated" (Charmaz, 2006, p.114). As already noted, in this study individuals were not targeted for inclusion in the study on the basis of theoretical concepts emerging from data. Rather, concepts were tested in later interviews for the purpose of extending analysis and testing possible meanings for different individuals. In this way, theory was tested to establish if new theoretical categories or properties of existing categories emerged.

In the course of coding and analysing the data from this study, each new interview brought new themes and while these themes may well have merged with existing ones in a comparative analysis, this did involve expanding the definition of the original theme to incorporate this new meaning. Theoretical saturation then, as defined above, was not reached in this study. Each new child brought a unique story, a unique self and a unique family. It is suggested that the complexity of sexual abuse experiences does not lend itself to the concept of theoretical saturation, much as was pointed out in the literature review, a typical pattern of disclosing may not exist. The criterion of theoretical saturation in Grounded Theory studies has not gone unchallenged. As Morse (1995, cited in Charmaz, 2006) notes, researchers often proclaim they have achieved theoretical saturation in their data analysis but do not present the proof of this. According to Dey (1999), the idea of saturation is simply a researcher's conjecture and cannot be proven unless one undertakes the 
analysis. He contends that categories are suggested by data, not saturated, and offers the term "theoretical sufficiency" as a more appropriate goal for grounded theory research. However, even theoretical sufficiency may be difficult to achieve. As Charmaz points out, achieving saturation depends on the complexity of the research questions asked.

It is evident from the analysis of data in the present study that if data collection continued, so too would the generation of theoretical ideas. All themes pertaining to the experience of sexual abuse disclosures were not encapsulated in this study. None of the participants in this study reported direct abuse by female abusers or abuse that was directly facilitated by female carers. A few young people in this study suggested that such experiences might be more difficult to tell about while one young person did not believe it was possible for a woman to abuse a boy. Abuse in the form of child pornography production or exposure was not represented in this sample nor the use of the internet and mobile phone technology as means of engaging children and young people in sexually abusive behaviour. It is possible and quite likely that these various forms of sexual abuse would uncover additional themes relevant to the process of containing the secret of child sexual abuse. Thus, the theoretical framework emerging from this study must be viewed as a work in progress, acknowledging that further theoretical sampling would elicit additional theoretical concepts and indeed re-visiting existing data from different perspectives would reveal new insights.

\section{Ethical Issues}

Ethical approval was obtained from three sources for this study: Trinity College School of Psychology Ethics Committee, The Children's University Hospital Ethics Committee and the Eastern Regional Health Authority Ethics Committee. Ethical approval was also sought from an additional children's service and although ethical approval was granted, attempts at accessing children were not successful within the time frame remaining in the study. This research study was informed by the Children's Research Centre Ethical Guidelines of Trinity College Dublin (Children's Research Centre, 2006).

Several authors have written about ethical issues in conducting research with children such as obtaining informed consent to participate, adults' role as gatekeepers, and confidentiality (Greig \& Taylor, 1999; Hill, 2005) and some have written specifically about research with children who have been sexually abused (Amaya-Jackson, Socolar, Hunter, Runyan, \& Colindres, 2000; King \& Churchill, 2000; D. Runyan, 2000). The key ethical issues of concern discussed here are informed consent, the welfare of the participant, empowerment, and limits of confidentiality. The role of gatekeeper is discussed in relation to all four issues. 


\section{Informed Consent}

As already noted earlier in this chapter, access to child participants was obtained through a series of layered screening processes which in their own way contributed to the process of both informing children about the research and, it is hoped, ensuring that children had both time to think about participating in the research and the option to give or withhold consent. Collaboration with the clinical team was crucial at all times throughout the process of gaining access to children. The team represented the first protective barrier and in many cases the strongest. As discussed in the section above on access to participants, professionals did not directly ask families to participate if they considered that this would not be in the best interests of the children or families concerned. There was therefore some selection bias operating in the samples used in this study, which will be discussed in Chapter 7 in the section on limitations of this study and future directions.

The study was discussed with children and adult participants either by their parents or their therapist and their consent obtained prior to them being contacted by the author. The study was explained in detail at the beginning of the interview and their written consent obtained (Consent Forms are in Appendix E and Appendix F for adults and children respectively). The form explicitly states that they could withdraw from the study at any time, including after the research interview.

\section{Empowerment}

In some cases, parents approached about the study declined participation without raising it with their children directly. It could be argued that parents (and indeed professionals) may have perceived participation in research to be more distressing for their children than it would in fact be. Parents themselves can be very distressed after the discovery that their child has been abused. However, parents' well-being and comfort in participating in research is also important for the child's well-being: the family will be left to deal with the aftermath of participating in the research long after the research study is over. These issues therefore need to be balanced in any discussion of the rights of children to participate in research.

In this study, attempts to address the imbalance of power between the researcher and the participant included giving as much information as possible about the research study and how information would be used, emphasising the purpose of the study as hopefully benefitting others and giving the participant as much choice as possible. It was explicitly stated at the outset of the interview that the purpose of the study was to find out more about children's stories so that we could help other children in this situation. A question specifically seeking the participant's advice for other children was included in the interview schedule. Many of the children interviewed spontaneously mentioned their altruistic motivation in participating in the study, stating clearly that they wanted to help others. 
Research participants were offered a choice of where to be interviewed, the service where they were attending or in their own home. The vast majority chose to be interviewed in their home. Thus, participants were given as much choice as possible within the practical constraints of the research project.

\section{Welfare of the Participant}

All children and adults seen were linked into a therapeutic service that they were either still attending or had attended. In the latter case, the option was there for them to return for support if they so wished.

There was also a concern that some parents might agree to participate due to their wish to help others but it may not be in their best interests or their child's best interests to do so. In some instances professionals did not approach families if they were having difficulty engaging the family in the service. Professionals used their own clinical judgement as to whether to approach families or individuals about participating in the study. Thus, if participation was perceived by professionals or parents to be too distressing or disruptive, clients were not asked to participate.

\section{Limits of Confidentiality}

All participants in this study, children and adults alike were informed of the limits of confidentiality at the outset of interviews. Participants were informed that the material would be edited while transcribed to remove any identifying information such as people's names, place names or any information unique to an individual that the Researcher deemed to be in some way identifying.

Participants were informed that if any information was disclosed which related to either their own or another person's experience of abuse and that suggested that a child might be currently at risk of abuse, this information would be relayed to the child's therapist or the relevant professional dealing with the family. This practice is in line with Children First, the Department of Health and Children's guidelines for the protection of children (Dept. of Health \& Children, 1999). Participants were also informed that if any other information came to light that raised concerns as to the well-being of the participant, this information would be given to the relevant professional. In two instances, young people disclosed information about abuse that had not been reported to the relevant authorities. The young people were encouraged to discuss this with their therapist and the therapist was directly informed of such concerns by the researcher. In several instances, abuse experiences by adults who participated in this study had not been reported to the child protection authorities. Identifying information and information on the current whereabouts of the alleged abuser were not forthcoming, if known, from these individuals as they did not want this 
information reported. In one instance, a follow-up telephone call to an adult participant raised concerns about their mental health and the adult's therapist was contacted and informed of this.

\section{Reflexivity}

According to Charmaz (2006), reflexivity refers to the researcher's scrutiny of what they themselves bring to decisions and interpretations, thus acknowledging the involvement of the researcher in the process and the influence of their own experience in the outcome of the inquiry. Guba and Lincoln (2005) describe it as "the process of reflecting critically on the self as researcher" (p.210). In research, the researcher is a research instrument much as in therapeutic work, the therapist is a therapeutic tool. Reflexivity then in qualitative research is akin to personal awareness in therapeutic work, both sharing a common purpose: to make conscious or explicit the thoughts, feelings, behaviours that may influence the therapist/researcher in their therapeutic/research work. This reflects an acknowledgement that both researcher and research participant influence the research process. In therapeutic work with children who have been sexually abused, a conscious awareness of one's own family history and the potential influence this has on one's development, one's own attitudes to sexuality and child sexual abuse as well as a willingness to seek help with unresolved conflicts are essential as the therapist's own life experiences influences their belief systems and how they work therapeutically (O'Shea \& McElvaney, 2001).

In this study, attempts to remain reflexive included: the use of a reflective diary; writing memos on coding and theory development; discussing emerging ideas on an ongoing basis with my research supervisor; discussing the study with professionals who had expertise in the field of sexual abuse; consulting with a fellow doctoral student who did not have experience of sexual abuse and who read a selection of interview transcripts with accompanying coding; consulting with an expert on using NVivo software in qualitative research; presenting the study at conferences; documenting feedback from attendees; and member checking. These practices not only facilitated reflexivity but also acted as credibility checks (Elliot, Fischer \& Rennie, 1999).

\section{Reflective Diary}

A journal was kept in the NVivo programme that detailed the researcher's thinking on the coding and analysis process as it unfolded. This diary documented the comparative analysis or axial coding process in particular, detailing why codes were merged with each other, and if so detailing the expanding definitions of the new codes or why codes were deleted due to overlapping meanings. In addition, memos were written outlining the conceptual thinking in relation to particular themes as they emerged in the data. 


\section{Consultation}

Consultation was availed of from a fellow doctoral student who had no experience in the area of child sexual abuse. This latter resource was particularly important given the researcher's background as a clinical psychologist specialising in the area of child sexual abuse. This colleague read through a selection of interview transcripts (four child interviews, two parent interviews and two adult interviews) which depicted 'coding stripes', a facility in the NVivo software package which shows clearly what excerpts from the transcript are coded for particular categories. A printout of node descriptions was also made available and feedback sought on whether the labels reflected the meaning conveyed in the text. Where further clarification was indicated, definitions of nodes were expanded or re-written. Text was re-coded when a consensus was reached that the code did not fit well with the data. This consultation process was a helpful adjunct to a regular practice of reviewing nodes after each set of transcripts was coded. A consultation was also held with an independent consultant/trainer with expertise in the use of NVivo software in qualitative research. This expert reviewed the database in May 2007 and gave feedback on coding and analysis at the various levels of abstraction and on theory development. Finally, the process of coding and analysis was discussed at regular supervisory meetings with my research supervisor. These meetings were challenging requiring me to define and re-define the meanings conveyed by my coding categories and in particular, to respect the diversity in the data and resist the temptation to neatly package the findings into one coherent theoretical framework which might apply to all the research participants.

\section{Professionals' Meetings}

The group of professionals through which the study samples were accessed represented an important resource for this study. Ongoing consultation and feedback was both sought and welcomed throughout the study. As already stated, both groups represented a mix of disciplines. In the adult counselling service, the disciplines of psychology, social work, psychotherapy and counselling were represented while in the child sexual abuse unit these disciplines were also represented with the addition of representation from psychiatry. Two formal meetings were held with the staff group from the adult counselling service and three with the team in the children's service. The purpose of the initial meeting was to outline clearly the purpose of the research and the procedure for accessing participants and conducting the study. This was also an opportunity for professionals to raise questions of concern. Questions raised at this meeting included the potential impact on clients of engaging in the study and the question of obtaining informed consent when participation is introduced by the client's therapist. A follow up meeting was held with the children's service team to discuss additional strategies of accessing participants following difficulties experienced in the early months of the study. Finally, a meeting was held with each of 
the two services when the data collection period was complete and preliminary coding and analysis phases had been conducted. The purpose of this meeting was to give the professionals feedback on the findings of the study and to seek feedback from them so as to contribute to the process of theory building. In this way, it was possible to avail of the considerable expertise and experiences of these professionals who had worked in the field of sexual abuse for many years. Memos were written following these meetings, outlining any comments made on coding and the themes identified in the data.

\section{Feedback from Presentations}

Finally, the researcher availed of three opportunities during the course of the study to present various stages of the study at conferences and thus invite feedback from attendees. Notes were taken following each of these presentations outlining conceptual developments in coding and analysis that had been influenced by this feedback.

\section{Member Checking}

Four research participants, one young person, her two parents (i.e. a couple) and one adult were invited to engage in a follow up interview as a 'member checking' exercise. The four individuals were given a printed copy of their interview transcript that depicted the 'coding stripes'.

Definitions of nodes were also given to these research participants. Each participant read through their transcript and the ensuing conversation was audiotaped. Clarification was sought by the adult participant on the definition and meaning of themes. None of the participants registered disagreement with the coding. The theme of pressure cooker was 'checked' with both the child participant and the parents, in particular whether this term captured the meaning intended and whether the term would be familiar to young people in general. These participants strongly agreed with the use of this term in the theoretical framework as resonating with their understanding of the build up to disclosure and believed that young people would identify with the meaning conveyed.

\section{Conclusion}

This chapter has outlined the choice of Grounded Theory as an appropriate methodology for exploring the process of how children tell of their experiences of sexual abuse. To ensure rigour in how the study was conducted, guidelines offered by Henwood and Pidgeon (1992) and R. Elliott, Fischer, \& Rennie (1999) informed the study. The sample was accessed through two clinical services, one for children and families and a counselling service for adults. The interview was the primary data-gathering tool. Descriptive data were obtained from children's service files. Twentytwo young people were interviewed (sixteen girls and six boys) ranging in age from seven years to eighteen years, fourteen of whose parents were also interviewed (three couples, one father and ten 
mothers). A sample of seven children's stories was told by their parents. Ten adults who had experienced sexual abuse in childhood were also interviewed, five of whom also participated in the parent sample. The interviews were transcribed by the author and a process of coding involving open coding and comparative analysis of codes was developed, leading to higher conceptual level coding. To facilitate transparency, a detailed account of the coding process is given here. Memos were written throughout the study to facilitate the process of analysis and to provide a paper trail of how the theoretical framework developed. Detailed quotes are offered in the following three chapters to facilitate the reader in judging for themselves whether the study lives up to the standards of rigorous qualitative research.

The process of developing key themes such as containing the secret, pressure cooker effect, being believed and being asked is described. Two prototypes, one of a young person and one of an adult are presented to illustrate the theoretical framework that was developed in this study. The challenge of theoretical saturation is discussed in the context of investigating the complexity of how children confide experiences of sexual abuse and the possible inapplicability of such a concept to this subject is suggested. Ethical issues encountered during the course of this study are discussed, including issues of informed consent, empowerment, welfare of the participants and the limits of confidentiality. A reflexive approach was facilitated through keeping a reflective diary, credibility checking, professionals' meetings, feedback from conference presentations and member checking. It is suggested that the process of containing the secret of child sexual abuse involves three key dynamics, that of active withholding on the part of the child, a pressure cooker effect which represents a build up of conflicting needs to both keep the secret and tell, resulting in a disclosure which can best be conceptualised as confiding. The findings that support the development of this framework are presented in the next three chapters.

\section{CHAPTER 3: HOW CHILDREN TELL}

This chapter presents the findings relating to the central research question of this study, that is, how children disclose experiences of child sexual abuse. The key themes presented in this chapter 
therefore describe the process of how children tell (See Table 3). Firstly, the themes of disclosure as a process, too hard to say it, not wanting people to know, denial and how few people know are presented which suggest that a dynamic of active withholding is central to the experience of how children tell. This is followed by the presentation of the themes to tell or not to tell, the unplanned nature of disclosure, signs of psychological distress, and if they had not told then, all of which suggest a second dynamic of the pressure cooker effect. Finally, the themes choice of confidante, context of confiding and confidentiality represent the third key dynamic of the process of how children tell as identified in this study, that of confiding. These three key themes, active withholding, pressure cooker effect and confiding describe the process of how children tell which is conceptualised here as the process of containing the secret of child sexual abuse.

Table 3. : Key Themes: How Children Tell

\begin{tabular}{|c|}
\hline Active Withholding \\
Disclosure as a process \\
Too hard to say it \\
Not wanting people to know \\
Denial \\
How few people know \\
Pressure Cooker Effect \\
To tell or not to tell \\
Unplanned nature of disclosure \\
Signs of psychological distress \\
If they had not told then \\
Confiding \\
Choice of confidante \\
Context of confiding \\
Confidentiality \\
\end{tabular}

First key theme: Active Withholding

The first key theme, active withholding is suggested by five sub-themes, disclosure as a process, too hard to say it, not wanting people to know, denial and how few people know.

\section{Disclosure as a Process}

Most of the people interviewed in this study described disclosure as a process that occurs over time and sometimes in incremental steps. It occurs over time in two respects, firstly in terms of the 
unfolding of the story and the details of what happened, and secondly in terms of telling different people at different times. Many people disclosed over a period of time. $\mathrm{C}^{2} 3^{2}$ described filling out her asylum application form "I was given like 2 weeks to fill it out and it took me like 4 weeks" (C03). According to C53's mother, "there was a lot more other stuff" than what her son had first told her.

He came out with like it came out over two or three days so you know....he'd say well I've something else to tell you ...the bad stuff last.... what hurt him most and what he's saying what hurt him most (C53).

The telling in itself took different forms, ranging from giving some indication that something was wrong, making vague comments about being hurt, writing notes for self or others or clearly giving details of the experience. The actual disclosure for some was preceded by several attempts to tell. C01 wrote out her experiences in a diary "see I wrote it down took a year and a half maybe two years to do it" (C01), before she told a family friend. During C10's assessment, she described attempting to tell her mother about what happened by writing a letter and putting it under her pillow but she later had second thoughts about it and she removed the letter. One young person described her first attempt to tell her mother that her father had raped her but receiving such a negative reaction from her mother that she made no further attempt.

$\mathrm{C}^{3}$ : I went up and I was trying to tell her she goes 'Well crawl back to where you came from ...'

$\mathrm{R}:$ and did you tell her what actually happened?

C: no (C20)

C17 described trying to tell her mother 'loads of times' but that her tendency to argue constantly with her mother probably did not help their communication. She said that she had told her mother on several occasions that she had depression and needed help but that her mother did not want to accept this and put it down to her hormones, her periods and being a teenager "she used to always say well I used to get a little bit depressed when I was your age and I'd say you didn't sit up in your room with scissors and dya know?" (C17). According to C17, this was her way of looking for help.

A11 tried to tell a teacher and her neighbours "it was going on for a while em like I didn't give any names or anything I just said things I was really hurt and stuff like that $\left(\mathrm{A} 11^{4}\right)$. However, she received a beating at home and did not attempt to tell anyone else after that.

People may think about telling long before they tell anyone. A06 recalled her parents joking when her brother was present and wondering "imagine if they knew what he was doing to me"(A06).

\footnotetext{
${ }^{2}$ Children are referred to in this thesis by their code number. C03 refers to the third young person interviewed.

${ }^{3}$ When a dialogue is represented in quotes, $\mathrm{C}$ refers to the child in the conversation, and $\mathrm{R}$ refers to the researcher.

${ }^{4}$ Adult participants are referred to in these chapters by their code number. In this case, A11 refers to the last adult interviewed.
} 
Similarly A08 thought about telling her mother when her mother's partner left. Neither ever told their parents.

C02 had sent a text message to her friend when the abuser left the room but switched off the phone when her friend tried to ring her back. Shortly after the abuse experience (i.e. the same night) she was confronted by her sister who had been told immediately by the alleged abuser that something had happened. She initially denied it but then told her sister, "I didn't tell the full story...I just told her that he tried it on with me and then when we went upstairs after he went out I told her everything that happened" (C02).

C03 noted how she told the social worker some of her history but other parts she had to write down.

I couldn't tell her most things but I just gave things to her to read... I told her at first I told her bits of it and em then just the others. I finished writing and then I gave them to her.... later I told her that it was the father as well (C03).

When $\mathrm{C} 07$ was seen for assessment she told her interviewer that she had told her friend "something had happened, not the full story" $\left(\mathrm{R} 07^{5}\right)$.

The following excerpt from the interview with C09 describes how she told her father about her experience of abuse with the assistance of her boyfriend and through this disclosure revealed that she had not told her boyfriend all the details.

though I didn't actually tell him (her boyfriend) the full story ...I just told him like that I kindof had like a little incident with me uncle and everything ... an then the next day then I went down to my boyfriend's house .... an then I told him the rest of it

I told him like an he was like 'oh my God' he said 'and did you tell her all this?' an I said 'no' an he said well I'm glad you told her the bit you told he said but you do need to tell people the rest of it $\mathrm{CO} 9$ he said what's the point in just saying one little bit ...me Dad was just saying to me an all like 'is there any more CO9?' an I was like 'yeah' an then I just told him the rest of the story like ... it was only kindof a few days later (C09).

I remember after saying I was like (boyfriend) I'm after telling somebody an he was like did you and I said yeah and he said very good like and I was like but (boyfriend) there's more and he was like 'aw CO9 I don't believe you like why didn't you tell me?' like an 'I coulda helped you' an I was like just too hard like (C09)

Her father told his end of the story:

I said is there anything else she said no I said are you sure I said you needn't be afraid of him now it's over it's gone you're never ever gonna cry you're never gonna be afraid of anything I didn't know what I was actually saying out you know so what she said this Christmas will be the best Christmas we've ever had cos everything's gonna be ok you know mam and dad are here bla bla bla so she told me the rest of it of another incident and

\footnotetext{
${ }^{5}$ When file records are referred to in this study, the code R precedes the child's code number, referring to the file report as the source of this data.
} 
then she told me of another incident and I was just kinda I actually remember not even able to feel myself cos I was so afraid of what she was going to say do you know what I mean $\left(\mathrm{P} 09^{6}\right)$.

The assessment report revealed that this later disclosure was about penetrative abuse (R09).

C10 described a protracted process of first telling her mother when she was six or seven

"something like oh something happened or (abuser) does things to me and I don't like it or (abuser) was mean to me I can't really remember". She was seen by a social worker a few years later as part of an investigation into allegations of physical abuse by the alleged abuser and was afraid to say anything as the alleged abuser was sitting outside the room. According to C10's assessment report, she remembered trying to convince her mother not to go to work because she felt unsafe with the abuser. At the age of thirteen, she rang Childline, a national helpline for children provided by the Irish Society for the Prevention of Cruelty to Children (ISPCC) which set in motion a series of events leading to her being seen for assessment in the child sexual abuse unit and making a garda statement. At the time of the research interview she noted that "I didn't tell all of it like get it all out until like 2 months ago" $(\mathrm{C} 10)$. C10 was asked why she thought she had disclosed in such an incremental fashion.

R: Why do you think it was that that each time you spoke to somebody you said more C: Yeah I was thinking about that last night actually

$\mathrm{R}: \mathrm{Mm}$

C: Em because each time I said it I got a good reaction so I'd say oh that was ok last time I'll try a bit more I'll try a bit more I'll try a bit more

$\mathrm{R}$ : And how what was a bad reaction you know what would've been a bad reaction what what kind of reaction could you have got that would've given you a message ok I'm not gonna say any more?

C: If they don't seem interested or if they didn't really like do anything about it. Or if or they even if they sounded like they were on (alleg abuser)'s side whatsoever oh ok you don't want to know I won't say it then...Another bad reaction is almost bursting into tears cos then you have to wait to say something else cos you're like oh no I'm after hurting then but you're not even though it wasn't my fault I'm still after saying something maybe I should stop now (C10).

C21 told her boyfriend that she had been sexually abused but a year and a half later told him the details of this experience. C14's mother described getting the story from her daughter over a period of a few weeks. Even C15 who told immediately was described by his mother as giving small pieces of information over time "there was still kinda little parts that were coming out" as he was afraid she would be annoyed with him "I think he kept that back cos he was saying well maybe if I wasn't in his room cos he was able to say mammy I know what was on the computer so I think he was thinking I was gonna say well what were you doing in his room looking at the computer"(P15).

\footnotetext{
${ }^{6}$ When parents' comments are referred to in this study, the code P precedes the child's code number, inthis case the parent of $\mathrm{C} 09$.
} 
Similarly, P51 described how his son told him in bits and pieces,

I knew there was something something bothering him and then just bit by bit it came out what he told me what had happened you know or roughly but not the full details or anything

...

I asked him and he told me then what happened you know roughly you know not all the details of everything just... so I squeezed it out of him ...it's all bits and pieces" (P51).

It was not unusual for additional details of the abuse experience or additional experiences to be revealed only when the child was seen for assessment. C10 revealed additional details in assessment than she had previously and gave even further details when she made her garda statement. One father (P51) described how he and his wife discovered their younger son had been abused by the same teenage boy that abused their older son. The younger boy disclosed to his older brother and was subsequently seen for assessment, where it was revealed that there had been a prior incident that the parents were unaware of. C11's father thought he had known the full extent of his son's abuse experience until C11 was seen for assessment

so what hurt me more than anything else was ... to actually turn around and be told that when we were in this person's home down in the country that this happened 10 times down there without our knowledge ... I'll tell you my heart sank... that just made me sick I couldn't believe it and we knew nothing about it (P11).

They had not asked their son for further information as it did not occur to them that it had happened prior to the time it was discovered.

For $\mathrm{C} 12$, his mother asked him after his teacher discovered him engaged in sexual play with other children. He told his mother the details of the sexual play and discussed this in formal assessment but, despite being asked if he had any other experiences like this, did not disclose ongoing sexual abuse by his father for another two years.

In summary, the experiences of respondents in this study suggest that children can make several attempts at disclosing before succeeding, and that many tend to disclose over a period of time, sharing pieces of information over time, either in verbal or written format. The incremental manner in which some children disclosed can be repeated in different experiences of disclosure with different individuals and may depend to some extent on the reaction of the person to whom the disclosure is being made. Some young people disclosed additional information about their abuse experiences when directly asked if there was more information to reveal, whether by a parent or in the context of a professional assessment.

\section{Too Hard to Say it}

For many young people, it appears that it may be easier to keep the secret than to disclose it. This may be because they are simply not able to say it as reflected in this quote from a teenage boy: 
We were watching a programme ... and it was about this fella who had been sexually abused as a kid. And me ma was like isn't that sad and all that? An I...I was just sitting there I didn't know what to say. I couldn't say it...I was like I wanted to say it but I couldn't (C08)

The emotional difficulty in saying the words was evident in how young people described how they felt while telling. C16 described how she was shivering telling her counsellor because she was so scared to tell. C07 talked about wanting to tell her "I really did well at the same time I didn't and the fear kindof overpowered me" (C07). C01 described how it was too difficult to give details. She first told a family friend that 'something' had happened so she wrote it down and showed it to the family friend "sometimes putting words on it when you first think about it (is) too hard too embarrassing and shameful" (C01). C13 also wrote it in a note because she didn't want to say the words. C03 tried to tell her social worker but only managed to say some of it. "I was like no I can't do this and then I was just crying all the time..I couldn't tell her most things but I just gave things to her to read" (C03).

C03 was asked what aspects of her life story she had talked about and what aspects she had chosen to write about instead. She explained that she was able to write down the parts about being neglected and her early life history of being abandoned by her mother but when she came to the stage of telling about the sexual abuse, she wrote this down.

I dunno but for me if. If I'm writing about it I'm talking to myself so it's not like I'm talking to someone. And it's it's kindof you can say everything you want to say. And it's then you go back and rub out what you don't want. And em. It's just like there's no thought of is this person going to believe me or not? You're just writing it down. (C03)

Through writing about her experience, this young woman was able to maintain some level of control of the information. She was able to stay in charge and this feeling of empowerment may have given her the emotional strength to relate her story. The idea of needing courage to be able to disclose is referred to later.

For some, the delay in telling exacerbated the difficulty telling. C07 described how the delay in telling made it even harder to tell.

It was really really difficult...I felt terrible for not having told her as well cos it had been so long since it happened and I hadn't said anything to her. (C07)

This difficulty in talking about the abuse is not just experienced the first time the story is divulged. The young people in this study continued to experience difficulty in talking about the abuse. C17 talked about how difficult it was trying to tell two friends one night. This had been after she had made the initial disclosure to her boyfriend and then to her mother "I was crying but I couldn't get it out and they were like what is it just get it out and I couldn't get it out". She described how she did want to tell them but just couldn't. C09 first disclosed to her boyfriend who encouraged her to tell her parents “and I was like I can't like you're the first person I told like an I can't tell anybody 
else I ca.. don't want to hurt my family" (C09). To some extent, the passage of time and the experience of telling does help the young person to be able to talk about it without getting too upset. C10 talked about it being easier now to talk about it having done it already "if you had asked me about all this a few months ago there would've been just an explosion I would be so upset but I'm better able now" (C10).

In addition to the difficulty talking about abuse at each new experience of disclosure is the difficulty disclosing new abuse experiences. Having disclosed one experience of abuse to a trusted other held no guarantee that subsequent abuse would be disclosed. Two adult women disclosed information shortly after abuse they experienced when they were younger but later withheld information about subsequent abuse. A07 first told a friend as a teenager about her grandfather abusing her when she was younger. As a young adult she told her mother and also some friends over the years. However, she was six months attending a counsellor before she disclosed that her brother too had abused her. This was the first time she had ever disclosed this abuse to anyone. Although she had told her mother about the abuse by her grandfather she never told her about the abuse by her brother.

R: that didn't help you tell her about your brother?

A: no I just wouldn't want to upset her you know ..there's no point in knowing that information at her time of life .. it wouldn't do any favours so no (A07).

The above reflects the difficulty young people described in telling of their experiences, a difficulty not just associated with the initial disclosure. The experience of confiding in others continues to present an emotional challenge for young people in subsequent experiences of disclosure.

\section{Not Wanting People to Know}

It is clear that children often do not wish others to know about what happened. This is evident from the extent to which children and adolescents think about telling but do not do so and are aware of their holding back and the reasons for this. C13 wrote a note that she intended giving to her mother when she was eighteen but was clear she didn't want anyone to know about it at the time.

Young people talked about making up stories to deter people from asking questions or to 'throw them off the scent'. C02 planned a story with her sister to explain why her sister was leaving the alleged perpetrator because her father would have asked questions. C09 pretended that she was sick when she was in bad form or that she was crying over her grandfather's death to deter her parents from asking questions.

C14 tried to avoid being abused by not babysitting for her sister, making up excuses as to why she couldn't babysit. One girl talked of telling her friend's sister that someone had tried to assault her but that she got away, to deter her from being suspicious as to why she was so upset. She believed 
that if she had told her the truth, her friend's sister would have insisted on telling her mother "oh yeah definitely there's no doubt about it.. she'd like come with me to talk to my Mam or something" (C07).

As with some of the young people in this study, A08 was asked by a friend when she was seven, where she had got the money the abuser had given her. She pretended it was her Communion money.

Making up stories to contain the secret carries through into different relationships and over time. C10 had not told her boyfriend of the abuse and when he asked her why she was seeing the researcher in this study, she pretended it was someone from the Health Service checking that she was alright following her mother's separation. Some young people withheld from their friends that they were attending therapy as they could not explain why without divulging the abuse.

A09 was the only adult interviewed who referred to always wanting to tell her mother.

A: ... I loved me Ma like and I didn't want me sisters to be eh getting on to me Ma ... let her die in peace I wouldn't like to yeah you know bring that up and I always wanted to ... I remember always wanting to say it to her (A09).

\section{Denial}

In this study, many young people denied that they were abused at some point. On occasion, this denial was an instinctive reaction followed immediately by a disclosure. On other occasions it represented a determined effort to contain the secret. Both $\mathrm{C} 01$ and $\mathrm{C} 02$ described being asked by counsellors if they had been abused and they denied it. C08's sister discovered a cousin behaving inappropriately with C08's younger brother and asked him if this cousin had ever touched him “.... and I kinda started crying, said 'no no no' and walked out, ran out of the room and went back onto the road" (C08). Seven or eight years later, having first disclosed to friends, he told his sister that he had been abused. Also, people denied in different ways. While three young people denied when directly asked, others denied that there was anything wrong. C03's friend was suspicious of the way someone was looking at her

C: she kept on asking me 'are you ok?' I said 'yes I'm fine' ... she kindof said something about the way the brother looks at me 'what is he doing to you?' I said 'nothing'. She's like 'you're lying'

$\mathrm{R}$ : And was he doing anything to you at that time?

C: Yeah (C03).

While C15's mother was simply concerned without having any suspicion of abuse (as indicated in her interview):

C: I couldn't say it to me Mammy ...cos I was too shy and my Mammy said 'Is there something bothering you?' and I said 'no'

$\mathrm{R}$ : right ok and was there something bothering you? 
C08 recalled getting upset in class when discussing childhood abuse or rape or abortion and being asked by a teacher what was wrong but saying "Nothing I'd just say 'I'm grand I'm fine"” (C08).

As stated above, denial may be an instinctive reaction that is followed immediately by a disclosure: "Like she knew by me face like there was something up. She was saying 'tell me'. I was saying 'God no way no' and I just told her.'(C04). C19 told his cousin who then told his father but when his father asked him about it on the phone "I denied it for a while....but then I em up and telling him" (C19).

There was less evidence of denial in the adult interviews and this appears to be associated with very few of the adult sample ever having been asked directly if they had been abused, or indeed asked if anything was wrong. While half of the 22 children interviewed were asked in some form by someone in their close network, none of the adult sample were asked as children and as adults they were asked only by professionals. A04's son was abused and during the course of assessment, both he and his wife were asked if they themselves had been abused and they both denied it.

A: I was asked was I ever abused and I was there straight I said no and the reason why because I was afraid that they'd try and put two and two and make four out of it as regards the kids were concerned

$\mathrm{R}$ : As in?

A: I didn't want the kids taken away from us (A04).

A conscious effort on the part of the research participants to 'block out' the memory of the abuse was more commonly referred to by the adults in this study than by the young people. Only two young people used this language to describe their not thinking about the abuse "I kinda blocked it out of my head.... I hadn't kindof remembered it for seven years when it came back to me" (C01). In the adult sample, 'blocking' was commonly referred to, in various ways most of which reflect an active conscious process of not thinking about what happened. "I just put it out of my mind"(A02) "I dunno what happened then I just blocked it out"(A03) "I just never ever ever did think about that ... just blocked out really"(A07) "it's easier to blank things" (A10) "I blocked it for years" (A03) "I buried it for a long time.... and you know it tended to come into my mind I'd you know change my mind and distract myself'(A08).

A11 described a more unconscious process of forgetting the details of the experience, although she had always remembered that she had been abused.

I think I was so badly beaten by my mother over it....that I blocked it out completely and I had forgotten about it and it was only when I went to counselling I actually started to remember....it was like a big jigsaw trying to put pieces together and I kept on saying no this is probably not real you know it took me a long time to think oh my God this actually happened. (A11). 
In summary, denial took many forms and can be viewed on a continuum ranging from unconscious forgetting of many of the details of the abuse, consciously not thinking about the abuse, to actively denying even when directly asked if they had been abused. Taking account of this broad spectrum of forms of denial, this theme featured prominently in the young people's stories in this study.

\section{How Few People Know}

Analysis of who knew about the abuse at the time of the research interview indicated that for most young people interviewed, the knowledge that they had been abused was confined to a small group of people. Withholding information continued even after the first disclosure. Secrecy in the form of confidentiality is maintained about the experience of abuse, even after it is initially disclosed, at different levels, between friends, within families and within professional services. This may have been in relation to disclosing further information "me Ma was just like trying to get more information out of me but I wouldn't give it to her" (C02) or preventing other people from knowing about it at all "I didn't want my Mum or anyone to know" (C01). C09 described how she had to self-monitor the extent of information she gave when disclosing "when I was telling (aunt) I was like oh my god I'm telling somebody and I was like right ... that's enough" (C09). C03's description of being able to regulate the level of detail she revealed through writing the account rather than telling has already been referred to earlier. On occasion, young people asked others not to tell anyone else "and I asked her not to say anything" (C02).

The time delay between first disclosure and the research interviews ranged from months to a few years. For most young people, the number of people who now knew of the abuse was still quite limited. Some young people $(n=6)$ had only told members of their own family. Two of these were younger children whose parents did not encourage them to tell others. Some older children were very clear that they did not wish their friends to know. Schools were not always aware that the young person had been abused. Eleven young people in this study indicated that their school was unaware of the abuse. In two cases, siblings were unaware of the abuse. In both of these cases, the alleged perpetrator was the father of these siblings. In two instances, members of the extended family were not told. In one of these, the side of the family of the abuser knew but the other side of the family was not told.

The conscious decision to only tell people who can be trusted to keep the confidence was evident for some young people in this study. It was clear that confidentiality was important and that only people who could keep the information in confidence would be trusted. The theme of needing confidentiality captures the idea of needing the secret to be contained "I don't want to tell my friends.....some of them are like kindof blabbermouths" (C16). C02, although encouraged by her mother to tell her boyfriend, decided against it "Coz I don't like spreading me life around...rather just keep things to myself" (C02). Two teenage girls both told their friends having obtained a 
promise that they would not tell anyone. C19 worried, having told a friend, that she would tell other people. One girl talked of not being able to tell her own mother because of her fear that her mother would tell others and "I didn't want everybody to know" (C04).

C11 advocated not telling friends, that this would not help "keep it in your family" (C11). C10 didn't want her father to know, or her friends "no just coz it's private stuff" (C10). C13 was annoyed at her father telling his family "cos it was only meant to keep for him and he went and told" (C13). She said she wouldn't tell a friend unless they were in the same situation and then she might. One person described her fear that if certain people were told, it would open the floodgates: "I told her not to tell my Dad because I dunno why I was just afraid of everybody knowing" (C17).

C14 was able to acknowledge that the people in her life may need to talk about it but that the information does need to be contained 'you don't want to be gossip you don't want sympathy off people either .....you don't you don't really need that like when you're going through what you're going through" (C14).

$\mathrm{C} 08$ and $\mathrm{C} 20$ referred to the more unkind reactions of their peers:

I wouldn't confide in people ... I'm afraid it'd get around the area and people coming up and slagging me about it ....they don't care as long as they get a laugh out of you (C08)

they could think like some people like aw but I bet you they deserved it an all....some people do think that (C20)

This in itself is evidence that the young person did want to tell but in a contained way, did need to talk about it but within a safe space.

For me it made some stick because I had to withhold a lot of information .... I just didn't want to tell anybody I wanted to sit down and talk it over with someone and know that this was me saying without it going to someone else (C01)

Although all of the research participants advocated that the young person should tell about their experience, most people added a word of caution when this was explored further. It was clear that young people should be careful about who they should tell. "Cos if you tell a neighbour or a priest who'd like that or somebody like that they might judge you in some way" (A02). Instead, A02 advocated that the person should tell a good friend or a close relative. C20 advised children to tell a priest “cos they can't say anything no matter you can go up and tell them you murdered someone they can't say it so they're the best people to go to if you don't want anyone to find out is the priest" (C20).

Findings from the adult interviews show that even over an extended period of time, the secret is still very much contained in a small group of people. It must be acknowledged when comparing this issue between the adult interviews and the child interviews in this study, that these samples are 
very different cohorts in terms of culture. The most striking differences are in respect of this theme - who knows about the abuse. In the adult sample, the secret of sexual abuse is much more tightly contained. Within the more informal context of family and friends, four out of ten had never told any friends, one woman had not told her husband and three had not told their parents.

\section{Summary: Active Withholding}

The findings from this study support the idea that for the most part, and particularly in older children and adults, non-disclosure is not a passive non-disclosing experience but rather an active withholding of information "I went held onto it about from the age of 9 until about 15" (C08) "I carried that for over 30 years you know" (A04). Active withholding was evident in this study in the above five themes: disclosure as a process, too hard to say it, not wanting people to know, denial that the abuse occurred, disclosure as a process and an analysis of how few people know about the abuse. For most of the young people interviewed, the disclosure was preceded by a period of time when they actively withheld the information that they were abused. For the most part, they did not want people to know what happened. Many children and young people find it easier not to tell because the experience of telling is perceived as too emotionally overwhelming. In this study, young people denied on occasion when asked, they made up stories to ward off suspicion or fend off possible questioning and even when they did disclose they still wanted the information contained. Denial took many forms. People did to some extent deny to themselves that the experience occurred by not thinking about it, by minimizing either the strangeness of the experience or the impact of it. This dynamic is akin to the psychological defense mechanism of dissociation and was more commonly referred to in the interviews with adults. Denial also took the form of denial to others by actively withholding the information or by actually denying it when asked.

Participants in this study were selective about who they told, whether people could be trusted not to tell anyone else. Young people were careful in their choice of confidante and anxious that this person would not tell others whether this be a friend or parent. The young people needed this private information to be contained among those they trusted. In addition to the need for privacy, they were also aware that people's reactions would not always be sympathetic or understanding and that this information could be used against them. Although adults did not talk about their need for other people to keep this information confidential, the fact that very few people knew about the abuse at the time of the research interview is evidence in itself of how well they had maintained this secret over the years.

Apart from withholding the information from family and friends, some people also withheld this information from professionals they were attending for help. C01 was seen by a social worker after she disclosed to a family friend but she refused to give any details of her experiences as she did not 
want her parents informed. When she was seen for assessment several months after her disclosure, her father had been told some of the details of the disclosure but her mother was unaware of any details other than that there was an allegation that her son had sexually abused his sister. A11 attended counselling in secondary school and recalled talking to her counsellor about the physical abuse she experienced at home but never talked about the sexual abuse. She was also careful that the counsellor wouldn't guess too much "I woulda been clever enough not to go too much" (A11). Although attending a psychiatrist for many years, A09 never disclosed to the psychiatrist that she had been abused. A02 attended several counsellors for individual help, including one who suggested hypnosis to uncover whatever dramatic experience she must have had in the past to cause her difficulties at the time. A02 did not make the connection between this advice and her experiences of childhood abuse. She subsequently attended family therapy and did not disclose the abuse, even though at this stage she had confided in her partner.

The initial response to the experience may not be active withholding but rather that it did not occur to them to tell due to their young age at the time "I don't think it even came to me to tell" (C04) or not thinking of telling because they didn't realize it was wrong "When it happened I didn't know that there was anything wrong" (C05). However, at some point they did actively withhold this information when for instance it did occur to the person to tell or they did realize that it was wrong. Active withholding is therefore not just a feature of delayed disclosure but can operate before young people tell anyone, while they are in the process of disclosing i.e. controlling how much information they divulge at a time or to certain people, and when they have already disclosed but seek further containment through promises of confidentiality, or continue to withhold from other people. Following disclosure, information about their experiences was kept confidential within a small group of people, either close friends, family or professionals.

Another example of the idea of active withholding not fitting with young people's experiences is that of the telling being too difficult as opposed to the information being actively withheld. After she had already told her boyfriend and then her mother, C17 described trying to tell two friends, I was close to the both of them I tried telling them one night and I was crying but I couldn't get it out and they were like 'what is it? just get it out' and I couldn't get it out and I just went home and I spent about an hour in the room trying to get it out and I couldn't (C17).

It may be that the longer it is actively withheld, the more difficult it is to tell. According to C19, the longer she kept it in the more she wanted to keep it in.

Some of the adults interviewed talked about it not having occurred to them to tell. "I don't think I ever thought about it em.... I thought it were normal all brothers and sisters done stuff like that I thought it were part of growing up in a way you know" (A07). Nevertheless, as she got older and discovered that what had happened was not normal, she did not want anyone to know. A10, 
similarly, described how he didn't think of telling anyone "like the first time I said right that's it that won't happen again and then it did couple of months later so it was private ....I actually just never thought of saying it to anybody" (A10).

This man was persistent in making the point that he just never thought of telling anyone and appeared reluctant to explore why that was. He "never even considered it.....I say what happened that was it". It wasn't a big deal "....compared to other kids what happened to me was minor" and then later in the interview "It was minor it's actually I just didn't want to tell anybody that was it" (A10). This excerpt reflects how the conversation of talking about the experience of disclosing helps the person gain some insight into their own story as they tell it in the research context. While it appeared initially that these stories did not fit with the concept of active withholding, on further exploration, it may be that the dynamic of active withholding can apply to these individuals but it may develop over time.

Second Key Theme: The Pressure Cooker Effect

The second dynamic identified in the findings of this study is now presented in the form of the themes to tell or not to tell, the unplanned nature of disclosure, signs of psychological distress, and if they had not told then, all of which support the superordinate theme, the pressure cooker effect.

\section{To Tell or Not To Tell?}

Why is it, then, that so many children, young people and adults do eventually tell? While there is clearly an active process of withholding information for many children, there is also a wish for others to know, "I wanted to say it but I couldn't" (C08). There is ambivalence about telling, representing the conflict between wanting to tell and not wanting to tell, for instance for young people wanting to tell their mothers:

I did want to tell her I really did. Well, at the same time I didn’t. (C07).

I always wanted to tell someone. I remember going into her bedroom and leaving a note I used to wrap it up in her nightie. And then I'd think 'No I can't tell' and I'd run in and get it back. I did that loads of times (C10).

Similarly, the deliberation about whether to tell friends reflects a seesaw process between thinking about telling and changing one's mind.

C: And then I'm like maybe I shouldn't ...they're gonna want to say it to someone else ...but at the same time I'd like to be able to talk to them. And yet at the same you don't want them to think any less of you either (C10). 
This ambivalence may be there from the beginning or it may emerge as the young person appreciates the seriousness of the abuse or understands the potential consequences of not telling about the abuse such as the possibility of risk to other children.

The gradual process of coming to the decision to tell may occur over an extended period of time, "I did want to tell people I started to want to tell people like maybe a year or maybe a year and a half before I actually did" (C17).

C: I tried so many times to tell me Mam to tell me dad like to tell me brother. Like I used to just come in and say 'Mam I've something to tell you' and then she'd say 'what?' an I'd say 'No it doesn't matter I'm only messing with you' ... and then I used to even think about telling me old primary school teacher ... an then I tried to tell me brother. I remember one day he was coming out of his bedroom an I was like '(brother)' he said 'what?' an eh I said 'ah nothing it doesn't matter'. He said 'what's wrong with you?' an eh I says 'Nothing it doesn't matter' an like I remember that night like and just crying and crying like and not knowing what to do like ringing (boyfriend) and saying 'oh I can't tell anybody I don't know what to do'.

....

$\mathrm{R}$ : it sounds like you were really trying so hard

$\mathrm{C}$ : aw it was unreal

R: how long was that going on for that you were actually trying to tell somebody?

C: about 2 years (C09).

C14 described how she was constantly making up excuses not to babysit for her sister after her sister's husband abused her. She found it difficult to keep this up

... I think they kindof copped on after a while you know that it was getting a bit strange so I couldn't keep that up for a long time obviously because I didn't want them getting suspicious either $(\mathrm{C} 14)$

obviously I had all the friends an the more they told me and explained and you know told me how big a deal this was the more I kindof understood and just changed me whole view....you know the kids might want to be around him an all and I don't mind that I can't do anything about that but at least you know I won't have that pressure of oh I never said anything (C14)

The conflicting instincts of not wanting to tell and wanting to tell also manifests itself in the form of the unplanned nature of many of disclosures reported in this study, the signs of psychological distress which accumulate over time and the belief of many young people that if they had not told then, they would not have told at all or for some time.

\section{The Unplanned Nature of Disclosure}

Many of the disclosures described in this study were described as unplanned, often triggered unexpectedly. The cumulative process of conflicting thoughts and reasoning about whether to tell or not was evident:

it just happened on that day and it was just mad cos like I just came out with it (C20) I just broke down (C05) 
I never actually knew why I turned around and said (boyfriend) this is what actually happened to me...but I suppose everything just builds up an then finally just comes out into you like" (C09)

we were talking about our problems... and em we were trying to help her with that. And then like out of nowhere like I just felt like saying it. Cos it was like built up and all of a sudden I just said it" (C08)

em I think it was just such a shock. Because like, she wasn't expecting it at all. And I did actually just say it out of the blue like" (C10).

Although these disclosures were purposeful in the sense that these young people were not asked directly if they had been abused, it is clear from their narratives that there was not a conscious decision made to tell when they did "Like I never actually planned to turn round and tell somebody. I never said 'right today's the day I'm gonna tell somebody'" (C09). Six young people did tell their parents or an adult in a planned manner. Two were young children under eight years of age and this was the first disclosure. The remaining four were teenagers. One was out late with friends and decided to tell her parents when she went home, accompanied by her friend. Another told her mother, accompanied by her boyfriend, while two girls told their teachers amidst fears that they were pregnant. Only one of these disclosures by teenagers however refers to an initial disclosure of the abuse experience. For the teenagers in this study, the typical pattern of disclosure was unplanned.

\section{Signs of Psychological Distress}

For many young people, there was an emotional cost to keeping the secret. The psychological distress of actively withholding the secret became too much to cope with. "I didn't tell anyone for a good few months and it was killing me" (C20), "I kinda just tried to bury it and it didn't work cos it kept coming up to the surface every now and again and I'd get angry and cry and I'd run up to my room" (C08). At some point in time, the pressure of keeping the secret from others outweighs the pressure to tell. Many talked about the internal conflict created between the wish to keep the secret and the need to talk to their parents or another person about the experience.

This internal conflict may have manifested itself as signs of psychological distress that indicated to others that something was wrong. For some young people it was the build up or cumulative impact of the psychological distress that led to the disclosure. Five teenage girls were self harming, two were being disruptive at school or missing school, and three were being disruptive or rebellious at home. The emotional pressure described by the young people in this study captures the idea of a pressure cooker simmering away and building up to disclosure. "I just felt bad really like holding it in...it was just like I had to tell or it was just gonna be there for ever and ever and it's just gonna annoy me I just had to tell" (C12). "I dunno when I would have said it or who I would've said it to but there was no way I would have been able to keep that" (C10). The pressure for C09 came in the 
form of a trusting relationship with her boyfriend and feeling that it was unfair to keep her secret when he was sharing his secrets with her.

The reason why I told him was .... He used to say to me like 'are you alright like do you not want me touching you?' and I was like 'ah no like it's grand' and he'd like 'are you sure? cos you kindof..' and I was like going 'No, honestly like I'm grand' Me and him were kinda getting to a deeper relationship .....you know telling each other different things that like our families and everything. That's when I really kinda trust him dya know that kinda way like he was able to tell me (about his family)... how he felt like so ...I was thinking like he trusts me enough to tell me a secret like that. Like I should be able to trust him and like. So then I just told him what happened that night but I didn't actually tell him everything. I just told him that he was kinda feeling me and things like that (C09).

After it happened then I had all these like emotions and feelings dya know what I mean? And didn't understand half of them I didn't know why half of them were happening. I didn't know why I couldn't forget about it. I didn't know what I had done you know that he would do that ....and like that's a lot for a twelve year old...to start off thinking about without it happening in her head for four years dya know what I mean? (C17).

The emotional pressure to tell may also have come from other factors such as C01's fear that she was pregnant or C17's fear that she needed medical attention due to discovering blood in her underpants.

Although these signs of psychological distress may be clues to others that something was wrong, the young people themselves may not be aware of why they are behaving in the way they are “because I was angry with myself I didn’t really know why" (C01). For some young people, being challenged on their behaviour acted as the catalyst for the disclosure.

I was really getting in trouble for smoking in school and eh I was actually getting brought down to the office ... they were wondering what was wrong with me why are you acting like this? and I broke down (C08).

I told him because I was really depressed ....and I was close to him and he knew there was something wrong like he knew I wouldn't be like that for nothing (C17).

For some, it is in retrospect that it becomes clear that the young person was trying to reach out, that there were clues that something was awry. C13 would ask her mother if she could sleep with her sister as she believed this would deter her mother's partner from coming to her bed at night. Her mother did think this strange "and I'd just be like oh no reason I just want to sleep with someone" (C13).

Parents reported that some of these clues were misinterpreted and attributed to the developing autonomy and independence of these young people during their adolescent years. Acting out behaviour can complicate matters further in that it may distance the young person from their parents thus introducing the possibility of not being believed "and because so much had happened since that like my behaviour and everything. I was afraid that they wouldn't believe me dya know what I mean? cos like I got a bit off the wall my behaviour was crazy" (C17). 
A few young people described an expectation that their parents should know what's happening, that it is so obvious that something is wrong they should see it.

I would kinda think 'how do you not know?' dya know what I mean? ... 'why don't you, why don't you try and find out what's going on?' and then I thought 'oh cos she doesn't care' cos that cos I'm a bad person (C17).

For $\mathrm{C} 17$ the fact that her boyfriend tolerated her 'crazy' behaviour engendered her trust in him "so I just thought if I told him he'd try to see some see he'd see like a way make it better dya know what I mean cos he was fine about everything else" (C17).

When young people experienced considerable psychological distress following disclosure it may have been from the fallout of the disclosure, the reactions of those around them and the consequences, particularly for family members. It may also represent an unleashing of emotion that has been tightly contained for a long period of time.

For some, the initial disclosure to a friend diminished the emotional pressure while for others it increased it. For $\mathrm{C} 09$, she found herself getting upset more after she told her boyfriend because she now gave herself permission to be upset "all the time coz before I used to hold everything into meself and I learned how to deal with it by myself ... just crying in me room and things like that" (C09). The psychological distress noted following disclosure can be interpreted in many ways. It could be that the stress of holding the secret was cumulative resulting in an outburst of emotional distress that had previously been held back along with the secret. It may also have been a result of the impact of people knowing about the abuse and this being upsetting in itself. For some young people the fallout from the disclosure was considerable in the extended family, particularly in cases of intrafamilial abuse, and this was understandably distressing in itself.

I'd have flashbacks when I was sleeping and I'd wake up in a cold sweat. I ended up sleeping for about 2 months on the floor in my sister's room coz I couldn't sleep in my own bed...I felt like if I closed my eyes on my own I'd be back I'd get the flashbacks... like the flashbacks got a bit like they got worse after I told cos I knew that everyone knew then (C08).

For many young people it is in the relief described by the young people after telling that one gets a sense of the pressure they felt under beforehand "cos I kept it in here not talking about it and then when I talked about it I felt much better I did" (C16).

This emotional pressure can be experienced for each new experience of disclosure. One girl talked about telling her father one night after she had been drinking. She had already confided to friends and to her mother prior to this.

I was like really drunk and I came back crying and he was like why are you crying? And I was sitting in the sitting room crying and I couldn't stop. And he was like 'why are you crying?' and I just blurted it out like. But I was completely drunk when I told him (C17). 
One adult recalled how as an adult about seven years ago she was sitting in the car with her mother:

And we were driving along and she started talking about a film she had seen the night before about abuse. And she went on about this little boy being abused and dya know. 'dreadful dreadful dreadful' and you know it was all building up inside o'me. And just out of nowhere, well not out of nowhere, I just said to her 'whatever happened to the man who abused me? And there was silence in the car. And she says 'em do you still remember that?' she says, 'you were only four'. I said 'I was six and I will never ever forget it'. And em you know she was silent and she said 'em well' she said 'em we did want to bring charges' she said 'against him' she said 'but em his son came down and pleaded and said that he would never do it again' (A08).

The possibility that telling friends may have resulted in a delay in telling parents was explored. In some instances, friends knew about the abuse for some time (varying from months to years) before the young person told an adult. It may well be that this disclosure in some way alleviated the pressure felt by the young person which in itself delayed telling an adult of the abuse.

\section{If They had not Told Then}

Many young people commented that if it wasn't for the particular set of circumstances pertaining at the time they told, they would not have told anyone at all or would not have told for some time. C02 said she would not have told her mother if the alleged abuser had not telephoned her mother complaining about her. Her mother also shared this view “that was a fact I'd say if (abuser) hadn't a rung up she wouldn't a told me. Well I'd say she would've eventually but I dunno how long down the road it woulda went" (P02).

C04 who disclosed while watching a television programme about abuse was asked would she have said it if the programme had not been on and she said she would not. C10 however would have told "I definitely would have said I wouldn't have kept it" (C10). C13 who disclosed to her friend in a game of 'truth or dare' said she would not have told her friend if they had not been playing the game, "no I don't think I would've ... if I didn't tell I woulda always kept it in me all the time" (C13). She had planned to give her mother a note when she was eighteen. As it turned out, her mother found a note she had written about the abuse. Similarly, C16 said: "I'd probably keep it in I wouldn't tell anyone".

C18 was bleeding and went to her teacher as she knew she needed a doctor. She was asked if she would have gone to the teacher if she hadn't needed a doctor "if I wasn't too serious no I probably wouldn't have told ". It appeared from her file that she had been 'in a relationship' with this man for some time prior to this incident. C20 disclosed in an assessment and commented on how she couldn't tell at her first interview as her father had brought her for the assessment. He did not accompany her to her second interview and she disclosed the abuse. When asked if she would have told if her father had come with her for the second interview, she replied: "I wouldn't a told. 
There's no way I woulda told" (C20). C21 disclosed to her grandmother after an argument with the alleged abuser:

C: I often do think to myself God if we actually didn't have that argument would I have told

$\mathrm{R}$ : and what do you think?

C: I don't think so

R: you don't think so

C: Unless we I had an argument down the line with him (C21).

The above young people appeared to believe that if the particular circumstances which triggered the disclosure had been different, they would not have told. Other young people also felt that they would not have told then but would have told eventually. C03 thought that if her friend had not persisted in asking her that she would probably have told her later on. $\mathrm{C} 12$ also commented that he probably would have told his mother 'eventually' because “you could end up killing yourself if you were walking around with that for the rest of your life just like you have to give people like time like but it is just better to tell" (C12). C11 was asked would he have told if his father hadn't discovered him with his cousin and he said he probably would have told him straight away.

However, the assessment report indicated that $\mathrm{C} 11$ had been abused on a number of occasions prior to this incident and had not told. C17's boyfriend persisted in encouraging her to tell her parents. When asked if she would have told her mother had her boyfriend not persisted, she thought that she would "no I think I would have still told her I'm just like that I just do things when I'm ready to do them" (C17).

C19 said that moving away from the alleged abuser helped him to be able to tell. Asked if he had not moved away, would he have told, he said no.

$\mathrm{R}$ : for ever and ever?

C: not for ever

$\mathrm{R}$ : how long do you think?

C: I dunno a few years (C19).

C22 thought he would not have told if his sister had not asked him directly but he said he would have told as he got older "probably yeah older and stronger".

A11 believed that she would have eventually told her husband but she described how she was challenged by one sister to tell another sister when in both their company "I was in a situation where I had to tell her then" but said that if she hadn't been 'put in that situation' she would never had told this sister.

Some of these discussions reinforced the idea of emotional pressure building up and the young people's beliefs that they would eventually tell because they would not be able to keep it in. Others were very clear that if they had not said it then, they would not have said it at all 
The question posed above of to tell or not to tell represents the struggle between the need to actively withhold information and the need to tell. The themes presented, i.e. the unplanned nature of many of the disclosures described in this study, the signs of psychological distress and the belief of many young people that if they had not told then they would either not have told at all or would not have told for some time all contributed to the development of the superordinate category or theme of pressure cooker effect that, it is suggested here, precedes disclosure.

Many of the young people's descriptions of how they told are characterised by the unplanned nature of their disclosure, captured so well in the phrases 'out of the blue' and 'it just came out'. This unplanned characteristic of disclosure is further supported by many young people's assertion that if they had not told at that time, they would not have told for a long time, if ever. For many participants, disclosure appears to have been as a result of the emotional pressure of not being able to "hold it in" any longer whether from within or from others. This emotional pressure was sometimes observed by others in the form of signs of psychological distress and was sometimes confined to intrapsychic distress, unnoticed by others but according to some young people 'should have been noticed'. Finally, the idea of a pressure cooker effect is supported by many young people's admonitions that if they had not told then, they would not have told for many years, if ever "Maybe after like 10 years but not anytime soon" (C03).

Thus, the pressure cooker effect was evident in this study as representing an experience preceding disclosure when conflicting pressures compete to trigger a disclosure from the young person. The unplanned nature of many disclosures, described by some as an emotional breakdown or resulting from psychological distress, an inability to contain the secret any longer and the belief that if they had not told then they would not have told for some time, if ever, all support the pressure effect as being a significant theme in understanding the disclosure process.

Third Key Theme: Confiding

Finally, having experienced the conflict between the wish to tell and the wish to withhold this information, the secret is disclosed. The third key theme identified in this study, that of confiding, is suggested by three sub-themes, choice of confidante, context of confiding, and confidentiality. The findings suggest that the term 'confiding' better captures the experience of disclosure. The secret is confided, not just disclosed.

Choice of Confidante 
As already presented in Chapter 2, fifty two percent (52\%) of the young people whose stories were represented in this study had first confided in a peer, while twenty four percent had confided in parents and twenty four percent had confided in others such as family friend, relative or in one case, a professional. The person to whom the young person first confided was usually someone they felt close to, "and we're real close we are so eh do I so I just told her what happened to me" (C13), "I wouldn't be able to keep that from them like if there's anyone that I'm close to it definitely would be my friends" (C06). Even when young people delayed telling their parents, they referred to the close relationship they had, "my Mum have a really close relationship so em he (her friend) brought me down and I finally told her" (C07). Many young people referred to their choice of confidante as being based on being able to trust that person "the problem is there's only a slight few friends you can confide in and I was lucky I found two" (C08) or trust them not to tell anyone else, “it wasn't hard telling them cos I knew they wouldn't say anything” (C05) which was sometimes offered as an argument for not telling friends "they're gonna want to say it to someone else" (C10) "Cos they'd just send rumours around and everyone in the school would know" (C11).

$\mathrm{R}$ : so it sounds like you'd be careful about telling people C: yeah that's I know they wouldn't say anything back they're not the type of people I know them for ages. (C13).

Trusting people's reactions was also important “I didn't want people to be like saying oh look at (C10), poor (C10)... oh she's disturbed" (C10). In advising young people to tell if something like this happened to them, C06 suggested "just tell someone a close friend a principal a teacher if anyone would understand what happened it would definitely be some of them probably someone you know, really close to, or a family".

Parents emphasised the importance of only telling someone who can be trusted "They'd want to be really good friends to trust with something like that" (P11) and also the importance of having a trustworthy friend in helping children tell "I think if they have a friend that confide in they can trust and support them" (P14).

\section{Context of Confiding}

Many young people described their experience of confiding in friends as occurring in the context of a mutual sharing of confidences "we were talking about our problems" (C08), and young people telling each other about their problems. For some, this mutual confiding produced the pressure cooker effect referred to earlier in this chapter. One young person described this pressure cooker effect, that at the time, she resisted:

C: well a friend of mine actually told me that something had happened her with her nextdoor neighbour... and I wanted to say something but I just couldn't

R: right 
C: It was almost as if I was trying to speak but my voice was just cut off it was like I was just miming it but nothing was coming out

$\mathrm{R}$ : what do you think was holding you back?

$\mathrm{C}$ : because I find it extremely hard to trust people so I think that element is kindof saying

no don't say anything

$\mathrm{R}$ : because?

$\mathrm{C}$ : because young people can tell everybody

R: ok ok and you didn't want other people to know

$\mathrm{C}$ : no because I was ashamed (C21).

\section{Confidentiality}

It is noteworthy how family members reacted to the idea of telling others about the child's experience of abuse. C10's mother described a conversation with her own father.

And he says you know it's not right if people knows because they might victimise her ... you don't want people to think less of her. That's my Dad who really cares about her. That's what he thinks. People would think less of C10 because that happened to her" (P10).

People's wish and stated need for confidentiality in relation to their disclosures is further evidence of the theme of containing the secret. A04 recounted the consequences of his confiding about his parents' physical abuse of him to a doctor in school.

He said to me 'I believe you're afraid of your parents' ... he said 'look anything you tell us it'll be kept confidential we won't say anything to her'. He was the worst person to talk to because he did he broke his confidence you know. And em rang me mother. Told her everything what I was after saying so em we got the hot and heavy when we went home (A04).

A09 described feeling relieved when she disclosed in counselling for the first time the experience of abuse when she was aged 12 by her mother's partner "I was getting it out and it wasn't going to be told back to me or me family or you know what I mean" (A09).

\section{Summary: Confiding}

The third key theme identified in these findings therefore which completes the first cycle of disclosure is that of confiding the secret. This study suggests that the term confiding is a closer reflection of how young people talk about their experiences "I suppose I just really needed someone to confide in" (C14). The concept of confiding is consistent with the choice of confidante as someone who is trusted and is perceived as close to the young person, the context within which the secret was confided, often as a mutual sharing of confidences between peers and the confidentiality with which this information is treated by others and is sought for by those confiding. 
The conceptual framework proposed in this study is that the process of how children tell needs to be understood in the context of the process of containing the secret of sexual abuse. Containing the Secret can be conceptualised as a process, not just because of the temporal aspect of the experience in that disclosure often occurs some time after the event and in itself over a period of time but by the ongoing attempts on the part of the child and family to contain the information that the child has been abused. A second feature of the temporal aspect of containing the secret is the tendency for many young people in this study to disclose in an incremental manner whereby the child may think about telling and make attempts to tell, verbally or non-verbally or may give additional pieces of information over time. The level of containment varies but for the most part is limited to family, close friends and professionals. Why it is that people need to contain the secret of child sexual abuse is addressed in the next chapter. An illustration of this theoretical framework is presented in Figure 2.

The process of containing the secret involves a cyclical pattern of active withholding, accompanied by a pressure cooker effect, leading to confiding in others that continues throughout the lifespan. The active nature of the withholding concept is clear from the findings presented in this chapter. Non-disclosure is conceptualised here not as a passive 'not telling' but as an active dynamic process. For the most part, the participants in this study actively withheld information about their experiences of abuse. They did not want others to know of their experience, on occasion they denied being abused if they were asked, and they made up stories to ward off suspicious questions from others, all in an attempt to contain the secret. The findings indicate that the concept of denial needs to be understood in both informal and formal contexts and not confined to denial in the context of formal settings such as investigative interviews. Experiences of telling can be preceded by, consist of, and be followed by, elements of denial.

Active withholding is also reflected in how disclosure often occurs over time from the time of the first experience of assault through the experience of the first disclosure and continuing through subsequent experiences of disclosure as the young person navigates the sub-systems of relationships in her world. Active withholding is clearly a relational process as information is being withheld from others.

Figure 2

Theoretical Framework: Containing the Secret of Child Sexual Abuse

Containing the Secret of Child Sexual Abuse

Secret is contained in larger system
Active withholding ${ }^{14}$

Disclosure as a process Too hard to say it 
The conflict between wanting to tell and wanting to withhold information as experienced by participants in this study is conceptualised as a pressure cooker effect. The cumulative impact of a range of factors and circumstances resulted in the initial confiding and continued to operate and influence later experiences of confiding. While many of the experiences of telling appeared to be random, coincidental and "out of the blue", further scrutiny of the young people's stories point to a range of influencing factors as outlined in the next chapter which appear to have converged to trigger the experience of confiding. In particular, the extent to which young people felt under emotional pressure supports the idea that they needed to tell and that the telling was often preceded by this pressure cooker effect. Characteristics of the disclosure itself such as the unplanned nature 
of the disclosure, the evident emotional pressure described by young people and the accompanying psychological distress and the belief held by many of the participants that if they had not told then, they would not have told for some time, all support the theme of disclosure as being preceded by a pressure cooker effect.

The experience of confiding is also heavily dependent on the quality of relationships the young person enjoys with others. Participants in this study were selective in their choice of confidante. The secret is confided to those who are deemed trustworthy by the young person, who will not tell others, who will not judge the young person. As the secret is confided, other people in the young person's world continue the legacy of containing the secret. This is particularly clear from the small number of people in the child's or adult's social network who knew about the abuse at the time of the research interview and the clear intention of many of the participants to exercise caution in confiding to others in future. Nevertheless, the telling continues:

A: I still have never discussed in detail with anybody about it other than what I've said to you is the most I've ever said

$\mathrm{R}$ : even to (therapist)?

A: anybody (A06).

Rhodes, Hill, Thompson and R. Elliott (1994), in illustrating their findings of a study on clients' recall of major misunderstanding events in therapy use a "pathway" prototype to present the application of their qualitative theoretical framework. As argued in Chapter 1, an emphasis on diversity rather than typicality may be more helpful in understanding the complexity of children's and adults' experiences of disclosing child sexual abuse. The method used here to give an example of how the proposed theoretical framework in this study might apply to an individual is through the use of a prototype narrative. In order to preserve the anonymity of the research participants in this study, the prototypes presented below do not refer to any individual interviewed in this study but rather draw on an amalgam of experiences.

\section{Prototype 1: A Child's Story}

Ann, a 16 year-old girl was abused by her mother's partner when she was eight years old, involving him touching her on her genitals on a regular basis over a period of three years. She never told anyone until she was twelve (active withholding). In the context of a 'truth or dare' game (pressure cooker), she confided to a friend (confiding). Her friend encouraged her to tell her mother but she did not want to upset her mother and was afraid that the family would break up as a result of her telling (pressure cooker). When Ann was fifteen, she met her boyfriend. As the relationship progressed, he noticed that Ann tended to pull away from him when he became intimate. He asked her what was wrong but she always dismissed these questions (active withholding). He persisted, however, (pressure cooker) and she eventually confided in him about her experience of abuse (confiding). He insisted that she tell her mother and said that if she didn't, he would (pressure cooker). He went home with her and they told her mother together (confiding). 
Prototype 2: An Adult's Story

Mary, a 60 year-old woman, was first abused at the age of six by a stranger who called her into his car and touched her on her vagina. She ran home upset (pressure cooker) and told her mother (confiding). Many years later, as a teenager, she recalls walking home from school one day and her friend telling her about her problems. Mary described how she didn't intend telling her friend about her own experience, "it just came out" (pressure cooker). She asked her friend not to tell anyone (confiding). She never told another person about this experience (active withholding) until she was admitted to psychiatric hospital at the age of 55 years following many years of suffering from clinical depression and several suicide attempts (pressure cooker). A doctor asked her if she had ever experienced abuse as a child (pressure cooker) and she told him about this experience (confiding). However, she did not tell him about another experience she had (active withholding).

When Mary was eight years old her brother began abusing her. This abuse began with genital fondling and progressed to intercourse within two years. The abuse continued into her teenage years. After Mary confided in the doctor about her abuse by a stranger, she was referred to a counselling service for people who had been abused in childhood. As part of her initial assessment she was asked if she had experienced any other form of abuse or had other abusive experiences (pressure cooker). She denied that she had (active withholding). Twelve months into counselling, Mary began group therapy where other women were sharing experiences of abuse in their childhood. Mary described feeling a strong urge to confide about her experiences by her brother (pressure cooker). Others were trusting her, why could she not trust them? However, her fear of people knowing about this experience outweighed her urge to tell. She did however, confide in her counsellor (confiding).

The next chapter addresses the motivation for containing the secret of child sexual abuse as evident in this study.

\section{CHAPTER 4: WHY CHILDREN DO NOT TELL, WHY CHILDREN TELL}

There are many reasons why the secret of abuse was withheld and why it was then told. These reasons operate on a number of levels. Different reasons may operate when a young person is withholding this information from their friends than when they are withholding it from their parents, child protection or policing agencies. Similarly, different motivating factors may operate from one context to another and within different relationships. 
The key motivating factors for withholding the secret for young people that emerged in this study were identified as being believed, shame/embarrassment/self-blame, fear, concern for others (not wanting to upset) and being told not to tell (See Table 4). Factors influencing the active withholding of information can influence the individual at an intrapersonal level, an interpersonal level, a family level and a societal level. For example the theme of being believed can refer to whether the child believes what is happening to them, their expectations of whether others will believe if they tell, and whether people do actually believe or their actions convey that the child is believed.

Motivation for telling includes both those factors that contributed over time to the telling experience and those themes that represent immediate triggers for telling. The latter were usually discrete events that prompted the young person to tell while motivating factors usually represented thoughts, feelings and behaviour of self and others over time. However, motivating factors and triggers for disclosure are not mutually exclusive. For instance, being asked for some young people was the trigger for their disclosure. For others, being asked contributed to the pressure on them to tell someone, even if they denied it when initially asked. Similarly, some young people told an adult as a direct result of pressure from peers while others spoke of peer pressure as a contributing factor over time which, combined with other factors, led to them telling. Six key themes emerged as motivation for telling in this study (See Table 4), being asked, concern for other children, peer influence, contact with the alleged abuser, alcohol as facilitator and the role of the media and film.

Table 4. Key Themes: Why Children Do Not Tell, Why Children Tell 


\section{Motivation for withholding the secret \\ Being believed \\ Shame/Embarrassment/Self-Blame \\ Fear \\ Concern for others (not wanting to upset) \\ Being told not to tell \\ Motivation for telling \\ Being asked \\ Concern for other children \\ Peer influence \\ Contact with the alleged abuser \\ Alcohol as facilitator \\ The role of the media and film}

The themes for both withholding and telling the secret are in some instances interrelated. For instance, the themes of being believed and being asked are not necessarily mutually exclusive categories. To some extent, they represent two aspects of the issue of believing insofar as a readiness or openness to believe can be a pre-condition for being asked. Similarly, concern for others (not wanting to upset) was identified in this study as a key motivating factor for withholding information and concern for other children was identified as a key motivator for telling. Both themes speak to the altruistic theme of concern for other people. The interrelatedness of themes representing the active withholding and telling aspects of the process of containing the secret highlights the cyclical nature of this process. These themes are therefore presented in this chapter in a format that reflects this cyclical characteristic. The theme being believed is presented first, followed by being asked. This in turn is followed by concern for others, which incorporates both worries about upsetting others as a motivating factor for withholding and concern for other children as a motivating factor for telling. The remaining themes are then presented, each alternate theme representing a motivating factor for active withholding and for telling, peer influence, fear, contact with the alleged abuser, being told not to tell, alcohol, as facilitator and the role of the media and film.

\section{Being Believed}

The issue of being believed was the single most common theme mentioned by all those interviewed and was consistently referred to as a reason why children may find it difficult to tell "I think the main fear of most people was not being believed that's be the biggest one" (C01). It is also possibly the most complex issue in relation to understanding difficulties in disclosing sexual abuse.

The theme of being believed was referred to in this study as an intrapersonal, interpersonal, familial and societal dynamic in the process of containing the secret of child sexual abuse. Many young 
people spoke about not quite believing themselves that this had happened. For some this was an initial response and for others it was in response to other's disbelief "you're so confused about yourself that you know you don't know whether to believe yourself if no one else believes you, you start to not believe yourself" (C01). When asked why it was that young people have such doubts about people believing them, $\mathrm{C} 14$ responded: “em I think it's a doubt in yourself to be honest I don't think it's about the actual people" (C14). The psychological coping strategy of not thinking about the abuse may contribute to a lack of acknowledgement for the young person that the abuse has occurred. C14 described how in a way she didn't really believe it was happening until she said it to a friend, i.e. saying it makes it more real "cos it's a crazy it is a crazy situation ...cos I never believed it for a long long time until I actually told me friends and they were like listen you know what I mean this is major" (C14).

The lack of acknowledgement on the part of the abuser can feed into the doubt on the part of the child that something did happen when the abuser's behaviour subsequent to the abuse, or in all other contexts, continues as normal.

C: Because we never talked about it like like em he'd never sit down and say oh remember that time that happened. Once it happened he never spoke about it again it was like at that point and he was like it was like he was a different person even and em I I was just em I would be because he was so convincing I was like you know if he's able to convince me he's definitely able to convince them cos they don't even know as much as I know (C10).

C: he's just going on like nothing happened ...... and you're kinda you know you're sitting there saying is he for real? or you know what I mean, is he? am I imagining things? what's going on? dya know what I mean? (C14).

When memories of childhood abuse are recalled having been in some way forgotten for many years, it can be even more difficult for a person to believe that they have been abused. A11 described how her memories of the abuse were triggered while she was in counselling and she spoke to her husband about it “you know something's after coming out I don't know whether to believe it or not" (A11).

Interestingly, one young person herself was quite sceptical of other stories of abuse. She described how the helpline, Childline, has children ringing all day everyday about their parents "me parents did this and me parents did that and maybe it's a loada lies". She also described someone in her school alleging that her father had beaten her and that it wasn't true. When asked how she knew it wasn't true, "I heard her Da even saying that it wasn't true and her mother even said it so that's how I know it's not true" (C18). This young woman also recounted a story of someone who said that she had been raped but she didn't believe this. Similarly, A07 described knowing about a girl in school, "they used to say that her dad used to have sex with her ..but it were only well as far as I were concerned you know just gossip or whatever" (A07). 
It is possible, as $\mathrm{C} 14$ pointed out, that the concern about being believed by others is strongly influenced by young people's difficulty believing it themselves.

I don't know I think it's just a fear it's really unexplainable because after a while you think about it and you say like why wouldn't they trust you why would they believe you they're your family and all? (C14).

Some young people were proved wrong in this concern that they would not be believed, "they believed me straight away so to me that was a big thing because that was my main worry...I used to always think that people would never believe me that was kindof one of the main reasons why I never told anybody but everybody did" (C09). "I thought she wasn't going to believe me at the start but she did cos I don't I just told her what happened and she took it into consideration she ring the guards" (C13). Others were proved right in their doubts about not being believed. C19 thought some people would believe her and some wouldn't and this turned out to be the case. For others, they were proved wrong when they thought they would be believed. "I thought family members would believe me but turned out they were the worst" ( $\mathrm{C} 01)$. It was also the case that some people thought they would not be believed but, perhaps after initial doubts, they were. C20 made a false allegation against her mother's partner. Her mother did not believe her, nor did anyone in her family network except her grandmother. She later retracted the allegation but was seen for assessment when she disclosed a credible account of abuse by her biological father "then I started crying and then me ma started crying I go 'I told you I wasn't lying', she says 'I didn't think you were lying I had to make sure"” (C20).

C13 retracted her initial allegation. While the reasons for retraction are complex, her perception was that when she made the initial allegation some people did not believe her whereas when she retracted, everyone believed the retraction. One of the contributing factors to her retraction was being constantly asked 'was it true?'.

an I was telling her I'm not lying I told her the truth ... and she just kept on asking me 'tell me the truth, tell me the truth, I want to know the truth, nothing but the truth' like everything, just the truth. 'Cos I don't want you to make a mistake' (C13).

She eventually retracted "aw here like they're not believing me I might as well just say here fine don't believe me then I'll just go and make up a load of lies" (C13).

An ex-boyfriend challenged her in a social setting " and he goes like yeah you're making up a load of lies I bet you're just trying to get him out of the house isn't that right? (C13).

As with the young people interviewed, some of the adults referred to the possibility that they would not be believed "it was years before I told anybody because em in them days just nobody would believe you" (A02). In relation to whether she thought her mother might have believed her if she had told "she probably would've said 'oh don't worry about it, you're only making it up' and left it like that" (A02). For A03 and A11, their mothers still do not believe them, "I went home and I told 
my mother and she says 'how dare you talk about that nice man like that'. She wouldn't believe me you know" (A11).

Whether the abuser was someone within the family did influence the extent to which people believed the disclosure. The data on this theme are presented in Chapter 6 with respect to systemic issues.

At a societal level, children's beliefs about how society perceives sexual abuse can influence them in their wish to contain the secret. According to C03, "where I come from, the guards, they don't believe children ...very few people believe children unless it's your like your daughter that's when you're gonna believe a kid" (C03). C05 was worried that the gardai mightn't believe her "cos they're the guards" (C05). Children can be told by the abuser and others that no one will believe them. When $\mathrm{C} 03$ told her abuser's wife about the abuse, this woman physically beat her "the wife used to tell me like there's no one you're gonna tell that's going to believe you" (C03). In this case, the child's belief that no one would believe her was also linked to the fact that this was a very respectable family and this appeared to contribute to her belief that she would not be believed, "then there's me, tiny me, saying something" (C03). A02 told no one as a child about her experience of abuse. She later told her mother who she said does not believe her. She noted that in the past people did not believe children. However, when her own daughter disclosed sexual abuse she expected people to believe her daughter and was surprised when her own mother doubted her.

For $\mathrm{C} 10$, nothing was said to her directly about not being believed but she overheard her abuser talking to her mother about it "and he goes 'oh she dreamt it' and 'oh no one would believe her anyway"” (C10). In the case of $\mathrm{C} 02$, her own psychiatric difficulties were used by the abuser to cast doubt on her ability to be believed "That because I'm on tablets for depression and used to cut myself that I'm not in a state of mind to say what happened to a judge" (C02).

C18 stated that although the abuser was charged, many of her peers and neighbours did not believe her "everybody believes him.... cos people do be saying aw there's the person that ..got (alleged abuser) locked up" (C18).

In one instance, the Director of Public Prosecution (DPP) had decided not to proceed with a prosecution that the young person interpreted as her story not being believed.

C: They didn't believe me...Well the court case was thrown out by the DPP

$\mathrm{R}$ : you think that means they didn't believe you?

C: (Nod) (C09)

C14 highlighted the difficulty for people in believing something that they had no prior experience of: 
It's not that people don't love you I think it's just if they haven't dealt with something like this before .. they probably wouldn't understand or you know, know what to do (C14).

Delay in disclosing can contribute to young people's expectations as to whether they will be believed or not, "are people gonna believe me an cause it's so long like coming out?" (C09). According to C05, if you were abused when you were 6 and you didn't say until you were 20 "no one would believe you ... they'd say what took so long to tell?" (C05). Similarly, A02 talked about feeling that people were judging her, thinking that she made it up to get the abuser in trouble " and why didn't I come forward why didn't I report this years ago?". C14 described how the delay in telling also contributes to a sense of it being even more unbelievable "I had to deal with it for a long long time and I dunno it just as it goes the more you leave it unsaid the more unbelievable it it becomes you know what I mean" (C14). The delay in telling makes it harder for the young person to feel that they will be believed 'it's not that I didn't trust my Mam and Dad it's just I didn't know what they were gonna think and I didn't know what they were gonna think about me not telling them before" (C17). Similarly with C09, "but then I knew like my mam and Dad like of course they'd believe me like dya know the way it was just it was going on for so long" (C09).

Ironically, one young person talked about how typical it was for people not to tell straight away and that perhaps because she told immediately, people may have doubted her "an they were probably a bit shocked that I told straight away so I dunno if they believe me or not" (C06).

Young people can be concerned that their behaviour can contribute to people not believing. C17 described how she "got a bit off the wall my behaviour was crazy" and that this made her afraid that her parents wouldn't believe her.

Unfortunately, many of the young people in this study described not being believed following their disclosure or people in their family or social network doubting the credibility of their disclosure. C02's brother in law was the alleged abuser. Her brother who was a good friend of the alleged abuser didn't believe her "He told me that (alleg abuser) wouldn't do that" (C02). C07 had two friends who thought she was lying. C09 first told a teacher who was challenging him on his behaviour in school "he didn't believe me at first like come on tell me what .. eh tell me what happened and I did I told him why I was so upset and off the rails " (C08). It is possible that young people themselves doubt whether they are believed even when they are believed or that while the initial response may have been one of disbelief, the actions of others (such as this teacher) would indicate that these people to believe.

For adults in this study, the experience of not being believed was more common than for young people, particularly on the part of parents. A03 had a conversation with her mother about 2 years prior to the research interview "She said well I don't believe anything happened to you" (A03). 
Similarly, A11's mother does not believe her, “Me ma doesn't believe it ever happened...Ma thought I was mad, was gonna have me signed in somewhere" (A11). A11 also described an experience as a child with a dentist:

I'll never forget it. It was horrible he was trying to kiss me and everything. I don't know how I got away I did and I went home and I told my mother and she says 'how dare you talk about that nice man like that' she wouldn't believe me you know (A11).

Parents can offer some insight into how young people perceive whether they are believed or not. Even when parents did believe their children's disclosure, they described their initial reaction of disbelief when they were told of the abuse. In these instances, there was no question of not believing their children but the feeling of disbelief is captured. C09's father described his reaction when he was first told that his daughter had been abused. His first thought was that something had happened his parents. He didn't believe it at first “it wasn't kindof hitting home at all ...couldn't comprehend what I was after hearing" (P09).

Similarly, when C09's father told her mother, she too described the feeling of disbelief:

I don't know how to tell you this he said it's the worst thing that's ever going to happen to you ... and it kinda went over my head I kindof ...I continued on and came in and she was sitting there I just put my arms around her and said 'are you ok?' I just started to open the case and showed her what I bought her (P09).

Shock as a reaction was a common theme mentioned by many of the young people ( $\mathrm{C} 06, \mathrm{C} 07, \mathrm{C} 08$, C10). C10's mother described how she nearly crashed the car when her daughter told her.

Similarly, some of the adults recalled people's reactions when they told them, when they were believed. A11 recalls telling her sister who did believe her but "she was shocked ....she couldn't believe it" (A11).

C15's mother described how she searched in her own mind for an alternative explanation of what her son was saying because what she was hearing was so incredible.

He said to me 'em Mammy (alleged abuser) touched my bum' and I was a bit I was a bit embarrassed at first. He just said it out and there was a busload of people and then I kinda just went .. 'what are you saying things like that for', you know? ..I just said 'well maybe it was an accident when he was going to look for you'. Like I was presuming this game what he was describing like hide and seek ... I just kinda I put it down to an innocent thing that a child would do (P15).

At this point, C15's mother thought that the child in question was a similar age to her son.

At the time so I was placing my head that it was a ten year old that did this and that maybe it was an innocent thing as in he was behind a door or under a bed or something and he grabbed him and he put his hand on his bum and he made C15 feel uncomfortable and that was why he told me (P15).

However, when her son told her the following day about a second incident, 
First of all I was like I couldn't believe like .. I was freaking it in my head I was going ballistic but I was like right I got him to say it again because I couldn't believe the first time (P15).

She described telling her husband "I had to tell (father) ten times before it registered" (P15).

And of course, people do not believe: "the father (of the alleged abuser) actually collared me one day and said children are always lying like at that age" (P15).

The need for both being able to say it and being heard is captured in the following quote from an adult woman who has never told anyone about the abuse by her brother outside the context of counselling: “how in God's name can you explain yourself to people who's going to listen?" (A03)

Being believed is an intrapersonal, an interpersonal and a societal factor influencing the process of containing the secret of sexual abuse. It is intrapersonal insofar as the child may have difficulty believing it has happened. This was more commonly reflected in adults' retrospective accounts than in children's more recent retrospective accounts. This 'unbelievable' sense of the experience may be compounded by the abuser behaving as if nothing had happened, thus in some way nullifying the experience as worthy of remembering. Children may have expectations of not being believed which are unfounded or they may be correct in their estimation of whether they will be believed or not. At an interpersonal level, incredulity is a common reaction when children disclose sexual abuse in that the behaviour itself, for most people, is unbelievable, 'something that doesn't happen to my child'. This is evident in parents' reactions even when there is no question of not believing that the child is telling the truth e.g. "I couldn't believe it". The unbelievable nature of the behaviour being disclosed by the child is compounded by not wanting to believe at both the intrapersonal and interpersonal level "If you don't say it out loud it didn't happen". For both the child and the person to whom the disclosure is made, it is perhaps easier not to believe. Some of the parents in this study described an instinctive reaction to the disclosure such as wanting to kill the abuser.

At a societal level, there can be an expectation that the child may not be believed. An example of this is a parent in this study who was seeking corroborative evidence by asking her son what was playing on the computer when the abuse occurred. Also, the experiences of children being "grilled" to establish the veracity of their accounts reflects a doubting of children's truthfulness. Some people do not believe children when they disclose experiences of sexual abuse, some believe that children tell lies 'all the time'. In the face of denial by the abuser, the burden of proof is placed on the child. When the abuser is part of the child's family or social network, those close to the child are forced to choose whom to believe. In a society that demonises abusers, making this choice has enormous consequences. If the child is not telling the truth, a person's life may be destroyed. If the 
child is telling the truth and is not believed, the psychological fallout for the child is tremendous. When a prosecution is not taken, this can be interpreted by the young person as not being believed. When the abuser is a child himself, societal attitudes about abusers militate against the child's parents being able to believe that their child was capable of such a thing.

\section{Being Asked}

In this study, some of the young people described being asked explicitly if they had been abused, while others referred to being asked what was wrong with them. Those who were asked explicitly had either been discovered at the time of the abuse or were exhibiting severe signs of psychological distress such as self harming behaviour, or getting into trouble in school. Those who were asked "what was wrong" were exhibiting signs of psychological distress or displaying disruptive behaviour at school or home. On occasion, being asked was the trigger that prompted the disclosure, and at other times being asked was part of the process that led to a disclosure. Some young people were asked by parents, some by friends, some by professionals. From the young person's perspective, people sometimes asked because "they just knew" that something was wrong. Other young people felt that someone should have known and should have asked. Being asked was a theme relevant to both initial and subsequent disclosure experiences.

For some young people in this study, being asked directly about abuse was prompted by an adult witnessing the abusive behaviour. A father became suspicious at how quiet his son and nephew were while playing upstairs in the family home. He went to his son's bedroom and seeing his nephew pulling up his trousers, drew his son aside and asked him directly what had happened. A mother discovered her two children, boy and girl, in the bathroom together. There had been previous incidents of inappropriate sexualised behaviour when the children were younger and on this occasion the mother arranged for the school counsellor to ask her daughter about the incident. A school teacher witnessed children engaging in sexualised behaviour in the school and asked the children directly about this. All of these incidents led to further disclosures by these children of other abusive behaviour, occurring over an extended period of time and in one instance to a disclosure two years later that a boy had been abused by his father. While these young people 'disclosed' for the first time in response to being asked, they did not give the full details of their experiences at that time. Being asked was the beginning of the process of disclosure referred to at the beginning of Chapter 3 and representing support for the theme, active withholding.

Other young people described being asked if they had been abused and although they denied it at the time, it may have contributed to their finally disclosing. Two teenage girls described being asked by their counsellor, because they were self-harming. One of these girls had already told a 
friend a few years previously and when her counsellor asked her "I didn't tell her what happened but I was saying things that made her think it made her think that it happened but I didn't tell her" and the following week she disclosed to a youth group leader "the leader said something and then I got upset ... and I couldn't stop crying and one of the leaders asked me what was wrong and I told her" (C05). The second girl disclosed to a adult family friend while attending counselling "everyone was asking me coz obviously I had signs of it you know I was cutting myself I wasn't eating" (C01).

C09 was concerned about the abuser minding his children. Her father noticed her strange mood and asked the girl's aunt to have a chat with her. She had already told her boyfriend some months beforehand, again in response to being questioned about feeling uncomfortable with intimacy.

From the young person's perspective, some were asked because people close to them - friends, mothers 'just knew' that something was wrong. One teenage girl described how her friend observed the way the alleged abuser looked at her:

she was asking me she kept on asking me are you ok? I said Yes I'm fine and she was like are you ok? ...she kindof said something about the way the brother looks at me what is he doing to you? ... she was the kind of person that would see through you ....she just she just kindof knew I dunno how but she knew (C03).

This young person finally came into contact with professional services, but did not disclose the abuse until she was asked directly. "I think she probably had an idea that but she didn't know it was that bad she had an idea that something probably something bad happened to me" (C03).

C17 described how she felt her boyfriend 'knew' there was something wrong before she told him I think he just knew because like if anybody made jokes about it or something I was real touchy ... I think he had an idea that it was something like that but I don't think he knew like exactly what it was ... he knew I wouldn't be like that for nothing (C17).

and how a male friend subsequently asked her directly if she had been abused "he was like he said that he knew there was something wrong like why was I so depressed and whatever" (C17).

Similarly, C02 referred to her mother asking her what was wrong:

$\mathrm{R}$ : Em ok And when you say that your Mum was asking you what was wrong with you what? why was she asking you that? What...?

M: Coz she just knew by..me.. the way I was acting that there was something wrong $\mathrm{R}$ : Really can you remember what was it about the way you were acting?

M: Well I was real quiet and aw like I felt real depressed and me Ma knows when I feel depressed coz I dunno what it is, probably a vibe she gets off me (C02)

In the parent interview, this mother described how she had no idea of what had happened to her daughter, and had attributed her strange behaviour to something else. She noted that she would not have persistently asked her daughter what was wrong if the alleged abuser had not telephoned her 
making allegations about her daughter and calling her names. However, several young people referred to their mothers in particular 'knowing', such as when C04 was watching a TV programme about abuse with her mother "like she knew by me face like there was something up" (C04). C16 believed that her mother knew there was something wrong but not what it was. "I think she just knew because I was eh em always protecting (younger sis) and I was always just let I'd never let her out of my sight an all an then me ma knew there had to be something wrong" (C16).

Another dimension to the theme of mothers or friends 'just knowing' something is wrong is when young people felt that mothers should know or should have known there was something wrong. On occasion this is associated with the young person giving vague signals that something is wrong without clearly communicating what is wrong.

R: so you didn't say what had actually happened

C: No I didn't say that but I thought she knew. I kinda thought she knew even though I hadn't told her like I knew I hadn't told her but I thought she would have figured it out (C10).

In addition, misunderstandings can contribute to the confusion young people feel about whether parents know what is going on or not. $\mathrm{C} 05$ recalled one night when the alleged abuser was staying over. He was supposed to sleep in her bed but ended up sleeping on the couch. Her mother returned home "giving out to me for making him sleep on the couch an everything ...An I thought she was talking about not letting him near me" (C05).

C17 described feeling somewhat resentful that her mother didn't guess what was wrong, that she should have asked her directly, as "Mams just know things I was kinda hoping that she would guess" (C17).

I dunno I even said to my Mam like part of the reason I didn't tell her is because I was waiting for her to guess dya know what I mean like. I was waiting for her to say to me look has this happened? (C17).

When asked if she would have told her mother if her mother had asked her directly: "I don't think I would've said yeah but I think I would have made it quite obvious that that's what woulda happened" (C17).

Similarly, C20 felt that her grandmother should have known by her behaviour

She shoulda known that there was something wrong with me....the way I was going on an all cos I really wasn't meself... she shoulda guessed that there was something wrong with me $(\mathrm{C} 20)$.

Only one adult in this sample referred to being asked as a trigger for telling. In this instance, the woman was experiencing difficulties in her sexual relationship with her then boyfriend when she was nineteen 
There were times I'd cry or you know I'd waken up from nightmares and he thought that it was him you know like if you're in. It'd be like flashbacks... he wanted to know what was wrong you know. Was it him? or what was happening? and so I told him (A11).

A further associated issue that emerged in this study that is related to being asked is the idea of being ready to tell. Being ready to tell was mentioned by three young people in the context of discussing what we can do to help young people tell. According to C08, there isn't much you can do to help young people tell because "it depends on whether the person's ready to tell or not" (C08) while C16 thought "probably better off waiting til they tell you"(C16). C17 had been encouraged by her boyfriend to tell her mother and although she felt this helped her to eventually tell, "I told her when I was ready to" (C17). C20 said that it would depend on who asked her, if she had told earlier. For instance, she would have told her mother but would not have told a teacher.

\section{Concern for Others}

Concern for others was a predominant concern for young people interviewed in this study. This took two forms, firstly a concern about not wanting to upset others by confiding in them about the abuse experience, and secondly, a concern for other children which prompted many young people to tell someone of their experiences.

\section{Concerns about Upsetting Others}

Both worries about upsetting the family and concerns about families breaking up were predominant concerns for young people that deterred them from disclosing their experience of abuse. C10 tried to tell her mother by leaving a note for her in the bedroom but always changing her mind and taking it back. When asked why she would change her mind about leaving the note she had this to say:

You see it would happen in a row and I'd think ok she has to know. So I'd leave it under her pillow and then they'd make up. They would have had an argument her and (alleged abuser) and then they' $d$ be all friendly again and I'd take it back because I'd think Oh they're alright now I don't want to make things worse again. I didn't want to be responsible for them breaking up. Even though I wanted them to split up but not because of me (C10).

As C01 pointed out,

R: Em do you think different things stopped you from telling different people?

C: Yeah

R: So, what would you say were the different reasons for the different kind of people?

C: Different relationships (C01). 
The actual consequences of disclosure for one young person highlights the enormous emotional burden placed on a young person who is dealing with the fallout of disclosing abuse within her own family. C13 was abused by her mother's partner who was also the father of her younger siblings.

I didn't want them to grow up with no Dad and just looking at the other friends at their other little friends having their Dad holding their hand I felt like I was taking their Dad away from them but at the same time I didn't want anything to happen to them like I was keeping them safe and then I knew that was the right thing to do but at the same time I felt like 'what am I doing?' 'it's their Dad, I can't let, I can't let them live without their Dad' like like that's what that's what was keeping me from not telling. (C13).

She described how subsequent to her telling her mother and the alleged abuser leaving the family home, her sibling would constantly ask:

'When is Daddy coming up?' And I just couldn't take it...aw here no I'm telling ... I'm just telling I made up a lie just to get him out of the house ....cos they were all like 'where's Daddy?' and everything. 'I want Daddy in the house like I love him where's Daddy?' an I felt real I felt depressed like I felt like crying all the time (C13).

In this instance, this emotional burden was too much to carry and the young person retracted the allegation, although the truth was subsequently revealed.

A07 mentioned the issue for children of perhaps feeling like they are betraying the abuser by speaking out. This theme is not well represented in this study. Few people referred to a concern about the abuser, concern was more for not wanting to hurt other people in their lives.

Finally, A11 who was abused by his brother, said that he didn't think anything would have been done if he had told "an times were hard enough in them days without giving any more problems to your family" (A11).

Young people's concerns that people would be upset if they told them were valid. C05 told a male friend "he started crying" (C05). C07's mother "couldn't understand why I had left it so long to tell her and she was really upset by it as well" (C07). When C08 told his sister, "she started crying she started hugging and all" (C08). C08's brother told his parents in his presence "and my brother (name) started crying and said I got I was sexually abused by (alleged abuser) and em me ma started crying me dad started losing it me Da was going mad" (C08). C08's mother also described the scene:

(brother) started crying he said 'Mam (C08) has been abused' and you may as well have took me off the wall I went hysterical. I said 'how?'. Cos I've always protected him I never left him with babysitters because of what happened to me you know I never put them out there at risk. Even when they go anywhere, I have to know where they are. And it's not just being overprotective it's knowing if anything happened I could find them and I just couldn't handle it at all. I have to be honest it broke me heart broke me heart (P08).

C09 described reactions to her disclosure: 
(aunt) kinda just played it cool when I told her on the stairs. She was kinda 'aw right like I won't tell anybody'. Just kinda like a girl to girl conversation. And then when I was up in (aunt)'s house like she was crying and me Dad was crying and I was crying like me Mam she went mad she did... an I was roaring crying like cos I could hear her screaming. Then I just remember me Dad saying it to her now I couldn't hear me Dad saying it to her but all I could hear was 'I'll kill him I'll kill him' like an trying to get out the door and everything an that was getting me more upset like (C09).

C09's father described it from his perspective:

with me it was the end of the world the whole world has caved in on me ... it was the worst thing that ever happened and it killed me really really ate me up ..it woulda been better a death ...for the first 8 months I thought this was the worst thing that ever happened nothing worse could ever happen now (P09).

Two girls described how their boyfriends reacted when they first told them: "who is he? like I'll kill him" (C09); "he said he was gonna kill me da but (sigh) you know what fellas are like" (C20).

C11's father described how his wife said "I don't want to hear anymore" when her son was telling about what happened. When asked if his parents were upset when he told he said his Da wasn't, "he was fuming" (C11). His father also described how the mother of the alleged abuser reacted: "as soon as she walked in to the sitting room I said your son is sexually abusing my son yesterday you know like that she virtually collapsed in the chair broke down crying" (P11). C15's mother described how she hadn't told her own siblings about her son's experience of abuse "I also didn't want to upset other people either cos my mum and dad were devastated" (P15). And C16's mother who discovered that her own son had abused her daughter: "I cried I was screaming crying I thought (son) was dead and that's how it felt for me" (P16).

Consequences were, on occasion, violent. A11 tried to tell her mother that her uncle had raped her sister "when me mam came home I was crying I said I said he's after hurting (sis) and ... punched me right in the nose for saying things like that" (A11). She also tried to tell a neighbour about the physical abuse at home: "I actually got a hiding for going up and that was the last time that happened I never tried to tell after that then" (A11). And when her father was told about her uncle raping her sister: "me Dad sent my uncle out and he kneecapped him over what he had done" (A11). C18 was physically assaulted by the alleged abuser a few weeks after she made a garda statement "he attacked me and bit the finger off me as well" (C18).

There was a continued concern that there would be violence if the secret could not be contained on an ongoing basis. C15's mother explained why some of her family don't know about the abuse "I'll tell you why because that person wouldn't be alive to-day if ... because I'd be afraid ... because as I said men don't think they act out (P15).

C08's mother was concerned that her older sons may get into trouble in the future: 
And to this day they said that if if (C08) doesn't get justice they're gonna give him a hiding. My kids have never been in trouble with the police. That's the only thing I said. Please, we'll go through the law (P08).

C11's father described how C11 had been engaged in sexual behaviour with a nine year old neighbour when he was six years of age. "C 11 was only 6 and I put it down to young children exploring" (P11). He had been advised by the social workers not to approach the other family but when he did mention it to the boy's mother a few months later, she was very unhappy that the social workers had been informed. "I says look I'm not making a big deal of it but unfortunately she was you know then she started threaten her husband on me" (P11).

P15 described how the parents of a fifteen year old who abused her six year old son reacted to the allegation:

the mother and father went on absolutely disgraceful shouting at $\mathrm{C} 15$ calling him a fucking liar saying there was something wrong with him that he was em the language was unreal ... she kept on screaming I'd say about six times in his face fucking liar there's something wrong with you you're sick this that and the other my son is the salt of the earth wouldn't do nothing .... and then the father was a bit more calm he said he said who do you think you are accusing my son ... six year olds are always lying they're liars at that age ...but he (her son) was very upset then because the mother was screaming to (his) face at that stage ... the father said em he said eh there's no way there's no way my son would do anything like that ...he was after doing the right thing and he was getting major time punished (P15).

It is clear therefore that many of the concerns expressed by young people in this study were justified. People did get upset and on occasion violent when they were told of the abuse experience. Families did rupture and break up.

\section{Concerns for Other Children}

A common theme raised by young people was their concern for other children as a motivating factor for disclosing their experience of sexual abuse. $\mathrm{C} 02$ referred to always being afraid it would happen to her eight year old niece, the daughter of the alleged abuser. C09's disclosure to an adult was prompted by her concern at her alleged abuser minding his children for an overnight visit one weekend. C20 was worried about her little brother and sister who visit the alleged abuser, their father, every weekend.

I thought like he could do that to me and I can't tell anybody they can he can do it to them and they won't tell anybody... an maybe I'm wrong like maybe he would never do it to his own kids dya know that kinda way but I always thought you'll never do it to me like dy'a know that kinda way .....and if I hadn't told and a few years later (his children) turned around and well he done that to me a year after what he done that to you I woulda never forgiven meself I really would've just lost it altogether ... (C09).

C18 was conscious of the alleged abuser standing outside a local shop "he'd have around ten children around him a day and he'd be giving them money and sweets an all dya know what I mean". For some, it was their peers who pointed out the need to think about other children and the 
possible risk to them. C13's friend pointed out "look what could happen to your sisters and when I thought of that I just my mouth just dropped and I was like no I've got to tell I don't want it to happen to them I don't want their lives ruined". Another teenage girl was similarly concerned about the children of her brother-in-law, the alleged abuser "if anything happened them children I would have been devastated... and I just wasn't gonna let that happen (C14).

Concern for other children could at times be outweighed by other concerns.

$\mathrm{R}$ : what happens in situations where maybe if children don't tell and the person who did it can go on and do the same thing to other people what would you you know? C: yeah I know what you em I can see where you're coming from but for me it didn't matter I had people saying that to me as well like $\mathrm{C} 07$ what if he goes and does it again like why don't you you just be the one to deal with it now it's easier said than done it's like you're only a child and you're facing up to something that you shouldn't have to deal with nobody should have to deal with (C07).

Concern for other children was for one young person the motivation for retracting her disclosure as the alleged abuser, her stepfather, left the family home following the allegation and her younger siblings were upset about this. Concern for other children was a significant theme for the young people in this study. It did not feature in the narratives of adults who had been abused as children.

\section{Shame, Embarrassment, Self-blame}

Feeling ashamed of what happened or feeling embarrassed about it was mentioned by just less than half of the young people and all but one of the adults in this study. C01 and C17 talked about being too embarrassed to discuss such matters with their parents. One young boy when asked said it was not embarrassing for him but did not elaborate further (C05), and one girl said she felt dirty (C07).

Self-blame, or the young person in some way blaming themselves for what happened (and this acting as an impediment to disclosing) is a common feature in studies of people who have been sexually abused. Self-blame may arise from many different sources. C01 described how "there's always that thought that you let it happen" when talking about abuse at the age of 7 by her older brother and his friend. For her, the matter was further complicated by the experience of a sexual assault as a teenager by a peer. When she disclosed this to a close family friend, the reaction was that this time it was her own fault because of her promiscuous behaviour "I just didn't want anyone to know. I was so angry with myself ashamed with myself that it would happen again" (C01).

The self-blame may arise from the child's inaction or not fighting back, pretending it wasn't happening, a common coping strategy for children. "I was awake like but I didn't turn around and say here like stop I didn't push his hand away you know that kinda way" (C09). In the absence of an explanation as to why it was happening, some children blame themselves "is it my fault is it 
why did it happen?" (C12). Or sometimes, children just expressed how they felt: "I felt like it was my fault" (C13).

On occasion the self-blame felt by children was actually instilled into them by the abuser. C03 was told "I was the cause of it that's because I'm bad ... he said that I was bad that's why this is happening" (C03).

Unfortunately, the issue of self-blame extends beyond the experience of abuse itself and can be associated with the consequences of telling about the abuse. C16's brother had to be removed from the home and she felt responsible for this. $\mathrm{C} 02$ described feeling guilty that her sister's children no longer saw their father because of what happened. C13 retracted her story in part because of the guilty feelings she experienced when her siblings missed their father and did not understand why he couldn't live with them anymore.

Self-blame may arise as a consequence of not telling about the abuse and therefore not having the opportunity of an adult telling the child that it was not their fault. Some young people described how the reasons why they could not tell changed over the years and for some, self-blame became an issue as the years progressed.

it wasn't even about the threat anymore, it was about, because I thought it was my fault... I think that as I got older I started to think ... I couldn't think of any reason why would he do that to me like I musta done something or I must just be a certain type of person dya know what I mean? (C17).

This theme of self-blame can operate for many years without being challenged. One young person described how, over time, she realised she was not to blame:

at the start I did like when I was first thinking about it am I gonna get in trouble but like after a while like just kinda just kinda let it just stop thinking about it and then when I started to really think about it I just realised like it wasn't my fault I was scared I didn't do anything wrong (C12).

A08 described how she was hanging around the place where the abuser worked and so she believed she would be blamed "so the best then would be not to tell" (A08). A09 described how the adult looks back on her childhood experience with adult logic and bafflement as to why the child of seven could not have stopped the abuse:

I mean you say to yourself God why did I not eh run out of the room when he opened the door .... why could I not say to me Ma 'now Ma I don't want this this man here he's eh messing around with me' ....I really I musta been really thick....it's always that shame that you feel God I coulda stopped that you know? (A09).

A08 talked about how in adulthood she got help and through this met others who had similar experiences. This helped her to realise that the abuse was not her fault and the feeling of shame subsided over the years, making it easier to tell about her experiences. The transcript of A11 gives 
a deeper understanding of the complex factors that make up the dynamic of self-blame, how this changes over time but may still act as an obstacle to telling but for different reasons. She describes how she felt to blame for the abuse until she was about fifteen when she stood up to her brother and the abuse stopped. This helped her realise that it wasn't her fault. Her brother was just two years older than her and this too contributed to her confusion as to who was responsible for the abuse itself. As she describes, he was only a child himself when it started but he continued it into adulthood. Finally, the lack of physical coercion in the later years of the abuse contributed to her belief that she let it happen. Disentangling this story, not just challenging the belief, helped her in counselling to understand her lack of culpability.

it's like there was only two years in the difference and that's when you start thinking well he was only young himself ......at one stage he did pin me down and then after that it wasn't it was just taken kindof a thing that's where I woulda been ashamed of is the fact that I had let him because I had no choice.....you know em it's my fault so what's the point in saying anything?..... think when you're told then ok yeah he came into my room so that's where your brain your brain is starting to say 'well I wasn't I didn't go into his room' and start making you realise then 'oh God maybe is that my fault'?... you know that he was the one that approached my room I didn't approach his room (A11).

Interestingly, one young person (C10) talked about how she never felt it was her fault because when her parents separated it was always instilled in the children that it was nothing to do with them. One woman explained why she didn't mind her adult children knowing about the sexual abuse experience she had when she was nine but did not want them to know about abuse by her mother's partner which occurred when she was twelve. She described feeling much more selfblame in relation to the latter experience. At a later stage in the interview she acknowledged that she had felt sexually aroused during this latter experience of abuse and this no doubt complicated matters for her in relation to feeling in some way to blame for what happened.

Some young people described how they blamed themselves following their disclosure, because of the consequences of their disclosure. For $\mathrm{C} 02$, there was significant fallout in her family. After she told, the alleged abuser hit her sister "that was my fault, well I thought it was my fault em then he went out and wrecked her car so I felt really, I felt afraid and guilty" (C02). Her sister had not met with the family since the disclosure and the family had had no contact with her children.

I don't know em there's a part of me says that I'm glad I told but there's another part of me says that I shouldn't have because I splitted up the family... if I hadn't a told nobody would have findin out woulda been only me sister (C02).

Although shame, embarrassment and self-blame are discussed in this section, these three themes were not necessarily interrelated for participants in this study. 


\section{Peer Influence}

It is clear from some of the quotes presented earlier that relationships played a key role in influencing young people's disclosures. We saw in an earlier section how relationships influenced young people's decision to withhold information as they did not want to upset others and how concern for other children helped them to tell. Similarly a few young people and two adults talked about how intimacy in their relationship with a boyfriend motivated them to share the secret and confide, "I had to tell him cos I felt bad not telling him like" (C20). Similarly, two adults described confiding in their partners "It might've been because I think I found that he was open minded and that he was you know talking about things in the open and so he brought me out of my shell a lot" (A02).

Of the 22 young people interviewed, 10 had first confided in a peer, be that friend, boyfriend or cousin before they had told an adult of the abuse. Often the context of the disclosure was that of a mutual sharing of difficulties.

I told my friends first we were talking about our problems em (boy) was talking about how he was feeling suicidal because ... And (girl) was telling us her problems. Like she has an eating disorder and em we were trying to help her with that and then like out of nowhere like I just felt like saying it. Cos it was like built up and all of a sudden I just said it I mean they were the first two I ever told and I confided in them (C08).

C10 also referred to a tendency to tell people things when you're older:

but when you're older you know and you tell people things. So it's easier when you're older like I tell me Mam everything I just. Ever since I would say anything to her like I didn't tell her about this but I would tell her everything else (C10).

For some, the motivation to tell an adult came from friends whom they had confided in. C09's boyfriend encouraged her to tell her parents and when she first disclosed to her father but did not give all the details, her boyfriend persisted in encouraging her to tell her father everything that had happened. Similarly, C13 referred to her friend "she just kept on nagging me ah eh she says C13 do tell tell your mam it's the right thing to do". As mentioned earlier, C07's friend was pointing out the risks to other children "what if he goes and does it again like why don't you? You just be the one to deal with it now". C14 referred to the benefit of having an older friend "cos she had a bit more cop on an...like she was able to tell me like this is a very bad situation and you know ... really serious" and encouraged her to tell her parents. She acknowledged that her friends were putting pressure on her not to babysit for the alleged abuser and to tell her parents. 
Similarly, C14 explained how increased pressure from her friends helped her to understand the necessity of telling about the abuse:

C: obviously I had all the friends an the more they told me and explained and you know told me how big a deal this was the more I kindof understood and just changed me whole view

$\mathrm{R}$ : mm I'm wondering did that help you or did that actually make things more complicated?

C: well I think it helped because the more you understand how bad it is and you know the whole situation of there's children involved and you know

$\mathrm{R}$ : right

$\mathrm{C}$ : and I think the easier it is for you to tell

R: ok

$\mathrm{C}$ : cos you're giving yourself more reason $(\mathrm{C} 14)$

Only one adult recalled telling a friend (other than a boyfriend). She was a teenager at the time and had been abused when she was aged between seven and nine years old.

I remember walking to school one morning ...I just said to her 'oh yeah my granddad used to touch me'. And she were like did he and that were it. Then we started talking about something else and that were that (A07).

For the most part, it was not an option for the adults in this study to confide in a friend. A02 said that she wouldn't have confided in friends as a child or teenager the way she would as an adult. "I wouldn't have discussed anything like that with my friends no not at that age at all it was just you didn't do it. You were afraid you were kept it to yourself" (A02).

\section{Fear}

Fear is a theme that recurs throughout the interviews in this study. Fears expressed by children and adults range from feeling afraid during the experience of abuse, feeling afraid of telling and being scared of the consequences of telling which related to both what was said to them as children and what they imagined themselves might happen if they told. Fears of consequences were many and varied. A fear that there would be no one to take care of them was expressed by one child. Three young people expressed the fear that the abuser would get into trouble and a further three feared that their father or relative would kill the abuser. Their concern was not for the alleged abuser but for their own father or relative. Three young people were afraid that they themselves would get into trouble and two young girls and a boy feared for their own safety. Two young people were afraid of what people might think, while two teenagers expressed the fear that their freedom would be curtailed if they told. Five young people feared that their disclosure would break up their family and one young person worried about how the family could survive financially if she told as the alleged abuser was her mother's partner. 
C09 described how she felt afraid at the time of the abuse. Her uncle came to her bed and fondled her and she described how although she wanted to push him away she didn't "I was so afraid of him like I couldn't believe that he's actually doing this to me" (C09). C07 and C08 described feeling fearful at the time of disclosing "it was one of the scariest things I've ever had like thought thought of ever saying" (C08). A09 was abused by her mother's partner while she slept with them in their bed. She recalled one occasion when her mother left the room during the night and she was abused.

R: and can you remember how you felt can you remember whether you wanted to tell her when she came back into the room?

A: no never. Always, I was dead scared (A09).

C08 also talked about being afraid that he might say it "as I got older ... I started getting scared of what I could say of what I might say. Cos there's been plenty of times over the years I coulda said it but I didn't'” (C08).

A few young people talked about feeling afraid and scared without being able to articulate what it was they were afraid of. C03 talked about feeling more afraid of what would happen if she told than of what was happening "this is bad but it's better knowing what's happening than knowing what's going to happen but then.. but then I was still scared" (C03). C11 talked about why children might find it difficult to tell: "they're probably afraid of telling it eh in front of their ma and da" (C11). Two young people talked about being afraid or scared of people knowing.

For the most part, people talked about feeling scared of what would happen if they told.

This fear of the consequences of telling was sometimes instilled by the alleged abuser and was related to what the abuser might do to them or to their family. Sometimes this was explicit in the form of threats where the alleged abuser threatened the young person that something bad would happen if they told. For instance, that the child would be killed if she or he told anyone, that he would do something to the child's father, or grandmother. Some of the alleged abusers were also reported as being physically abusive. C16 described an incident when "he actually smacked me mam's head off the counter". C20 said she was told he would kill her and she believed he would because "he boxed me up before". C10's stepfather was described at the assessment as being physically abusive towards her mother and siblings. C03 described the mother of the family she lived with as physically abusive to her - this woman's husband and son sexually abused her. C18 feared that the abuser's friends would attack her on the street if she told.

Sometimes the abuser played on the childish beliefs of children and the ease with which children can be terrorized into believing drastic consequences of telling a secret. $\mathrm{C} 03$ described how she kindof believed the threat that she would die if she told but she didn't really believe him "but that 
kind of childish fear of gonna die and all that" (C03) still prevented her from telling anyone. A09 was specifically told that she would get into trouble if she told.

For other young people it was left up to their imagination what would happen if they told "hurt me or kill me or something" (C12) or "this will sound crazy but I thought he would bring me over to (country) or something or he would kill me. Well, I didn't really think that but I did kinda like" (C10).

A09 was in an institution and visited home frequently. Looking back, she noted that if she had told the likelihood is, she wouldn't have been allowed visit home. Although she had no recollection of ever thinking this at the time it would certainly have been a powerful deterrent to her telling.

Young people also talked about their fear of what they or their family might do to the alleged perpetrator. $\mathrm{C} 08$ talked about his fear of his own anger towards the alleged abuser "every time he comes in the house I stay upstairs and like I barricade my door because I'm afraid I'll run down and punch him" (C08). C20 talked about her fear of how a male friend would react "he did say if he catches who it was he's gonna kill him .... and then he'll be the one getting locked up" (C20) and so although he knew she had been assaulted, she couldn't identify the perpetrator to him out of fear of his reactions.

Some young people, teenage girls in particular, had fears of how their father would react. C09 was worried that her father would go and kill the perpetrator and would then get in trouble with the police. She described how she begged him not to do anything. C14 was also concerned about what her father would do when he found out "I didn't want him to do anything irrational...I said to him please I want to deal with this the right way an he was like I never said I was gonna do anything. You know, I was jumping to conclusions" (C14). C18 was afraid her aunt "was going to go out and kill the fella or do something to him" (C18).

Fear of the formality of legal proceedings was also expressed by a few of the young people in this study. "I had an awful fear about standing up in court in front of him" (C09). C18 described being "terrified to give a statement... I was even terrified to get examined in the hospital" (C18).

Some young people were afraid that their disclosure would result in the family breaking up. While in some instances this was inevitable and indeed did happen, other young people's fears were unfounded yet powerful in preventing them from talking of the abuse. C08 had seen a video in school that showed people's reactions to being told of abuse, including families breaking up. He feared that his mother and father would separate if he told as it had been his father's nephew who had abused him. C10 was also concerned that her mother and her partner would separate but in this 
instance he was the perpetrator "I wanted them to split up but not because of me" (C10). For C05, this fear extended to the wider family, not wanting to split up the family 'an' lock your cousins' dad away" (C05). C04 anticipated what it would be like to tell "I'd feel bad coz he's get in loads of trouble an everything and then I was saying God like this is much easier not to say anything"(C04). Finally, the extent of the burden felt by young people in negotiating the dilemma of whether to tell or not and the possible consequences this may have for their family is reflected in the section above on concerns about upsetting others. C14 was acutely aware of the distress of her younger siblings who no longer had their father living with them, following her disclosure of abuse by him.

Fear of being judged by others was articulated as a reason why young people were reluctant to tell friends or others outside their family. Young people described their fear of being judged e.g. being called a "weirdo" or a "queer" or "she's disturbed", people thinking they were looking for attention, or that "I just I don't want to be pitied" but this was less significant as a reason for not disclosing within families. For some, this fear of being judged by others may have been a reflection of their own self-blame feelings in relation to the abuse. C09 talked about being afraid of what people might think which was clearly linked to her own self-blame abuse "like I lay there I let him do that to me". A11 was also reluctant to tell friends due to a fear of how people would see her "it's how people would see you then...cos back then you know things would have been so much harder to speak about you know to say it you know" (A11).

Children's fears, therefore take on many forms in terms of acting as inhibitors to telling about their experiences of abuse. Feeling frightened at the time of the abuse, feeling scared to tell, feeling afraid that people would get hurt or killed if they told, fear that they would get into trouble themselves, fear of how people would react, scared of having to deal with gardai and the courts, fear of the impact on family relationships and possible family breakup, and fear of being judged were the fears articulated by the respondents in this study. The range of fears described here reflects the range of possible reasons why children might be afraid to tell and the role that fear plays in the process of containing the secret of child sexual abuse. According to one young person "I didn't feel I was brave enough to say it" (C09). Having the courage to tell was mentioned by other young people: "if you have the guts to go and say it..." (C13). For some, the courage to disclose was associated with age. C14 talked about how difficult she found it to tell when she was 11 and felt that it would be much harder for younger children to tell "you have to have a lot of ball" (C14). According to A07, the person has to be strong if they are able for the aftermath of disclosure. Everyone would find out so this would make it harder to cope with.

Some young people feared negative consequences that didn't materialise, such as C08's concern that disclosing the abuse would break up the family. His family were very supportive when he disclosed. However, other children's fears of negative consequences for their families were not 
unfounded. For C14, who was also abused by her sister's husband, her sister left and returned to the C14's family home with her two children. This resulted in significant stress for both her and her children and for C14 and the family until she secured her own accommodation. C14's sister's attempts to maintain a relationship between her children and their father put a strain on her relationship with $\mathrm{C} 14$ who could not understand why these children should have any contact with this man.

you know sometimes the kids'd be crying that they'd want to see their Da and I'd say no I shouldn't have told you know why did I say anything (C14)

Contact with the Alleged Abuser

For some young people, increased contact, reduced contact or lack of contact with the alleged abuser facilitated their disclosure. Both $\mathrm{C} 10$ and $\mathrm{C} 19$ referred to feeling safe as a result of a lack of contact with the alleged abuser for some time before they told. C10 found that after her mother and the alleged abuser separated, she became more angry with the alleged abuser "I was like no he can't get away with it. I have to do something and he does think he's gotten away with it and that's not fair" (C10). C18 also described feeling angry with the alleged abuser and described how the fact that she was living with him exacerbated her feelings of anger, resulting in increased arguments. It was in the context of such an argument that she disclosed to her grandmother. C13 disclosed to her mother when told that her mother was intending to separate from the alleged abuser, her mother's partner:

and then I thought it gave me a bit of confidence so ... I said I think this is what I should say I think I should just go and tell me Mam what happened right now since she thinks she's since she's going to break up with him. And I told her (C13).

\section{Being Told not to Tell}

Many young people were told not to tell. On occasion, something the alleged abuser said during the experience of abuse may have acted as an inhibitor to telling, ranging from being told that it was a secret, to direct instructions not to tell anyone to talking about the experience as if it was not abusive. Several were told that it was to be a secret that it was "just a game" or simply told not to tell or "warned not to tell". Three young people described being told that if they told anyone, the alleged abuser would kill them. One young person was told that her granny would be hurt if she told. C22 was told to promise not to tell and "at the time when I was say I was saying well I didn't really want him to get into trouble at that stage I still cared about him". 
A08 recalled being told that she would get into trouble if she told. A09 was told that if she said anything "he'd put me and me ma out and we'd have nowhere to live". For some, the instruction not to tell was indirect. C10's mother recalled her daughter telling her about the abuse "she mentioned to me that one time he said to her if you tell I'll know I'll just know ... he had so much control he didn't even threaten her after that he just assumed". C14 told how the alleged abuser questioned her each time if she had told her friend about what had happened. Although she denied it, she had in fact told her each time about the abuse after it had happened.

\section{Alcohol as Facilitator}

C14 described how the combination of having had a few drinks at a friend's party, not being able to keep up the pretence anymore that everything was alright, and concern for the alleged abuser's children helped her tell, "people would kinda look at me saying are you for real like you coulda stopped all that" (if those children were subsequently abused) "so I kinda thought about that a lot and then I just decided to come home and tell them" (C14). This was two years after the abuse had occurred and a year after she had told her two friends. Two adults referred to disclosing their experience while under the influence of alcohol, in one case to friends and in the other to a sister 'I think what it sorta made it easier I was drunk when I said it you know I think that sorta made it easier" (A10) "we were having a few drinks and it came out" (A11).

The Role of the Media and Film

C01 described how memories of her childhood abuse were triggered while watching a film with her brother (who was the alleged abuser) about a child being abused. C04 was watching a programme on television about a father abusing his daughter and her mother's reaction to this film prompted C04 to confide in her mother "the programme was about this girl like she was, her father was abusing her, like sexually, and I just. Me ma was saying something like 'God if that ever happened to any of my kids' like she'd go mad and all and I just, I just told her" (C04). C10 referred to seeing various items about sexual experiences on television soap operas that she could identify with "And it kinda just made me think" (C10). C13 also referred to a programme 'true movies' where people discuss their experiences of abuse and going to court. She said that this programme helped her be able to talk about her own experiences, after she had first told. C14 referred to the online chat website "Bebo" where people shared stories of their own experience of abuse and advised others using the site, "don't hold it in". 
References to abuse in the media were not always experienced as helpful. Some young people referred to the negative impact of the media. C09 saw a video in school showing the negative consequences of disclosure in that a family split up as a result and he feared this would happen to his family. He subsequently saw a programme on television and described how he had to leave the room due to the psychological distress of wanting to tell his mother and yet not being able to. C21 went to the cinema and saw a "fifteen minutes advert on the big huge screen about abuse and it made me feel horrible...it was really in your face and I think that was a bit overboard now".

She felt that such adverts should be more subtle and suggested that there might be negative effects of such ads:

but say if you're a child and you see that and you're being abused but it's not as bad as that you're probably gonna start thinking 'God is that gonna happen me? am I gonna be left sitting on the floor fending for myself?'... (C21)

\section{Summary}

In summary, the key themes outlined in this chapter as motivating the process of containing the secret of sexual abuse were: Being Believed, Being Asked, Concern for others, Shame/Embarrassment/Self-Blame, Peer Influence, Fear, Contact with the Alleged Abuser, Being Told not to Tell, Alcohol as Facilitator and The Role of the Media. While some of these factors clearly motivated the young person to withhold information about the abuse and others clearly motivated them to tell, some factors acted as influencing both withholding and telling either simultaneously for the same young people, or operating in different ways for different young people.

The need to tell parents or adults may be an emotional build up within the young people, as evident in the pressure cooker effect presented in the previous chapter, because they feel bad withholding this information or it may result from a combination of internal pressure and pressure from without. Being Believed was identified as a complex theme presented here as an intrapersonal, interpersonal, familial and societal dynamic in the process of containing the secret. This was evident in terms of self doubts, expectations of being believed or not being believed and actual experiences of both being believed and not being believed. Parents' responses to disclosures also highlight how it is difficult for parents to believe what has happened to their child. A surprising number of young people in this study recalled being asked either directly (have you been abused?) or indirectly (what's wrong? Is there something wrong?). This was a significant factor in motivating young people to tell, as an immediate trigger for some or contributing to the process of disclosing for others. Concern for others in the form of not wanting to upset others, particularly mothers, was identified as a key motivating factor for young people actively withholding the secret 
of abuse in this study. A similar altruistic motive, concern for other children who may be at risk of abuse by the abuser prompted many to tell the secret.

Shame, embarrassment and self-blame were cited by most participants in this study as reasons for not wanting other people to know about the abuse and contributed to their not telling. It is clear from some of the adults' stories that these dynamics continue to operate for many years. The role of peer influence was also highlighted in this study. This can be in the context of intimate relationships where the relationship itself has presented a pressure in the form of boyfriends questioning why the girl feels uncomfortable with intimacy, or teenagers who have confided in friends being challenged about the need to tell others and the need to protect other children and being encouraged to tell. On occasion, children were told not to tell. Internal pressure to tell can build up even more with the removal of external pressure not to tell as seen in the case of a young girl who felt more pressurised to tell when the abuser had left the home, combined with feeling less under pressure not to tell. Thus, contact with the alleged abuser influenced a few young people in that increased contact contributed to the pressure cooker effect as outlined in the previous chapter while reduced contact for two young people helped them feel safe to disclose as this explicitly addressed fears about possible consequences of disclosing. Finally, as with contact with the alleged abuser, media coverage of child sexual abuse acted as both an inhibitor and a facilitator of disclosure for some young people. For some, media coverage was upsetting and unhelpful while for others it helped them be able to talk about their experiences. Some of the themes outlined above are re-visited in the next chapter where a developmental systemic perspective is taken in analysing the data in this study using Belsky's $(1980,1993)$ ecological conceptual framework. 


\section{CHAPTER 5: A DEVELOPMENTAL SYSTEMIC PERSPECTIVE}

This chapter examines the data in this study drawing on Belsky's $(1980,1993)$ conceptual framework of child maltreatment as discussed in Chapter 1. In his ecological analysis of the etiology of child abuse and neglect, he advocated for a recognition of the interrelatedness of the various systems within which the child's development is embedded to guide empirical enquiry. This chapter then examines individual factors such as age and gender of the child (ontogenic development), forces within the family and school (microsystem) and the community (exosystem) and culture (macrosystem) in terms of their influence on the process of containing the secret of child sexual abuse. Developmental issues were identified as a contributory factor to describing the differences in experiences of disclosure from the pilot phase of the study. Gender differences and the influence of schools were identified in the earlier stage of the study and the interview schedule was adapted to explore this issue with subsequent respondents. The influence of the wider community and culture, while not directly addressed through the interview schedule, emerged in the data as having a contributory influence in terms of how services, both civil and criminal, responded to a report of sexual abuse. This chapter presents the relevant data on these issues.

The Child: Age and Gender

Age

Age or developmental stage and the potential contributing influence of developmental factors to the issue of withholding and disclosing the secret were explored in this study. The issue of developmental differences in how people perceived the experience of wanting to or not wanting to disclose was first highlighted by an adult interviewed as part of the pilot phase of this study. This woman pointed out that she had different reasons for not telling at different stages in her life. A question was added to the interview schedule: does age make a difference? That is, do younger children find it easier to tell or is it easier for older children? In exploring developmental factors, some of the reasons for why these differences might be involve revisiting themes already highlighted in the previous two chapters, such as shame, embarrassment and self-blame, concern about the consequences of telling, concern for other children and confiding in friends. These themes are re-visited here with a particular focus on how these issues may affect young people differently at various stages of development. Firstly, however, developmental differences as perceived by the participants in this study are explored.

\section{Age at Time of Abuse and Disclosure}

Most young people thought that it is easier to tell when a child is older. As with many of the themes identified, understanding that the abuse was wrong was seen as both a facilitator and an 
inhibitor to telling. A small minority thought that age did not make any difference to difficulty in disclosing and one adult thought that children of all ages would find it easy to tell now compared to when she was a child, fifty years ago. According to some participants, the younger child has an advantage in that they might say it immediately without realising the seriousness of what they were saying. Perceptions of younger children as innocent, naïve and curious along with a tendency not to think or dwell on things were seen as facilitating factors in being able to tell. However, increased understanding was perceived as possibly helping older children to tell in terms of realising the seriousness of what happened, the need to tell someone and knowing that there would be consequences of telling. Nevertheless, the heightened self consciousness of teenage children was referred to as a potential inhibitor to telling.

\section{Knowledge as Both an Inhibitor and Facilitator to Telling}

Cognitive understanding of the abuse as 'wrong' was identified as a recurrent theme in interviews with participants. However, there were varying views about whether knowing it was wrong made it easier or more difficult to tell about. Some people felt that not understanding about abuse makes it easier for younger children to tell while this may also make it harder to communicate. Increased understanding may make it easier for older children to tell but this increased understanding is accompanied by an increased awareness of the potential consequences of telling and increased embarrassment about the experience which may then inhibit telling. This can therefore make it more difficult for teenagers to disclose experiences of sexual abuse.

Some young people talked about knowing that it was wrong but not really understanding the significance of this until they were older. Therefore, their limited knowledge about the sexual behaviour made it more difficult, in their opinion, to tell. C08 thought that his young age (6 or 7) and not knowing what was happening made it harder to say it "If I was older I would've known about it I would've known to say it straight away but I didn't at the time.... If I was 10 years old when it happened to me I woulda said it straight away". This teenage boy did come to understand that it was wrong when he was 'about 9' but did not tell anyone until he was fifteen.

Similarly, C14 felt that it would be harder for younger children to tell because they wouldn't understand what was happening or they would be just too afraid but on the other hand their naivete could make it easier for them to say it spontaneously without realising the seriousness of it. P10 referred to how younger children can be easily tricked into believing that the behaviour is 'no big deal' and therefore there is no need to tell anyone about it.

However, other participants thought that not knowing the abuse was wrong makes it easier for younger children to tell. $\mathrm{C} 07$ believed it was easier for younger children because "they wouldn't 
have a clue" or they would ask their parents out of curiosity. She suggested that if they hadn't told by the teenage years "they'd hold it in maybe all their lives" (C07).

Younger children might dwell on the experience less:

when I was younger it was easier to forget because I'd be out playing an like I wouldn't be thinking of it. When I was getting older when I had more time to myself dya know what I mean ....I was kinda thinking. (C04).

Some adults said that it is easier to tell when you have a limited understanding of what has happened (A06, A07) because of the embarrassment, shame and self-blame experienced as children approach adolescence. P31 was herself older when she disclosed her own abuse than the age her daughter was when she disclosed. P31 believes that her awareness of possible consequences inhibited her from telling while her 3 year old daughter was unaware of what would happen and this made it easier to tell. C20 thought that it is easier for small children to tell "cos like their ma's are so close to littler kids than they are to bigger kids like they'd know straight away if something was wrong with them", whereas "they reach teenage years then no hope'. When asked what age she started being a teenager, she replied "nine".

According to P16, father of $\mathrm{C} 16$, not knowing the repercussions of telling makes it easier for the younger child to tell. According to him, over the age of 10 or 12, children know that someone is going to get in trouble. C16's mother disagreed. Their younger daughter had not disclosed abuse by her brother despite corroborative evidence of abuse. She believed that it is easier to talk about these matters as one gets older. She herself only disclosed her own experience of abuse in adulthood.

C09 said that she didn't like what was happening but now that she's older she is clearer about it being wrong. This made it easier to tell. "I was nine then so yeah I knew then it wasn't ok well I always knew it wasn't ok but I was beginning to understand more then". According to C10, when it happened she didn't see it as a big deal but an increased understanding of what had happened made it easier to tell. However, C10 pointed out that it is also harder to tell when a child is younger.

I think as you get older you kinda start realising ....before I wouldn't have known like what he was doing to me... I knew I didn't want it to be done to me and I knew I was afraid....whereas now if he came over tried to do something I'd stop him like if I hadn't had past experience of it I know that I'd stop him now (C10).

According to $\mathrm{C} 11$, knowing more makes it more embarrassing. $\mathrm{C} 17$ referred to the embarrassment of having your parents know "you're having sex at such a young age". Parents in particular were conscious of the potential for young people to feel more embarrassed about their experiences of sexual abuse as they get older. P10 noted that it may be harder when the child is younger due to limited vocabulary and understanding but that the older child may find it harder due to embarrassment, shame and self-blame. P12 similarly referred to it being harder for older children 
"because when they hit 14, 15 they'd be embarrassed" and they begin to think of what they should have done to prevent it or to stop it from happening. According to P14, the embarrassment is also associated with body image and peer pressure.

An adult noted that as they get older, young people begin to question themselves: "why didn't I stop it? Why did I allow this to happen?" (A06). A09 had two abuse experiences, one at age nine by a workman that she told about and another at age eleven by her mother's partner that she didn't tell anyone about until adulthood. She described feeling too embarrassed about what happened when she was eleven whereas when she was nine, she didn't understand what was happening and had told in innocence soon after the event. C21 referred to the shame she felt as she got older. She felt frightened and disgusted and as she approached her teenage years, she began to question if it had been her fault.

The increased understanding of the meaning of abuse was accompanied by an increased realisation of the possible consequences of telling. Knowing there will be consequences makes the decision harder to make (A07). Fears of people's reactions such as anger or disbelief make it harder for older children to tell.

I think it's harder as you're older ...cos you know more you know more. Em you know that it is bad and it is wrong and that there would be consequences so you've got to make that decision haven't you? If you're older, I suppose you've got to be strong. If you're able for the aftermath and everything an so that's why it's harder. And everybody'd probably find out about it an you know (A07)

A09 had experienced police and medical intervention following her disclosure of abuse at age nine. She was very clear that this inhibited her from disclosing further abuse by her mother's partner at age eleven as she was then aware of what the possible consequences might be, including that she might be prevented from visiting home (as she was in care). She found it easier to tell in adulthood.

Teenagers in particular discussed the negative consequences of other people knowing. When children are older, they are more sensitive to what other people think and more fearful of being judged.

well when you get to the teenage years you're gonna be afraid of people finding out and what people are thinking of you .... and what people would be saying about you how they look at you like it just you get paranoid you really do. You think that people are looking at you (C07)

Similarly, C21 pointed out “especially teenagers because we're so self conscious about ourself it's unreal". Finally, C19 suggested that it is harder when you are older as "you're keeping it in for longer and the longer you keep it in the more you want to keep it in". 
Some participants noted that increased awareness may precipitate disclosure because of the emotional impact of keeping the secret. P51 believed that older children find it easier to tell because they get so upset that they probably can't cope anymore and this is what helps them tell. C12 also talked about the fact that "it's probably more stress on like a person like my age"

Even when no elaboration was offered as to why it is that being older makes it harder, the idea of knowing more in itself was the reason given by some "cos when you're getting older you know" (C11).

Increased cognitive ability also influences the role which threats play in keeping the silence. Some young people talked about understanding more as they got older that for instance, they might not be killed if they told.

I think if you're younger you wouldn't really be able to tell...I was seven when it happened and I didn't want to tell and em when I as I got older I told...I was eleven....because I see my brother said if you ever tell I'm going to kill you (C18)

C05's parents had differing views about the impact of age on facilitating or inhibiting disclosure. Her father thought that being a teenager when she told had made it harder to tell. Her mother disagreed. She thought that if her daughter had told at the time it happened "it wouldn't have been as dirty or as bad as it is being a teenager. She has issues around it now. She will always have issues ". Both parents interestingly felt that for them it would have been worse if their daughter had told when it had happened. Her mother said it would have been even more distressing for herself seeing the size of her at eight" and "one of us woulda been in prison" because of the way they think they would have reacted to the disclosure.

Many of the adults interviewed advocated that children from the age they can walk and talk should be educated about sexual abuse and told that they can tell a trusted adult if someone touches them in this way. A07 suggestd that age-appropriate materials could be used in educating children about abuse and P53 advocated for advertising targeted at times when children are watching television. This, they felt, would better equip children for the task of telling. A06 believed that younger children are more likely to tell in bits and pieces and that they rely on experienced adults to 'unscramble' the meaning of what they say. P15 also felt that it was harder for younger children to describe how they feel. Increased cognitive understanding of abuse was seen then as a factor which would both make it easier to tell and make it harder to tell. Understanding the seriousness for some young people would make it easier to tell.

In summary, the perspectives of the participants in this study, for the most part, were that children of different ages find it harder or easier to disclose for different reasons. A minority of individuals felt that age made no difference to the difficulty in telling. Most young people thought that it is 
easier to tell when you are older because of increased understanding. Increased understanding may involve a) a clearer sense of the behaviour as morally wrong; b) that the alleged abuser was responsible for the abuse; $c$ ) that there will be consequences of telling which may have serious implications for the young person and his or her family; and d) that other children may be at risk if they don't tell. Increased understanding as the child approaches teenage years can make it easier to tell but these years also bring a heightened sensitivity to discussing sexual matters and an increased self-consciousness. This, accompanied with the sense of embarrassment, shame and self-blame for the abuse, can make it harder for the teenager to tell. Conversely, the limited understanding of the younger child can make it more difficult to disclose but the lack of sensitivity to sexual issues and less self-consciousness may make it easier for the younger child.

\section{Gender}

While some people interviewed saw no difference between genders in terms of whether it was easier or harder to tell, when a difference was seen, it was always in favour of girls finding it easier to tell. People were very clear that the impact of the abuse was no less on girls than boys but they did perceive a difference in the difficulty of telling.

I think sometimes people think girls are more inclined to talk about things more inclined to talk about their feelings...Girls are more able to explain what happened to them fellas they more like shy away (C09)

cos girls can cry but whenever a boy cries everyone like don't cry if you're a boy you're not supposed to cry an all (C20)

It was seen by some as more embarrassing for a boy to disclose as it might be seen as a sign of weakness "yeah could a boy not stick up for himself dya know that kinda way" (C09)

There was a further difficulty which according to some compounded the issue and that was the gender of the abuser. According to $\mathrm{C} 09$, it might not be so hard for a boy to say that he was abused by a girl but if a boy was abused by a boy, this was much harder to tell.

Abuse might be seen as less credible by others if it was a boy "they would be more 'boys don't get raped' dya know what I mean" (C17), particularly if it was same-sex abuse: "would people believe me that a girl was after doing that to me like why would a girl want to do that to another girl like" (C09). One person noted that they themselves would not believe that a boy could be abused "I could not see a young fella being raped by a fella or a girl no way... like I never heard of a boy being raped no I don't know" (C18). 
According to A06, it is more difficult for boys to tell because it is more unusual for a boy to be abused and if the boy is abused by a man, the fact that it is someone of the same sex makes it more difficult.

Disclosure then was seen to be easier for girls than for boys. Partly because girls talk more, because boys think they can cope better on their own, because it may be more socially acceptable for a girl to be upset than a boy and as boys are more likely to experience same-sex abuse, disclosing abuse may make them more vulnerable to being stigmatised and bullied.

\section{The Family}

Family issues influenced the experience of containing the secret of sexual abuse for participants in this study in several respects. Firstly, family members were often the first person in whom the child confided. Even when young people confided firstly in friends, this was usually followed closely by confiding in a family member, usually a mother. The data supporting this is presented in Chapter 2. Secondly, whether the abuser was a member of the family or outside the family influenced whether the young person told and the delay in telling. Thirdly a large proportion of the parents of the young people in this study had themselves experienced sexual abuse in childhood. Finally, parents in this study expressed views about the importance of containing the secret as a protective measure for their children.

\section{Intrafamilial and Extrafamilial abuse}

In the sample of 29 children whose stories are represented in this study, 17 of these children experienced intrafamilial abuse and 14 experienced extrafamilial abuse (two children experienced both intrafamilial and extrafamilial abuse). Intrafamilial relationships included brother, father, sister's husband, mother's partner (where he was living in the family home), male carer (in a substitute parent role), cousin, uncle, and grandmother's partner. In the adult sample, eight of the ten adults interviewed reported being abused by a family member.

Three girls were abused by their mother's partner. In two of these families, the girl's mother had already separated from her partner. This was a contributory factor to the girl being able to disclose the abuse. In the third family, the breakup of the relationship directly resulted from the disclosure of sexual abuse although the initial disclosure to mother occurred in the context of the mother telling her children that she planned to separate from her partner. In the case of the two young people who were abused by their brother, in one case the brother was removed from the family home as a direct result of the disclosure. In the second case, the child was not living with the brother at the time of disclosure. Similarly, for the two girls abused by adult male carer figures - 
father and male carer, the girls disclosed when they were no longer living with the abuser. Contact with the abuser at the time of disclosure was identified as a theme for these seven young people. In the case of the two girls who were abused by their sister's husbands, one of these marriages broke down as a direct result of the disclosure while the other family remained intact but alienated from the remainder of the extended family. The fallout in the larger extended family was therefore significant.

C08 commented on how difficult it was to tell about his cousin - he delayed nine years - as the families were very close and he was afraid that his parents would separate if he told. Three young people commented that they might not be believed if it was someone in the family. Two of these young people had been abused by a family member. One young person who was abused by her brother and the abuse was discovered, said that if she had told, the abuser would have denied it and then she would have been called a liar. Another girl said it depended on the reputation that person had in the family. The person who abused her was held in high esteem and most of her family believed his denial when she disclosed. One young girl (C17) who was abused by someone outside the family pointed out that if someone within the family was the abuser, the child would be asking the family to choose between them and the abuser. C16 also did not want to get her brother into trouble "I really did love my brother" (C12). Similarly, A07 who was abused by her brother was afraid that he would be taken away if she told: "I know I hated him an all but I still like liked him an all" (A07). When the abuser was a sibling, this presented a challenge to the loyalties of the parents as well as the young person. $\mathrm{C} 17$ described the story of her friend who was raped by her brother:

and he still gets invited up to the house for Christmas while she's there. And she still has to bump into him walking on the road and dya know they completely ignore the fact that he did that like dya know what I mean? And it's terrible for her... dya know that's still her Mam's son (C17).

C21 described why it might be more difficult to disclose abuse by someone within the family: say you were raped walking along the street and you didn't know the person. I find it's easier to tell someone you trust about it but when someone you trust has done it to you your trust goes away so it starts making you question every other person you trust. So that's how it's so much harder to tell when it's someone you trust that has done it to you. That it makes you question everybody (C21).

Another woman who had already been raped by her uncle in her family home and had not told anyone, described being touched in her genital area by a dentist and told her mother immediately when she went home. She commented that it was easier to tell about someone outside the family.

From a parent's perspective, P14 described the burden on the child of disclosing given the impact it will have on the family unit "cos things will change". Her daughter was abused by her son-in-law. 
"You have the solidarity of the family when it's a stranger but when it's within the family it's very hard" (P14).

When abuse occurs within the family then the issue of disclosing the abuse presents challenges to both the young person and to the parents. Young people may fear not being believed, they may feel torn between loving the abuser and not liking what they are doing to them, they may be concerned about the consequences of telling and the impact on the family, fears which as already highlighted in the previous chapter are justified and realistic. Finally, young people's ability to trust others with the secret of the abuse may be compromised by having been abused by someone they trusted. An added challenge to parents is when one sibling abuses another, as was the case for one of the children in this study. Her parents described feeling torn between loving their son who had abused their daughter and loathing what he had done. This was particularly challenging for the mother in this family who had herself experienced abuse by her own brother when she was a child.

\section{Parental History of Abuse}

As outlined in Chapter 2, a high proportion of the young people interviewed in this study had parents who were also abused in childhood. If we include those children whose stories were represented by their parents, i.e. a total of 29 children's stories, ten of these children had parents who had been abused themselves, four children where both parents had experienced childhood abuse and an additional six children whose mothers had experienced childhood abuse. None of the abusers referred to in this parental history of abuse were the same perpetrator as that alleged in their son or daughter's case. In examining whether there was any discernible relationship between whether having a parental history of sexual abuse was related to any of the key themes highlighted in this study, no particular patterns emerge. For instance, the hypothesis of whether the young person was more likely to be asked directly if they had been abused by a parent who had themselves experienced abuse was tested by examining the data. While some of these parents did ask their children directly, this was sometimes prompted by others raising concerns such as teachers or siblings and sometimes prompted by their own observations that something was amiss with their child. Parents who had their own history of abuse were no more likely to ask their child directly if they had been abused than parents with no history of sexual abuse.

\section{The School}

Schools often played a role in the containment/disclosure process. C01 was attending a school counsellor and self-harming so was referred to a private counsellor. This counsellor asked C01 on many occasions if she had been abused and during the course of this counselling C01 disclosed to a family friend. P14 noted that her daughter had told a counsellor in school who encouraged her to 
tell her parents and this helped her daughter disclose to her parents. When one girl was sexually assaulted as a teenager, a teacher in school was the first person she told. She described how helpful it was to have a counsellor in secondary school "I probably wouldn't have done half talked about half the stuff' (C01). C06's school principal was told by her mother and she found this very helpful. Schools were not always informed about the young person's experience.

Teachers were perceived by some as someone who could be trusted. C08 referred to a primary school teacher that she thought of telling (when she was in secondary school) because she believed that she could say it to her and it wouldn't get back to her parents.

C03 was often kept home from school to do household work:

The teachers they tend to ask like 'what's wrong with you?'. I think one of them she probably thought I was being like mistreated just mistreated not that like not as bad as... she was actually nice to me. She used to send me to buy lunch for her and then when I'd come back she'd tell me to eat it (C03).

A07 reflected that there was one teacher in school who was a potential confidante:

There were a teacher in school who I liked em but I'd say if she'd have probably copped on a bit more and spent a bit more time I mighta might have told her I don't know (A07).

Stories about school were not all good. C09 described seeing a video in school:

I think I was around 8 or 9 cos we watched the video in school about it and that's when I found out it was kindof wrong. And I watched it and I watched cos it had reactions about what happened after people told and em it scared me it really did (C09)

A11 told a teacher in school that she was being beaten at home. The teacher rang her mother and she was beaten again "and I remember sitting in the classroom back in the building and no one ever said anything" (A11). She did, however, talk to a counsellor in secondary school about the physical abuse she experienced, but not about the sexual abuse. She described how she just went to see this counsellor occasionally "I woulda been clever enough not to go too much" (A11) in case the counsellor would have been suspicious that there was more to tell.

In a parent interview, the Stay Safe programme was mentioned. As discussed in Chapter 1, this abuse prevention programme was introduced to primary schools in Ireland by the Department of Education in 1991. A question about whether the young people had undertaken this programme and whether they found it helped them to tell was added to the interview schedule. Many of the young people in this study did not recognise the Stay Safe programme by name but did recognise it when it was described as helping with bullying. It was unclear, therefore, whether all of the young people had received this programme as part of their schooling. Five young people knew nothing about it, even with additional explanations about what the programme is about. Few saw any connection between the Stay Safe programme and their experience of sexual abuse or thought that 
it helped them in any way to disclose. Three young people associated it with bullying alone. One young person said that it did help her to disclose the physical abuse she experienced but not the sexual abuse. In general, responses indicated that there was little specific reference made to sexual abuse in the classroom but most thought that this would be helpful. A minority felt it would be unhelpful.

Some young people participated in the programme while the abuse was occurring. None disclosed the abuse at that time. C14 did the programme and found it helpful. She mentioned that she thought it would be easier for a child if the abuse was by someone outside the family and thought it would be helpful if the programme included information about intrafamilial abuse. Two sets of parents were critical of the Stay Safe programme in terms of the focus being on extrafamilial abuse when in their case, their children were abused by someone within the family - in both cases, a brother of one of the parents. An exasperated parent talking about overhearing young people talking on the street "all this stuff they're being taught in the schools it's not having any effect on them" (P05). C17 did not think it helped him tell. The young girl whose parents had not given permission for her to do the programme said that she did not do it until sixth class and she then realised that what happened was wrong. C12 did the programme after she had disclosed and thought it might have helped if she had been given this educational input earlier.

\section{What can Schools do to Help?}

Respondents were asked what schools could do to help young people in this situation. Two key themes emerged, that of raising awareness and the need for educating young people about abuse and that of having a designated person in primary schools to whom young people can go if they have concerns about sexual abuse.

A few young people suggested that having notices in schools about abuse could raise awareness of what to do and where to go if a person has been abused. "If they had like a notice up in the school like if that was the case when I first went to the school I probably woulda gone to it" (C09). This young girl was referring to secondary school.

C03 also commented on the role of teachers in noticing changes in children when something is going wrong in their lives. C13 felt that young people in schools should be made aware of the benefits of telling and shown examples of young people who did tell and how much better they feel that they did. C18 also felt that there should be education in schools on child abuse

C: that's one thing I can't understand that's one thing that they don't talk about in school is child abuse and things like that

R: really right do you think they should?

C: yeah you should never go off with strangers that you don't know and things like that I think now in my school there wasn't very much of that being said (C18). 
C20 suggested that an anti-abuse campaign would be a good idea, akin to the anti-bullying campaign she was aware of and that someone from an advocacy organisation for child abuse could come to the schools and give a talk on abuse.

A02 thought that it was important to educate children and make them more aware of abuse situations, teaching them to be more assertive, say no, tell somebody and report it straight away. A07 suggested that children could be read stories in school where she felt they would pay more attention. She acknowledged the difficulty that children might have in telling someone in a school given that they might feel they are betraying a family member if they are being abused within the family. However, she felt there was a lot of value in finding creative ways of communicating with younger children for example "if you've ever felt uncomfortable click on the orange sticker".

One boy's father believed there should be more advertising in schools about child abuse "If there was more advertising. I mean you go into the hospital and you see signs if something happens tell! Tell! but that's only in the hospital it should be out there in the schools" (P11). "I think primary schools that if there was something on even if there was one class a week right throughout their school years that that dealt with you know problems" (P13).

The second idea put forward was that a designated person be available in schools. Some felt this should be a counsellor. $\mathrm{C} 01$ believed that there should be counsellors or people in primary schools for children to talk to about such matters, not just in secondary schools. "Cos there's always one teacher in the school that you really can talk to" (C02).

P13 did not see any value in advertising campaigns "no a lot of people just pay no attention to advertisements that they see I think it's gotta be done through the Department of Education it's gonna have to be set in that way where schools have a specific counsellor" (P13). A03 felt that education should start early in the child's life and that there should be liaison teachers or support workers in primary schools so that children would have someone to talk to. According to one parent, each school should have direct access to a social worker so that if a teacher had concerns, the teacher could speak to the social worker and the social worker could approach the parents

they would have if that's their job and they have the authority to do something like that whereas school teachers don't they can only do so much within the classroom but legally they're not entitled to go into delve into people's personal lives......and I dunno I jus think if children know that there's a place that they can go within the school apart from a family or having to wait for things to happen that they would be more likely to take advantage of it even at a young age (P13)

Concerns were expressed about whether such intervention by teachers would be welcomed by children, would be helpful or would be considered appropriate by teachers. Both C07 and C10 did not like the idea of their school knowing and along with C19 did not think the schools could help in 
helping children disclose. C03 cautioned against teachers being too intrusive. She felt that schools were not the best place to discuss sexual abuse issues as this may draw unwanted attention to young people who have been abused. C07 was also of this view and while she did not like the idea of teachers knowing that she was abused, she thought that this might help some young people.

C10 did suggest that if a teacher was concerned about a child, they could mention it to the child's parent and that might help, as long as it wasn't the parent who was abusing the child. C12 also felt that the best way schools could help is by noticing that there might be something amiss with a child.

C17 thought that although children need to be educated at an early age it might be embarrassing for them to be taught this in school so perhaps it might be better taught at home "they should be told if a man touches you there there or there it's wrong dya know what I mean" (C17).

Two young people didn't think it would be a good idea to discuss the subject in school because then people might be suspicious that someone in the school is being abused "and those people are gonna feel weakened and then it's gonna look obvious and they'll probably get bullied" (C20).

Some participants felt it wasn't up to the school to intervene. According to $\mathrm{C} 03$ "but the thing about it that the teachers don't want to meddle because there's no social worker there's no like your child is your child whatever happens that's your child so it's kind of not really no one's business" One parent noted how a child in the school was having problems but the teacher did not see it as her role to speak to the parents about it. While she felt that teachers are the best people to notice that something is wrong in a child's life, she pointed out that they don't have the responsibility or authority to deal directly with the parents on this issue.

For some young people, school teachers played a pivotal role in assisting children with disclosing their experiences of sexual abuse. For a few young people, a teacher was their first confidante and others considered telling a teacher. For this sample of young people, the child abuse prevention programme, Stay Safe had little impact on facilitating disclosure. Nevertheless the majority of respondents considered that education and awareness raising was necessary in primary schools to help children disclose abuse. Two key interventions were suggested. Firstly, the introduction of educational programmes (this parent was unaware of the Stay Safe programme) teaching children what to do if they have been abused and secondly, the availability of a designated person in a school or associated with a school to whom children can go and talk to if they have concerns about sexual abuse. For some children, the idea of schools having a role in intervention was not considered helpful but intrusive and embarrassing and possibly contributing to leaving the child vulnerable to bullying. The varying views on this subject highlight the need to recognise the 
individual needs of children and the diversity of interventions that might be needed to address how schools could help children in disclosing sexual abuse experiences.

\section{The Legal System}

Although the experience of civil authority intervention was not the focus of this study, many of the respondents discussed those experiences and these are presented here in terms of the potential impact this may have on children disclosing experiences of sexual abuse. Some respondents mentioned that they were reluctant to disclose because they were afraid that the gardai would become involved. $\mathrm{C} 07$ cited this as a reason for not telling. She was afraid that pressure would be put on her to go to the gardai "and I just didn't want that" (C07). She finally disclosed to her mother a year after the alleged assault. At this stage she thought she would not have to go to the gardai.

Like there'd be absolutely no proof then so what would be the point?...but then that wasn't true cos I had to go to the guards anyway so it didn't make a difference... so it's hard enough living in the same area as him than living in the same area as him and having gone to the gards $(\mathrm{C} 07)$.

One teenage girl was unhappy about having to make a garda statement,

I didn't want to and it annoys me cos I didn't have a choice in the matter that annoys me $\mathrm{R}$ : $\mathrm{mm}$ what do you think should have happened?

C: well I wanted to just talk about it an deal with be able to kinda get over it I didn't want it to go anywhere I just wanted to be able to deal with it (C07)

Similarly, C13 did not want legal involvement.

I didn't want to tell ... when they said that I could go to court with it but he'd be put in jail I did not want that... it was my own decision I had I could or I couldn't and I just felt like I couldn't because I didn't want the feeling that I put him in jail like that's just a terrible feeling for me (C13).

When A08 disclosed at the age of six, "all hell kinda broke loose the police were called eh police car came down and took us away". When she was abused again at the age of eleven, she did not tell anyone. She felt that her previous experience acted as a deterrent for her telling again "getting into trouble because I thought the police and the shame you know bringing all that on the family you know having to go to the police was a terrible thing you know" (A08).

For many of the young people interviewed, contacting the police was a natural consequence of telling. In most cases, where abuse was disclosed in childhood, the police were contacted without delay. Some parents made direct contact with the gardai before contacting child protection agencies and some contact with the gardai was as a result of notification by child protection services. When C13 told her mother, she telephoned the police and they came to the house that evening and spoke directly with the young person. They then confronted her mother's partner outside the house and 
asked him not to go back into the house. She went to court the next morning to seek a barring order and obtained a protection order. Most of the young people interviewed had been brought to the garda station to make their statement. C15's mother described this as traumatizing for her six year old son. She described how her son was asking her why he was being brought to the police station, because they had no proper people to deal with it. He was brought into a smelly like room interview room that a person that's be getting arrested would be interviewed you know with table and chair nailed to the ground like ... you know you tell a child like that it's not their fault things like that still they're brought to the police station cos he kept saying why do I have to go to the police station? you know (P15).

C08's mother also queried why children should be brought to a garda station to make the complaint "they wanted me to bring him down to the police station I said but the child done nothing wrong I said I don't think it's fair that you have to go to the police station" (P08). Some young people had mixed feelings about garda involvement. According to C04,

Oh god is it worth all this? ... didn't really want the police brought in an everything but like if it was one of my kids like dya know the way I woulda done the same...I didn't mind at all but then I was thinking God I shoulda kept my mouth shut you know that part all the police and all the trouble (C04).

C06 found the police investigation both scarey and a nuisance : "I didn't really mind but like speaking to the gards about it is a bit scary cos and being in the garda station an all" (C06). The gardai had asked her mother to make a note of the details of the allegation so her mother was asking her repeatedly about dates and times and she just wanted to forget about it. C10 initially did not want to make a formal complaint but found it easier than she expected

well I spoke to (garda) ... and she said it would take ages like hours and you'd have to remember every little detail like what time it was and everything and I didn't want to do it but then we had a chat and I'm going to do it.

R: and how do you feel about that?

C: I think it won't be so bad because I've already said it in (assessment) like if I hadn't gone there it would be really hard but I hope because I've done it there I'll be able to do it again like without any explosion. If you had asked me about all this a few months ago there would've been just an explosion. I would be so upset but I'm better able now. I didn't tell all of it like get it all out until like 2 months ago in (assessment)...it was actually easier saying it to the garda's face with my Mom beside me because like I didn't have to say I didn't have to come up with everything myself. The garda knew what kind of questions to ask me and I was able to answer without you know. She was able to explain to my Mom and stuff $(\mathrm{C} 10)$.

Experiences of dealing with gardai as individuals was mostly positive and people found the police helpful in their investigation, " the guard was very good. She called out, she kept in touch an everything else" (P54). However, one young person was critical of gardai in general: "I found it very hard to go to the guards actually. Cos you know guards are rats sometimes and they can muck about everything so em that's why I don't like going to the guards cos they can be a bit like they can be rats sometimes" (C18). 
The legal process was experienced by most of the young people as a lengthy process. Of the 29 children's stories represented here, reflecting 31 abuse experiences, 19 formal complaints were being processed. The time period between these young people being seen for assessment, to the time of the research interview ranged from a few months to a few years. Yet of the 19 formal complaints, 2 had a known outcome. In one case, the Director of Public Prosecutions was not pursuing a prosecution and in the other, the abuser was found guilty. Some comments about the legal system are enlightening.

like when I heard about the DPP saying like that it wasn't going to go ahead an everything I couldn't believe like I felt like everything was a waste. Like not telling like I was glad I told but just em going down the police station giving me statement going down to (Unit) an' giving me statement. Everything seemed to be dragged out so much for nothing d'you know that kinda way. That's just the way I felt then. Now, aw well, it had to be done (C09).

This young person also felt that because the case wasn't pursued, she wasn't believed. C14 referred to the length of time the process had taken,

we made the complaint to the police and then eh you know we didn't hear anything for a long time and then last I think it was about two weeks ago we got a phonecall and eh there's two sergeants at the door ... so I just met them then they were lovely and they told me that there's a court date .. so it's going it's going to trial and obviously I'm a bit nervous about that but I'm delighted as well because obviously they feel that the evidence is good enough you know to put him away for as long as they can like so I'm happy with that $(\mathrm{C} 14)$.

C18 had been waiting a long time for a trial,

I was waiting for two years for the court case and the any time of the day it would come up and then it'd be put back down again for another date and whole lot it was too much three times it happened me. So I was saying 'look I'm giving up I don't want to even go to court' dya know what I mean? to face him and to look at him any every day (C18).

When the date finally came, she did not attend court. C20 was still waiting for the gardai to get back to him "that's what me Ma was saying it could take years. An I was like but I'm trying to get over it how can I get over it if they're gonna keep bringing it back up?” (C20). According to C21, the alleged abuser was supposed to have been arrested four months previous

still nothing has happened...dragging out...there was so many people to go through ... so I think that's why it's taken so long the garda that was actually on my statement got sick for a while too and then we got a phonecall and we're told yeah he should be brought into the garda station ... nothing's been said since (C21).

According to $\mathrm{C} 22$, the alleged abuser was let out although the reasons for this were unclear.

$\mathrm{R}$ : the people that are on the case aren't working?

C: yeah weren't working on the day that he was brought in so he was let back off let back out I think it was only a day or something he was in for and then he was let away (C22). 
C54's parents were awaiting feedback as to whether a prosecution would proceed. They were expecting to hear news a few months before the research interview "but there's a backlog in the DPP's office, the usual" (P54).

In summary, although only two of the sexual abuse experiences of adults in this study were reported to the police, the majority of children's experiences constituted formal complaints leading to a criminal investigation. Thus, the criminal nature of these offences was clearly recognized by both the parents and the young people in this study. However, delays in the legal process were clearly evident from the comments of some of the young people and parents in the study. Only two young people had an outcome to report: one where the DPP had decided not to prosecute and one where the abuser was found guilty but was released from jail on a legal technicality during the course of the research study. Two young people were making arrangements to make a formal complaint and the remaining families were either in the midst of preparing the garda file for the DPP or waiting for feedback from the DPP's office as to whether a prosecution would proceed.

There was some evidence that a negative perception of the criminal process inhibited young people from disclosing sexual abuse. Two young people specifically referred to not wanting to tell anyone as they did not wish the police to be involved. Others spoke of the idea of going to court as a frightening prospect. Several parents questioned the practice of expecting children and young people to go to a garda station to make their statements, particularly given the possibility that young people might interpret this as them having done something wrong. One parent also commented on the unsuitability of the facilities and inadequate training of the gardai for taking such statements. The legal process was perceived by some parents as a long drawn out process that may not be in the best interests of their children. Two young people referred to wanting to forget about the experience and move on with their lives, and questioned how they could do this given the lengthy legal process.

\section{Experiences of Professionals and Services}

Although adult participants in this study were not directly asked about their experiences of the services they came into contact with in responding to their children's disclosures of sexual abuse, many offered some insight into some of the weaknesses of the child protection system. The inadequacies of the system may in themselves act as a deterrent to families seeking help. Some young people experienced some regret in telling due to the process of engaging with garda and child protection services.

I was frightened I was cos I didn't expect it to turn out like that. Cos I thought if I told my Mam it would be all over and done with. But there's more to it than just telling. Cos you have to go through the police to put it on his file and then go to (Unit) to get it out. Then go 
counselling if you're really upset just to make your life a bit better it's a lot of wo it's a lot it is (C13).

If I could go back because there was so much hassle caused over it I wouldn't (tell). I'd deal with it myself when I was older with just without everyone else. Cos at the age I came out with it I had no control over it. It was just everyone took control and I I couldn't deal with it the way I needed to deal with it. It was I was told to deal with it a certain way and that I found the hardest part really...I needed to do it my own way and I didn't get that freedom $(\mathrm{C} 01)$

C07's mother described how both she and her daughter were unhappy with how her daughter's counsellor dealt with reporting the matter to the civil authorities. "they weren't clear with her or with me either from the very beginning as to what the process would be and they kindof pushed us and pushed us like to make decisions like with regard to going to the gardai. While the outcome was great, in the long term it was pushed a little bit too much" . C07 had been told about the limits of confidentiality but did not realise it related to her experience. According to the file report:

After four weeks of discussing it with therapist, she was told it would have to be reported. She was very annoyed at this and 'felt betrayed by her therapist'. She dropped out of counselling and requested a different counsellor (R06).

C13's mother was unhappy at a male social worker taking her 12 year old daughter in to talk to her on her own. "and he kept taking her inside on his own and she says look I'd still rather you were there and I'd said it to him but he was still seeing her by himself". According to C13's mother this was very embarrassing for her daughter. She requested a female social worker but this was refused. She also commented on the waiting list being very long (months) for the assessment. She also described the social worker as implying that she was "sticking up for (alleged abuser) that's the way he was more important than my kids". She described a long drawn out process where she looked for help but wasn't given what she needed. "no one will talk to me when I'm on my goddamned own you know and when I make phonecalls why don't you's return them there and then? Because like I can't talk when (alleged abuser)'s there in the house and he makes sure he's here you know". She was frightened of her partner. At one point, according to C13's mother, she was given an ultimatum by the social worker that she either confront the alleged abuser with her daughter's disclosure and ask him to leave the family home "either tell him to-day or I'll be up tomorrow with the guards and you'll either lose the kids or whatever". She told the alleged abuser and constantly tried ringing the social worker but it was during a holiday period and it was 2 months before they returned her calls "he destroyed my fucking life he really did", referring to the social worker.

P16 was also unhappy with how the social services dealt with the revelation that her son was abusing her daughter. While her daughters were given counselling, no help was offered to her son. "you know your child is going for counselling telling stuff and then they're being brought back to the same environment again". After some time, the file was closed "and then when this happened 
then to C16 it was like an explosion and they were like they panicked". C16's parents were unhappy with one of the professionals who assessed his daughter

F: it's supposed to be an assessment to help you you feel worse

M: when I was walking out the door em I think it was (professional) had said to me you might need counselling after this. And I say that's terrible you know. You're being pulled apart and you're let walk away like that you know. Cos you know it's not for your kids either that their parents have to come home feeling that way. And we're lucky that I mean I suppose the kids are lucky you know that we really really care about them there's some parents out there. I mean my mother would kill me if I had put her through that (P16)

According to C16's mother, "if a child tells that it's great if the service is out there" but she felt the services were inadequate to deal with the issue of sexual abuse both for the child and for the alleged abuser.

C54's parents were also very unhappy with how the system dealt with their son's needs. They first reported it to the gardai but were later informed that because he had made a full statement to the gardai, he didn't need any help. The correspondence was drawn out over several months while the family tried to access a service for their son but they were being passed between two services. "it really was a disgrace" (mother) and "each blaming each other for 6 months" (father). P54 described the response of the services as 'atrocious' "she didn't want to listen to any explanation she didn't want to even meet she wouldn't agree to meet she wouldn't write out a letter she wouldn't answer a phonecall". When they finally managed to get a service, they were very happy with it.

When asked what they would recommend, based on their experience, they suggested firstly that the assessment service should stop being a nine-to-five service:

F: 9 to 5 Monday to Friday that's a joke

M: Mm cos it doesn't happen between 9 to 5

F: em that has to be available 24 hours a day that a child's makes a complaint and you call the gardai and you can go either immediately or within a day or two to to make a statement.

M: it's just not good enough for a child...six months of we didn't know if we were doing right or wrong were we to talk about it were we to keep quiet

...

the one thing we want is for it not to happen to another child and family like they shouldn't have to go through what we went through like you're in a bad enough state when it happens but then to have to start fighting to get what is right for your child (P54)

A06 had difficulty finding where to get help when her daughter disclosed to her that she had been abused. She rang the voluntary agencies - the Samaritans, and the ISPCC - and discovered the obligation to report child abuse. She did not wish to make a formal report "I just want you to tell me how to cope with it". She then went to visit her family doctor and confided in her. The doctor contacted the child protection services and a social worker came to visit her. However, she was 
very unhappy that the social worker was a man "I said you have to be a woman why didn't they send a woman". He told her things would get worse "well the one thing I have to say to you is that you're not going to like he said but I have to tell you I have to be honest with you he said this will only get worse". According to A06 "It couldn't be any worse than this. This is the worst thing ever happened in my life". However, she now says that she regrets reporting it.

A08 first looked for help about fifteen years ago. "I didn't really get the help I needed and I just got tablets and more tablets". A11 described the first time she went for help. She saw a psychiatrist

he said 'the animal kingdom' like them days, 'everything everyone brothers sisters' all this and he made me feel so small walking out there I'll never forget it $\mathrm{R}$ : what did he mean?

A: .. it's like accepting things you know and this does happen in life and this does happen in families it's the animal kingdom you know more than likely it was like em well you obviously consented to it I'll never forget it I came home screaming and crying to (husband) I'll never forget it. (A11)

Finally, some respondents reflected on the attitude in society towards sexual abuse and how this might influence young people's feelings about disclosing their experiences. Two young people made reference to a legal situation operating in Ireland at the time of the study. A legal challenge had been brought to the Supreme Court as a result of which a number of convicted sex offenders were released from prison on a technicality. One of these offenders had been found guilty of raping a young person in the study. She didn't understand why he had been released, just that "all the fellas that was in for rape got out, all them did" (C18). C17 described hearing the debate on the radio "I swear to God my blood was boiling and then when I heard about that some fella might be let out today who had sex with a six year old of, what was it? four girls between six and ten?". Parents also described their own frustration towards a system that seems not to care.

F: I don't think society realises

M: the only people that cares is the people that's been abused (P08).

A father found his own attitude changing towards people who are gay because his son was abused by a gay man:

F: I wouldn't trust any of them em you can't say $100 \%$

M: they're not all that way

F: they're not (pause) I think it definitely influenced it it's a thing I never would have thought thought it before

well I mean even looking at people in Europe people who are gay over here there's a certain age limit the same in the UK you go to Holland and look at have sex with children 1314 now is that paedophilia? is it paedophilia in one country and not another?(P54).

The fact that a disclosure of child abuse cannot be kept confidential, according to A11, "turns people off telling". C01 didn't want anyone told when she confided in a family friend.

and social services said no you have to tell the parents you know if you don't we will. So they told my Dad so then it just kinda got taken out of my hand completely...That was the worst part coz it just felt like I was being abused all over again (C01). 
She was very critical of what she saw as the rigid adherence to protocol in dealing with disclosures of child sexual abuse.

I think one of the difficulties with the system is that even though people try to have flexibility within it there is a standard way of doing things regardless of the circumstances in a way ... For me it made some stick because I had to withhold a lot of information ...I wanted to sit down and talk it over with someone and know that this was me saying without it going to someone else you know (C01).

She argued that putting pressure on children to tell before they are ready militates against a successful prosecution “you can't force the child to do it straight away the counselling needs to be done first. You can't, it's like they won't give you everything you need to get the person unless they are emotionally ready" (C01).

C10 engaged in a conversation about whether one should keep a confidence if a child really wanted it kept confidential.

Em I think that maybe I think that if they say it to them and they say don't say it to anybody else that that that person should keep it just even say for a few days and then ask them again and say 'is that still happening?' And if they say yes say then maybe explain to them that you know I have to do something about it that's like what I have to do and you have to trust me and that...but I don't think they should go and say it as soon as they say it (C10).

C14 also debated this issue. She had told two friends prior to disclosing to an adult. They kept her confidence while encouraging her to tell her parents and the abuse continued.

R: right I'm just wondering I'm just kinda curious what if they had told?

$\mathrm{C}$ : well to me if they had told it woulda been devastating because in my mind they had no right to even though I confided them it's still kinda none of their business $\ldots$

R: so you think it's good that they kept it secret

C: I do yeah

R: and if you hadn't told at all and it had continued I'm just curious you know trying to follow this through if you never told anybody and it continued do you still think it would be good that don't that they keep the secret?

C: no (pause) no

R: no tell me what what do you think? What do you think?

C: em I dunno I think they would kind of have a little bit of responsibility

R: yeah it's really difficult isn't it?

$\mathrm{C}$ : but at the same time I'd never want them to kinda say anything because if I was in a reverse role and I was someone they told all I'd do is encourage them as much as I can (C14).

C07's disclosure, according to her assessment report was prompted by her counsellor who told her it would have to be reported. According to the report, $\mathrm{C} 07$ was very annoyed at this and "felt betrayed by her therapist" (R07). She dropped out of counselling but confided in her mother with the help of a friend. C17 described how two of her friends went to her parents and told them she 
was using drugs "so they I think in their own way they did were trying to tell they didn't know even at that time but they knew something"(C17). She appreciated this intervention of her friends.

\section{Change over Time}

Although it was not possible to take a lifespan perspective through theoretical sampling of different age cohorts in this study, the theme of change over time emerged, in particular, from the adult interviews. This theme reflects perceptions people held about things being different now from when they were children, and a change in their own perceptions as they got older. Adults in this study referred to how things were different now, compared to when they were children and also how awareness of sexual abuse has changed. A02 compared how she was at her daughter's age to her daughter now, describing her daughter as more mature and open minded about everything than what she herself had been "you know it was a very taboo subject". With regard to the word 'sex', "there was never a mention of the word we didn't know what the word meant".

A02 thought that people nowadays are more likely to believe children when they say they have been abused "Whereas if you did it years ago oh yeah so and so was saying that somebody molested her and she's probably making it up" (A02).

A03 thought that people were now more aware of abuse "it's different people are more aware but it's more common I'm not saying there's more happening now but it's all the time", referring to media discussion on the subject. Similarly, one adult woman referred to children being more aware nowadays compared to when she was a child: "children of my age at that time we didn't know we didn't know that it it shouldn't happen or you know that it was bad" (A06). C15's mother similarly felt children are more aware to-day:

M: I definitely do believe six year olds are more aware .. because parents are more aware of what goes on now and it's going on. It's very frequent thing. Years ago you wouldn't hear about it and it wouldn't even be mentioned in the household whereas this day and age you have to mention it you know and they do like safe pass in school .. they get talked about bullying and stuff like that

R: stay safe programme

M: yeah and then they go onto like eh you know talking about people approaching you and stuff like that and maybe touching you inappropriately (P15).

A06 referred to the lack of education when she was young and also the lack of awareness on the part of parents as to what to do if your child does disclose such an experience.

you know in those times there was nothing in school or there was no there was nobody warning you about anything like that you know whereas now like I woulda reared the children you know all the time saying your body is very private and you know only you bla bla but that for me like the way Mammy handled it God love her you know she didn't know what to do I suppose she did her best in everything she did but that was that was a bomber (A06). 
Two parents described how fortunate children are to-day that their parents will put their needs first. One of these women was abused as a child and her mother did not believe her when she disclosed as an adult. Her daughter was also abused.

the kids are lucky you know that we really really care about them there's some parents out there I mean my mother would kill me if I had put her through that (P16).

However A06 did not think that awareness would stop abuse: "it's happening every day it's not going to stop you know and it's not going to stop now just because children are more aware you know". A08 described her sister knowing that the police car came to the house after her disclosure when she was a child but she wasn't sure if her sister was ever told why, "and you don't ask questions not like children nowadays". In all, children nowadays were seen in a positive light, with more self-confidence:

I look at young girls now to-day and they're going with their heads up and they're so confident that's, I love to see that

me Ma always used to get the impression that em em you know that eh we were getting on alright and I I never showed em ike the way the kids would show to-day I was a very quiet person in meself you know (A09)

I admire the women today of no secrets you hear that no secrets ...no way is it swept under the carpet now and I do say fair play to them you know... do you know what I do think you know the way they were talking about em the young girls the way they dress ...they're half dressed and yet they look lovely I do say God they look lovely especially when nice and slim they look the real they imitate what they see on the television but God help them they're putting theirselves in danger you know what I mean but I mean why should they kinda too cover theirselves up because it still happened us and we were walking around in rags (A08).

A08 also had a perception that the way children are abused now is different to the way it was before "you see the way they're doing it now being em all so sneaky you know what I mean whereas years ago you'd be walking up the stairs and a man would put his hands up your your clothes". She referred to the tolerance there was for inappropriate sexual behaviour in the past.

A10 did not agree. He believed there is still a taboo:

even at this day and age it is there is a certain taboo about it ... I mean you can see people's attitude when you do start talking about it ...I mean if you see any sexual offender on the telly or anything like that you walk you scumbag or you call them all the names under the sun and it's it's eh it's I feel sorry for people.

Some felt there was more tolerance for this kind of behaviour in the past "in them days like Jesus people really got away with murder didn't they really when you think of it" (A11), while a parent had the impression that sexual abuse is more prevalent to-day "you have all these paedophiles now but what has happened to society what has happened to make people so sick?” (P08). 


\section{Summary}

This chapter outlined the potential influence of factors pertaining to the individual child, the family, the school and the wider child protection and legal systems which all contribute to the process of containing the secret of child sexual abuse. Individual factors discussed included the age or developmental stage of the child and gender differences noted in the study as well as historical or generational differences described by adults in this study. People have different reasons for withholding information or confiding their experiences of abuse at various developmental stages across the lifespan. Children of different ages find it harder or easier to disclose for different reasons but those reasons can be understood in the context of the cognitive, emotional, social and moral development of the child, adolescent and adult. Gender was understood by most of the participants to be an influencing factor insofar as it was perceived to be more difficult for boys to disclose sexual abuse than for girls. This difficulty was associated with people's views that girls have better expressive communicate abilities, it would be more embarrassing for boys to disclose, and people might be less inclined to believe that a boy can be abused. In addition, the experience of same-sex abuse in boys might leave a boy more vulnerable to teasing by others.

The child's experience of containing the secret is also seen to be influenced by the wider systems within which the individual's development is embedded. The role of the family, the school and the wider child protection and legal systems are examined. Intra-familial abuse was seen to be more difficult to disclose for a child than extra-familial abuse due for the most part to the consequences of disclosure and the perceptions of responsibility not necessarily for the abuse but for the disclosure itself. The role of schools was identified as important for some and suggestions as to how schools could raise awareness through advertising campaigns and having a designated person in a school who could be available to children to discuss such concerns was highlighted by both young people and adults in this study. The families' experiences of professional services, including child protection services was also presented and suggestions offered as to how these services might be improved. The potential influence of the experiences of the police, the court system and the legal process are outlined. Finally, the adults in this study, i.e. parents and adults who were abused as children, referred to changes over time in two respects. Firstly, that children to-day compared to when these adults were children, are seen to be more assertive and better able to disclose and secondly, that society is more aware of abuse to-day and therefore more open to children's disclosures. Overall, the impression was that things are better now than in the days of these adults' childhoods. 


\section{CHAPTER 6: DISCUSSION \& CONCLUSION}

This study set out to explore children's experiences of telling someone that they had been abused. The focus was on the experience of telling with a view to developing a theoretical framework of how children disclose sexual abuse. What became clear as the analysis progressed was that the disclosure of sexual abuse is but a stage in the process of containing the secret of sexual abuse. Much emotional energy is channelled into keeping the secret, even when it has been disclosed. The findings of the study, therefore, suggest a conceptual framework for understanding how children contain the secret of abuse.

The process of containing the secret of child sexual abuse, it is suggested, consists of three key dynamics: active withholding, pressure cooker effect, and confiding the secret. Most of the young people in this study actively withheld the information about their experience for a period of time prior to disclosure. Active withholding is reflected in five sub-themes: disclosure as a process sometimes occurring in incremental steps or over a period of time, too hard to say it reflecting how difficult it is to communicate the experience of abuse, not wanting people to know, denial that the abuse occurred, and how few people know about the abuse at the time of the research study. Disclosure often occurred over time consisting of verbal and non-verbal attempts to communicate distress. For the most part, young people did not want people to know what happened and when asked, sometimes denied it. Even following disclosure, for those who disclosed immediately and for those who delayed in disclosing, information about their experiences was kept confidential within a small group of people, close friends, family or professionals.

Children both want to tell of their experiences of abuse and do not want to tell. Disclosure by young people in this study was often preceded by a pressure cooker effect whereby motivating factors to share the secret competed with an increasing wish to tell someone of the abuse. The evidence for this pressure cooker effect is seen in the dilemma, to tell or not to tell?, the unplanned nature of disclosure, the signs of psychological distress of the child and the belief that if they had not told then, they would not have told either at all or for a long time. Disclosures were triggered by a variety of events, circumstances, or emotions that often represented for the child or adolescent 'the last straw'. The actual telling experience, conceptualised here as confiding, results from a hiatus reached by the young person whereby they can no longer, for a variety of reasons, contain the secret at an intrapersonal level. It is suggested that the term "confiding" better represents the experience of telling as "disclosure" implies an opening out of information without acknowledging the need for ongoing containment. Confiding also reflects the choice of confidante and the context of confiding, often one of mutual sharing in intimate or peer relationships, within which the secret is confided. It also captures the confidentiality both sought and offered in response to confiding. 
All three dynamics - active withholding, pressure cooker effect and confiding - underscore the involvement of the child as an active agent in this process, actively withholding the secret, struggling with the pressure to tell or not to tell and actively taking the brave step to confide.

The findings of this study also suggest that the process of containing the secret has distinctive characteristics. Firstly, the findings suggest that the process is an adaptive one for the individual. While certain dynamics within the process may become maladaptive over time, the need for containment is an adaptive way of coping with the unmanageable anxiety manifest in the psychological response to the abuse experience. Secondly, the process is conceptualised here as a cyclical process involving increasingly larger systems that contain the secret as the individual develops across the lifespan. Each experience of containing the secret can be symbolised as a series of circular processes, not unlike Bronfenbrenner's (1979) illustration of a series of concentric circles that represent different systemic networks that influence human development. In Bronfenbrenner's framework, the boundaries between these systems are permeable, just as in the theoretical framework suggested in this study, the story can be leaked out into ever increasing systems in the child's network but continues to be contained in terms of who knows about the abuse at any given point in time. The process may need to be re-negotiated over the course of the lifespan in the context of different relationships.

Thirdly, the process is influenced by multiple factors operating within and between multiple systems in the child's network including family, friends, school and wider society that both directly and indirectly influence the child. The theme of $f e a r$ is discussed in the context of the pressure cooker effect, and those of peer influence and concern for others are discussed in the context of systemic levels of influence, while those of being believed, being asked, and

shame/embarrassment/self-blame, are discussed as distinct concepts. All of these influencing factors operated at the level of the individual, family, peer, school and wider society.

Finally, the process changes over time. The cycle of active withholding, pressure cooker effect and confiding is re-negotiated in different relationships over the course of the lifespan and the factors that influence the process also change over time.

This chapter will review the theoretical framework suggested, drawing on the findings in the previous three chapters, in the light of existing research findings and clinical literature in the field of child sexual abuse. The limitations of the current study will be outlined and implications for clinical practice and future research will be suggested. 


\section{Containing the Secret}

This study describes the various manifestations of the process of containing the secret of child sexual abuse. What has previously been described in the literature as the disclosure process is conceptualised here as a cyclical process of active withholding, pressure cooker effect, confiding and containing which may be repeated across the lifespan in different relationships.

As is evident from this study, the secret may never be fully disclosed. Initially the only people who may know of the experience is the child and the abuser. Even when confided, it is only in part because at any point in time only some people know about it. It is still contained within a small group of people.

The term "containment" is used in the psychoanalytic literature to refer to the function that the mother performs for her child in managing emotions so that the child can internalise this function and perform it for herself as she develops. The child who has been abused and tells no one must find alternative ways of finding this mental containment, often manifested in the various psychological difficulties that emerge following the experience of abuse.

Bion (1962) proposed a model for processing emotional experience that significantly influences the structuring of the developing personality. The mother, according to Wadell (2002), thinks for the infant, acting as a container for the infant's fragmentary impulses and emotions, until the infant learns to perform this function for herself. By containing the infant's anxiety, that which is unmanageable becomes more manageable. Winnicott (1965) has described this as giving back to the baby, the baby's own self. Wadell refers to how this process is captured by the story Peter Pan:

Mrs. Darling first heard of Peter when she was tidying up her children's minds. It is the nightly custom of every good mother after her children are asleep to rummage in their minds and put things straight for the morning, repacking into their proper places the many articles that have wandered during the day....... When you wake up in the morning, the naughtiness and evil passions with which you went to bed have been folded up small and placed at the bottom of your mind; and on the top, beautifully aired, are spread out your prettier thoughts, ready for you to put on. (Barrie, 1911, p.12, cited in Wadell, p.35)

According to Bentovim (2002), the child who has been abused experiences responses to the abuse which are "unmodulated and uncontained" (p.29). These responses may manifest themselves in either internalising (avoidance, dissociation, anxiety) responses and/or externalising responses (hyperarousal, explosive outbursts) in an attempt to contain the overwhelming emotions. Friedrichs (2002) emphasises the importance of the child's ability to self regulate emotions in determining the long term psychological impact of the abuse experience on the child. 
That such unmanageable anxiety is associated with the experience of sexual abuse is borne out in this study by the extent to which the theme of fear reverberates throughout the narratives of both the young people and adults interviewed. As outlined in Chapter 5, the fears expressed by participants ranged from feeling afraid at the time of the abuse to feeling afraid of telling and the emotions triggered by telling others and being scared of the consequences of telling. GoodmanBrown et al., (2003) found in their study of children that fear of the consequences of disclosure was the most predictive influencing factor for delay in disclosure. As pointed out earlier, many of these fears were not unfounded. Relationships were affected. Those close to the child did get upset. Some people did not believe the child. Families did break up, resulting in significant family conflict and loss of contact with children in the extended family and for many, life did get worse before it got better. One way of managing this fear and one chosen by many is not to tell and therefore avoid the realisation of these fears. Not telling then becomes a way of containing the fearful emotions engendered in the child. Fear has been identified in the research as associated with the experience itself (Finkelhor \& Browne, 1985; Herman, 1992) and as a barrier to disclosure in the form of fear of perpetrator \& fear of consequences (Goodman-Brown et al., 2003).

For children who do confide, the relationship then becomes the container for the information that the child has been abused (the unmanageable information) and through the process of containment, this information becomes manageable.

Containment therefore takes on a meaning not just of being confined within a relationship or a group of people but also a psychological response to the unmanageable anxiety associated with the experience of the abuse itself. Containing the secret, for the child, can be seen then as an attempt to self-regulate the emotional impact of the abuse. The child needs containment to facilitate the process of regulating emotions elicited by the experience of abuse so that they can take control of the overwhelming distress for themselves. According to Petronio, Flores and Hecht (1997), the decision making process for children in relation to whether to tell or not is a way of gaining control over an event that systematically had the effect of disempowering them.

\section{Dynamics of Containing the Secret:}

Active Withholding, Pressure Cooker Effect and Confiding

The process of containing the secret is characterised by three key dynamics: Active withholding, Pressure Cooker Effect and Confiding. By directing the analysis of this study to the overall containment process - the inhibition to tell, the motivation to tell, the telling experience and the consequences of telling, this work extends the work of previous researchers. 


\section{Active Withholding}

As noted in Chapter 1, Sgroi in the United Kingdom, Summit in the United States, and Furniss in Germany all identified secrecy as a core dynamic in the experience of child sexual abuse (Furniss, 1990; Sgroi, 1982; Summit, 1983). The research is unequivocal that a significant proportion of children who have experienced sexual abuse do not disclose immediately, and Summit's stage of silence has a "strong empirical foundation" (London et al., 2005, p.203). The idea of the abuse being intentionally withheld, involving an active process, has received less attention in the literature. Disclosures were generally categorised as purposeful or accidental, spontaneous or elicited with little attention focused on the active withholding of information. Alaggia (2004) highlighted this gap in the theoretical literature and suggested a framework that incorporated intentionally withheld disclosures, acknowledging this as a distinct category of disclosures. The thesis put forward in the present study is that to some extent information about the experience is always intentionally withheld. It is not just confined to some and it is not confined to initial disclosures. Even when the secret is disclosed to some, it is withheld from others and confined to a finite group of people. While this was a clear finding in this study, there is little evidence from studies of larger samples to support this hypothesis as this question has not been examined. Sas \& Cunningham (1995) interviewed 135 children about the disclosure process following involvement in litigation and referred to $12 \%$ of their sample who consciously decided not to tell. Alaggia, in her qualitative study of adult women referred to a quarter of her sample $(n=7)$ intentionally withholding information about their experiences of childhood sexual abuse, i.e. not wanting to tell others. However, these studies were referring to an initial experience of disclosure, not examining how the secret is managed after the initial disclosure.

According to Lovett (2004), Summit's CSAA Syndrome suggests that the child believes that revealing the secret is dangerous and therefore, from the child's perspective, failing to disclose is adaptive. Viewing the secret as being actively contained as opposed to viewing it as a passive "not telling' acknowledges that this is an adaptive process for the young person. It is what they need at that time. Only when the rationale for telling outweighs the benefits of containing the secret at an intrapersonal level, as captured in the pressure cooker effect, can the child tell.

The conflicting evidence on denial as a characteristic of children's disclosures was discussed in Chapter 1. This theme of denial was first written about by Summit (1983) and has been the subject of much controversy in the research literature over the past few decades, particularly in the literature on forensic interviewing. Summit, however, was basing his syndrome on children who were disclosing in an informal context, not when being asked by professionals. The latter was the focus of the present study. There was some evidence from this study to support Summit's theory that although denial is perhaps not a typical pattern, it is certainly not atypical. As mentioned, 
information about the informal disclosure of the child is lacking in many studies. It was suggested in Chapter 1 that perhaps denial is more of a feature of children's informal disclosure stories. This might account for the discrepancy between the rates of denials found in samples of children in therapy in comparison to those samples of children who were asked about abuse in the context of investigative interviews. There is little mention of denial in the literature on adult retrospective studies. These are mostly surveys and it may be that denial was not explored by the researchers. Alaggia's (2004) qualitative study did note denial as a feature in her findings. However, in the clinical literature, denial is recognised as a psychological defense or coping strategy to minimise the psychological impact of the abuse. According to Bentovim,

The thinking processes of both the victim and the victimizer alike are characterized by deletion of thought, minimization of the experience, dismissal of the event, or blame of self or other. This process of dissociation and separation from the experience and the actions is a characteristic coping style which enables individuals to continue in what appears like a day-to-day existence." (2002; p.23)

The concepts of active withholding and denial are consistent with the idea of the child as an active participant in the process of containing the secret. This is further supported by the theme of readiness to tell. As pointed out in Chapter 1, Richardson (2003) has made the point that the low levels of denial seen in studies of children involved in investigative interviews may be due to the fact that children who are seen by professionals for assessment are often at a later stage in the disclosure process and ready to tell. Readiness to tell was mentioned by some young people in this study (see Chapter 4). The idea of being ready to tell is consistent with the cost-benefit analysis theories implying that the young person has to some extent weighed up the pros and cons and is ready to make the decision to tell. It is also consistent with the idea that children need to stay in control of their telling experiences and will resist attempts to pressurise them to tell before they are ready. According to Bacon and Richardson (2000), the disclosure process must evolve at the victim's pace and should not be driven by adult agendas.

It may be that some children do not experience the dynamic of active withholding before they first tell. They may tell immediately after the experience, without any inhibition to tell. This appeared to be the case for one young boy in this study who told his mother at the first opportunity. After confiding in his parents, he continued to talk openly to friends about going to the Garda station, much to his mother's alarm. In this family, it was his parents who were actively withholding the secret of abuse, from members of their families and others in the community, not the child himself. It would be interesting to conduct follow-up interviews with such families to ascertain whether children as they get older take on the dynamic of active withholding themselves. A second participant described going to see her mother immediately after the first time her father sexually assaulted her with the intention of telling her mother. She did not get the opportunity to do this and actively withheld this information for over a year. Nevertheless, it would appear that her first instinct was to tell. 
These two young people highlight that active withholding as an instinctive reaction to the experience of abuse is not universal. Understanding the differences between the need to tell and the need to actively withhold needs further exploration. Containing the secret as an adaptive response to the experience of abuse has been discussed. Active withholding may be adaptive and as is the case with many psychological responses, may become maladaptive over time. If we set aside (theoretically) the implications of children needing to tell for the purpose of child protection and intervention with the abuser, the question is raised: do children need to tell for their own mental health? This question was not addressed in this study but is worthy of further exploration.

\section{Pressure Cooker Effect}

In this study, children's experiences of telling about the abuse, both initial and subsequent, were characterised by a build up of pressure, internal or external, culminating in their confiding in someone about the abuse. The unplanned nature of many young people's disclosures and the descriptive comments about this experience as 'out of the blue' are consistent with a conceptualisation of this process as akin to a pressure cooker effect. For some, it was a slow gradual process where young people could identify a range of contributing influences that converged to trigger the telling experience. For others, the overwhelming emotional impact of keeping the secret became too much for the young person and they told in the context of simply not being able to keep it in any longer. Either way, the symbol of the pressure cooker can be used to represent this dynamic reflecting the build up of emotional pressure and the unplanned nature of telling.

The conflict between wanting to tell yet fearing to tell has been referred to previously in the literature. According to Lovett (2004) "most victims of child sexual abuse both long and fear to reveal the secret" (p.356).

for the child victim this process of telling may include an internal psychological struggle stemming from the child's attempt to cope with the trauma. The wish to tell originates from the desire for safety. However, this wish to tell is countered by the fear that revealing the abuse will bring further harm (Lovett, 2004, p.366).

The concept of competing influences informing the decision to tell has also been well recognised. However, the focus has usually been on the cognitive processes involved implying a conscious decision to tell. According to Goodman-Brown et al., children often weigh the consequences of their actions prior to disclosing. Bussey \& Grimbeek (1995) and Leonard (1996) refer to the cost benefit analysis involved in the decision making process where disclosure occurs when the anticipated benefits of disclosure outweigh the feared consequences for children. Drawing on the secrecy literature, Lane \& Wegner (1995, cited in Paine \& Hansen, 2002) proposed a preoccupation model of secrecy in which the act of keeping a secret triggers a series of cognitive 
processes that result in obsessive preoccupation with the secret thought. Of relevance to child sexual abuse, the main elements of this model are symptoms characteristic of posttraumatic stress disorder (i.e. suppression and intrusion of unwanted thoughts). As Paine \& Hansen point out, Arata's (1998) study of female undergraduates produced a finding that disclosure was positively correlated with fewer intrusive and avoidant symptoms, thus providing some evidence for Lane and Wegner's model.

Paine and Hansen point to some work outside the field of abuse that focuses on keeping the secret rather than disclosing. As Paine \& Hansen (2002) point out, many of the disclosure concerns of sexually abused children are not unique to sexual abuse. An Israeli study conducted by Last and Aharoni-Etzioni (1994, cited in Paine \& Hansen, 2002) proposed four main categories of motivations for secrecy in a non-clinical population of children in relation to keeping a "very personal" secret. They are: shame; fear of punishment; exclusiveness (privacy, fear of losing exclusive possession or accessibility); and empathy (including the need to avoid hurting others or breaking a promise to keep a secret). All of these categories are commonly referred to in the literature on factors inhibiting disclosures of child sexual abuse. Apart from 'exclusiveness' these categories are similar to those highlighted in this study. Thus there is some support for the adaptive function served by keeping the secret.

However, many of these models do not capture the emotional distress described by the young people in this study that was evident before they revealed their secret. It is central to the idea of the pressure cooker effect that the build up is an emotional build up, not just a preoccupation with thinking about telling or not telling. While previous studies have acknowledged the child's fear of consequences of disclosing as a significant contributory factor to the disclosure process (GoodmanBrown et al., 2003), the pervasiveness of the emotion of fear throughout many aspects of both the abuse experience itself and the aftermath is not addressed in these models. The courage that is required to cope with this fear has received little attention in the research literature. The costbenefit analysis theories of telling and not telling do not capture the emotional seesaw described by participants in this study. For many, the disclosure was unplanned and not a conscious decision at all. The balance tipped, for many unexpectedly. The models reviewed in Chapter 1 that contributed to our understanding of sexual abuse as a secretive experience (Summit, 1983; Furniss, 1990) and the psychological impact of the abuse experience (Finkelhor \& Browne, 1985) did not focus on emotionality as have more recent authors (Friedrichs, 2002; Bentovim, 2002). One of the key features which both Friedrich's and Bentovim's models have in common is the importance given to regulation of emotion. While Finkelhor \& Browne discussed how difficulties with emotion regulation are manifested in behavioural and cognitive difficulties, they did not acknowledge as both Friedrichs and Bentovim have done, that the psychological impact of the abuse experience depends to a large extent on the individual child's ability to self-regulate emotions. Bentovim refers 
to the impulses of the abuser as being felt as 'overwhelming' and 'beyond control' and highlights the severe effects on the emotional lives of children (Bentovim, 1995). These are the impulses that the emotionally immature child is faced with, "the pressure not to see, not to hear, not to speak, means that there is no processing of experiences" (Bentovim, 2002, p.23). Alaggia (2005) referred to adult women in her study whose disclosures were often precipitated by a breakdown or hospital admission whereas Lovett (2004) suggested that intentional disclosures reflect that the victim is better able to contain her anxiety in that she has actively made the decision to disclose the abuse and seek help. Staller and Nelson-Gardell's (2005) participants referred to a sense of urgency preceding their disclosures.

The pressure cooker effect then represents the build up of emotions which may at times be felt as overwhelming, resulting in unplanned disclosures in the context of emotional outbursts or a need to confide the secret to a trusted person. The unplanned nature of many disclosures reflects the belief of some that they would not have told if it had not been for the particular set of circumstances pertaining at the time of their disclosure. To some, this trigger might appear innocuous, incidental. In this study, some young people's beliefs that they would never have told if not for the particular set of circumstances pertaining to the time they disclosed supports the idea of the build up of pressure resulting in telling.

This pressure cooker effect is likely associated with both the psychological impact of the abuse itself and the psychological impact of actively withholding the secret of the abuse.

\section{Confiding}

It is suggested here that the term 'disclosing' does not capture the intimate experience of telling as described by the participants in this study. Rather, the telling represents a sharing of confidence in the context of a trusting relationship. The term confiding also captures the idea that the secret is still contained. Although the term disclosure fits the experience of opening out, confiding captures the fact that the secret continues to be kept in confidence by those trusted with it. This is evident in the manner in which the confidence is kept private in informal networks within which people confide, and also in the wider professional system where confidentiality is regarded as central to clients' needs. The secret still needs to be kept confidential even when it is shared with professionals, either in the child protection context (Wattam, 1999) or in the therapeutic context (MacDonald, Lambie, \& Simmonds, 1995; O'Shea \& McElvaney, 2001). Wattam highlights how children and families often experience a sense of loss of control when a train of events are set in motion resulting from a report to child protection agencies. The psychological dynamic of secrecy that operated during and following the experience of abuse extends to the process of disclosure and reporting the abuse and is experienced by children and their families as a need for confidentiality. 
Confiding captures the intimate contexts in which children often tell about these private experiences. One adult woman described how as a child she told her granny while sitting on her granny's bed. Young people told their friends in the context of intimate conversations about each others' problems. One girl told a friend while playing truth or dare in her friend's bedroom. A boy told his friends while they were sharing their own personal difficulties. A girl told her boyfriend in the context of him sharing confidences about his parents' difficulties. The idea of confiding is also supported by the choice of confidante: for the most part, someone close to the young person, who they trusted. This is well supported in the literature outlined in Chapter 1. For the most part, children and young people disclose initially to their parents or primary caregivers, and to peers. Kogan (2004) referred to the most common initial confidante for his sample of adolescents as a “close friend". Similarly, in D.W. Smith et al.'s national probability sample of adult women who had experienced rape before the age of 18 years, close friends were identified as the most common confidante. Pipe, Lamb, Orbach, Stewart, Sternberg, \& Esplin (2007) found that across all age groups in their study of children in a forensic interview context (4-6 years, 6-8 years and 9-13 years) children were most likely to make their initial disclosure to an immediate family member. The use of the term 'confidante' in the literature in recent years (Petronio et al., 1997; D.W. Smith et al., 2000; Staller \& Nelson-Gardell, 2005) attests to the description of disclosing as confiding.

\section{Characteristics of the Process of Containing the Secret}

In addition to identifying the key dynamics of the process of containing the secret, the findings of this study also highlight the key characteristics of this process. Containing the secret, it is suggested, is an adaptive response to the experience of sexual abuse. It is a cyclical process that may proceed in incremental steps over time and is re-enacted and re-negotiated in new relationships across the lifespan. The process is influenced by multiple factors operating at multisystemic levels that interact with each other. Containing the secret operates at the intrapersonal, interpersonal and societal level. Key sub-systems that influence and are influenced by the child in this process are the family, the peer group, the school and the wider society in terms of awareness of sexual abuse and attitudes towards both victims and perpetrators of abuse. Key motivating influences on the process of containing the secret such as being believed, being asked, self-blame, shame and embarrassment and concern for others reflect these multiple layers of reciprocal influence.

\section{Containing the Secret as an Adaptive Response}

Containing the secret, it is suggested, gives the child a sense of self-efficacy and safety in an unsafe world. Thus, containing the secret for individuals in this study was an adaptive response to the 
experience of abuse for the child. According to Summit (1983) by staying silent about the experience of abuse within the family, the status quo in the family is maintained.

Containing the secret as an adaptive response was explored further in this study through the introduction of a question to the interview protocol: "if people talked more openly about sexual abuse, would that help children tell?" As shown in Chapter 3, while most participants agreed with this suggestion, they themselves were reluctant to talk openly about their own or their child's experience of abuse. Fears of being judged by others, feelings of shame and embarrassment and a wish to protect one's privacy outweighed the positive benefits of talking openly about sexual abuse for participants in this study.

It may become maladaptive for the child who actively withholds the secret but is experiencing the pressure cooker effect and resists confiding. This is represented in the dynamic of actively withholding at the intrapersonal level. Although for the participants in this study, this dynamic did become maladaptive over time, caution is needed in applying this theoretical framework to individuals who have never confided their experiences of abuse. The focus of this study was on individuals who have told and how this is experienced, and the same dynamics may not apply to those who have never told.

\section{Containing the Secret and Confiding as a Cyclical Process that may be Re-negotiated Across the Lifespan}

Disclosure of sexual abuse has been conceptualised in the literature, for the most part, as a process (Bacon \& Richardson, 2000; Coulborn Faller, 2007; Sorenson \& Snow, 1991). Petronio et al. (1997) suggest that children require permission to disclose, using incremental disclosure to 'test the waters' before revealing more details. If we consider immediate disclosure to mean a spontaneous purposeful telling immediately following the event or at least at the first opportunity, then only one child in this study meets this definition. For most of the young people in this study the abuse experience was not a discrete event. Disclosing the experience, like the experience itself, occurred over time, sometimes in an incremental fashion, giving more details as time went on. It manifested itself in various forms as young people negotiated this task in different relationships.

Earlier theories referred to in Chapter 1 portray disclosure as a sequential process although Summit later added that these stages should not be seen in a particular order (Summit, 1992). This study suggests that this conceptualisation does not reflect children's experiences and that viewing the process as cyclical is more helpful in understanding the experience of confiding. Recent qualitative studies have resulted in the expansion of conceptual frameworks to take account of the complexity of the disclosure process. Staller and Nelson-Gardell (2005) were the first to refer to the renegotiation of the disclosure task, the recurrent navigation of the process over the lifespan. The first disclosure experience does not complete the disclosure process. Previous studies, using 
quantitative methods to investigate factors influencing disclosure did not highlight or appreciate this characteristic of the process.

Sequential stages tend to get misunderstood as a fixed sequence of events ignoring the complexity and uniqueness of this process for each individual. Summit's accommodation syndrome of a typical sequence of phases is an example. Sequential processes also assume that when the abuse is first disclosed it is then out in the open, i.e. that one experience of telling captures the experience of disclosure. The ongoing negotiation of this psychosocial task has not been acknowledged until recently. Staller-Nelson \& Gardell drew attention to this aspect of disclosure. Also, Hershkowitz, et al. (2007) in their content analysis of 30 interviews with children specifically asked children to tell the interviewers about each experience of disclosure, acknowledging the diversity of experiences within this process.

The importance of recognising this process as needing to be re-negotiated is highlighted in particular by two participants in this study (two women who told as children about abuse but didn't tell of teenage abuse). They believed that their reluctance to tell was influenced by family relationships (in one case a brother, in the other a mother's partner) and the age at which they were abused. Both women referred to it being easier to tell about the earlier abuse because they were younger, and did not understand the potential consequences of disclosure. Both also referred to some confusion about their own culpability in the abuse experience.

The factors that influence disclosure in one context are not necessarily the same as those that influence disclosure in another context. Telling a friend is not the same as telling a parent. Telling in an informal context is not the same as telling a professional in the context of an investigative interview. As has been highlighted in Chapter 1, there has been insufficient attention paid in previous research to the continuous nature of the disclosure process, albeit periodic for many, and to the important distinctions drawn here between telling in an informal context and telling in a formal context.

Although Staller and Nelson-Gardell (2005) highlighted the issue of renegotiating future disclosures, studies have not reported data on how many people know about the individual's experience of abuse at the time of the study. Because this study did not confine itself to the first disclosure or treat disclosure as a uni-dimensional experience, occurring in a once-off fashion to one person, it was possible to highlight how information about the abuse experience continues to be contained for most people in the study. This ongoing containment was highlighted by the older adolescents in the study and the adults interviewed and also through exploring who one might tell in the future. It was clear that only those who could be trusted with this sensitive information should be told. The secret is contained therefore not only among those in the child's immediate 
context but also in the professional system with which the child and family come into contact as a result of the disclosure. Staller and Nelson-Gardell refer to the life-long implication of who knows and who does not know about the abuse and how participants in their study continuously evaluated trustworthiness, likely response and possible consequences of telling. Young people in the present study were very articulate about the cautious approach needed in deciding whether people could be trusted with this personal and private information. They also talked about instances where they regretted telling some because of their reactions and because of their lack of appreciation for the need to contain the information and keep it confidential.

Of note in this study was the extent to which adults did not talk about their experiences over long periods of time. Even for those who had confided in others, the subject was not raised again for many years, if ever. Two adult women mentioned their childhood abuse (that they had disclosed to their mothers as children) to their mothers as adults and both mothers reacted with shock. These mothers did not think that their children would have remembered that they were abused. In one of these cases, there had been a dramatic reaction to the disclosure and a police investigation ensued.

Goodman-Brown et al. (2003) suggested that as disclosure is typically a process that takes place over time, a longitudinal approach should be undertaken so that children could be followed up over time examining family outcomes, stressors, symptom progression, parental support. The child..."may even experience further rejection or isolation subsequent to disclosing" (Lovett, 2004, p.367).

The Process of Containing the Secret as Influenced by Multiple Factors at Multiple Levels of Reciprocal Influence

The findings of this study suggest that the process of containing the secret is influenced by a range of factors which themselves operate at multiple systemic levels and are characterised by reciprocal influences. While this study suggests that the child initially contains the secret of the abuse experience through the dynamic of active withholding, it also suggests that the secret continues to be contained at various levels in the child's world.

As noted in Chapter 1 and Chapter 5, Belsky's model of child maltreatment (Belsky, 1980, 1993) sees the phenomenon of child maltreatment as determined by forces at work in the individual, the family and the community and culture. It is clear from the presentation of data in Chapters 4 and 5 that those factors that influence the child's decision to tell or not to tell operate at all of these levels. As was pointed out in Chapter 4, the theme of being believed can be understood at an intrapersonal level in terms of the child doubting her own understanding of the abuse experience. It can be understood at the interpersonal level (family, peers, school) in terms of concerns about being believed by others or actually being believed and it can be experienced at the wider society level in 
the example given of the young girl who experienced the decision not to prosecute as the legal system not believing her.

Bronfenbrenner's acknowledgement of the reciprocal influences operating for the developing child applies to the containment process in that children both influence and are influenced by those around them in how the process of containment develops. As Staller and Nelson-Gardell (2005) note "Disclosure is not a one-way process. Children receive, evaluate and react to information based on how adults respond to them" (p.1423), although it is clear from the findings of this study that peer responses are also crucial.

\section{Influencing Factors: Key Themes}

As reviewed in Chapter 1, earlier research on disclosures of childhood sexual abuse focuses exclusively on what stops the child from telling of their experience. The disclosure experience, while seen as part of the experience of sexual abuse was of interest only insofar as the inhibitors to disclosure were deemed to be significant. Key factors identified included the young age of the child, fear of consequences of disclosure for self, and others, (Paine \& Hansen, 2002) and perceived responsibility for the abuse (Goodman-Brown et al., 2003) There has been little attempt to understand how these factors inhibit disclosure in children, how children are active participants in this process, and how children succeed in overcoming these barriers when they do tell. While the less commonly referred to themes of being told not to tell, contact with the alleged abuser, alcohol as facilitator and the role of the media have also been noted in the research literature, the discussion here will confine itself to the themes, being believed, being asked and shamelembarrassment/self-blame.

\section{Being Believed}

Being Believed has been treated for the most part as a simple dichotomous concept in the research literature, referring to whether the child is either believed or not. However, it is clear from the findings of this study that this concept is much more complex than has been recognised in the literature. Some children may have difficulty believing themselves that they have been abused and as they withhold the secret into adulthood, may experience doubts due to limited recall that it really happened. Children may be believed by some and not by others. A child may not be believed initially but doubts may remain on the part of parent or carer that may facilitate a later disclosure. A child may be believed initially but later appear not to be believed on the basis of people's actions towards the abuser. Finally, a child may be met with initial disbelief, not of the child but of the fact that such a thing could happen. These various manifestations of this dynamic underscore the dynamic of being believed as operating at both the intrapersonal and the interpersonal level, the intrapersonal level for the child in terms of not believing herself, and the interpersonal level in terms of being believed by others. Summit (1983) described the context of the abuse as lending to 
the unbelievability of the experience for children. Being abused in bed at night either before or during sleep and in a defenceless state may lead them to question whether what happened was real or a dream. Furniss (1990) also described a typical context for abuse referring to the abuse often occurring in a dark room, with curtains drawn and no eye contact between the child and the abuser, adding to the secrecy but also the incredulity and a sense that 'this is not happening'. One young person described the incongruence between the alleged abuser's behaviour after the abuse in front of others, behaving as if nothing untoward had occurred, leading her to question herself and the likelihood of anyone believing her. The references to 'blocking' out memories of the experience, as pointed out in Chapter 4 in themselves constitute a form of denial or not accepting that this has happened. In the clinical literature, this is manifested in its most extreme form as dissociation leading to an inability to remember the experience, which according to many authors, serves an adaptive function for coping with overwhelming emotional trauma (Bentovim, 2002; Rogers, 2006).

The issue of children not being believed has long been recognized in the child abuse literature. According to Coulborn Faller (2007), "sexual abuse engenders controversy because both believing and disbelieving sexual abuse reports have grave and far-reaching consequences for the children, adults, and institutions involved in such allegations". (p.vii). Sirles and Franke (1989) in their study of 193 families found that $22 \%$ of mothers did not believe their children when they disclosed experiences of sexual abuse within the family. Sirles and Franke found that the three most influential variables were the relationship of the offender to the mother, the nature of the abuse and the mother's location during the abuse. If the offender was an extended family member, the mother was more likely to believe the child than if the abuser was her boyfriend or the child's stepfather. They were more likely to believe the child if the offender was the child's biological father than if it was her stepfather or boyfriend and digital penetration was found to be more believable than intercourse. Finally, mothers were more likely to believe the child if the abuse occurred while the mother was away from the home. In the present study, parents for the most part believed their children when they were first told of the abuse. Some parents did discuss, in the context of the research interview, how they had doubts that such a thing could have occurred but at the same time knew that their child would not lie about such a matter. The difficulty in believing was associated with the sexual abuse, not the child. Others, however, doubted the child's veracity.

When Summit proposed his syndrome in 1983, it was, according to him, in the context of a society where children are not believed. "Unless specifically trained and sensitized, average adults.....cannot believe that a normal, truthful child would tolerate incest without immediately reporting" (p.186), highlighting how the delay in disclosing contributes to the difficulty in being believed. Although in Sirles \& Franke's study younger children were believed most often, according to Alaggia (2004), "unfortunately, trends still indicate that at any age disclosure of csa is 
viewed skeptically" (p.1222). Palmer et al. (1999) in their study of 384 adults found that $24 \%$ of their sample was not believed when they told. Similarly in her study of 24 adults, Alaggia found that "those who eventually disclose still find that their credibility is questioned because of the long delays (why didn't they tell earlier?) or skepticism that they repressed the trauma (how can they forget something so horrible?)" (p.1222).

The vascillation that some people experience in moving from stances of believing to disbelieving or vice versa is illustrated by the story of the young person in this study who recanted her allegation. When she first told her mother, her mother believed her but others in her extended family doubted her. Under emotional pressure from the fallout of her disclosure, she recanted. According to her, everyone then believed her. Certainly the status quo was re-established. Her mother's partner moved back into the family home, his children had their father back. As long as the young girl could keep the secret to herself, the family could function. It appears that it was easier for this family to believe that this did not happen. Believing was associated with accepting that it had happened and having to live with the consequences. Lovett (2004) found lack of support associated with pressure to recant. She described the young person's sense of time and "inability to foresee that things within the family will get better with time" (p.358). A.N. Elliott \& Carnes (2001) however drew a distinction between mothers believing their children's allegations and supportive or protective responses to children.

A second story highlighting the fluctuation between believing and disbelieving is reflected in one girl's story about her sister to whom the abuser admitted the sexual contact and who initially encouraged the young girl to go to the police. However, after a few days, this same sister broke off all contact with her family and has appeared to take a stance of not believing. Alaggia (2002) found that mothers' responses to disclosure may vascillate between belief and disbelief and that this dynamic is poorly understood by others in the mother's social networks and by professionals. She refers to a paper by Carter (1993, cited in Alaggia, 2005). Carter studied a sample of 24 mothers who reported feelings of social isolation as a result of conflicting responses by family and friends to their child's disclosure, citing the lack of emotional support from others in dealing with the situation. This vascillation is also noted in the literature in relation to society's wavering between belief and disbelief of sexual abuse as a phenomenon throughout history. Examples of this include Freud's initial seduction theory where he documented accounts of incestuous experiences reported by his patients and following public disbelief and threats of discredit, he retracted in 1900. Olafson, Corwin and Summit (1993) have described how awareness of child abuse has been suppressed and 'rediscovered' several times during history. Disbelief ranged from not believing that such a thing could have happened e.g. attributing venereal disease to other causes and to seeing the child as the active seducer (Bender \& Blau, 1937; Smart, 2000, cited in Goode et al., 2003) 
The lack of awareness of sexual abuse itself adds to the unbelievability of the experience. As mentioned, most of the young people interviewed in this study did not know anyone who had been abused prior to their own experience of confiding yet after confiding, they became aware that people they knew - family members, friends - had been abused. While this was not cited spontaneously by any of the participants as a reason for not telling, their lack of awareness that others in their family or social circle had been abused is testament to the extent to which the secret is contained in society. In fact, many of these children's parents had experienced abuse that their children remained unaware of, at the time of the research study. Not knowing that such a thing exists, it could be argued, makes it more incredible. Finally, the mechanisms in the child protection and legal systems may send out a message to children that the legal dictum 'innocent until proven guilty' detracts from children's credibility. Requiring children to undergo specialist assessments to ascertain whether the child is giving a credible account of abuse appears to start from a premise that the story is unbelievable and needs to undergo scrutiny. It is not sufficient for a child to tell their story. A professional opinion is needed as to the credibility of the account.

As pointed out in Chapter 1, children who disclose experiences of sexual abuse that is not corroborated by other sources such as a professional opinion are excluded from research studies. Decisions by the Director of Public Prosecutions not to proceed with a prosecution can be interpreted, as it was for one young person in this study, as the system not believing. The adversarial nature of our legal system places an emphasis on corroborative evidence. One parent in this study described questioning her six year old son about what he had seen in the alleged abuser's room at the time of the abuse, knowing that this information may be needed as corroborative evidence to support the child's story. This suggests an expectation that the child would not be believed and the allegation may need to be proved in some way. Nevertheless the majority of children's stories that were represented in this study (68\%) were formally reported to the gardai, possibly reflecting some confidence in the legal system.

Research has not acknowledged that disbelief may be a normal adaptive reaction to hearing that one's child has been sexually abused. The behaviour itself has many qualities which are unbelievable and as Summit has pointed out "protective denial surrounding sexual abuse can be seen as a natural consequence (of)...the need of almost all adults to insulate themselves from the painful realities of childhood victimization" (p.179). Disbelief then serves a protective function for the person listening to the disclosure. Some parents described how they did react with disbelief and shock even when they did believe their children. Their disbelief was associated with an incredulity that such a thing could have happened rather than doubting the child's truthfulness. Research has not attended to this instinctive reaction but focussed more on whether the child was actually believed. One parent described how the parents of the teenage boy who abused her six year old son reacted to the allegation. This couple, according to the parent interviewed in this study, did not 
believe the allegation against their son, was shocked that such a thing could be alleged, insisting on their son's innocence and pointing out that 'all children lie'. A later apology from these parents when their son admitted the abuse highlights the difficulty for parents in believing that their own children could be capable of such behaviour.

In examining the trends in research on disclosures as described in Chapter 1, it could be argued that the research community has shown a reluctance to engage with the question of believing children. As mentioned above, children who disclose abuse without corroborative evidence are excluded from research samples. The emphasis of research on disclosures has focused on those conditions which elicit false accounts of abuse from children while the conditions that favour children who do not disclose experienced abuse have been relatively neglected (Coulborn Faller, 2007; Horowitz, 2007). A concern with false positives motivated researchers to examine how children were being interviewed and the possibility that suggestive interviewing practices were leading to high disclosure rates. There was less concern about false negatives i.e. children who were abused but not disclosing. Even within this narrow field of study, the attempt to build an evidence base for structured interview protocols has relied on children who were co-operative, ready to disclose and able to disclose in response to open questions (Coulbourn Faller, 2007). These children have already been identified by the research literature as more likely to disclose (i.e. children over 7 years of age).

The more challenging task of examining how to help children who experience difficulty disclosing in investigative interviews has only recently received attention. Previous studies did acknowledge that a sizeable minority of children who do not disclose in response to these questioning techniques still give rise to concern but research did not focus on these children. Even more recent attempts to examine children who do not disclose in investigative interviews are confined to highly selective samples. An example of this is a study by Hershkowitz et al. (2005) who investigated the mutual influence and transactional processes between the non-disclosing child and the interviewer. While this study provides supporting evidence for the reciprocal nature of the containment process as suggested by the present study and the dialogical nature of telling as suggested by Alaggia (2004), it does exclude children who may have been abused but lack the corroborative evidence to support their story. This is not to suggest that all accounts of sexual abuse should be believed, regardless of their veracity. Nevertheless, children who disclose experiences of sexual abuse are being excluded from research studies while adults who disclose without such corroboration are not. It is suggested here that this practice speaks to the question of whether children are believed less than adults.

Being believed then operates as a complex dynamic at the level of intrapersonal, interpersonal and societal systems that have a significant influence on the child's motivation to withhold the secret, to confide the secret and to contain the secret. 


\section{Being Asked}

A somewhat surprising finding from this research study is the extent to which young people disclosed in the context of being asked by friends, relatives or teachers. The theme of being asked covers a wide range of scenarios where young people were asked both directly if they had been abused and indirectly if there was something wrong. Some of these scenarios led to a disclosure and some did not. While the distinction between purposeful, elicited and spontaneous disclosures has been well recognised, the extent to which young people tell only when asked is unclear. In the SAVI study in Ireland (McGee et al., 2002), telephone interviewers asked respondents directly if they had been abused and $47 \%$ of those who said they had been were disclosing this information for the first time, saying they had never been asked before. However, the relevant literature suggests that this constitutes a significant trigger or contributory influence to children's and adults' disclosures. Goodman-Brown et al. (2003) reported information on whether or not disclosure was 'voluntary or involuntary' $(n=194) .23 \%(n=45)$ were considered to have made an involuntary disclosure (e.g. a parent or another adult elicited the disclosure). Hershkowitz, et al. (2007) note that $43 \%$ of their sample of 30 children only disclosed abuse after they were directly asked. It would appear that the increased attention being paid in research to disclosures in informal contexts reveals significant percentages of young people only disclosing following direct questioning. This phenomenon has not been recognised by studies examining this process solely in the context of investigative interviews.

A key difference between the adult and child sample in this study was the extent to which young people were asked both directly and indirectly. While very few adults reported being asked, it may of course be that adults were asked indirectly and they did not associate the question with their experience of abuse and therefore did not recall being asked. In Alaggia's (2004) study of adult women, only two disclosures were elicited or prompted during childhood. However, it is also true that levels of public awareness of the issue of sexual abuse have been raised considerably over the past five decades. Adults in this study are referring to experiences of abuse 30-50 years ago. Young people in the study are referring to abuse experienced up to 10 years ago. Public perceptions of sexual violence were investigated in the SAVI study referred to earlier. This study, surveyed over 3,000 adults. The majority (88\%) said that their parents had not discussed sexual abuse with them as children but over half of those who were parents had discussed it with their children (McGee et al., 2002). There has been a significant increase in reports of sexual abuse both to child protection authorities and to gardai by both children and adults. As outlined in Chapter 1, Ireland has seen an unprecedented level of media discussion on the issue of sexual abuse in the past two decades. Leon (2000) suggests that the increased awareness of sexual victimisation within Irish society may have prompted and encouraged victims to report such offences resulting in a 50\% increase in reports during the mid 1990's. Figures from Irish Rape Crisis Centres during this period also indicated an 
increase in the percentage of clients who involved the Gardai (Leon, 2000). It is reasonable to suggest that increased public awareness of the issue will lead not only to an increase in formal reporting to statutory authorities but also will help create an environment where children will be encouraged to disclose experiences of abuse more readily. In addition, the introduction of the Stay Safe programme while not cited in this study as helping children tell may have had indirect influences not elicited in this study. Certainly, the context of disclosure for children in the 1990s or millennium years is markedly different from that of the childhood years of adults in this study.

A related theme that emerged in this study was that of young people feeling that their parents should have known and should have asked. This theme was also identified by Alaggia (2004) in her qualitative study of adult women.

Many of these young people experienced significant fallout in relationships following their disclosure but were able to reflect on this at the time of interview in a mature and balanced way and acknowledge that the benefits far outweighed the losses they experienced.

\section{Shame, Embarrassment, Self-Blame}

Several young people spoke about feeling embarrassed or ashamed about what happened, questioning whether they themselves were in some way to blame for it. Kellogg and Huston (1995) found shame and embarrassment to be the most commonly cited reason for delay or non-disclosure in their study of young women attending a family practice clinic.

There is some suggestion from this study that this theme is one that develops over time when children do not tell about the abuse. Shame, embarrassment or self-blame were not referred to specifically by younger children although one child said that children might not want to tell because they are afraid of getting into trouble. Saywitz, Esplin and Romanoff (2007) refer to research (Tangney, 1999, Siedner, Stipek, \& Feshback, 1988, cited in Saywitz, 2007) that suggests that the development of embarrassment and self-consciousness emerge around seven years of age. The belief on the part of children that they would get into trouble if they told suggests some sense of perceived responsibility. Adults in this study referred to their belief as a child that they would get into trouble. This may however reflect perceived attitudes of their parents rather than feelings of self-blame alone. Self-blame can be implied from the narratives of research participants even when not explicitly identified by them. Alaggia (2004) quotes an adult participant in her study "I never admitted it" (p.1220), suggesting that abuse was something to 'admit'. Similarly in the present study, a young boy referred on a few occasions to 'confessing' that he had been abused. When teenagers spoke of this in this study, they referred to feeling that they were to blame as they got older. This was explicitly explored with one teenage girl who confirmed that she had not felt these emotions until some time before she disclosed at the age of 12 . She did refer to being afraid 
that she would get into trouble and feeling afraid of telling but not feeling ashamed or embarrassed. Shame and embarrassment may therefore be features of late childhood and early adolescence that inhibit disclosure while these feelings may not be prominent in younger children.

Goodman-Brown et al. (2003) discuss the role of perceived responsibility and suggest that children who blame themselves will take longer to disclose. Wyatt and Mickey (1987) found that children were less likely to disclose if they had attributed the cause of their victimization to internal rather than external events. However, it may be that the delay in disclosing itself contributes to the development of self-blame. In the present study, older children talked more about blaming themselves than the younger children interviewed and almost all of the adults talked about this. Goodman-Brown et al.'s study examined the predictive value of factors influencing disclosure but their hypothesis regarding the age of the child and perceived responsibility for abuse was based on the assumption that younger children would feel more responsibility for the abuse because of greater Piagetian egocentricity. Little is known about children's understanding of this dynamic. Confining understanding of egocentricity to that outlined by Piaget is confining this concept to the child's cognitive skills. It may be that increased autonomy of the developing child with increased cognitive and emotional competence brings with it an increased emotional egocentricism. When younger children disclose, they create the opportunity to be told that it was not their fault. Children who do not disclose forego this opportunity. Self-blame may be as much a result of containing the secret as resulting from the abuse experience itself. Whatever level of compliance the child felt in the abusive experience, they do actively keep the secret and perhaps therefore in their own eyes are colluding with the abuser and 'doing something wrong' thus feeding into the self-blame. While they may have had some doubts as a child as to who was responsible for the abuse, the lack of opportunity for this to be challenged - which could only happen if they told - provides fertile ground for the development of self-blame. It is also noteworthy that some research has found that older children are more likely to be blamed by others for sexual abuse experiences than are younger children (Back \& Lips, 1998; Waterman \& Foss-Goodman, 1984, cited in Goode et al., 2003).

Goodman-Brown et al. (2003), in acknowledging the need for more longitudinal studies of the disclosure process, suggest that it would be helpful to explore whether children experience increased self-blame for actual negative consequences to the family after the child's disclosure.

\section{Levels of Influence}

\section{Individual Influences}

A key theme emerging from the analysis in this study and one related to the issue of peer influence is that of adolescence as a potential pivotal time for disclosure. While it is acknowledged that the vast majority of young people in this study were adolescents and therefore comparisons were not 
possible with a younger age cohort, nevertheless this hypothesis is worth exploring for a number of reasons.

The significance of adolescence as an important life stage has been well recognised in Developmental Psychology for many years. It is the second major 'growth spurt' and a time of significant change at many levels - biological, cognitive, and emotional. In particular, it is a time of development of autonomy, identity, cognition, morality, emotion, and the self-processes of self concept and self-esteem (Adams \& Berzonsky, 2006). According to Wadell (2002), it is a pivotal time for the re-structuring of the personality characterised by a re-activation of emotional and impulsive states that were suspended during the preceding latency stage of middle childhood. Whether these changes are manageable for the adolescent depends to a large extent, according to Waddell, on the earlier containment and stability experienced by the young person and the extent of both internal and external pressures on the young person.

Little is known about whether there are 'critical periods' for disclosing experiences of sexual abuse. Campis et al. (1993) found that older children have the cognitive capacity to inhibit disclosure and this may place them at higher risk than younger children for maintaining the secret while DiPietro et al. (1997) suggested that older children are perhaps less influenced by the perpetrators' demands for silence. Some studies do indicate that the intentional nature of disclosure varies with age: younger children are more likely to disclose accidentally while more older children disclose purposefully (Campis et al., 1993; Farrell, 1988; Sauzier, 1989; Sorenson \& Snow, 1991). Triggers for disclosure have also been given some attention. Sorenson and Snow (1991) found in a sample of children aged 3 to 19 years that younger children more often disclosed following a school based education programme while the most common trigger for adolescents to disclose was anger. Herman (1981) suggested that the onset of puberty brings a heightened awareness of sexuality that in turn leads many young people to disclose abuse they had experienced many years beforehand.

Byrnes (2006) reviewed the literature on adolescents' decision-making abilities and points to studies which have found that older adolescents are more capable of considering multiple options resulting in meeting different needs, (Byrnes \& McClenny, 1994; Byrnes, Miller \& Reynolds, 1999; cited in Byrnes, 2006) and anticipate a wider range of consequences of their actions (Lewis, 1981; Halpern, Felsher, \& Cauffman, 2001; cited in Byrnes, 2006). According to Byrnes (2006), cognitive skills do develop in several important ways during the adolescent period. Older adolescents and adults not only have more knowledge than younger adolescent and children, they demonstrate greater facility in making use of this knowledge to remember, reason, make decisions, and solve problems. Byrnes also suggests that adolescents are more likely to make good decisions when they have meta-cognitive insight into the factors that affect the quality of decision-making 
(D. C. Miller \& Byrnes, 2001; Ormond, Luszcz, Mann, \& Beswick, 1991). Meta-cognitive skills refer to the ability to reflect upon and evaluate one's own knowledge or someone else's knowledge. It includes the ability to reflect upon the source of their knowledge and what they and others believe to be the case (Moshman, 1998). Thus the child who has been told that if they disclose the abuse it will be seen by others as the child's fault begins to challenge these beliefs as the developing adolescent learns more about how society views child abuse and appreciates the imbalance of power between the adult who abused them and the child they were. The child who was told it was just a game begins to understand the abuser's rationale for portraying the sexually abusive behaviour as a game "I didn't really understand. I was only like 7 years old and I was told it was a game. I thought it was normal” (C01). In addition to the improved decision-making capabilities of the adolescent compared to the younger child, there is now evidence to suggest that continued brain development through adolescence may contribute to the adolescents' abilities with respect to such social cognition tasks as perspective taking. Recent research in the field of neuroscience suggests that the brain structures that underlie these functions continue to develop beyond early childhood, contrary to what was previously believed, and that the efficiency of the ability to take another's perspective continues to develop during adolescence (Blakemore $\&$ Choudhury, 2006).

Part of being a good decision-maker, according to Byrnes (2006) is being able to use selfregulatory (e.g. self-calming) strategies to manage the effects of emotions. This capacity was referred to above in the section on the pressure cooker effect. Given the emotional turmoil of conflicting emotions which many adolescents reported in this study such as fear of the consequences of disclosure, upsetting loved ones, wanting to protect others, fear of being judged, concern for other children who may be at risk of being abused, it seems no wonder that young people experience such difficulty struggling with containing the secret about their experiences.

Cognitive development does not happen in a vacuum. It is through the interactive debate with others that adolescents become more aware of other points of view. However, in the absence of being able to discuss their beliefs about sexual abuse and the impact of the abuse on them, distorted belief systems go unchallenged, for many well into adulthood. Some of these beliefs may be based on what the abuser said to them at the time of the abuse, such as threats to kill the child or someone close to the child. The fear of consequences of disclosure cited in the literature includes children's fears that they would be judged by others and seen as responsible for the abuse, thus causing more trouble to themselves, fear that parents would be upset and wishing to protect parents from this knowledge.

As children develop increasing autonomy and independence they also develop cognitive, social and emotional skills that facilitate the process of confiding personal experiences that previously they 
have kept to themselves. Decision making skills which enable the young person to consider alternative consequences to their behaviour, multiple outcomes and an appreciation of the diverse perspectives of others enables them to weigh up the relative advantages and disadvantages of disclosure. The growing awareness of risk to other children reflects an empathic response that was noted by teenagers in this study as helping them to tell of their abuse. Increased empathy enables them to appreciate the vulnerability of other children to abuse yet also sensitises them to the distress inevitably caused when loved ones discover that the abuse has occurred. Those emotional skills and abilities which are developed or enhanced in adolescence and which, according to Rosenblum and Lewis (2006), serve as the building blocks for adult emotional functioning include the ability to experience and reflect on mixed and conflicting emotions, and the capacity for a mature experience of empathy. Emotional self-regulation is needed to contain the 'pressure cooker' of conflicting emotions which young people describe in struggling with protecting and seeking help.

For the most part, the prevalence of disclosure during adolescence has been attributed to the increased cognitive capacity of adolescents and this is much of the basis for Bussey and Grimbeek's (1995) socio-cognitive framework and Leonard's (1996) cost benefit analysis. However, in this study, it is suggested that in addition to the critical cognitive development that occurs in adolescence, the increased moral awareness and in particular the emotional sensitivity of this stage of development is what helps young people tell. The pressure cooker dynamic suggested in the theoretical framework put forward in this study is an emotional dynamic, not a cognitive one, although cognitive factors do influence the pressure on the young person both from within and without. Developmentally, adolescence is an emotionally sensitive time with one of its key developmental tasks that of emotional self-regulation. As Waddell (2002) points out, "impulse tends to be to act rather than to think...to experience the world, the self and other people in extreme terms, of good and bad" (p. 146). It may be that this tendency to sharpen the distinction between good and bad, ignoring the subtleties, is what helps young people to take the brave step to tell.

One hypothesis arising out of the present study then is: are children more likely to disclose in adolescence, regardless of the age at which they were abused? Farrell (1988) found that the age of the child was associated with intentional disclosure and that older children were more likely to disclose regardless of the age at which they were abused. While it was not possible to compare age cohorts in this study given the small numbers of younger children interviewed and the overrepresentation of adolescents in the study, it is reasonable to suggest that given the cognitive, emotional and moral developmental tasks associated with the teenage years, that these dynamics play a strong role in the process of confiding experiences of sexual abuse. Both the concern in relation to upsetting others and the concern for other children being at risk are consistent with the growing altruism, empathy, and ability to take another's perspective along with the growing body 
of knowledge about the ongoing risks to other children. McGee et al. (2002) found that in their nationally representative study, $67 \%$ of abused Irish girls and $62 \%$ of abused Irish boys in their sample had experienced abuse by twelve years of age. McGee et al. did not examine age at time of disclosure but $47 \%$ of their sample of adults had not disclosed until adulthood, i.e. at the time of their study.

\section{Family Influences}

As was noted in Chapter 5, family issues influenced the experience of containing the secret of sexual abuse for participants in this study in several respects. Firstly, family members, in particular mothers were sometimes the first person in whom the child confided. Even when young people first told friends, the next person was usually a parent. The extent to which the theme being asked emerged in this study was unexpected. As clarified in Chapter 4, this theme referred to young people being asked directly if they had been abused and indirectly if there was something wrong. Parents were often the ones to ask and for many young people, this experience of being asked led to their confiding either as an immediate trigger or as a contributing factors.

As young people were accessed through a specialist sexual abuse agency for this study, and parental consent for participation obtained, all of the young people by definition had confided in their parents prior to participation in the study. For some young people, the parent was the first confidante and for others there was some delay in telling a parent. Only in the adult sample was it possible to explore the issue of not confiding in parents at all, as many of these had not confided in their parents.

Secondly, whether the abuser was a member of the family or outside the family significantly influenced the young person's reluctance to tell and the delay in telling. Research has clearly supported the distinctive influence of the relationship between the child and the abuser, in particular where the child is abused by a family member or someone in a caring role or a position of trust. Abuse by a family member has been identified as contributing to both non-disclosure and delays in disclosure (Goodman-Brown et al., 2003; Connolly \& Read, 2007). Fears of the consequences of disclosing when the child is abused by a family member is a contributing factor to these difficulties (Goodman-Brown et al., 2003) and as highlighted in this study, these fears are often well founded. The burden of responsibility for the consequences of abuse is placed on the child as in reality, these consequences are only realised when the abuse experience is disclosed and can therefore be perceived by the child as a consequence of disclosure rather than a consequence of the abuse.

Young people in this study who were abused by someone within the family described their reluctance to tell due to their belief that it would split up their family. As mentioned earlier, two 
adults in this study described having reported childhood abuse as a child but later experiencing abuse in their teenage years which they did not divulge for many years into adulthood and never to their parents. This reluctance to disclose the later abuse was attributed in part to the response to the earlier disclosure (i.e. a police investigation or the reaction of the parent) and in part to the relationship to the abuser in that in the later experiences the abusers were either a family member or the child's mother's partner. In the sample of young people, there was an insufficient representation of different experiences of abuse to enable comparisons. However, it was clear from the narratives of adults that different familial relationships can exert a differential influence on children. Four adults who had experienced abuse by their brothers never told anyone of this abuse until adulthood and in two of these cases, only told when they began counselling.

Thirdly, young people expressed concerns about how their parents would react if they told them. Most young people did not want to upset their parents and this was a factor in inhibiting confiding. This was the case whether the abuse was intra-familial or extra-familial. Many of the adults in this study referred to not having a close relationship with their parents while they were children and thus not feeling able to tell their parents about the abuse. Almost all of the young people described a good relationship with their parents and one that facilitated disclosures of other concerns. Having a close relationship was not a factor that helped children tell in this study. In fact, this factor to some extent acted as an inhibitor for children as young people believed that their parents would be upset if they knew about the abuse. This fear was realised for many young people and parents were both described as and described themselves as extremely upset when their daughter or son told them of their experience of abuse. This dynamic has also been found in other studies where children cited their reasons for not telling as wanting to protect others (Crisma et al., 2004; Jensen et al., 2005). Herman and Shatzow (1987, cited in Alaggia, 2005) noted that concern about mothers is usually in the context of families where mothers themselves are vulnerable or victimized.

Goodman-Brown et al. (2003) found that children's fear of consequences was a significant contributing factor to young people delaying disclosure and noted that this fear was related to a fear of negative consequences to others, not to the self or the defendant. However the present study highlights a typical reaction of parents to discovering one's child has been abused and the basis in reality for these concerns of young people.

According to Lovett (2004), the response by caregivers and professionals has the power to assist victims with recovery or further traumatise them. The focus on reactions to disclosure, particularly mothers' reactions has been prompted by the interest in how such reactions impact on the child's recovery from the impact of the abuse. More positive outcomes for children who receive support when they disclose have been noted (Adams-Tucker, 1982; Conte \& Schuerman, 1987, cited in Lovett). According to Lovett, "familial response to abuse may be at least as important as professional therapy “(p.369). Staller and Nelson -Gardell (2005) highlight the importance of the 
response to disclosure as an influencing factor on future disclosures suggesting that positive responses are more likely to lead to further disclosure while a negative response is more likely to inhibit further disclosure. The vast majority of young people in this study received a positive response by those close to them when they confided about their experiences of abuse. Narratives that featured negative responses by parents or caregivers to the explicit telling about abuse were exclusively from the adult sample. This may be a feature of the differences between the samples in two respects. Firstly, the adult sample was describing experiences some decades ago, when awareness of sexual abuse was poor. Secondly, the sample of young people in this study was accessed through an intervention service. Thus, by definition, the latter sample was listened to, believed, and help sought for them. The first sample was accessed through an adult counselling service. None of these people had received counselling or other interventions related to their experience of abuse as children until they sought help themselves as adults.

In addition to the above family influences, two themes were also prevalent that pertain to family issues. A number of the parents of the young people in this study had themselves experienced sexual abuse in childhood. For the most part, the young people in this study were unaware of their parents' history of abuse until after they themselves confided their experiences of abuse. Some remained unaware of this fact at the time of the research study. The impact on families of intergenerational abuse has received some attention in the research literature (Smyth, 2007) but how this may impact on children's disclosures is unknown. Secondly, parents in this study were actively containing the secret of their child's experience of abuse as a protective measure for their children. Thus, the process of containing the secret is not just an active process for the child but also for the parent and other members of the family.

\section{Peer Influences}

The significance of peer relationships for development has become increasingly recognised in recent years. While case studies of Anna Freud and Sophie Dann (1951) after the First World War supported the view that children can provide one another with security and self-enhancement, and when adults are absent, support ego development, it is in more recent years that research attention has been focused on friendships as a developmental advantage for children. Hartup (1999) points out that outcomes vary depending on whether one has friends, who one's friends are (socially competent versus antisocial) and the quality of friendships (e.g. having elements such as supportiveness).

In this study, peer relationships were found to be an important source of support for adolescents. Of the 22 young people interviewed, 9 had first confided in a peer, be that friend, boyfriend or cousin, before they had told an adult of the abuse. Often the context of the disclosure was that of a mutual sharing of difficulties. Disclosures to friends were met with an outpouring of support. All 
responded by encouraging disclosure to an adult, usually the parent and in two instances the friend was present when the young person told their parent. Many young people described how their friends persisted with encouraging them to tell their parents. Some friends responded by pointing out the potential risk to other children. While there is some evidence that young people rely more on peer relationships when family relationships are poor (Barber \& Olsen, 1997), in this study most of the young people interviewed described a close relationship with their parents that they indicated was a barrier to being able to confide in them about the abuse.

The data in relation to confiding in friends take on even greater significance when we consider the research on peer relationships reviewed by Ladd (2005) that shows that peer relationships (combined in complex ways with many other personal and contextual factors) affect later adjustment. Positive peer relationships are associated with better mental health and educational achievement because they provide social support, opportunities for developing skills, protection from the occurrence and/or effects of negative peer relationships, and opportunities for developing a positive view of the self. According to Carr (2006) peer relationships may be either maintaining or protective factors for many common clinical problems. Perhaps this important resource for young people could be harnessed in the context of encouraging young people to disclose sexual abuse. Educating young people about how to respond if a friend disclosed sexual abuse could have far reaching consequences for children who have been sexually abused.

For children who first told a friend, the secret was contained within this peer relationship in some cases for several months and in one case for over a year. It may well be (and this was confirmed by one young participant) that this disclosure in some way alleviated the pressure felt by the young person which in itself delayed telling an adult of the abuse. D.W. Smith et al., (2000) found that although friends were the most common recipient of disclosures for their sample of adult women reporting childhood rape, only $12 \%$ of these experiences had been reported to civil authorities. As their data was confined to initial confidante, it was not possible for them to explore whether these women had subsequently told an adult. However, the authors emphasise the importance of peer support and propose that increased efforts should be made to teach children appropriate ways to seek help for their friends who confide in them that they have been abused. In the present study, for the majority of young people in the study, once an adult was told the authorities were informed. However, even in this process, the information was withheld in many cases from members of the extended family, while some children were encouraged by their parents not to tell their friends

\section{School Issues}

Greene (1994) has suggested that the role of schools in Ireland may play an even stronger role in the lives of children than in other comparable societies due to the strong involvement of schools in the religious and moral education of the child, the unusually early age of starting formal schooling 
and the high value placed on education in the Irish culture. The potential role of schools in helping children tell was explored directly with participants in this study with mixed findings. Despite the introduction of the Stay Safe programme into primary schools in Ireland since 1991, many young people and their parents did not recognise this programme as a child abuse prevention programme, associating it more with bullying. Some young people suggested that a teacher would be a good person to tell while others did not think a teacher would be a likely confidante. Most participants suggested that schools should be involved in awareness-raising campaigns to educate children about abuse although some young people pointed out that talking about sexual abuse in class might bring unwanted attention to those who have been abused.

Despite some criticism of school-based sexual abuse prevention programmes as ineffective, inappropriately placing a burden on children, and possibly having negative effects on children (Catholic Medical Association, 2006, cited in Finkelhor, 2007), the prevailing view from a review of the relevant research is that such programmes are worthwhile (Finkelhor, 2007). As Finkelhor points out, however, additional prevention strategies such as campaigns to deter and control offending behaviour should be used in conjunction with prevention programmes for children.

The reported lack of explicit reference to sexual abuse in the educational prevention programmes in which the young people in this study participated may reflect an unwillingness to face up to the reality of sexual abuse in Irish society, despite several high profile cases and much media discussion on the subject. Although for the most part, children in this study had participated in child abuse prevention programmes, most young people reported being unaware of sexual abuse prior to being abused and unaware of others in their family or social circle who had experienced abuse until after their disclosure.

\section{The Wider Society}

Despite the contribution of media coverage to increasing awareness of sexual abuse as a phenomenon in Irish society, many people remain unaware of people in their social circles who have experienced abuse. Most of the young people in this study were not aware of anyone who had previously been abused although others did confide in them following their sharing of the secret. Given the reported prevalence of child sexual abuse in Irish studies (McGee et al., 2002), it is unlikely that these young people did not know anyone who had been abused but rather they did not know that they had been abused. Indeed, many described how others confided in them following their own disclosure. While most agreed that talking about abuse more openly would encourage young people to tell, this consensus of opinion was not reflected in their own actions and many added a note of caution to the idea of talking openly about one's own experience of sexual abuse. A few young people had told no friends at all, only family knew due to concerns of being judged by others, being seen differently or concerns about confidentiality. The young people's arguments for 
maintaining the secret were compelling. A teenage girl talked of how her ex-boyfriend challenged her in a social setting in front of friends, that she only made up the story about her mother's partner abusing her because she wanted him out of the house.

As noted in Chapter 1, the Catholic ethos has been strong in Ireland where the vast majority of citizens are Catholic and links between the state and the Catholic Church are strong. Greene (1994) points out that Ireland is less permissive in sexual matters than other countries, referring to the attempts at legislative change on issues such as contraception, abortion, divorce and homosexuality. Duncan (1994) suggests that Irish attitudes are much more flexible and sympathetic to such issues as abortion and divorce as would be evident from voting patterns in referenda. He points to results of opinion polls that suggest that Irish attitudes are much more relaxed in relation to humanitarian issues in individual cases than in relation to abstract general principles.

Greene (2003) refers to the increasing awareness in developmental psychology of the need to "locate people in their cultural and historical context" (p.114). The cultural and historical contexts of children and adult participants in this study show marked differences. Increased awareness of sexual abuse has been evident in recent decades in Ireland through media coverage of legal proceedings. The impact of this context on participants in this study was not directly explored. However, adults interviewed in this study commented on how different young people are today compared with when they were children. Characteristics such as being more assertive, more aware of abuse and consequently more likely to tell were attributed to children of to-day. Some differences between the stories of children and adults in this study may reflect cultural changes over the past few decades with respect to the issue of sexual abuse. In the adult sample, the theme of being believed was particularly poignant with respect to a fear on the part of participants that their parents would not believe them. This issue was much less evident in the interviews with young people, most of whom did not doubt that their parents would believe them. Nevertheless, the concern about being believed by others such as peers, extended family and members of the community, suggests that while family cultures may have changed in the past few decades, societal culture may have changed little. McGee et al. (2002), in their survey of over 3,000 members of the Irish public, found that $40 \%$ of respondents felt that accusations of rape are often false. When children make allegations of sexual abuse in Ireland, the standard practice is to undertake an investigative interview in order to form an opinion as to credibility. This practice in itself could be construed as 'not believing the child' in the first instance, much as the legal practice of the accused being innocent until proven guilty in itself can be construed by children and adults as them not being believed.

The extent to which young people in this study were asked about sexual abuse compared to the adult sample would appear to reflect a cultural shift and increased awareness on the part of parents 
and professionals of the possibility of sexual abuse occurring. Children and young people in this study described experiences of being asked that were noticeably absent from adults' narratives. The social acceptability of talking about such experiences was perceived by adults in the study as very different for young people at the present time when compared to the time of their childhood. While there was little evidence that young people at the present time knew someone who has been abused prior to the time they confided in someone, the experience of disclosing did lead to reciprocal disclosures, thus increasing their awareness. The adults in this study did not have this opportunity as the vast majority did not confide during childhood.

In the legal arena, reporting rates to gardai differed significantly between the adult and child samples in this study reflecting a cultural change towards the recognition of sexual abuse as a criminal offence. As only two cases had known outcomes, the likely prosecution rate for this sample is unknown. In Ireland, reporting rates have not translated into prosecution rates. According to Regan and Kelly (2003), who reviewed conviction rates for rape and sexual assault, Ireland has the lowest conviction rate in Europe at 1\%, despite comparable reporting rates with other European countries.

The role of the media as a potential cultural influence on disclosing sexual abuse was also highlighted in Chapter 1. In this study, mixed views were held as to whether media coverage was helpful or unhelpful to both young people and adults. While media coverage in some instances contributed to the pressure cooker effect by acting as a trigger for telling, for others it was experienced as intrusive, distressing and unwanted. Nevertheless, public attitudes are strongly influenced by media coverage of sexual abuse. Goode et al., (2003) conducted a telephone survey among members of the public ( $\mathrm{n}=1081)$, and found that the media were reported as the main source of information on child sexual abuse. The media therefore has a key role to play in raising awareness of this issue in Irish society. The nature of media coverage, is however, a cause for concern. Language used in media as demonising abusers was noted by one parent in this study, reflecting a poor understanding on the part of media professionals of the issue itself. This parent highlighted the challenge of keeping an extended family intact where intra-familial abuse has occurred in the context of a society which rejects those who abuse children as reflected in both media attitudes and the lack of services available for families who wish to work together to resolve the difficulties presented to them.

The increasing cultural diversity evident in Irish society due to high rates of immigration in recent years is likely to highlight cultural differences in experiences of disclosing, if such differences exist. One young person in this study emphasised the powerless of children in her country of origin, seeing a clear distinction between the availability of services for children in Ireland compared to 
her home country. Nevertheless some parents in this study reported dissatisfaction with the lack of information about how to access services and the delay in receiving a service.

\section{Conclusion}

This study describes the various manifestations of the process of containing the secret of child sexual abuse. Through interviews with young people, their parents and adults who were themselves abused in childhood, it was possible to depict the rich and complex process that describes how the secret of sexual abuse is contained. Containment, it is suggested, is a suitable word to use to describe how the secret is kept confidential for the most part between friends, within families and within professional services. It is also suggested that containment, as a psychological response to children and families is needed for the unmanageable anxiety that is associated with the experience of abuse. The active withholding dynamic of the process, when it occurs at the intrapersonal level (before the child has confided) may give the child a sense of self-efficacy and safety in an unsafe world. Keeping the secret may be a way of gaining and maintaining control over the experience through controlling the flow of information and the accompanying distress associated with sharing this information. Confiding in another may reflect the need for containment on the part of the young person, sometimes manifested as a struggle with competing emotional pressures that are challenging for the young person who is attempting to self-regulate their emotions and conceptualised here as the pressure cooker effect.

Although the disclosure process has not been conceptualised in the literature as one of containing the secret, research findings are consistent with such a conceptualisation. The secret is initially contained by the child, then by family and/or friends and then by the professional system. The child is involved in the overall process as an active agent.

It is suggested that the term confiding more appropriately conveys the meaning associated with the experience of telling as a sharing of intimate information. The process of confiding is not linear and sequential as suggested in the early literature on child sexual abuse but is, as Stellar and NelsonGardell (2005) suggest, a dialogical process that is re-negotiated and influenced by each experience of disclosure. This process is best conceptualised as a cyclical process of withholding information followed by a pressure cooker effect and the experience of confiding. It may continue in a "stopstart" fashion throughout the lifespan whereby the initial experience of telling is followed by more withholding and confiding as young people form relationships or come to trust those around them. Resolution of the conflict arising from the pressure cooker effect, i.e. pressure to actively withhold and pressure to tell, is negotiated within different relationships and further confiding, when it occurs, represents an expansion of the system within which the secret is contained. These 
conflicting pressures are cognitive, emotional, social and moral, are influenced by developmental factors and are important to understand if we are to help young people tell. The process is progressive in two respects: telling more details and telling more people. It is dynamic, constantly changing. Influencing factors for withholding or confiding the secret change over time and in different relationships.

In examining the experiences of confiding for participants in this study, it is suggested that the decision-making models of weighing up the costs and benefits of confiding do not capture the emotional intensity of this experience and how for many, the disclosure itself, is unplanned. Rather, it is suggested, a pressure cooker effect applies, whereby conflicting thoughts, and emotions build up over time resulting in the young person confiding in another. The choice of confidante is important in that those in whom the secret is confided are for the most part people who are close to the young person or someone they feel they can trust. The reciprocal process of confiding was identified in this study in that young people were often asked, either directly or indirectly, if they had been abused or if something was wrong and this contributed to their ability to tell. Recent research suggests that this feature of the process is much more prevalent than had previously been highlighted in the literature (Hershkowitz et al., 2007).

Key influencing factors for containing the secret identified in this study included being believed, being asked, shame, embarrassment, self-blame, and concern for others. Although a fear of the consequences of disclosing has been identified as a significant predictor of delay in disclosing (Goodman-Brown et al., 2003), what has not been highlighted in previous studies is how warranted these fears are for children. Many children are not believed, they are judged and blamed for the abuse or for disclosing the abuse. The burden of containing the secret at an intrapersonal level - by actively withholding the secret from all - is a significant one, not to be underestimated. Exploration of this dynamic reveals altruism on the part of young people previously unacknowledged in the literature. In this study, this was associated with the fact that young people, for the most part, described supportive relationships within their families. The issue has been highlighted in more recent research that young people sometimes do not tell because of wanting to protect others, particularly mothers who are perceived as vulnerable and in need of support. This is not set in the context of how often parents (both mothers and fathers) do get upset upon hearing that their child has been abused, how often families do break up following this discovery, and the impact of this on the child who has been abused and her family. An additional theme that has received little attention in previous research is the extent to which young people in this study referred to their concern for other children as an incentive for their telling. Thus, it is suggested here, both the decision not to tell and the decision to tell reflect courage on the part of children. 
The extent of non-disclosure noted in Chapter 1 begs the question: is there an adaptive function to non-disclosure that needs to be better understood? Reconceptualising "disclosure" and "nondisclosure" as aspects of a process of containing the secret is more consistent with viewing these processes as adaptive for the child. It would appear from this study that these fears are well founded and that, as Summit suggested in 1983, for many children it is adaptive coping strategy for children, not to tell.

Feelings of shame, embarrassment \& self-blame are common themes long recognised as being associated with the experience of sexual abuse. In this study, these dynamics appeared to be more prevalent in older adolescents and adults although it is acknowledged that the small numbers interviewed in this study prohibit conclusions on this issue. However, it is suggested that selfblame may develop during the process of active withholding and may be exacerbated by not being able to confide in others and therefore not have the opportunity for many of the beliefs of young people about perceived responsibility to be challenged.

Motivating factors for containing the secret operate at various levels - individual, family, peer group, school and within wider societal contexts. At the individual level, it is suggested that adolescence may be a pivotal time for disclosing sexual abuse, regardless of the age at which the child was abused. Although prevalence rates for disclosure are higher in adolescence (DiPietro et al, 1997; Hershkowitz et al., 2005, 2007; Keary \& Fitzpatrick, 1994) there is insufficient data to support the thesis that this is regardless of age at the time of the abuse. Farrell (1988) did find that older girls who were abused by their fathers were more likely to disclose in adolescence regardless of age at time of abuse and the findings of the present study do indicate that this hypothesis is worth testing for children who have experienced both intrafamilial and extrafamilial abuse. The convergence of cognitive, emotional, social and moral development all support the thesis that adolescents are better equipped for the developmental task of confiding experiences of abuse than their younger counterparts. However, it also needs to be acknowledged that while adolescents might be better equipped than younger children in some respects, young children may have some advantages. In addition to the position put forward by Bussey \& Grimbeek that younger children may be less inhibited to purposefully disclose, the psychological impact of the abuse experience, in particular that of self-blame, shame and embarrassment may be more prevalent in those who delay disclosure than for those who confide their experiences promptly. There is some evidence from Goodman-Brown et al. (2003) to support this position. In their study, children who were older, and delayed disclosure, perceived themselves to be more responsible for the abuse than those who were younger and disclosed more promptly. What is not clear from their findings is whether the delay in disclosing in itself contributed to the feelings of self-blame. There was some evidence from the present study that young people's understanding of their reluctance to tell changes over time and that self-blame may be a dynamic that develops in the absence of being able to confide the abuse in others. 
At the family level of influence, concern for others in the form of not wanting to upset others, particularly parents, was identified as a key motivating factor for young people in actively withholding the secret of abuse in this study. As the sample of young people who were interviewed in this study was predominantly adolescent, it is suggested that this altruistic wish to protect parents may interact with the developmental tasks at the adolescent stage of life, among other factors. Parents' wish to protect the privacy of the young person through containing the secret at a broader systemic level was also noted. Some of the experiences of young people in this study who told others in their social network support these parents' concerns for their children, that they would be judged or thought less of because they had been abused. It was also found that a high proportion of parents in this study were themselves abused, for the most part unknown to their children. Peer influence was found to be a significant factor in influencing the process of containing the secret of sexual abuse for young people in this study. The frequency with which young people confided in friends was noted in this study and builds on a growing body of evidence that peers are an important source of support for young people who need to confide difficult experiences. This is consistent with a growing recognition in developmental psychology of the role of peers and more attention to this issue in the field of child sexual abuse. The role of peers in this study in encouraging the young person to tell an adult suggests that peers may be an important target audience for educational and awareness intervention programmes.

Finally, despite an explosion of public awareness of the extent of sexual abuse in Ireland during the past few decades, as discussed in Chapter 1, young people in this study were remarkably unaware of people in their social network who had experienced abuse, until after they themselves confided about their own experience of abuse. Despite having participated in school-based sexual abuse prevention programmes, many of the young people did not recall any reference to sexually abusive behaviour in these programmes and views on the helpfulness of these programmes were mixed. The divergence of views on the helpfulness or otherwise of teachers' roles and the media coverage of child sexual abuse in helping children tell about experiences of abuse highlights the need for multiple approaches to helping children tell. While preventative efforts need to involve schools it needs to be acknowledged that although for some children this is helpful, for others it may not be helpful.

Approaching the data in this study with the lens of Belsky's ecological systemic framework (1980, 1993) has assisted with the conceptualisation of the multiplicity of influences on the child's experience of containing the secret of sexual abuse. Through extending our understanding of the complexity of influences on this process, it is possible to consider both the potential strengths and difficulties inherent in addressing the task of how to help children tell. Although the choice of research methods used in this study in itself supports viewing children as active contributors to the 
research process, the theoretical framework suggested by the findings underscore this active involvement and agency of the child in the process of containing the secret of child sexual abuse.

\section{Limitations of this Study and Future Directions}

This section will address the limitations of this study and identify possible future directions both in terms of methodological approaches and topics worthy of further investigation. It is acknowledged that both method and theory are interrelated as seen in the discussion below.

\section{Reflections on Method}

The methods used in this study and the rationale for such methods are detailed in Chapter 2 of this thesis. However, there was also a recognition that various methods could be used to investigate the central research question of this study, how children tell. Alternative methods may have altered the findings of this investigation. Firstly, data were gathered, with the exception of the first three child interviews and the first adult interview, in the context of a once off interview with the research participant. This was considered sufficient for the purpose of this study in terms of having the research questions addressed but also in recognition of the interview as a construction of a story at one point in time. However, many of the children and young people whose stories are represented in this study were seen for interview, or their stories told, a considerable length of time after their first disclosure. Longitudinal studies could access children at an early stage following their first experience of confiding and explore the process contemporaneously. This would significantly enhance our understanding of this process. The story of disclosure for many is elusive and difficult to clarify. It can be fragmented with insights and revelations coming to light each time it is discussed. Parents in this study were still struggling to understand what influenced their children to disclose during the research interview and many young people referred to the reasons for not telling changing over time. A longitudinal approach could capture experiences over time and also perspectives as they change over time. Charmaz (2006) has conducted follow-up interviews over a long period of time as a form of theoretical sampling to develop theory further.

With regard to member checking, it is the practice of some researchers to revisit the transcripts with all research participants, not just a sample as was used in the present study.

Although a second service for children was approached late in the development of the study for the purpose of targeting a younger age cohort, this service could have been approached at the beginning of the study. It was not anticipated that a) it would be difficult to access children of different ages; and b) the predominant age cohort attending the service during the course of the study would be adolescents. 
Exploring developmental differences would benefit from sampling that would target different age cohorts. A number of questions are raised from the present study that could be explored. Firstly, in exploring whether adolescence is in fact a pivotal time for disclosure, it would be important to distinguish between those adolescents who experienced abuse during adolescence and confide this abuse in a more timely fashion and those adolescents who experienced abuse in their earlier childhood and delayed confiding. Secondly, there has been some indication from the literature that influencing factors on the disclosure process have a differential impact on children of different ages. A question arising from this study worthy of further investigation is the extent to which the impact of shame, embarrassment and self-blame as impediments to disclosure are associated with developmental factors. An additional question is whether these dynamics are influenced by the experience of disclosing and the consequences of disclosing.

Difficulties with representative sampling in the field of child sexual abuse have been highlighted in Chapter 1 and ethical implications for research in this area were referred to in Chapter 2. Research in this area has relied on highly selective samples and this was also the case in this study. Some of the discrepancies in findings between the child sample and the adult sample in this study is possibly attributed to sample differences in that the children were brought for help following their telling while the adults for the most part initiated the search for help themselves. All of the young people interviewed in this study were attending therapy. It may be that the experience of therapy itself influenced children's understanding of their own experiences and their ability to engage in a conversation with the researcher about these experiences. Access to children who have less positive experiences of being heard and being believed is therefore more difficult but not impossible. Helpline services for children are a potential source of information on this group of children that are under represented in the research literature. While it is possible that a small proportion of these children may be reporting erroneous allegations, they may in many respects constitute a more representative sample of those children who have experienced sexual abuse.

Although methodological issues in child sexual abuse research were discussed in Chapter 1, additional issues were identified during the course of this study. By exploring different perspectives on a child's story of how they first told, discrepancies arose that highlight the value of including multiple perspectives. In comparing children's accounts with their parents' accounts, it was possible to discern that on occasion parents did not know that their son or daughter had already confided in a friend before they had told their parents. Relying on parents' accounts alone would not elicit this important information. A second issue noted in the interviews with young people was that although the question of whom the young person first told was asked early in the interview, on occasion it emerged that the person identified at this stage was not the first person told but sometimes the first adult told. The question of how young people interpret questions is well 
documented in the forensic interviewing literature (Walker, 1999). The research interview provides the facility for clarifying how young people interpret questions and how their answers are interpreted. It also emerged during the course of this study that young people's and adults' understanding of this process under investigation changes over time. If participants had been interviewed many months earlier, their perspective might have been different. Some participants referred to their own understanding of their reluctance to tell changing over the course of their lifespan. Interviewing participants at one point in time captures only a snapshot of this process.

This study examined the process of how children tell. By definition, therefore the focus was on a verbal telling of the experience of abuse and the methodology employed in this study was to elicit verbal accounts of this telling experience. However, as Alaggia (2004) notes, there are many ways of telling. Signs of psychological distress emerged in this study as a sub-theme of the pressure cooker effect. This theme highlights the emotional pressure experienced by young people to both actively withhold the secret and tell. However, as noted in Chapter 1, Alaggia included behavioural manifestations in her conceptual framework of patterns of disclosure. These referred to the nonverbal attempts on the part of the child to tell or behavioural effects or symptoms as a means of communicating the disclosure. Rogers (2006) also refers to the story of trauma as " the unsayable...something that moves toward speech and away from speech at the same time" (p.57). Rogers links the experience of speaking about abuse with remembering abuse. Not wanting to or not being able to talk about abuse is associated with not wanting to remember or feel the emotional pain associated with the abuse experience itself. By focusing on the verbal aspects of telling, this study may have limited application for those children who have communicated their experiences of abuse without relying on words to tell their story.

\section{Reflections on Theory}

Although the increased use of qualitative methods of enquiry has provided rich insight into some aspects of disclosure, as Staller \& Nelson-Gardell (2005) point out, both Petronio et al. (1997) and Alaggia (2004) studied discrete points in the disclosure process. Petronio et al. focussed on choice of confidante and Alaggia on descriptive categories of disclosure. Staller and Nelson-Gardell took a broader view and attempted to investigate the entire process, close to the time the disclosure occurred. The present study takes a similar broad view of the disclosure process, seeking to explore the pre-disclosure and post-disclosure thoughts, feelings and behaviours of young people but goes further in several respects. While Staller and Nelson-Gardell's study was based on a secondary analysis of data elicited on treatment experiences, this study directly interviewed young people about their disclosure experiences. Secondly, the study attempted to explore the disclosure process from different perspectives - that of the child, the child's parent and the adult who was abused in childhood. Thirdly, the complexity of people's abuse experiences, rather than being reduced to facilitate analysis, was retained in all its awkwardness and unmanageability. Successive 
experiences of disclosure were explored. The distinctive experience of disclosing different experiences of abuse by different perpetrators was incorporated into the analysis. Through the use of qualitative methods, diversity was welcomed, adding richness to the resulting analysis. Finally, by taking a developmental systemic perspective in the analysis, this study highlights the mutual contributions of the related fields of developmental psychology and child sexual abuse.

Nevertheless, some theoretical themes identified in this study warrant further exploration. A proportion of young people in this study had experienced abuse by peers. This is consistent with previous research which found that a significant proportion of victims of abuse are abused by peers, according to Sperry and Gilbert (2005), in equal proportions to those abused by adults. Kogan's (2004) study of adolescents found that $55 \%$ of unwanted sexual experiences occurred with a peer. A question could have been added to the interview protocol in the present study to explore this theme further. Sperry \& Gilbert compared experiences of children abused by peers to those abused by adolescents or adults in a retrospective adult sample. Although they found no differences in disclosure patterns, they did find that among those who did not disclose in childhood, participants abused by a peer anticipated less support from their parents and more anger from their mothers than participants who reported abuse by non-peers. It may be that distinctive dynamics operate for children abused by peers in the process of containing the secret. No participants in this study reported being abused by a female. This issue was explored in terms of participants' views about whether gender influenced willingness to disclose and there was some support for the finding that disclosing abuse by a female may be more difficult than disclosing abuse by a male. However, individuals who have experienced this abuse need to be asked about their experience of containing this secret to ascertain if additional dynamics apply, particularly given the increasing recognition of abuse by females both in clinical practice and in the literature (M. Elliott, 1997; Lambert, 2004).

The theme of pressure cooker effect was discussed with one young participant and her parents who endorsed this label as fitting with their experience. However, feedback from professional colleagues did question the applicability of this theme to a wider sample of those who have disclosed experiences of abuse. Although the pressure cooker analogy does capture the experience of pressure from without, it may be limited in capturing the internal pressures described by participants in this study. The concept as described here implies a feeling of relief following disclosure that while true for some participants, did not apply for others. The young person who was driven to recant her allegation that her mother's partner had abused her had experienced increased pressure (rather than relief) from others following her disclosure to her mother. In choosing an analogy, there is always a danger that the fixed and well defined characteristics of the analogous process become imposed on the conceptual development of the theme rather than allowing the theme itself to develop conceptually without such constraints. Engaging in further 
comparative analysis of data from participants with more diverse experiences of disclosing would undoubtedly facilitate the definition of this dynamic, described here as the pressure cooker effect.

Although this study did highlight the experiences of young people's experiences in confiding experiences of intrafamilial abuse and, in particular, the contrast between confiding intrafamilial and extrafamilial abuse experienced by the same individual, this data was "thin", in qualitative terms (Charmaz, 2006). Theoretical sampling of individuals with both intrafamilial and extrafamilial experiences of abuse would be helpful in exploring differences in these dynamics.

Additional themes which could direct theoretical sampling are a) whether the abuse was confided in purposefully or spontaneously or whether the confidence was elicited from the child through questions being asked; and $b$ ) exploring the process with young people who have been abused by teenage girls or women. Theoretical sampling would better reflect the diversity of experiences that have already been identified as having a differential influence on children.

Finally, an issue highlighted by my supervisor in the final stages of writing up this thesis was that of courage. Was courage not identified as a significant theme in the analysis? A node was created early in the study but did not feature in the later analysis. In August 2005, a memo records a comment on the node gave me courage: "I wanted to capture the word courage because I think children show great courage in telling about abuse" (Memo, 24.8.05). In addition to reviewing the transcript sections coded at this node in an early database, a search using the word 'courage' on all documents in the database retrieved the following results:

be brave and full of courage and say I'm sorry I don't care how you judge me I didn't do anything wrong (A02)

that kind of gave me courage $(\mathrm{CO} 3)$

I didn't have the courage to say it (C08)

I suppose you have to have a lot of ball (C14)

I think in some ways I was ready to say it but getting the courage to say it was another thing $(\mathrm{C} 21)$

she (mother of abuser) contacted the social workers, the guards, the whole lot like you know I have to give her her due like her courage as well like you know (P11)

These quotes do not capture the courage of those who participated in this study. The extent to which participants did not want others to know about their experiences, coped with the pressure effects of conflicting emotions and thoughts, yet did tell is a testimony to their courage.

To elicit this theme requires interpretation, although perhaps not through the process of line-by-line coding, the creation of conceptual categories, constant comparison and higher levels of abstract conceptualisation. Although there is value in "staying close to the data" as proposed by the methodology used in this study, this needs to be balanced with an interpretative analysis that the researcher brings to the data and is drawn from prior reading and experience. This theme is a good example of how data can be re-visited for the purpose of exploring and testing out hypotheses that may lead to further expansion and development of the theoretical framework. It also highlights the 
issue of theoretical saturation as an aspiration, the ongoing nature of data analysis and the need to revisit again and again the data, eliciting alternative interpretations to enrich theory.

\section{Clinical Implications}

The active nature of the process of containing the secret, the active involvement of the child in this process and the suggestion that this process is adaptive for many children raises the question: Whose needs are being met by encouraging children to tell? As was highlighted in Chapter 1, disclosure is needed for primary prevention to protect other children from being abused by the same perpetrator, for secondary prevention to stop the abuse and provide immediate therapeutic support if required and for tertiary prevention to provide therapy for those who are struggling with the long term psychological sequelae of their experiences. It is also needed to enable both therapeutic and legal services to intervene with the offenders. While adults - parents, professionals - need children to disclose sexual abuse experiences promptly, we also need to take account of children's needs. Westcott (1999) has expressed concern about how the child protection system responds to the needs of children for confidentiality and Bacon and Richardson (2000) suggested that the disclosure process must evolve at the victim's pace and not be overly influenced by the adult's agenda. The idea of being ready to tell has been identified in previous studies and in the present study. This readiness to tell does need to be balanced with society's need for children to tell. Perhaps the focus for helping children needs to be less on helping them disclose sexual abuse and more on helping them contain the secret of abuse in a way that is adaptive for them, their families and society. This effort needs to take account of the factors that inhibit disclosure but also the factors that facilitate confiding. A developmental systemic perspective in understanding these influences highlights the fact that they operate at various levels: the individual level, peer level, family level, and at the level of child protection and legal contexts. Helping children tell is complex and multifaceted and therefore multiple approaches are needed, drawing on the various systemic levels of individual, peer group, family, community and wider society.

At the individual child level, it is suggested that adolescence may be a peak time for facilitating confiding. As young people turn toward their peers as sources of support and confidantes, it is crucial that they are met with appropriate information and guidance. It is suggested that the influence of peer relationships on young people's development can perhaps be harnessed by ensuring that young people can respond appropriately to disclosures of sexual abuse. Kogan (2004) has similarly called for intervention programmes to be targeted at an adolescent population given the prevalence of adolescents as confidantes for their friends' disclosures of sexual abuse. In order to respond appropriately, young people need to be equipped with information about what to say and where to go to for help. This information could be incorporated into existing educational 
programmes for adolescents, such as the Relationships and Sexuality Education programme currently available in post-primary schools in Ireland. Services need to be able to respond to young people's needs, not just those who have been abused but those who have friends who have been abused.

The concerns expressed by young people in this study of wanting to protect others from the distressing knowledge that they have been abused need to be anticipated and understood if we are to find a way to respond to their needs. The courage shown by these young people needs to be met with a reciprocal courage on the part of adults to be open to sharing the burden of the secret of sexual abuse and to communicate our readiness and ability to hear their stories.

At the family, peer and school levels, the issue of asking young people directly if they have been abused was highlighted both in terms of the extent to which this helped young people in this study to confide their secret and in terms of what young people felt would help others tell. Being prepared to ask young people if they have been abused assumes a readiness and willingness to hear the answers and to respond. It also assumes a readiness to believing what one is told. In order to be able to ask, people must be aware of the possibility that abuse may have occurred (when asking directly) or that the experience of abuse may cause psychological distress and therefore something must be wrong in the person's life. As one parent put it: "what else could be going on?" (P54). Asking requires a willingness to be the container for the unmanageable, unedifying and shocking revelation that a child has been abused. As Summit (1983) pointed out, many adults react to this painful and distasteful knowledge by denying that such abuse could exist. Awareness that not only does abuse occur but that it occurs to a significant extent, not only to people "out there" but to many very close to home, within our own families, is crucial to the change in attitude that is required if children are to feel able to confide such experiences. The challenge for public health policy is to find a way to strike the balance between encouraging an openness to discourse on sexual abuse without normalising the experience and detracting from the potential traumatic impact of these experiences.

Therefore the focus of intervention may need to be on helping children contain the secret in a way that is adaptive for their functioning and supportive of their needs, both their child protection and mental health needs.

The findings of this study have implications for professional practice with regard to the forensic interviewing of children. Practice guidelines for interviewing children when concerns emerge that a child has been abused were referred to in Chapter 1. These guidelines (Home Office, 1992, 2000; APSAC, 1999) for the most part, recommend a practice of a once off interview with the child, deeming this to be sufficient to elicit a detailed account of the sexual abuse experience. The 
assumption is that children will, if asked, provide a full account of their experience. Several authors have challenged the appropriateness of such a model, in particular for younger children and for those who for emotional reasons are unable to give a full account of their experience in one interview (Carnes et al., 2001; Coulborn Faller, 2007). The current study suggests that this model is limited if the purpose of such interviews are to elicit a comprehensive account of an experience of sexual abuse that has not already been disclosed. The tendency to confide in incremental steps, the issue of readiness to tell and the extent to which young people in this study denied being abused when asked all present a challenge to the current model of investigative interviewing. Due to the active withholding dynamic evident in the process of containing the secret of sexual abuse, whether a child is ready to disclose will depend to a large extent on the competing forces, both internal and external, operating in the pressure cooker effect and the availability of a relational context as suggested in the dynamic confiding.

It is important for professionals to understand the key finding of this study, i.e. that the experience of telling is in the context of a process of containing the secret, a process that in itself may be adaptive for both the child and her family. Only one young person in this study, out of the twenty two interviewed, disclosed their experience of abuse for the first time in the context of an investigative interview. Previous research has already highlighted that children who have not previously disclosed in an informal context are much less likely to disclose in an investigative interview (Keary \& Fitzpatrick, 1994). The format of such interviews may therefore be much more suited to those children who have already given a comprehensive account of their experience in an informal setting to a trusted confidante and are therefore 'ready to tell'. In Ireland, gardai are beginning to implement new practices with regard to taking video-based evidential statements from children, drawing on many of the same assumptions underlying the interview protocols referred to above. The parent in this study who expressed bewilderment that her seven year old child would be taken to a garda station to be interviewed as if he had committed a crime highlights the great care needed by gardai in interpreting children's reluctance to give detailed articulate statements within a system more accustomed to interviewing perpetrators of crimes.

This study has also highlighted the importance of distinguishing between a child disclosing in a formal context such as an investigative interview and an informal context, such as confiding to a friend or parent and the dangers of assuming that the same dynamics apply to both settings. With an increased understanding of disclosure in an informal context, it may then be possible to explore with confidence, those factors that increase the likelihood of children being able to disclose in the formal context of an investigative interview. 


\section{REFERENCES}

Adams, G. B., \& Berzonsky, M. (2006). Blackwell handbook of adolescence. Oxford: Blackwell Publishing.

Alaggia, R. (2004). Many ways of telling: expanding conceptualizations of child sexual abuse disclosure. Child Abuse \& Neglect, 28, 1213-1227.

Alaggia, R. (2005). Disclosing the trauma of child sexual abuse: a gender analysis. Journal of Loss \& Trauma, 10(5), 453-470.

Amaya-Jackson, L., Socolar, R. R. S., Hunter, W., Runyan, D. K., \& Colindres, R. (2000). Directly questioning children and adolescents about maltreatment: A review of survey measures used. Journal of Interpersonal Violence, 15(7), 725-759.

APSAC (1999). Guidelines for psychosocial evaluation of suspected sexual abuse in young children, Chicago, IL: APSAC

American Psychiatric Association (2000). Diagnostic and statistical manual for mental disorders (4th Edition). Washington DC: APA

Arata, C. M. (1998). To tell or not to tell: Current functioning of child sexual abuse survivors who disclosed their victimization. Child Maltreatment, 3, 63-71.

Bacon, H., \& Richardson, S. (2000). Child sexual abuse and the continuum of victim disclosure. In C. Itzin (Ed.), Home truths about child sexual abuse: Influencing policy and practice, a reader (pp. 235-276). London: Routledge.

Baker, C., Wuest, J., \& Noerager Stern, P. (1992). Method slurring: the grounded theory/phenomenology example. Journal of Advanced Nursing, 17, 1355-1360.

Bandura, A. (1986). Social foundation of thought and action: a social cognitive theory. Englewood Cliffs, NJ: Prentice-Hall.

Bandura, A. (1989a). Social cognitive theory. In R. Vasta (Ed.), Annals of child development: Six theories of development. Greenwich, CT: JAI.

Bandura, A. (1989b). Human agency in social cognitive theory. American Psychologist, 44(9), 1175-1184.

Barber, B. K., \& Olsen, J. A. (1997). Socialization in context: Connection, regulation, and autonomy in the family, school, and neighborhood, and with peers Journal of Adolescent Research, 12(2), 287-315.

Belsky, J. (1980). Child maltreatement: An ecological perspective. American Psychologist, 35(4), 320-335.

Belsky, J. (1993). Etiology of child maltreatment: A developmental-ecological analysis. Psychological Bulletin, 114(3), 413-434.

Bentovim, A. (1995). Trauma organised systems. London: Karnac.

Bentovim, A. (2002). Developmental identity disorder: A developmental perspective. In V. Sinason (Ed.), Attachment, trauma and multiplicity. New York: Brunner-Routledge. 
Berliner, L., \& Conte, J. (1990). The process of victimization: The victim's perspective. Child Abuse \& Neglect, 14, 29-40.

Bettelheim, B. (1943). Individual and mass behaviour in extreme situations. Journal of Abnormal and Social Psychology, 38, 417-452.

Bettelheim, B. (1961). The informed heart: The human condition in modern mass society. London: Thames and Hudson.

Bion, W. R. (1962). Learning from experience. London: Heinemann.

Blakemore, S.-J., \& Choudhury, S. (2006). Development of the adolescent brain: implications for executive function and social cognition. Journal of Child Psychology and Psychiatry, 47(34), 296-312.

Blumer, H. (1969). Symbolic interactionism: Perspectives and method. Englewood Cliffs, New Jersey: Prentice-Hall.

Bolton, F. G., Morris, L. A., \& MacEachron, A. E. (1989). Males at risk: the other side of child sexual abuse. Newbury Park, CA: Sage.

Bottoms, B., Rudnicki, A., \& Epstein, M. (2007). A retrospective study of factors affecting the disclosure of childhood sexual and physical abuse. In M. E. Pipe, M. Lamb, Y. Orbach \& A. C. Cederborg (Eds.), Child sexual abuse: Disclosure, delay and denial. New Jersey: Lawrence Erlbaum Associates.

Bowlby, J. (1998). A secure base: Clinical applications of attachment theory.

Bradley, A. R., \& Wood, J. M. (1996). How do children tell? The disclosure process in child sexual abuse. Child Abuse \& Neglect, 9, 881-891.

Brannon, J. M., \& Larson, B. (1991). Peer counselling strategies: Facilitating self-disclosure among sexually victimized juvenile. Journal of Addictions \& Offender Counseling, 11(2), 51.

Briere, J. (1995). Trauma Symptom Inventory (TSI). Odessa: Psychological Assessment Resources.

Briere, J. (1996). Trauma Symptom Checklist for Children (TSCC) Odessa, FL: Psychological Assessment Resources.

Bronfenbrenner, U. (1977). Toward an experimental ecology of human development. American Psychologist, 32, 513-531.

Bronfenbrenner, U. (1979). The ecology of human development. Cambridge, Mass.: Harvard University Press.

Bronfenbrenner, U., \& Morris, P. A. (1998). The ecology of developmental processes In R. M. Lerner (Ed.), Handbook of child psychology: Theoretical models of human development (5th ed., Vol. 1, pp. 993-1028). New York: Wiley.

Browning, D., \& Boatman, B. (1977). Incest: Children at risk. American Journal of Psychiatry, $134,69-72$.

Bryman, A. (1988). Quantity and quality in social research. London: Unwin Hyman.

Budin, L. E., \& Johnson, C. F. (1989). Sex abuse prevention programs: Offenders' attitudes about their efficacy. Child Abuse \& Neglect, 13, 77-98. 
Burman, E. (1994). Interviewing. In P. Banister, E. Burman, I. Parker, M. Taylor \& C. Tindall (Eds.), Qualitative methods in psychology: A research guide. Buckingham: Open University Press.

Bussey, K., \& Grimbeek, E. J. (1995). Disclosure processes: Issues for child sexual abuse victims. In K. T. Rotenberg (Ed.), Disclosure processes in children and adolescents (pp. 166-203). Cambridge, UK: Cambridge University Press.

Bybee, D., \& Mowbray, C. T. (1993). An analysis of allegations of sexual abuse in a multivictim day care center case. Child Abuse \& Neglect, 17, 767-783.

Byrnes, J. P. (2006). Cognitive development in adolescence. In G. B. Adams \& M. Berzonsky (Eds.), Blackwell handbook of adolescence. Oxford: Blackwell Publishing.

Campis, L. B., Hebden-Curtis, J., \& DeMaso, D. R. (1993). Developmental differences in detection and disclosure of sexual abuse. Journal of the American Academy of Child \& Adolescent Psychiatry, 32, 920-924.

Carnes, C., Nelson-Gardell, D., Wilson, C., \& Orgassa, U. C. (2001). Extended forensic evaluation when sexual abuse is suspected: A multisite field study Child Maltreatment, 6, 230-242.

Carnes, C., Wilson, C., \& Nelson-Gardell, D. (1999). Extended forensic evaluation when sexual abuse is suspected: A model and preliminary data. Child Maltreatment, 4, 242-254.

Carr, A. (2006). Handbook of child and adolescent psychology. London: Routledge.

Charmaz, K. (2006). Constructing grounded theory: A practical guide through qualitative analysis. Thousand Oaks, CA: Sage Publications Ltd.

Children's Research Centre (2006). Children's research centre ethical guidelines. Dublin: Children's Research Centre, Trinity College Dublin

Christianson, J. R., \& Blake, R. H. (1990). The grooming process in father-daughter incest. In A. L. Horton, B. L. Johnson, L. M. Roundey \& D. Williams (Eds.), The incest perpetrator: A family member no one wants to treat (pp. 88-98). Newbury Park, CA: Sage.

Collings, S. J., Griffiths, S., \& Kumalo, M. (2005). Patterns of disclosure in child sexual abuse South African Journal of Psychology, 35(2), 270-285.

Connolly, D. A., \& Read, J. D. (2007). Canadian criminal court reports of historic child sexual abuse: Factors associated with delayed prosecution and reported repression. In M. E. Pipe, M. E. Lamb, Y. Orbach \& A. C. Cederborg (Eds.), Child sexual abuse: Disclosure, delay and denial (pp. 195-217). New Jersey: Lawrence Erlbaum Associates.

Conte, J. R., \& Schuerman, J. R. (1987). Factors associated with an increased impact of child sexual abuse. Child Abuse \& Neglect, 11, 201-211.

Corwin, D. L. (2002). An interview with Roland Summit. In J. R. Conte (Ed.), Critical issues in child sexual abuse: Historical, legal and psychological perspectives. Thousand Oaks, CA: Sage Publications Ltd.

Coulborn Faller, K. (2007). Interviewing children about sexual abuse: Controversies and best practice. New York: Oxford Universtiy Press. 
Courtois, C. A. (1988). Healing the incest wound: Adult survivors in therapy. New York: Norton.

Crisma, M., Bascelli, E., Paci, D., \& Romito, P. (2004). Adolescents who experienced sexual abuse: Fears, needs and impediments to disclosure. Child Abuse \& Neglect, 28, 1035-1048.

Cyr, M., Wright, J., Touopin, J., Oxman-Martinez, J., McDuff, P., \& Theriault, C. (2003). Predictors of maternal support: The point of view of adolescent victims of sexual abuse and their mothers. Journal of Child Sexual Abuse, 12, 39-65.

De Voe, E. R., \& Faller, K. C. (2002). Questioning strategies in interviews with children who may have been sexually abused. Child Maltreatment, 4(3), 217-227.

Dept. of Health (1987). Child abuse guidelines. Dublin: Dept. of Health

Dept. of Health and Children (1999). Children first: National guidelines for the protection and welfare of children. Dublin: Stationery Office

Dept. of Justice, Equality and Law Reform (1998). The law on sexual offences: A discussion paper. Dublin: Stationery Office.

DeVoe, E. R., \& Faller, K. C. (1999). The characteristics of disclosure among children who may have been sexually abused. Child Maltreatment, 4, 217-227.

Dey, I. (1999). Grounding grounded theory: Guidelines for qualitative inquiry. London: Academic Press.

Dhooper, S. S., Royce, D. D., \& Wolfe, L. C. (1991). A statewide study of the public attitudes toward child abuse. Child Abuse \& Neglect, 15, 37-44.

diGregorio, S. (2003). Analysis as cycling: Shifting between coding and memoing in using qualitative analysis software. Paper presented at the Strategies in Qualitative Research, Institute of Education, London.

DiPietro, E. K., Runyan, D. K., \& Fredrickson, D. D. (1997). Predictors of disclosure during medical evaluation for suspected sexual abuse. Journal of Child Sexual Abuse, 1(6), 133142.

Duncan, W. (1994). Law and the Irish psyche: The conflict between aspiration and experience. Irish Journal of Psychology, 15(2-3), 448-455.

Edelstein, R. S., Goodman, G. S., Ghetti, S., Alexander, K. W., Quas, J. A., Redlick, A. D., et al. (2002). Child witnesses' experiences post-court: Effects of legal involvement. In H. L. Westcott, G. M. Davies \& R. H. Bull (Eds.), Children's testimony: A handbook of psychological research and forensic practice. Chicester: John Wiley \& Sons Ltd.

Edwards, S. (1996). Sex and gender in the legal process. London: Blackstone.

Elliot, R., Fishcer, C. T., \& Rennie, D. L. (1999). Evolving guidelines for publication of qualitative research studies in psychology and related fields. British Journal of Clinical Psychology, $38,215-229$.

Elliott, A. N., \& Carnes, C. N. (2001). Reactions of nonoffending parents to the sexual abuse of their child: A review of the literature. Child Maltreatment, 6, 314-331. 
Elliott, D. M., \& Briere, J. (1994). Forensic sexual abuse evaluations of older children: Disclosures and symptomatology. Behavioral Sciences and the Law, 12, 261-277.

Elliott, M. (Ed.). (1997). Female sexual abuse of children: The ultimate taboo. Chicester: Wiley.

Emond, R. (2005). Ethnographic research methods with children and young people. In S. Greene \& D. Hogan (Eds.), Researching children's experiences: Approaches and methods (pp. 123139). London: Sage Publications Ltd.

Faller, K. (1985). Unanticipated problems in the United States child protection system. Child Abuse \& Neglect, 9, 63-69.

Faller, K. (1989). Characteristics of a clinical sample of sexually abused children: How boy and girl victims differ. Child Abuse \& Neglect, 13, 281-291.

Finkelhor, D. (2007). Prevention of sexual abuse through educational programs directed toward children. Pediatrics, 120, 640-645.

Finkelhor, D., Asdigian, N., \& Dziuba-Leatherman, J. (1995). The effectiveness of victimization prevention instruction: An evaluation of children's responses to actual threats and assaults. Child Abuse \& Neglect, 19, 129-139.

Finkelhor, D., \& Browne, A. (1985). The traumatic impact of child sexual abuse: A conceptualisation. American Journal of Orthopsychiatry, 55, 530-541.

Fontanella, C., Harrington, D., \& Zuravin, S. J. (2000). Gender differences in the characteristics and outcomes of sexually abused preschoolers. Journal of Child Sexual Abuse, 9, 21-40.

Freud, A., \& Dann, S. (1951). An experiment in group upbringing. In R. Eissler, A. Freud, H. H \& E. Kris (Eds.), The psychoanalytic study of the child (Vol. 6, pp. 127-163). New York: International Universities Press.

Friedrichs, W. N. (2002). Psychological assessment of sexually abused children and their families. Thousand Oaks, CA: Sage Publications.

Furniss, T. (1990). The multiprofessional handbook of child sexual abuse. London: Routledge.

Gil, E., \& Johnson, T. C. (1993). Sexualized children: Assessment and treatment of sexualized children and children who molest. Rockville, MD: Launch Press.

Glaser, B. S., \& Strauss, A. (1967). Discovery of grounded theory. Thousand Oaks,CA: Sage.

Goddard, C., \& Saunders, B. J. (2000). The gender neglect and textual abuse of children in the print media. Child Abuse Review, 9, 37-48.

Goldman, R. L. (1994). Children and youth with intellectual disabilities: Targets for sexual abuse. Journal of Disability, Development and Education, 41(2), 89-102.

Gomes-Schwartz, B., Horowitz, J. M., \& Cardarelli, A. P. (1990). Child sexual abuse: The initial effects. Thousand Oaks, CA: Sage Publications.

Gonzales, L. S., Waterman, J., Kelly, R., McCord, J., \& Olivieri, K. (1993). Children's patterns of disclosure and recantations of sexual and ritualistic abuse allegations in psychotherapy. Child Abuse \& Neglect, 17, 281-289. 
Goode, H., McGee, H., \& O'Boyle, C. (2003). Time to listen: Confronting child sexual abuse by catholic clergy in Ireland. Dublin: The Liffey Press.

Goodman-Brown, T. B., Edelstein, R. S., Goodman, G. S., Jones, D. P. H., \& Gordon, D. S. (2003). Why children tell: A model of children's disclosure of sexual abuse. Child Abuse \& Neglect, 27, 525-540.

Goodman, G. (1984). The child witness: Conclusions and future directions for research and legal practice. Journal of Social Issues, 40, 157-175.

Government of Ireland (1939). The Irish constitution, Dublin: Stationery Office

Government of Ireland (1991). The child care act. Dublin: Stationery Office

Gray, E. (1993). Unequal justice: The prosecution of child sexual abuse. New York: Free Press.

Greene, S. (1994). Growing up Irish: Development in context. Irish Journal of Psychology, 15(23), 354-371.

Greene, S. (2003). The psychological development of girls and women: Rethinking change in time. London: Routledge.

Greene, S. (2006). Nature vs. nurture and the missing child, Inaugural Lecture. Dublin: Children's Research Centre.

Greene, S., \& Moane, G. (2000). Growing up Irish: Changing children in a changing society. Irish Journal of Psychology, 21(3-4), 122-137.

Greig, A., \& Taylor, J. (1999). Doing research with children. London: Sage.

Gries, L. T., Goh, D. S., \& Cavanaugh, J. (1996). Factors associated with disclosure during child sexual abuse assessment. Journal of Child Sexual Abuse, 5, 1-20.

Groth, A. N., Longo, R. E., \& McFadin, J. B. (1982). Undetected recidivism among rapists and child molesters. Crime and Delinquency, 28, 450-458.

Guba, E. G., \& Lincoln, Y. S. (2005). Paradigmatic controversies, contradictions and emerging confluences. In N. K. Denzin \& Y. S. Lincoln (Eds.), The Sage handbook of qualitative research (pp. 191-215). Thousand Oaks, CA: Sage Publications Ltd.

Hartup, W. W. (1999). Peer experience and its developmental significance. In M. B. Bennett (Ed.), Developmental Psychology: Achievements and prospects. London: Psychology Press Ltd.

Hecht, D. A., \& Hansen, D. J. (1999). Adolescent victims and intergenerational issues in sexual abuse. In Van Hasselt \& M. Hersen (Eds.), Handbook of psychological approaches with violent criminals: Contemporary strategies and issues (pp. 303-328). New York: Plenum.

Henwood, K. L., \& Pidgeon, N. F. (1992). Qualitative research and psychological theorizing. British Journal of Psychology, 83(1), 97-111.

Herman, J. L. (1981). Father-daughter incest. Cambridge, MA: Harvard University Press.

Herman, J. L. (1992). Trauma and recovery: From domestic abuse to political terror. London: Pandora.

Hershkowitz, I., Horowitz, D., \& Lamb, M. E. (2005). Trends in children's disclosure of abuse in Israel: A national study. Child Abuse \& Neglect, 29(11), 1203-1214. 
Hershkowitz, I., Lanes, O., \& Lamb, M. E. (2007). Exploring the disclosure of child sexual abuse with alleged victims and their parents. Child Abuse \& Neglect, 31, 111-123.

Hershkowitz, I., Orbach, Y., Lamb, M. E., Sternberg, K. J., \& Horowitz, D. (2006). Dynamics of forensic interviews with suspected abuse victims who do not disclose. Child Abuse \& Neglect, 30, 753-769.

Hewitt, S. (1999). Assessing allegations of child sexual abuse in pre-school children. Thousand Oaks, CA: Sage Publications Ltd.

Hill, M. (2005). Ethical considerations in researching children's experiences. In S. Greene \& D. Hogan (Eds.), Researching children's experiences: Approaches and methods. London: Sage Publications Ltd.

Home Office (1992). Memorandum of good practice on video recorded interviews with child witnesses for criminal proceedings. London: Her Majesty's Stationery Office.

Home Office (2000). Achieving best evidence in criminal proceedings: Guidance for vulnerable or intimidated witnesses, including children. London: Her Majesty's Stationery Office.

Hogan, D. (1998). Valuing the child in research: Historical and current influences on research methodology with children. In D. M. Hogan \& R.Gilligan (Eds.), Researching children's experiences: Qualitative approaches (pp. 1-11). Dublin: The Children's Research Centre, Trinity College Dublin.

Hogan, D. (2005). Researching 'the child' in developmental psychology. In S. Greene \& D. Hogan (Eds.), Researching children's experiences (pp. 22-41). London: Sage Publications Ltd.

ISPCC (1996). Another brick from the wall: The case for the introduction of mandatory reporting in Ireland Dublin: ISPCC.

Jennings, K. (1993). Female child molestation: A review of the literature. In M. Elliott (Ed.), Female abuse of children: The ultimate taboo (pp. 241-257). Essex, England: Longman.

Jensen, T. K., Gulbrandsen, W., Mossige, S., Reichelt, S., \& Tjersland, O. A. (2005). Reporting possible sexual abuse: A qualitative study on children's perspectives and the context for disclosure. Child Abuse \& Neglect, 29(12), 1395-1413.

Jones, D. (2000). Editorial: Disclosure of child sexual abuse. Child Abuse \& Neglect, 24(2).

Jones, D., \& McGraw, J. M. (1987). Reliable and fictitious accounts of sexual abuse to chidlren. Journal of Interpersonal Violence, 2, 27-45.

Jones, L. M., Finkelhor, D., \& Kopiec, K. (2001). Why is sexual abuse declining? A survey of state child protection administrators. Child Abuse \& Neglect, 25(9), 1139-1158.

Kaufman, K. L., Hilliker, D. R., \& Daleiden, E. (1996). Subgroup differences in the modus operandi of sexual offenders. Child Maltreatment, 1, 17-24.

Kazarian, S. S., \& Kazarian, L. Z. (1998). Cultural aspects of family violence. In S. S. Kazarian \& D. R. Evan (Eds.), Cultural clinical psychology: Theory, research and practice (pp. 316347). Oxford: Oxford. 
Keary, K., \& Fitzpatrick, C. (1994). Children's disclosure of sexual abuse during formal investigation. Child Abuse \& Neglect, 18, 543-548.

Kelley, S. J., Brant, R., \& Waterman, J. (1993). Sexual abuse of children in day care centers. Child Abuse \& Neglect, 17, 71-89.

Kellogg, N. D., \& Huston, R. L. (1995). Unwanted sexual experiences in adolescents: Patterns of disclosure. Clinical Pediatrics, 34(6), 306-312.

Kendall-Tackett, K. A., Williams, L. M., \& Finkelhor, D. (1993). Impact of sexual abuse on children: A review and synthesis of the literature. Psychological Bulletin, 113, 164-180.

King, N. M. P., \& Churchill, L. R. (2000). Ethical principles guiding research on child and adolescent subjects. Journal of Interpersonal Violence, 15(7), 710-724.

Kogan, S. M. (2004). Disclosing unwanted sexual experiences: Results from a national sample of adolescent women. Child Abuse \& Neglect, 28, 147-165.

Koverola, C., \& Foy, D. (1993). Post traumatic stress disorder symptomatology in sexually abused children: Implications for legal proceedings Journal of Child Sexual Abuse, 2(4), 119-128.

Ladd, G. (2005). Peer relations and social competence. Yale: Yale University Press.

Lamb, S., \& Edgar-Smith, S. (1994). Aspects of disclosure: Mediators of outcome of childhood sexual abuse. Journal of Interpersonal Violence, 9, 307-326.

Lambert, S. (2004). Female sexual abusers: A review. Paper presented at the Psychological Society of Ireland Annual Conference, Cork, Ireland.

Lawson, L., \& Chaffin, M. (1992). False negatives in sexual abuse disclosure interviews: Incidence and influence of caretaker's belief in abuse in cases of accidental abuse discovery by diagnosis of STD. Journal of Interpersonal Violence, 7(4), 532-542.

Leon, C. (2000). Recorded sexual offences 1994-1997. Irish Criminal Law Journal, 10(3), 2-7.

Leonard, E. D. (1996). A social exchange explanation for the child sexual abuse accommodation symdrome. Journal of Interpersonal Violence, 11, 107-117.

Lerner, R. (1998). Theories of human development: Contemporary perspectives In W. Damon \& R. M. Lerner (Eds.), Handbook of child psychology: Theoretical models of human development (5th ed., Vol. 1, pp. 1-24). New York: Wiley.

Lincoln, Y. S., \& Guba, E. G. (1985). Naturalistic inquiry. Beverly Hills: Sage Publications Ltd. Lindblad, F. (2007). Reflections on the concept of disclosure. In M. E. Pipe, M. Lamb, Y. Orbach \& A. C. Cederborg (Eds.), Child sexual abuse: Disclosures, delay and denial. New Jersey: Lawrence Erlbaum Associates.

London, K., Bruck, M., Ceci, S. J., \& Shuman, D. (2005). Disclosure of child sexual abuse: What does the research tell us about the ways that children tell? Psychology, Public Policy, and Law, 11(1), 194-226.

London, K., Bruck, M., Ceci, S. J., \& Shuman, D. W. (2007). Disclosures of child sexual abuse: A review of the contemporary empirical literature. In M. E. Pipe, M. Lamb, Y. Orbach \& A. 
C. Cederborg (Eds.), Child sexual abuse: Disclosure, delay and denial. London: Lawrence Erlbaum Associates.

Lyon, T. D. (2007). False denials: Overcoming methodological biases in abuse disclosure research. In M. Pipe, M. Lamb, Y. Orbach \& A. C. Cederborg (Eds.), Child sexual abuse: Disclosure, delay and denial. London: Lawrence Erlbaum Associates.

MacDonald, K., Lambie, I., \& Simmonds, L. (1995). Counselling for sexual abuse. Melbourne: Oxford University Press.

MacFarlane, K., \& Krebs, S. (1986). Techniques for interviewing and evidence gathering. In K. MacFarlane \& J. Waterman (Eds.), Sexual abuse of young children: Evaluation and treatment. London: Cassell.

MacIntyre, D., \& Carr, A. (1999a). Evaluation of the effectiveness of the Stay Safe primary prevention programme for child sexual abuse. Child Abuse \& Neglect, 23(12), 1307-1325.

MacIntyre, D., \& Carr, A. (1999b). Helping children to the other side of silence: A study of the impact of the Stay Safe programme on Irish children's disclosures of sexual victimisation. Child Abuse \& Neglect, 23(12), 1327-1340.

MacIntyre, D., \& Carr, A. (2000). Prevention of child sexual abuse: Implications of programme evaluation research. Child Abuse Review, 9(3), 183-199.

MacIntyre, D., \& Lawlor, M. (1991). The Stay Safe programme. Dublin: Department of Health, Child Abuse Prevention Programme

Malloy, L. C., Lindsay, C., Lyon, T. D., \& Quas, J. A. (2007). Filial dependency and recantation of child sexual abuse. Journal of the American Academy of Child \& Adolescent Psychiatry, 46(2), 162-170.

May-Chahal, C., \& Cawson, P. (2005). Measuring child maltreatment in the United Kingdom (UK): A study of the prevalence of child abuse and neglect. Child Abuse \& Neglect, 29(9), 969-984.

McElvaney, R. (2002). Delays in reporting childhood sexual abuse and implications for legal proceedings. In D. P. Farrington, C. R. Hollin \& M. McMurran (Eds.), Sex and violence: The psychology of crime and risk assessment (pp. 138-153). London: Routledge.

McGee, H., Garavan, R., deBarra, M., Byrne, J., \& Conroy, R. (2002). The SAVI report: Sexual abuse and violence in Ireland. Dublin: The Liffey Press.

Miller, A. (1987). The drama of being a child. London: Virago Press.

Miller, D. C., \& Byrnes, J. P. (2001). Adolescents' decision-making in social situations: A selfregulation perspective. Journal of Applied Developmental Psychology, 22, 237-256.

Moshman, D. (1998). Cognitive development beyond childhood. In D. Kuhn \& R. S. Siegler (Eds.), Handbook of child psychology: Vol 2. Cognition, language, and perception (pp. 947-978). New York: Wiley.

Mudaly, N., \& Goddard, C. (2006). The truth is longer than a lie: Children's experiences of abuse and professional interventions. London: Jessica Kingsley Publishers. 
Muntarbhorn, V. (1996). Sexual exploitation of children. New York: United Nations Publication.

Nagel, D. E., Putnam, F. W., Noll, J. G., \& Trickett, P. K. (1997). Disclosure patterns of sexual abuse and psychological functioning at a 1-year follow up. Child Abuse \& Neglect, 21, 137-147.

Norton, L. (1999). The philosophical bases of grounded theory and their implications for research practice. Nurse Researcher, 7(1), 31-40.

O'Shea, D., \& McElvaney, R. (2001). Therapy with sexually abused children. In K. Lalor (Ed.), The end of innocence: Child sexual abuse in Ireland. Cork: Oak Tree Press.

Oates, R. K., \& Donnelly, A. C. (1997). Influential papers in child abuse. Child Abuse \& Neglect, 21, 319-326.

Olafson, E., Corwin, D., \& Summit, R. (1993). Modern history of child sexual abuse awareness: Cycles of discovery and suppression. Child Abuse \& Neglect, 17(1), 7-24.

Ormond, C., Luszcz, M. A., Mann, L., \& Beswick, G. (1991). A metacognitive analysis of decision-making in adolescence. Journal of Adolescence, 14, 275-291.

Paine, M. L., \& Hansen, D. J. (2002). Factors influencing children to self-disclose sexual abuse. Clinical Psychology Review, 22, 271-295.

Palmer, S. E., Brown, R. A., Rae-Grant, J. I., \& Loughlin, M. J. (1999). Responding to children's disclosure of familial abuse: What survivors tell us. Child Welfare, 78, 259-282.

Petronio, S., Flores, L. A., \& Hecht, M. L. (1997). Locating the voice of logic: Disclosure discourse of sexual abuse. Western Journal of Communication, 61(1), 101-113.

Pidgeon, N., Henwood, K., \& Hayes, N. (1997). Using grounded theory in psychological research. In Doing qualitative analysis in psychology. (pp. 245-273). Hove, England: Taylor \& Francis.

Pipe, M. E., Lamb, M., Orbach, Y., \& Cederborg, A. C. (2007b). Seeking resolution in the disclosure wars: An overview. In M. E. Pipe, M. Lamb, Y. Orbach \& A. C. Cederborg (Eds.), Child sexual abuse: Disclosure, delay and denial. London: Lawrence Erlbaum Associates.

Pipe, M. E., Lamb, M., Orbach, Y., \& Cederborg, A. C. (Eds.). (2007a). Child sexual abuse: Disclosure, delay and denial. New Jersey: Lawrence Erhbaum Association.

Pipe, M. E., Lamb, M. E., Orbach, Y., Stewart, H., Sternberg, K. J., \& Esplin, P. (2007). Factors associated with nondisclosure of suspected abuse during forensic interviews. In M. E. Pipe, M. E. Lamb, Y. Orbach \& A.C. Cederborg (Eds.), Child sexual abuse: Disclosure, delay and denial (pp. 77-96). New Jersey: Lawrence Erlbaum Associates.

Plummer, C. A. (2006). The discovery process: What mothers see and do in gaining awarenes of the sexual abuse of their children. Child Abuse \& Neglect, 30(11), 1227-1237.

Poole, D. A., \& Lamb, M. E. (1998). Investigative interviews of children: A guide for helping professionals. Washington DC: American Psychological Association. 
Pope, K., Tabachnick, B., \& Keith-Spiegel, P. (1987). Ethics of practice: The beliefs and behaviors of psychologists as therapists. American Psychologist, 42, 993-1006.

Poston, C., \& Lison, K. (1989). Reclaiming our lives. Boston: Little, Brown \& Co.

Quas, J. A., Goodman, G. S., Ghetti, S., Alexander, K. W., Edelstein, R., Redlich, A. D., et al. (2005). Childhood sexual assault victims: Long-term outcomes after testifying in criminal court. Monographs of the Society for Research in Child Development, 70(2).

QSR International (2002). Nvivo, Victoria: QSR International

Regan, L. \& Kelly, L. (2003). Rape: Still a forgotten issue. London: Child and Woman Abuse Studies Unit, London Metropolitan University.

Reinhart, M. (1987). Sexually abused boys. Child Abuse \& Neglect, 11, 229-235.

Reiser, M. (1991). Recantation in child sexual abuse cases. Child Welfare, 612-613.

Rhodes, R. H., Hill, C. E., Thompson, B. J., \& Elliott, R. (1994). Client retrospective recall of resolved and unresolved misunderstanding events. Journal of Counselling Psychology, 41(4), 473-483.

Richardson, L. (2002). nVivo qualitative research. Melbourne: QSR International.

Richardson, L. J. (2003). Disclosure patterns in children's allegations of child sexual abuse, Unpublished doctoral dissertation, Melbourne: University of Melbourne.

Roesler, T. A., \& Wind, T. W. (1994). Telling the secret: Adult women describe their experiences of incest. Journal of Interpersonal Violence, 9, 327-338.

Rogers, A. G. (2006). The unsayable: The hidden language of trauma. New York: Random House. Rosenblum, G. D., \& Lewis, M. (2006). Emotional development in adolescence. In G. Adams \& M. Berzonsky (Eds.), Blackwell handbook of adolescence. Oxford: Blackwell Publishing Ltd.

Runyan, D. (2000). The ethical, legal and methodological implications of directly asking children about abuse. Journal of Interpersonal Violence, 15, 675-681.

Runyan, D. K., Everson, M. D., Edelsohn, G. A., Hunter, W. M., \& Coulter, M. L. (1988). Impact of legal intervention on sexually abused children. Journal of Pediatrics, 113, 647-653.

Russell, D. (1983). The incidence and prevlance of intrafamilial and extrafamilial sexual abuse of female children. Child Abuse \& Neglect, 7, 133-146.

Russell, D. (1984). The secret trauma. New York: Basic Books.

Salter, A. (1995). Transforming trauma. Thousand Oaks, CA: Sage Publications Ltd.

Sas, L. D., \& Cunningham, A. H. (1995). Tipping the balance to tell the secret: The public discovery of child sexual abuse. London, Ontario: London Family Court Clinic.

Sauzier, M. (1989). Disclosure of child sexual abuse: For better or for worse. Psychiatric Clinics of North America, 12, 455-469.

Saywitz, K., Esplin, P., \& Romanoff, S. (2007). A holistic approach to interviewing and treating children in the legal system. In M. E. Pipe, M. E. Lamb, Y. Orbach \& A. C. Cederborg 
(Eds.), Child sexual abuse: Disclosure, delay and denial (pp. 219-249). New Jersey:

Lawrence Erlbaum Associates.

Saywitz, K., Snyder, L., \& Nathanson, R. (1999). Facilitating the communicative competence of the child witness. Applied Developmental Science, 3(1), 58-68.

Sgroi, S., Blick, L., \& Porter, F. A. (1982). A conceptual framework for child sexual abuse. In S. Sgroi (Ed.), Handbook of clinical intervention in child sexual abuse. Lexington, MA: Lexington Books.

Singer, M. I., Hussey, D., \& Strom, K. J. (1992). Grooming the victim: An analysis of a perpetrator's seduction letter. Child Abuse \& Neglect, 16, 877-886.

Sirles, E. A., \& Frank, P. J. (1989). Factors influencing mothers' reactions to intrafamily sexual abuse. Child Abuse \& Neglect, 13, 131-139.

Smith, D. W., Letourneau, E. J., Saunders, B. E., Kilpatrick, D. G., Resnick, H. S., \& Best, C. L. (2000). Delay in disclosure of childhood rape: Results from a national survey. Child Abuse \& Neglect, 24, 273-287.

Smith, J. A. (1995). Semi-structured interviewing and qualitative analysis. In J. S. Smith, R. Harre \& L. Van Langenhove (Eds.), Rethinking methods in psychology. London: Sage.

Smyth, C. M. (2007). Non-abusing mothers with a childhood sexual abuse: Their experiences of the disclosure and aftermath of their children's sexual abuse. Unpublished dissertation, Dublin: University of Dublin

Sorenson, S. B., \& Snow, B. (1991). . (1991). How children tell: The process of disclosure in child sexual abuse. Child Welfare, 70(3-15).

Sorenson, T., \& Snow, B. (1991). How children tell: The process of disclosure of child sexual abuse. Child Welfare, 70, 3-15.

Sperry, D. M., \& Gilbert, B. O. (2005). Child peer sexual abuse: Preliminary data on outcomes and disclosure experiences. Child Abuse \& Neglect, 29, 889-904.

Staller, K. M., \& Nelson-Gardell, D. (2005). 'A burden in your heart': Lessons of disclosure from female preadolescent and adolescent survivors of sexual abuse. Child Abuse \& Neglect, 29(12), 1415-1432.

Sternberg, K. J., Lamb, M. E., Davies, G. M., \& Westcott, H. L. (2001). The Memorandum of Good Practice: Theory versus application. Child Abuse \& Neglect, 25(5), 669-681.

Sternberg, K. J., Lamb, M. E., Hershkowitz, I., Yudilevitch, L., Orbach, Y., Esplin, P. W., et al. (1997). Effects of introductory style on children's abilities to describe experiences of sexual abuse. Child Abuse \& Neglect, 21, 1133-1146.

Steward, M. S., Bussey, K., Goodman, G. S., \& Saywitz, K. J. (1993). Implications of developmental research for interviewing children. Child Abuse \& Neglect, 17, 25-37.

Strauss, A. L., \& Corbin, J. (1998). Basics of qualitative research: Techniques and procedures for developing grounded theory, 2nd edition. Thousand Oaks, CA: Sage Publications Inc. 
Sullivan, P. M., \& Knutzon, J. F. (2000). Maltreatment and disabilities: A population-based epidemiological study. Child Abuse \& Neglect, 24, 1257-1273.

Summit, R. (1983). The child sexual abuse accommodation syndrome. Child Abuse \& Neglect, $7(2), 177-193$.

Summit, R. (1992). Abuse of the child sexual abuse accommodation syndrome. Journal of Child Sexual Abuse, 1(14), 153-163.

Swoboda, J. L., Elwork, A., Sales, B. D., \& Levine, D. (1987). Knowledge and compliance with privileged communication and child abuse reporting laws. Professional Psychology, 448458.

Torrey, M. (1991). When will we be believed? Rape myths and the idea of a fair trial in rape prosecutions. Davis Law Review, 24, 1013.

Toukmanian, S. G., \& Brouwers, M. C. (1998). Cultural aspects of self-disclosure and psychotherapy. In S. S. Kazarian \& D. R. Evans (Eds.), Cultural Clinical Psychology:Theory, research and practice (pp. 106-126). New York: Oxford University Press.

Ullman, S. E., \& Filipas, H. H. (2005). Gender differences in social reactions to abuse disclosures, post-abuse coping and PTSD of child sexual abuse survivors. Child Abuse \& Neglect, 29(7), 767-782.

Van der Kolk, B. A. (1994). The body keeps score: Memory and the evolving psycho-biology of post-traumatic stress. Harvard Review of Psychiatry, 1, 253-265.

Van der Kolk, B. A. (1996). Traumatic stress: The effects of overwhelming experience on mind, body and society. New York: Guilford Press.

Van der Kolk, B. A., \& Fisler, R. (1995). Dissociation and the fragmentary nature of traumatic memories: Overview and exploratory study. Journal of Traumatic Stress, 8(4), 505-525.

Waddell, M. (2002). Inside Lives: Psychoanalysis and the growth of the personality. London: Karnac.

Walker, A. G. (1999). Handbook on questioning children: A linguistic perspective. Washington, DC: American Bar Association.

Watkins, B., \& Bentovim, A. (1992). The sexual abuse of male children and adolescents: A review of current research. Journal of Child Psychology and Psychiatry, 33, 197-248.

Wattam, C. (1999). Confidentiality and the social organisation of telling. In N. Parton \& C. Wattam (Eds.), Child sexual abuse: Responding to the experiences of children. Chicester: Wiley.

Westcott, H. L. (1999). Communication. In N. Parton \& C. Wattam (Eds.), Child sexual abuse: Responding to the experiences of children. Chicester: Wiley.

Westcott, H. L., \& Littleton, K. S. (2005). Exploring meaning in interviews with children. In S. Greene \& D. Hogan (Eds.), Researching children's experiences: Approaches and methods. London: Sage Publications Ltd. 
Willig, C. (2001). Introducing qualitative research in psychology. Buckingham: Open University Press.

Winnicott, D. (1965). The maturational proces and the facilitating environment. London: Hogarth. Winnicott, D. (1971). Playing and reality. London: Tavistock Publications.

Wyatt, G. E., \& Mickey, M. R. (1987). Ameliorating the effects of child sexual abuse: An exploratory study of support by parents and others. Journal of Interpersonal Violence, 2(4), 403-414.

Wyatt, G. E., \& Newcomb, M. (1990). Internal and external mediators of women's sexual abuse in prevalence research. Journal of Consulting and Clinical Psychology, 58, 758-767. 
APPENDIXES 


\section{APPENDIX A: LETTER TO PARENTS INTRODUCING STUDY}

(Headed paper from Agency providing service to children and families)

Dear Parent/Guardian,

My name is Rosaleen McElvaney and I am doing research at the moment here in (name of agency). I worked here in the Unit as a psychologist for the past six years and am now doing a $\mathrm{PhD}$ in Trinity College Dublin. My PhD is on how children tell about their experiences of sexual abuse.

You will be asked by the assessment team for permission to be contacted for future research. I may ring you about this after the assessment is complete but in the meantime I am enclosing the attached information sheet so that you have a chance to look over it before I ring. I would prefer if you did not mention the study to your daughter/son until I speak to you. You may have some questions you would like to ask me before speaking to your daughter/son about it and I can explain more about the study when we talk.

Many thanks for your help.

Yours sincerely,

Rosaleen McElvaney 


\section{APPENDIX B: INFORMATION SHEET FOR PARENTS, INCORPORATING CONSENT \\ FORM}

\section{CONSENT FORM FOR PARENTS}

This research project is being carried out to try to find out what helps children tell someone about their experience of sexual abuse. I want to ask children directly about this and also to ask parents what you think about this. The results of the research project will be published and will hopefully help parents, professionals and the wider public to respond better to children who have been sexually abused.

The information I need is from my interview with you, my interview with your child, and information given as part of the assessment in (agency). This information will be kept confidential, subject to legal requirements, and any information used in the study will not identify you or your child. If you at any time decide that you would prefer that your information is not used in my research you have the choice to withdraw your permission at any time by contacting the secretary here in the Unit or myself directly either by telephone or in writing. There is no obligation on you to give this permission. It will not in any way affect the assessment of your child or any further service that may be offered to you by (agency).

You have the right to ask for a copy of the information that will be used for this study under the Freedom of Information Act.

Rosaleen McElvaney can be contacted either through (Agency name and telephone number) or through the Department of Psychology, Trinity College Dublin (01-6081886).

The above has been explained to me and I give my consent

Signed (parent)

Signed (parent)

Signed (researcher)

Date 
1. "We are doing a study on how children tell about their experiences of sexual abuse. If you would like to be a part of this study, this is what it would involve.

a. Coming back for a further appointment over the next few weeks to meet the researcher, Rosaleen McElvaney.

b. The appointment will last 40 minutes, 20 minutes to meet with you and 20 minutes to meet your son/daughter

c. Rosaleen will ask you questions about the time your son/daughter told you about what happened and what you think about that; and a similar interview with your son/daughter. You or your son/daughter will not be asked to talk about what happened, just about how and when they told about it.

d. The appointment will be taped so that Rosaleen can write down the details afterwards

e. The study will be published with no identifying details of children or families

f. Whether you take part in the research or not, it will make no difference to any help you may receive here in St. Clare's"

2. If parents are interested, give them the briefing note and ask for permission to be contacted by me after the assessment. I will then be contacting them by telephone to offer an appointment if they wish to take part.

3. Tick in the box opposite if parents are interested and give an indication of how the parents or child/young person responded

4. Child's name:

Thanks - Rosaleen 


\section{Research Study On \\ How Children Tell}

How can we help children to tell us about what has happened to them?

What helps children tell?

What stops children telling?

Can you help?

Contact: Rosaleen McElvaney, (name of agency)

Or ask the Secretary for details 


\section{APPENDIX E: CONSENT FORM FOR ADULTS}

\section{CONSENT FORM, ADULTS}

The researcher is a former member of staff of (agency), Rosaleen McElvaney. She is doing a PhD in Trinity College and her study will include both children and adults.

The purpose of the study is to try to find out about what helps children tell someone about their experience of sexual abuse for the first time. The study will also try to find out what it is that stops children from telling about sexual abuse. To do this, Rosaleen will be meeting with children and their parents and asking a lot of questions about the family, the nature of the sexual abuse experiences and how these experiences were discovered. She will also ask adults about their experience as children and how it was that they first told someone about this, whether this was as a child or as an adult and what it was that helped them or stopped them from telling.

The results of the research project will be published and will hopefully help parents, professionals and the wider public to respond better to children who have been sexually abused. Any information given by you will not be used in a way that would identify you. It will be kept confidential and will not be discussed with any member of staff in (agency) unless there is a concern that a child is at risk or that you yourself are a risk to yourself or to others. In these cases, your therapist will be informed of this information. If you at any time decide that you would prefer that your information is not to be used in the research you have the choice to withdraw your permission at any time by contacting Rosaleen directly or the secretary here in (agency). There is no obligation on you to take part in this research. It will not in any way affect the service offered to you by (agency.

You have the right to ask for a copy of any information used in the research project about yourself.

Rosaleen can be contacted in (agency name and telephone number) or Trinity College Dublin 6083908 if you wish to discuss this with her.

Name:

Address:

Signed (client) 


\section{CONSENT FORM FOR CHILD/ADOLESCENT}

I agree to meet with Rosaleen to talk about when I told someone about what happened to me.

I also agree to allow Rosaleen to tape our meeting.

The tape will be used so that Rosaleen can write down what we say.

If I want to stop talking at any time, I can just say this to the Rosaleen. I can change my mind at any time if I don't want to meet with Rosaleen. This won't make any difference to any help I get from (Agency).

I give Rosaleen permission to use my story to write about how children talk and feel about what happened to them.

I also give Rosaleen permission to look at my file here in (Agency).

Signed (child's/teenager's signature)

Signed (researcher's signature)

Date

Rosaleen McElvaney can be contacted here in (Agency name and telephone number) or in Trinity College on 016081886 


\section{Rapport Building Phase}

Ask about general interests. Explain research study and what will happen to information gathered.

Explain limits of confidentiality.

I want us to talk about the time you first told someone about ..........

I'm trying to learn more about what it's like for children/young people to tell about what happens to them. Is that okay?

(If yes, show child/young person the consent form and have it signed)

Rules (for pre-teenage children)

Before we begin, we need to talk about some rules that we use here.

"If you don't know the answers to any of the questions, you need to tell

me 'I don't know'. If I asked you what kind of dog I have, what would you say: (don't know) that's right, because you don't know, do you? Well done;

"If I get something wrong or make a mistake, I need you to tell me 'No, that's not right'. So if I said your sister's brother's name is Jane/Jim, what would you say? (no) That's right, because it's ... Well done;

"If you want to stop at any time, I need you to say 'I want to stop now';

"We only talk here about things that really happened" (give example).

\section{Open Question Phase}

Ask open question of all age groups, use prompts with younger children as appropriate and record which prompts are used.

Now I want to ask you some questions about when you told about.....

Tell me about the first time you told someone about ....

Tell me everything you remember about that.

Detail Clarification Questions (Prompts)

Who did you tell? Tell me about that

When did you tell? Tell me about that 
What did you tell? Tell me about that

Why did you tell them? Tell me about that

How did you tell them? Tell me about that

How did you feel after you told? Tell me about that

Who did you not tell? Tell me about that

Why did you not tell sooner? Tell me about that

Did you tell anyone else? Tell me more about that

Advice for others: What would you say to other children if this happened to them?

What do you think would help them to tell?

Do you think age/gender makes a difference?

Older/Younger

Boy or Girl

Do you think it makes a difference if it happens within the family?

Who all knows now?

Would you have told if you didn't tell then?

What can schools do to help?

Did you do the Stay Safe programme?

Did that help you tell?

Do you think it would help children tell? 


\section{DATA RECORD SHEET}

(this information to be abstracted from the child's report, omitting all identifying information such as people's names, locations)

Child's Research ID:

Date of Birth:

Dates of Assessments:

Family Composition:

Family Difficulties/Relationships:

Other Key Relationships/Supports:

Relevant Developmental History:

Functioning at time of assessment:

Story of Disclosure:

Details of abuse:

Other relevant information: 
NVivo revision 2.0.163 Licensee: Rosaleen McElvaney

Project: Sept 2 User: Administrator

Date: 25/11/2007 - 09:51:55 NODE LISTING

Nodes in Set: All Nodes

Created: $\quad$ 15/09/2005 - 14:56:37

Modified: $\quad$ 15/09/2005 - 14:56:37

Number of Nodes: $\quad 100$

1 Actual consequences

2 Age of disclosure

3 family difficulties

4 fear

5 know of abuse not disclosed

6 luck

$7 \quad$ Made up story

8 police lawyer

9 To whom disclosed

10 trust $\sim$ safe place

11 Who knows

12 (2)/Advice

13 (2 15)/Advice/For children

14 (2 15 1)/Advice/For children/don't believe them

15 (2 15 4)/Advice/For children/Run away

16 (2 15 8)/Advice/For children/take control

17 (2 15 10)/Advice/For children/Tell

18 (2 15 14)/Advice/For children/don't let it happen again

19 (2 16)/Advice/For adults

$20 \quad$ (2 16 1)/Advice/For adults/helpline

21 (2 16 2)/Advice/For adults/supervision

22 (2 16 3)/Advice/For adults/don't intrude

23 (2 16 5)/Advice/For adults/talk to kids

24 (2 16 6)/Advice/For adults/counselling

25 (2 16 7)/Advice/For adults/confidentiality

26 (2 16 13)/Advice/For adults/teacher school

27 (4) /Psychological distress

28 (4 1)/Psychological distress/Sleep difficulties

29 (4 2)/Psychological distress/took pills

$30 \quad$ (4 3)/Psychological distress/self harm

$31 \quad$ (4 4) /Psychological distress/eating

32 (4 5)/Psychological distress/I kindof became really quiet

33 (4 6) /Psychological distress/she knew I wasn't being treated well

34 (4 7) /Psychological distress/I was upset

35 (4 8)/Psychological distress/missing school

36 (4 9)/Psychological distress/rebelliousness

$37 \quad$ (5) /Feelings after told

$38 \quad(51) /$ Feelings after told/neutral

39 (5 11 1) /Feelings after told/neutral/just want to forget about it

$40 \quad\left(\begin{array}{lll}5 & 1 & 2\end{array}\right) /$ Feelings after told/neutral/should have told earlier

$41 \quad(52) /$ Feelings after told/positive

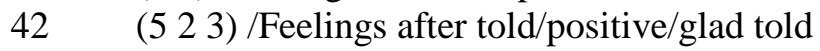

$43 \quad\left(\begin{array}{lll}5 & 2 & 12\end{array}\right) /$ Feelings after told/positive/relief

$44 \quad$ (5 6)/Feelings after told/negative

45 (5 6 1) /Feelings after told/negative/crazy

$46 \quad(562) / F e e l i n g s$ after told/negative/stupid 
(5 6 3) /Feelings after told/negative/wouldn't walk anywhere on my own

(5 6 4) /Feelings after told/negative/I didn't go out for like 4 months

(5 65 ) /Feelings after told/negative/didn't trust guys

(5 6 6) /Feelings after told/negative/feel people were staring

(5 6 7) /Feelings after told/negative/feeling guilt

(5 6 8) /Feelings after told/negative/feels unreal

(5 6 10) /Feelings after told/negative/regret telling

(5 6 11) /Feelings after told/negative/upset

(5 6 13) /Feelings after told/negative/is it worth all this

(7) /Beliefs

(7 1) /Beliefs/that someone knew

(7 2) /Beliefs/people don't believe children

(7 3) /Beliefs/Wouldn't have told

(7 12) /Beliefs/thought they would follow you here

(8) /difficult to talk about

(8 1) /difficult to talk about/took time

(8 2) /difficult to talk about/gave information in bits

(8 3) /difficult to talk about/feelings at time of disclosure

(8 4) /difficult to talk about/denial

(9) /How child told

(9 1) /How child told/telling

(9 1 ( 1 ) /How child told/telling/telling

(9 2) /How child told/wrote it down

(9 3) /How child told/Sent text message

(9 4) /How child told/someone else told

(10) /others' reactions

(10 1) /others' reactions/sympathetic

(10 3) /others' reactions/upset

(10 5) /others' reactions/didn't believe

(10 6) /others' reactions/disclosed own abuse

(10 7) /others' reactions/scolded abuser

(10 8) /others' reactions/wanted to tell others

(12) /Reasons for not telling

(12 1) /Reasons for not telling/fear of not being believed

(12 2) /Reasons for not telling/self doubt

(12 3) /Reasons for not telling/didn't remember

(12 4) /Reasons for not telling/not wanting to overreact

(12 5) /Reasons for not telling/no one to tell

(12 6) /Reasons for not telling/fear of being judged

(12 7) /Reasons for not telling/wouldn't make any difference

(12 9) /Reasons for not telling/Will cause trouble

(12 10)/Reasons for not telling/thought it was normal

(12 11) /Reasons for not telling/didn't get a chance to say it

(12 13) /Reasons for not telling/felt embarrassed ashamed

(12 14) /Reasons for not telling/angry with parents

(12 16) /Reasons for not telling/not wanting freedom curtailed

(12 17) /Reasons for not telling/Don't tell anyone

(14) /What helped tell

(14 1) /What helped tell/was asked

(14 2) /What helped tell/film

(14 3) /What helped tell/realising not normal

(14 4) /What helped tell/thought was pregnant

(14 5) /What helped tell/Concern for other children

(14 6) /What helped tell/fact that someone else was abused 
NVivo revision 2.0.163 Licensee: Rosaleen McElvaney

Project: Oct06 User: Administrator

Date: $28 / 10 / 2007$ - 12:58:45 NODE LISTING

Nodes in Set: All Nodes

Created: $\quad$ 18/10/2006 - 10:10:25

Modified: $\quad$ 18/10/2006 - 10:10:25

Number of Nodes: 118

1 change with time

2 Confidentiality

3 Consequences or Reactions of others

4 fear

5 feeling safe

6 high court ruling

7 how felt about telling

8 other secrets

9 police lawyer

10 signs of psychological distress

11 things are different now

12 thought was pregnant

13 websites

14 who cares

15 would they have told if not then?

16 (1)/Relationships

17 (2)/Containing the secret

18 (2 1) actively witholding

19 (2 2) confiding in friends

$20 \quad$ (23) made up story

$21 \quad$ (24) denial

22

23

24

(2 5) I'll show you mine

(2 6) ready to tell

(2 7) Who knows

(2 8) blocked out

(2 9) tried to tell

(2 10) partial disclosure

(2 11) self-blame

(2 12) didn't occur to tell

(2 13) telling would make it worse

(3) /Adult Variables

(3 1) family problems

(3 2) psychiatric History

(3 3) marital difficulties

(3 4) subsequent abuse

(4) /Search Results

(4 1) Single Text Lookup

(4 2) Single Text Lookup 2

(5) /Breaking the secret

(5 1) aware of other person abused

(5 2) being asked

(5 3) being believed

(5 4) pressure cooker

(5 5) uplanned

(5 18) difficult to talk about

$46 \quad(6) /$ Family Variables 
(6 1) family difficulties

(6 2) bereavement

(6 3) parental history of abuse

(6 4) domestic Violence

(6 5) parents separated

(6 6) protectiveness

(8) /Child Variables

(8 1) they were accused of abuse

(8 2) counselling

(8 3) staySafe

(8 4) School difficulties

(8 5) physical abuse

(8 6) psychiatric involvement

(10) /Abuse Variables

(10 1) alleg perp

(10 2) context of abuse

(10 3) things perp said

(10 4) When disclosed

(10 6) how felt about abuse

(10 7) others present

(12) /Reasons for not telling

(12 1) taboo subject

(12 5) no one to tell

(12 8) didn't have language

(12 11) didn't get a chance to say it

(12 13) felt embarrassed ashamed

(14) /What helped tell

(14 1) being open minded

(14 2) film

(14 4) thought was pregnant

(14 5) concern for other children

(14 6) fact that someone else was abused

(14 7) belief that someone knew should know

(14 8) thinking about it a lot

(14 9) sexuality pressure

(14 10) contact with abuser

(14 12) having told someone already

(14 13) anger at abuser

(14 14) not your fault

(17) /How child told

(17 1) had drink taken

(17 2) wrote it down

(17 3) Sent text message

(17 4) someone else told

(17 6) was discovered

(21) /Advice

(21 1) schools

(21 2) if people talked more

(21 3) tell!

(21 21) advice For children

(21 22) advice For adults 
NVivo revision 2.0.163 Licensee: Rosaleen McElvaney

Project: Feb07 User: Administrator

Date: 28/10/2007 - 12:59:22

\section{NODE LISTING}

Nodes in Set: All Nodes

Created: $\quad$ 26/02/2007 - 08:44:29

Modified: $\quad$ 26/02/2007 - 08:44:29

Number of Nodes: $\quad 72$

1 accurate info

2 being believed

3 change with time

4 Consequences or Reactions of disc

5 Disclosure as a Process

6 fear

7 other secrets

8 relationships

9 (1)/Containing the secret - Reasons

10 (1 1) didn't know what to do

$11 \quad$ (1 2) contact with abuser

12 (1 3) didn't know it was wrong

13 (15) threats

14 (1 11) self-blame

$15 \quad$ (1 12) didn't occur to tell

$16 \quad$ (1 13) telling would make it worse

$17 \quad$ (1 14) taboo subject

18 (1 16) eidn't have language

19 (1 17) didn't get a chance to say it

$20 \quad$ (1 18) felt embarrassed ashamed

21 (1 19) difficult to talk about

22 (2)/Containing the secret - Evidence

(2 1) actively witholding

(2 4) denial

(2 7) who knows?

(3) /Adult Variables

(3 1) family problems

(3 2) psychiatric History

(3 3) marital difficulties

(5) /Triggers - internal

(5 1) signs of psychological distress

(5 4) pressure cooker

(5 5) would they have told if not then

(5 12) feeling safe

(7) /Triggers - external

(7 1) relationship breakdown

(7 2) being asked

(7 3) confiding in friends

(7 6) peer pressure

(7 7) film www

(7 8) alcohol involved

(7 9) concern for other children

(7 11) belief that someone knew should know 


\begin{tabular}{|c|c|}
\hline 45 & (8) /Child Variables \\
\hline 46 & (8 1) they were accused of abuse \\
\hline 47 & (8 2 ) counselling \\
\hline 48 & (8 3) staySafe \\
\hline 49 & (84) school difficulties \\
\hline 50 & (8 5) physical abuse \\
\hline 51 & (8 6) psychiatric involvement \\
\hline 52 & (9) /Systems issues \\
\hline 53 & (9 1) comments re services \\
\hline 54 & (9 2) police lawyer \\
\hline 55 & (9 3) confidentiality \\
\hline 56 & (9 5) attitudes in society \\
\hline 57 & (9 8) things are different now \\
\hline 58 & (9 10) aware of other person abused \\
\hline 59 & (9 11) family Variables \\
\hline 60 & (10) /Abuse variables \\
\hline 61 & (10 1) alleg perp \\
\hline 62 & (10 2) context of abuse \\
\hline 63 & (10 3) things perp said \\
\hline 64 & (10 4) when disclosed \\
\hline 65 & (11) /Developmental Issues \\
\hline 66 & (11 1 1) Age \\
\hline 67 & (11 2) Gender \\
\hline 68 & (21) /Advice \\
\hline 69 & $\left(\begin{array}{lll}2 & 1 & 1\end{array}\right)$ schools \\
\hline 70 & (21 2) if people talked more \\
\hline 71 & (21 21) advice for children \\
\hline 72 & (21 22) advice for adults \\
\hline
\end{tabular}

Explanatory Notes

1. At this stage in the analysis, the evidence for the theme containing the secret was highlighted as being distinct from the reasons for containing the secret. The theme Containing the secret at this stage reflected the dynamic of not telling while the themes 'Triggers - external' and 'Triggers - internal' represented the experience of telling. Note that 'Triggers' in this framework replaced the earlier theme of 'how child told' and 'what helped tell'. 
NVivo revision 2.0.163 Licensee: Rosaleen McElvaney

Project: Sept07 User: Administrator

Date: 28/10/2007 - 13:01:45

NODE LISTING

Nodes in Set: All Nodes

Created: $\quad$ 04/09/2007 - 16:30:40

Modified: $\quad$ 04/09/2007 - 16:30:40

Number of Nodes: $\quad 67$

1 being believed

2 consequences or reactions of disclosure

3 contradictions in accounts

4 fear

5 other secrets

6 relationships

7 (1) /Containing the secret - Reasons

8 (1 3) didn't know it was wrong

$9 \quad$ (14) could not tell

$10 \quad(15)$ threats

$11 \quad$ (1 11) self-blame

$12 \quad$ (1 12) didn't occur to tell

13 (1 13) Telling would make it worse

$14 \quad$ (1 14) taboo subject

15

16

(1 17) didn't get a chance to say it

(1 18) felt embarrassed ashamed

(2) /Containing the secret - Evidence

(2 1) actively withholding

(2 2) disclosure as a process

(2 3) confidentiality

(24) denial

(2 5) would they have told if not then

(2 7) who knows?

(3) /Adult Variables

(3 1) family problems

(3 2) psychiatric History

(3 3) marital difficulties

(5) /Pressure Cooker

(5 1) signs of psychological distress

(5 4) pressure cooker

(5 12) feeling safe

(7) /Triggers - external

(7 2) being asked

(7 3) confiding in friends

(7 5) contact with abuser

(7 7) film www

(7 8) alcohol involved

(7 9) concern for other children

(7 11) belief that someone knew should know

(8) /Child Variables

(8 1) they were accused of abuse

(8 2) counselling

(8 3) StaySafe

(8 4) School difficulties

(8 5) physical abuse 
(9) /Systems issues

(8 6) psychiatric involvement

(91) comments re services

(9 2) police lawyer

(9 3) Intra Extra

(9 8) things are different now

(9 10) aware of other person abused

(9 11) family Variables

(10) /Abuse Variables

(10 1) alleg perp

(10 2) context of abuse

(10 3) things perp said

(10 4) When disclosed

(11) /Developmental Issues

(11 1) age

(11 2) gender

(11 3) change with time

(21) /Advice

(21 1) schools

(21 2) if people talked more

(21 21) advice for children

(21 22) advice for adults 